Universidade de São Paulo

Instituto de Física

\title{
Interações hadrônicas a altíssimas energias e o desenvolvimento de cascatas atmosféricas extensas
}

\author{
Hendrik Marques Soares
}

Orientador: Prof. Dr. Edivaldo Moura Santos

Tese apresentada ao Instituto de Física como requisito parcial para obtenção do título de Doutorado em Ciências.

Banca Examinadora:

Prof. Dr. Edivaldo Moura Santos - IFUSP

Prof. Dr. Marcelo G. Munhoz - IFUSP

Profa. Dra. Ivone F. da Mota e Albuquerque - IFUSP

Prof. Dr. Luiz Vitor de Souza - IFSC/USP

Profa. Dra. Carola Dobrigkeit Chinellato - UNICAMP

São Paulo 


\section{FICHA CATALOGRÁFICA}

Preparada pelo Serviço de Biblioteca e Informação do Instituto de Física da Universidade de São Paulo

Soares, Hendrik Marques

Interações hadrônicas a altíssimas energias e o desenvolvimento de cascatas atmosféricas extensas. São Paulo, 2018.

Tese (Doutorado) - Universidade de São Paulo, Instituto de Física, Depto. de Física Experimental.

Orientador: Prof. Dr. Edivaldo Moura Santos

Área de Concentração: Partículas Elementares

Unitermos: 1. Raios cósmicos; 2. Física de partículas; 3. Hádrons. 
University of São Paulo

Physics Institute

\title{
Hadronic interactions and the development of extensive air showers
}

\author{
Hendrik Marques Soares
}

Advisor: Prof. Dr. Edivaldo Moura Santos

Thesis presented to the Institute of Physics as

a partial requirement to obtain the Doctorate of Sciences degree

Approved by:

Prof. Dr. Edivaldo Moura Santos - IFUSP

Prof. Dr. Marcelo G. Munhoz - IFUSP

Prof. Dr. Ivone F. da Mota e Albuquerque - IFUSP

Prof. Dr. Luiz Vitor de Souza - IFSC/USP

Prof. Dr. Carola Dobrigkeit Chinellato - UNICAMP

São Paulo 

Dedico este trabalho à minha namorada Natalia e aos meus pais Rafael e Claudia. 



\section{Agradecimentos}

Primeiramente, agradeço à minha família pela realização dessa tese, principalmente aos meus pais que sempre me incentivaram e apoiaram durante esses anos de estudo no doutorado. Agradeço à Natalia Martins por sua paciência e ajuda em todas as suas leituras da minha tese em busca da melhor escrita e erros de português perdidos em meio a tantas palavras e equações. Quanto aos amigos de pesquisa Nikolas, Douglas, Johnnier, Denis e Washington, agradeço por horas de discussão sobre física, computação, padrões de escrita científica e o que fosse necessário para contribuir com essa tese.

A todos os professores, educadores e responsáveis pela minha formação agradeço o esforço e o tempo gasto comigo. Em especial, agradeço ao Prof. Dr. Edivaldo Moura Santos pela disponibilidade em orientar-me, pelas diversas discussões sobre

física e mostrar que era possível a realização dessa tese. À CAPES e ao Instituto de Física (IF/USP) agradeço pelo fornecimento de recursos e materiais para o desenvolvimento dessa tese sem os quais ela não seria possível. Pesquisa desenvolvida com o auxílio do CENAPAD-SP (Centro Nacional de Processamento de Alto Desempenho em São Paulo), projeto UNICAMP / FINEP - MCT e ao laboratório nacional para computação científica (LNCC/MCTI, Brasil) por prover recursos do supercomputador SDumont, os quais contribuiram para o desenvolvimento dessa tese. 



\section{Resumo}

O comportamento das interações hadrônicas para energias de centro de massa superiores a $50 \mathrm{TeV} /$ núcleon é uma fonte importante de incerteza sistemática na interpretação de dados de observatórios de raios cósmicos. Nesta tese, estudamos por meio de simulações de Monte Carlo observáveis dos chuveiros atmosféricos que pudessem ser correlacionados com aspectos dos diferentes modelos destas interações. Especial atenção foi dada à componente muônica que sabidamente é gerada do decaimento de partículas de natureza hadrônica na cascata. A precisão e a acurácia de uma rede esparsa de contadores de múons foram estudadas como função da granularidade da rede de detectores e da área de coleção de suas células. Mostramos, em particular, as diferenças na dependência radial da densidade de múons no plano transversal ao eixo da cascata para os diferentes modelos. Tais diferenças se mostram mais acentuadas na vizinhança do eixo e poderiam ser exploradas experimentalmente com um detector com alcance dinâmico suficiente para evitar saturação da eletrônica. Além disso, por meio de um tratamento fenomenológico, investigamos o impacto no desenvolvimento do chuveiro causado por variações na distribuição de pseudorapidez $d N / d \eta$ de secundários produzidos na colisão primária. Mostramos que diferentemente de quantidades como seção de choque inelástica, multiplicidade, razão de carga e elasticidade, mudanças em $d N / d \eta$ que preservem tais quantidades são rapidamente diluídas nas sucessivas camadas de interações posteriores à colisão primária.

Palavras-chaves: Raios cósmicos. Astropartículas. Chuveiros atmosféricos extensos. Interações hadrônicas. Observatório Pierre Auger. 



\begin{abstract}
The behavior of the hadronic interactions at center of mass energies greater than $50 \mathrm{TeV} /$ nucleon is an important source of systematic uncertainty on interpreting data from cosmic ray observatories. In this thesis, we study through Monte Carlo simulations the atmospheric shower observables that could be correlated with different aspects of these interactions. Special attention was paid to the muonic component that is known to be generated from the decay of hadronic particles. The precision and accuracy of a sparse grid of muon counters were studied as a function of the array granularity and the collection area of its cells. In particular, we studied the differences in the radial dependence of the muon density in the shower plane for different models. These differences are shown to be larger in the vicinity of the shower axis and, therefore, could be explored with a detector of sufficiently large dynamic range as to avoid saturation of its acquisition electronics. In addition, through a phenomenological treatment, we investigated the impact on the shower development caused by variations in the distribution of pseudorapidity $d N / d \eta$ of secondaries particles produced in the primary collision. We show that unlike quantities such as inelastic cross section, multiplicity, charge ratio and elasticity, changes in $d N / d \eta$ that preserve such quantities are rapidly diluted in successive interaction layers subsequent to the primary collision.
\end{abstract}

Keywords: Cosmic rays. Astroparticle physics. Extensive air shower. Hadronic interaction. Pierre Auger Observatory. 



\section{Lista de Figuras}

2.1 Esquema do desenvolvimento das três componentes de um chuveiro atmosférico extenso. . . . . . . . . . . . . . . . . . .

2.2 Esquema do desenvolvimento longitudinal de um EAS com destaque aos principais pontos importantes. . . . . . . . . . . . . . . . .

2.3 Perfil de desenvolvimento lateral de um EAS. Exemplo de espalhamento lateral da densidade de partículas, $\rho\left(r_{\text {core }}\right)$, em função da distância radial $r_{\text {core }}$ do eixo do chuveiro. . . . . . . . . . . . . . . . . . .

2.4 Representações, em diagrama de Feynman, das principais interações eletromagnéticas. Em (a) temos o efeito bremsstrahlung, e em (b) ocorre a produção de pares elétron-pósitron. . . . . . . . . . . . . . . . .

2.5 Visão esquemática do modelo de Heitler para chuveiros eletromagnético. O chuveiro inicia com uma partícula que viaja por uma distância fixa $X$, definida pelo comprimento de radiação $\lambda_{r a d}$, e interage produzindo duas partículas. Esse processo se repete $n$ vezes até atingir o número máximo de partículas. .

2.6 Simulação de chuveiro eletromagnético no meio Ferro. Os pontos são elétrons e fótons, e a curva mostra a energia depositada por comprimento de interação. Extraída da referência [1] . . . . . . . . . . . . . . . . . . . . . . . 40

2.7 Produção de ressonância $\Delta^{++}(1232)$ em interações de píons (esquerda) e fótons (direita) com prótons. Retirado da referência [2] . . . . . . . . . . .

2.8 Descrição da interação inelástica $1+2 \rightarrow 3+4$ mediada por reggeon. Retirado da referência [3]. . . . . . . . . . . . . . . . . . . . 43

2.9 Ilustração da interação intermediada por pártons para produção de mini-jatos. 43

2.10 Visão esquemática do chuveiro hadrônico. . . . . . . . . . . . . . . . . 44

2.11 Representação do Observatório Pierre Auger, os pontos azuis representam os detectores de superfície de luz Cherenkov e as linhas verdes representam esquematicamente a cobertura em azimute do campo de visão de cada um dos 6 telescópios de fluorescência presentes em cada uma das quatro estações de observação. 
2.12 Esquema mostrando os principais componentes do detector de luz Cherenkov utilizado no Auger. . . . . . . . . . . . . . . . . . . . . . . . . . . . 48

2.13 Detector de luz fluorecente do Observatório Pierre Auger. . . . . . . . . . . . 49

2.14 Configuração das estações do AMIGA, com os detectores de superfície e os módulos de cintiladores enterrados. . . . . . . . . . . . . .

2.15 Disposição dos detectores utilizados no projeto AMIGA. Detectores de superfície distribuídos por uma rede triangular, com separação de $750 \mathrm{~m}$, e cobrindo uma área de $23.5 \mathrm{~km}^{2}$. . . . . . . . . . . . . . . . . . .

2.16 Compilação de fluxo de vários experimentos de raios cósmicos. O fluxo foi reescalado por $E^{2,5}$ para que as características se tornem claramente visíveis.

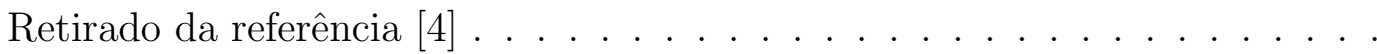

$2.17 \mathrm{O}$ espectro de energia obtido pelo OPA por combinação de medidas hibridas usando telescópio de fluorescência e detectores de superfície. Retirado da referência [5]. . . . . . . . . . . . . . . . . . . . . . . . .

2.18 Fator de modificação do espectro de energia para o cenário de composição mista, indicando que o tornozelo seria devido à transição de componente galáctica para extragaláctica. Retirado da referência [6] . . . . . . . . . . .

2.19 Fator de modificação do espectro de energia para o cenário do modelo do dip, indicando que o tornozelo é devido à perda de energia por produção de par. Retirado da referência [7]. . . . . . . . . . . . . . . . . . .

2.20 Medida de $\left\langle X_{\max }\right\rangle$, realizada pelo Observatório Pierre Auger, comparado com simulações de chuveiros atmosféricos usando diferentes modelos de interações hadrônicas. Retirado da referência $[8] \ldots$. . . . . . . . . . . . . . . .

2.21 Medida de RMS $\left(X_{\max }\right)$, realizada pelo Observatório Pierre Auger, comparado com simulações de chuveiros atmosféricos usando diferentes modelos de interações hadrônicas. Retirado da referência $[8]$. . . . . . . . . . . . .

2.22 Medida de $\left\langle X_{\max }\right\rangle$, realizada pelo experimento Telescope Array, comparada com simulações de chuveiros atmosféricos usando diferentes modelos de interações hadrônicas. Retirado da referência [9]. . . . . . . . . . . . . . .

2.23 Mapa do fluxo de partículas em coordenadas equatoriais, usando a projeção de Hammer. O gráfico mostra o fluxo de raios cósmicos para energias maiores que $8 \mathrm{EeV}$ suavizado com uma função "top-hat" de $45^{\circ}$. O centro galáctico está marcado com um asterisco e o plano galáctico é mostrado pela linha pontilhada. Retirado da referência $[10] \ldots$. . . . . . . . . .

2.24 Número médio de múons $R_{\mu}$ por energia $E$ do chuveiro como função da energia do chuveiro em escala logarítmica. Retirado da referência [11]. . . . . . . . . 
2.25 Valores de $R_{E}$ e $R_{\text {had }}$ com as incertezas estatísticas e sistemáticas, para os modelos QGSJETII-04 e EPOSLHC. Retirado da referência [12] . . . . . . . .

3.1 Gráfico mostrando a relação entre o ângulo da partícula em relação ao feixe e a variável $\eta$. . . . . . . . . . . . . . . . . . . . . . . . . . . . . 66

3.2 . Extraído da referência [13]. . . . . . . . . . . . . . . . . . . 69

3.3 Seção de choque inelástica para colisões próton-próton (esquerda), colisão próton-ar (linhas grossas à direita) e colisões píons-ar (linhas finas à direita). Na figura, o modelo QGSJETII é representado por linha tracejada vermelha, EPOSLHC por linha tracejada azul e o SIBYLL2.3 por linha tracejada verde. Figura extraída de $[14] \ldots \ldots \ldots \ldots \ldots \ldots \ldots$

3.4 Distribuição de pseudorapidez $d N / d \eta$ para eventos com ao menos uma partícula com $|\eta|<1$ (esquerda) e a distribuição correspondente de multiplicidade (direita) para interações próton-próton com energia $7 \mathrm{TeV}$. Na figura, os resultados do modelo QGSJETII são representado por linha tracejada vermelha, EPOSLHC por linha tracejada azul e o SIBYLL2.3 por linha tracejada verde. Figura extraída de $[14] \ldots \ldots \ldots \ldots \ldots \ldots$

3.5 Multiplicidade em função da energia para eventos próton-próton (esquerda) e próton-ar a direita. Na figura, o modelo QGSJETII é representado por linha tracejada vermelha, EPOSLHC por linha tracejada azul e o SIBYLL2.3 por linha tracejada verde. Figura extraída de [14] . . . . . . . . . . . . .

3.6 Elasticidade (fração de energia da partícula líder) para colisões próton-próton (a esquerda) e colisões píon-ar (linhas finas na figura a direita) e a inelasticidade próton-ar (linhas fortes na figura a esquerda) em função da energia de centro demassa . Simulações foram feitas com EPOSLHC(azul), DPMJETIII, (roxo) QGSJETII-04 (vermelho) e SIBYLL2.3 (verde). Figura extraída de [14]. 75

3.7 Mudança do parâmetro $X_{\max }$ dos EAS devido a modificações sistemáticas na seção de choque, multiplicidade, elasticidade e razão de carga por meio de uma constante multiplicativa $f_{19}$ aplicada aos valores de tais parâmetros em

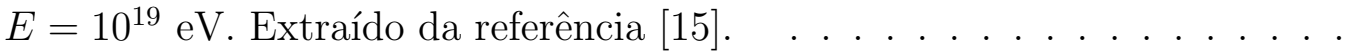

3.8 Número de massa médio em uma escala logarítmica como função da energia. Em verde e azul, temos os resultados da composição para os dois modelos da saturação de glúons. Quando comparados ao resultado do modelo do Glauber (SIBYLL), vemos que a composição para o modelo de saturação de glúons é de partículas mais leves do que o SIBYLL2.3. Retirado da referência [16]. 
4.1 Comparação entre os modelos EPOSLHC, SIBYLL2.3 e QGSJETII-04 sobre a distribuição lateral (LDF) média para 1000 chuveiros iniciados por próton com energia de $10^{19} \mathrm{eV}$ e ângulo $\theta=60^{\circ}$ e $\phi=0^{\circ} \ldots \ldots . . . . . .$.

4.2 Diferença entre os modelos EPOSLHC, SIBYLL2.3 e QGSJETII-04 sobre a distribuição lateral $(\mathrm{LDF}) . \ldots$. . . . . . . . . . . . . . . . .

4.3 Distribuição de $\rho_{1000}$ entre os modelos EPOSLHC, SIBYLL2.3 e QGSJETII04 para 1000 chuveiros iniciados por próton com energia de $10^{19} \mathrm{eV}$ e ângulo $\theta=60^{\circ}$ e $\phi=0^{\circ} \ldots \ldots \ldots \ldots \ldots$

4.4 Evolução do $\left\langle\rho_{1000}\right\rangle$ em função da energia para os modelos EPOSLHC, SIBYLL2.3 e QGSJETII-04 para chuveiros com energia entre $10^{18.5}$ e $10^{19.5} \mathrm{eV}$ e ângulo $\theta=60^{\circ}$ e $\phi=0^{\circ}$. Ao todo, foram simulados 1000 chuveiros para cada ponto

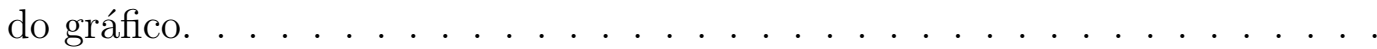

4.5 Comparação do desenvolvimento longitudinal de chuveiros atmosféricos iniciados por próton com energia de $10^{19} \mathrm{eV}$ e inclinação $\theta=60^{\circ}$. Na figura (a) estão representados os perfis médios de 1000 EAS para os modelos EPOSLHC (linha vermelha), SIBYLL2.3 (linha azul), QGSJETII-04 (linha verde) e na figura (b) é mostrada a diferença entre os modelos. . . . . . . . . . . . . . .

4.6 Distribuição de $X_{\max }^{\mu}$ entre os modelos EPOSLHC, e QGSJETII-04 para 1000 chuveiros iniciados por próton com energia de $10^{19} \mathrm{eV}$ e ângulo $\theta=60^{\circ} \mathrm{e} \phi=0^{\circ} .83$

4.7 Evolução do $X_{\max }$ em função da energia para os modelos EPOSLHC, SIBYLL2.3 e QGSJETII-04 para chuveiros com energia entre $10^{18.5}$ e $10^{19.5} \mathrm{eV}$ e ângulo $\theta=60^{\circ}$ e $\phi=0^{\circ}$.

4.8 Distribuição do número de múons para chuveiros iniciados por próton com energia de $10^{19} \mathrm{eV}$ e ângulo $\theta=60^{\circ}$ e $\phi=0^{\circ}$. Em vermelho é mostrado o modelo interações hadrônicas EPOSLHC, em azul SIBYLL2.3 e em verde

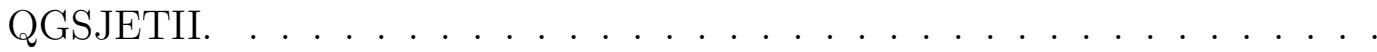

4.9 Evolução do número de múons para chuveiros com energia entre $10^{18.5}$ até $10^{19.5} \mathrm{eV}$ e ângulo $\theta=60^{\circ} \mathrm{e} \phi=0^{\circ}$. Em vermelho é mostrado o resultado com o modelo interações hadrônicas EPOSLHC, em azul com o SIBYLL2.3 e em verde com o QGSJETII-04. . . . . . . . . . . . . . . . . .

4.10 Distribuição de $X^{\mu}$ em função da profundidade atmosférica de um EAS iniciado por um próton com energia de $10^{19} \mathrm{eV}$. Sobre os dados foi aplicado um corte, $r_{c u t}>1700 \mathrm{~m}$, na distância ao ponto de impacto do chuveiro. Além disso, a linha vermelha representa o melhor ajuste da função Gaisser-Hillas através da minimização de máxima verossimilhança. . . . . . . . . . . . . . . 
4.11 Comparação da MPD de chuveiros atmosféricos iniciados por próton com energia de $10^{19,5} \mathrm{eV}$ e inclinação $\theta=60^{\circ}$. Na figura (a) é mostrado o perfil médio de 1000 chuveiros e na figura (b) está representada a diferença em porcentagem entre os modelos. . . . . . . . . . . . . . . . . . . . . . . .

4.12 Distribuição de $X_{\max }^{\mu}$ entre os modelos EPOSLHC, SIBYLL2.3 e QGSJETII04 para 1000 chuveiros iniciados por próton com energia de $10^{19} \mathrm{eV}$ e ângulo $\theta=60^{\circ}$ e $\phi=0^{\circ}$

4.13 Evolução do $X_{\max }^{\mu}$ em função da energia para os modelos EPOSLHC, SIBYLL2.3 e QGSJETII-04 para chuveiros com energia entre $10^{18,5}$ e $10^{19,5} \mathrm{eV}$ e ângulo $\theta=60^{\circ}$ e $\phi=0^{\circ}$.

5.1 Cobertura experimental de diversos experimentos, no LHC, em função da pseudorapidez $\eta$.

5.2 Distribuição de partículas em (a) e energia em (b) em função da pseudorapidez para chuveiros atmosféricos iniciados por próton com energia de $10^{19} \mathrm{eV}$ e inclinação $\theta=60^{\circ}$. Nesta figura foi utilizado o modelo de interação hadrônica EPOSLHC. . . . . . . . . . . . . . . . . .

5.3 Medida de densidade lateral para diferentes intervalos de $\eta$ para EAS iniciados por prótons com energia de $10^{17} \mathrm{eV}$, usando o modelo hadrônico EPOSLHC. Em (a) é mostrado o perfil da densidade lateral e em (b) a porcentagem de contribuição para cada intervalo.

5.4 Ajuste para distribuição de $d N / d \eta$ para 1000 interações próton-ar, simuladas com SIBYLL2.3, com energia de centro de massa núcleon-núcleon, $\sqrt{S_{N N}} \approx$ $140 \mathrm{TeV}$ equivalente a $10^{19} \mathrm{eV}$ no referencial do laboratório. . . . . . . . . .

5.5 Exemplo de modificações da distribuição $d N / d \eta$ para colisões próton-ar, cauda curta em verde e cauda longa em vermelho. . . . . . . . . . . . . . .

5.6 Comparação entre os modelos de distribuição $d N / d \eta$ para 1000 interações próton-ar com energia de $10^{19} \mathrm{eV}$ no referencial do laboratório, usando o modelo de interação hadrônica QGSJETII.

5.7 Comparação do desenvolvimento longitudinal de chuveiros atmosféricos iniciados por próton com energia de $10^{19} \mathrm{eV}$ e inclinação $\theta=60^{\circ}$. Na figura (a) é mostrado o perfil médio de 1000 chuveiros e na figura (b) está representado a diferença em porcentagem entre os modelos. . . . . . . . . . . . . .

5.8 Comparação da distribuição de $X_{\max }$ para as distribuições de pseudorapidez original, cauda curta e cauda longa. Foram usados 1000 chuveiros iniciados por próton com energia de $10^{19} \mathrm{eV}$ e ângulo $\theta=60^{\circ}$ e $\phi=0^{\circ}$. O modelo SIBYLL2.3, de interação hadrônica, foi utilizado nas simulações dos chuveiros. 
5.9 Evolução do $\left\langle X_{\max }\right\rangle$ em função da energia para as distribuições de pseudorapidez original (azul), cauda curta (vermelho) e cauda longa (verde) . . . . . 100

5.10 Comparação da distribuição de $N_{19}$ para as distribuições de pseudorapidez original(azul), cauda curta(vermelho) e cauda longa(verde). Foram usados 1000 chuveiros iniciados por próton com energia de $10^{19} \mathrm{eV}$ e ângulo $\theta=60^{\circ}$ e $\phi=0^{\circ}$. Foi utilizado o modelo de interações SIBYLL2.3 nas simulações do

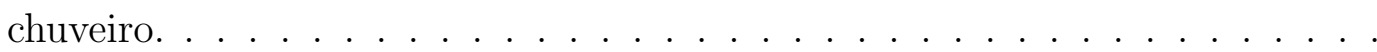

5.11 Evolução do $\left\langle X_{\max }\right\rangle$ em função da energia para as distribuições de pseudorapidez original, cauda curta e cauda longa. . . . . . . . . . . . . . . . 102

5.12 Comparação da produção de múons em função da profundidade para chuveiros atmosféricos iniciados por próton com energia de $10^{19} \mathrm{eV}$ e inclinação $\theta=60^{\circ}$. Na figura (a) é mostrado o perfil médio de 1000 chuveiros e na figura (b) está representada a diferença em porcentagem entre os modelos. . . . . . . . . . .

103

5.13 Comparação da distribuição de $X_{\max }^{\mu}$ para as distribuições de pseudorapidez original, cauda curta e cauda longa. Foram usados 1000 chuveiros iniciados por próton com energia de $10^{19} \mathrm{eV}$ e ângulo $\theta=60^{\circ}$ e $\phi=0^{\circ}$. O modelo SIBYLL2.3, de interação hadrônica, foi utilizado nas simulações dos chuveiros. 103

5.14 Evolução do $\left\langle X_{m a x}^{\mu}\right\rangle$ em função da energia para as distribuições de pseudorapidez original (azul), cauda curta (vermelha) e cauda longa (verde). . . . . . .

5.15 Comparação da densidade lateral de múons em função da distância ao ponto de impacto do chuveiro. Dados simulados são de chuveiros atmosféricos iniciados por próton com energia de $10^{19} \mathrm{eV}$ e inclinação $\theta=60^{\circ}$. Na figura (a) é mostrado o perfil médio de 1000 chuveiros e na figura (b) está representado a diferença da densidade lateral de múons em porcentagem entre os modelos. .

5.16 Comparação da distribuição de $\rho_{1000}$ para as distribuições de pseudorapidez original, cauda curta e cauda longa. Foram usados 1000 chuveiros iniciados por próton com energia de $10^{19} \mathrm{eV}$ e ângulo $\theta=60^{\circ}$ e $\phi=0^{\circ}$. O modelo SIBYLL2.3, de interação hadrônica, foi utilizado nas simulações dos chuveiros. 105

5.17 Evolução do $\left\langle\rho_{1000}\right\rangle$ em função da energia para as distribuições de pseudorapidez original (azul), cauda curta (vermelha) e cauda longa (verde) . . . . . . . 106

6.1 Representação gráfica do arranjo de detectores. . . . . . . . . . . . . . 108 
6.2 Representação gráfica do funcionamento do conjunto de detectores. Cada detector foi representado por um ponto preto, o número de múons que atravessaram o detector é proporcional a largura do ponto, a escala de cores mostra o tempo de disparo do primeiro múon que atingiu o detector e a seta indica a direção de entrada do chuveiro com sua ponta apontando para o ponto de impacto no solo.

6.3 Mapa bidimensional de densidade de múons para EAS iniciados por próton com energia de $10^{19} \mathrm{eV}$ e inclinação $\left(\theta=60^{\circ}, \phi=0^{\circ}\right)$, utilizando o modelo EPOSLHC.

6.4 Representação da geometria utilizada para reconstruir a informação do chuveiro por "dethinning".

6.5 Comparação da distribuição bidimensional de distribuição de partículas no solo para EAS iniciados por próton com energia de $10^{19}$ eV e inclinação zenital de $60^{\circ}$ e azimutal $0^{\circ}$. Em (a) temos o mapa original sem aplicação de "dethinning" e em (b) temos o mapa após a aplicação do algoritmo de "dethinning".

6.6 Reconstrução do parâmetro livre $T_{0}$ usando o método de minimização da frente de propagação curva. . . . . . . . . . . . . . . . . . . . .

6.7 Reconstrução do parâmetro livre $\theta$ usando o método de minimização da frente de propagação curva. . . . . . . . . . . . . . . . . . . . . .

6.8 Reconstrução do parâmetro livre $\phi$ usando o método de minimização da frente de propagação curva. . . . . . . . . . . . . . . . . . .

6.9 Reconstrução do parâmetro livre $R_{c}$ usando o método de minimização da frente de propagação curva. . . . . . . . . . . . . . . . . . . .

6.10 Reconstrução do parâmetro livre $N_{19}$ usando o método máxima verossimilhança.

6.11 Reconstrução do parâmetro livre $N_{19}$ para diferentes espaçamento dos detectores. A linha azul representa a reconstrução de $N_{19}$ para detectores separados por $375 \mathrm{~m}$, a linha vermelha para detectores separados por $750 \mathrm{~m}$ e a linha verde para detectores separados por 1500 m igual separação encontrada no Observatório Pierre Auger. . . . . . . . . . . . . . . .

6.12 Reconstrução do parâmetro livre $N_{19}$ para diferentes área de exposição dos detectores. A linha verde representa a reconstrução de $N_{19}$ para detectores com área de $90.61 \mathrm{~m}^{2}$, a linha vermelha com área de $40.71 \mathrm{~m}^{2}$ e a linha azul com área de $10.18 \mathrm{~m}^{2}$ igual a área do detectores encontrado no Observatório Pierre Auger. . . . . . . . . . . . . . . . . . . 
6.13 Reconstrução da distribuição de $\theta$ para os modelos de interação hadrônica SIBYLL2.3(azul), EPOSLHC(vermelho) e QGSJETII-04(verde). Foram reconstruídos 1000 EAS inciados por próton com energia de $10^{19} \mathrm{eV}$ e inclinação $\theta=60^{\circ}$ e $\phi=0^{\circ} \ldots \ldots \ldots \ldots \ldots$

6.14 Reconstrução da distribuição de $\phi$ para os modelos de interação hadrônica SIBYLL2.3(azul), EPOSLHC(vermelho) e QGSJETII-04(verde). Foram reconstruídos 1000 EAS inciados por próton com energia de $10^{19} \mathrm{eV}$ e inclinação $\theta=60^{\circ}$ e $\phi=0^{\circ} \ldots \ldots \ldots \ldots \ldots$

6.15 Reconstrução da distribuição de $N_{19}$ para os modelos de interação hadrônica SIBYLL2.3(azul), EPOSLHC(vermelho) e QGSJETII-04(verde).Foram reconstruídos 1000 EAS inciados por próton com energia de $10^{19}$ eV e inclinação $\theta=60^{\circ}$ e $\phi=0^{\circ} \ldots \ldots \ldots \ldots \ldots$

6.16 Evolução da reconstrução do número de múons para chuveiros com energia entre $10^{18.5}$ até $10^{19.5} \mathrm{eV}$ e ângulo $\theta=60^{\circ} \mathrm{e} \phi=0^{\circ}$. Em vermelho é mostrado o resultado da reconstrução para o modelo interações hadrônicas EPOSLHC, em azul, SIBYLL2.3 e em verde, QGSJETII. . . . . . . . . . . . . . . .

A.1 Distribuições da análises de $\rho_{1000}$ para chuveiros iniciados por próton. Esses resultados foram utilizados para geração do gráfico de $\left\langle\rho_{1000}\right\rangle$ em função da energia. . . . . . . . . . . . . . . . . . . .

A.2 Distribuições das análises de $\rho_{1000}$ para chuveiros iniciados por ferro. Esses resultados foram utilizados para geração do gráfico de $\left\langle\rho_{1000}\right\rangle$ em função da energia.

A.3 Distribuições da análises de $X_{\max }^{\mu}$ para chuveiros iniciados por próton. Esses resultados foram utilizados para geração do gráfico de $\left\langle X_{\max }^{\mu}\right\rangle$ em função da energia.

A.4 Distribuições das análises de $X_{\max }^{\mu}$ para chuveiros iniciados por ferro. Esses resultados foram utilizados para geração do gráfico de $\left\langle X_{\max }^{\mu}\right\rangle$ em função da energia.

A.5 Distribuições da análises de $X_{\max }$ para chuveiros iniciados por próton. Esses resultados foram utilizados para geração do gráfico de $\left\langle X_{\max }\right\rangle$ em função da energia.

A.6 Distribuições das análises de $X_{\max }$ para chuveiros iniciados por ferro. Esses resultados foram utilizados para geração do gráfico de $\left\langle X_{\max }\right\rangle$ em função da energia. 
A.7 Distribuições da análises de $N_{\mu}$ para chuveiros iniciados por próton. Esses resultados foram utilizados para geração do gráfico de $\left\langle N_{\mu}\right\rangle$ em função da

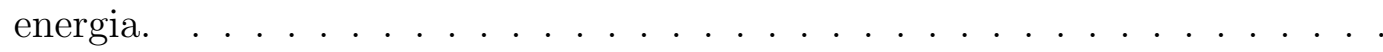

A.8 Distribuições das análises de $N_{\mu}$ para chuveiros iniciados por ferro. Esses resultados foram utilizados para geração do gráfico de $\left\langle N_{\mu}\right\rangle$ em função da energia. . . . . . . . . . . . . . . . . . . . .

B.1 Mapas bidimensional da distribuição de múons no nível de observação para um chuveiro com energia de $10^{17} \mathrm{eV}$ inciado por um próton com inclinação $\theta={ }^{\circ} .142$

C.1 Representação geométrica da propagação da frente de chuveiro plana. . . . . 144

C.2 Distribuições da reconstrução de $N_{19}$ para chuveiro iniciados por próton. Esses resultados foram utilizados para geração do gráfico de $\left\langle N_{19}\right\rangle$ em função da energia. . . . . . . . . . . . . . . . . . . .

C.3 Distribuições da reconstrução de $N_{19}$ para chuveiro iniciados por ferro. Esses resultados foram utilizados para geração do gráfico de $\left\langle N_{19}\right\rangle$ em função da energia. . . . . . . . . . . . . . . . . . . 



\section{Lista de Tabelas}

6.1 Valores da reconstrução de $N_{19}$ para diferentes distâncias entre os detectores e áreas de coleção. . . . . . . . . . . . . . . . . . . . . . . . 123 



\section{Sumário}

$\begin{array}{llr}1 & \text { Introdução } & 27\end{array}$

2 Raios cósmicos de altíssimas energias $\quad 31$

2.1 Contexto histórico . . . . . . . . . . . . . . . . . . . . 32

2.2 Chuveiro atmosférico extenso . . . . . . . . . . . . . . . . 33

2.2 .1 Componente eletromagnética . . . . . . . . . . . . 36

2.2.2 Modelo de Heitler para cascatas eletromagnéticas . . . . . . . . . . 38

2.2 .3 Componente hadrônica . . . . . . . . . . . . . . . . . . . . . 41

2.2.4 Modelo de Matthews para cascatas hadrônicas . . . . . . . . . . . . 43

2.2.5 Modelo de superposição para núcleos . . . . . . . . . . . . . . 45

2.3 Observatório Pierre Auger . . . . . . . . . . . . . . . . . . . 47

2.3.1 Detectores de superfície . . . . . . . . . . . . . . . . 48

2.3 .2 Telescópios de fluorescência $\ldots \ldots \ldots \ldots$

2.3 .3 Projeto AMIGA . . . . . . . . . . . . . . . . 50

2.4 Principais resultados de raios cósmicos . . . . . . . . . . . . . . 51

2.4 .1 Espectro de energia . . . . . . . . . . . . . . . . . 51

2.4 .2 Composição . . . . . . . . . . . . . . . . . . . . 56

2.4 .3 Anisotropia . . . . . . . . . . . . . . . . . 57

2.4 .4 Excesso de múons . . . . . . . . . . . . . . . . . . . . . . 59

3 Interações hadrônicas em chuveiros atmosféricos $\quad 63$

3.1 Variáveis de trabalho . . . . . . . . . . . . . . . . . . . 64

3.1 .1 Rapidez . . . . . . . . . . . . . . . . . . . . . . 64

3.1 .2 Pseudorapidez . . . . . . . . . . . . . . . . . . 66

$3.1 .3 \quad$ A variável de Feynman $x_{F} \ldots \ldots \ldots \ldots \ldots$

3.2 Modelos de interações hadrônicas . . . . . . . . . . . . . . . . . 68

$3.2 .1 \quad$ EPOSLHC . . . . . . . . . . . . . . . . . . . . . . . . . . . . . 69

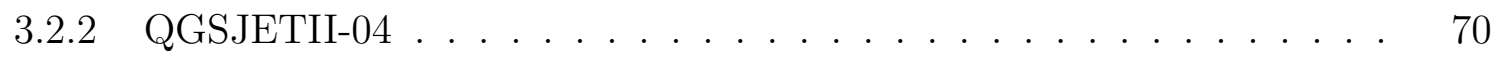




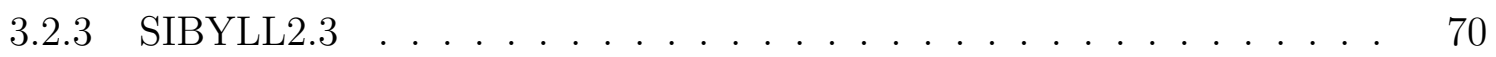

3.3 Comparação entre os modelos hadrônicos . . . . . . . . . . . . . . . 71

$\begin{array}{lll}4 & \text { Análise dos observáveis de chuveiros atmosféricos } & \mathbf{7 7}\end{array}$

4.1 Densidade lateral de múons . . . . . . . . . . . . . . . . . . 77

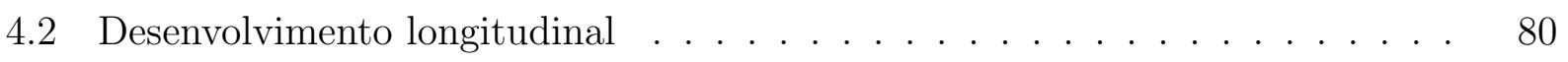

4.3 Número de múons no nível de observação . . . . . . . . . . . . . . . . . 83

4.4 Produção de múons em função da profundidade atmosférica $\ldots . . \ldots . .85$

$\begin{array}{lll}5 & \text { Distribuição de pseudorapidez e EAS } & 91\end{array}$

5.1 Distribuição de pseudorapidez no desenvolvimento de um EAS . . . . . . . 92

5.1.1 Modelando a distribuição de pseudorapidez . . . . . . . . . . . . . . 93

5.1.2 Remodelando a distribuição de pseudorapidez . . . . . . . . . . . 96

5.2 Resultado sobre observáveis de EAS . . . . . . . . . . . . . . . . . 98

5.2 .1 Desenvolvimento longitudinal . . . . . . . . . . . . . . . . . 98

5.2 .2 Número de múons no nível de observação . . . . . . . . . . . . . . 100

5.2 .3 Profundidade máxima de produção de múons . . . . . . . . . . . 101

5.2 .4 Densidade lateral de múons . . . . . . . . . . . . . . . . . 103

5.3 Consequência da distribuição nos observáveis . . . . . . . . . . . . . . 105

6 Inclusão de efeitos do detector $\quad 107$

6.1 Simulação do arranjo de detectores . . . . . . . . . . . . . . . . 107

6.2 Direção de chegada . . . . . . . . . . . . . . . . . . . . . . 110

6.3 Número de múons . . . . . . . . . . . . . . . . . . . . . . . 111

6.4 O problema do "thinning" em EAS . . . . . . . . . . . . . . . . . 113

6.4 .1 O método "thinning" . . . . . . . . . . . . . . . . . . . . . . 113

6.4 .2 Consequências em EAS . . . . . . . . . . . . . . . . . . . 114

6.4 .3 Processo de "dethinning" . . . . . . . . . . . . . . . . . . . . . . 114

6.5 Cenário de teste da reconstrução . . . . . . . . . . . . . . 116

6.6 Reconstrução com simulações de EAS . . . . . . . . . . . . . . . . . . . . 121

6.6.1 Reconstruindo a direção de chegada para dados de EAS . . . . . . . . 121

6.6 .2 Número de múons . . . . . . . . . . . . . . . . . . . . . . . . . 123

6.6 .3 Evolução em função da energia $\ldots \ldots \ldots$. . . . . . . . 125

$\begin{array}{llr}7 & \text { Conclusões } & 127\end{array}$ 
A Análise dos observáveis

A.1 Densidade lateral de múons em função da distância ao eixo do chuveiro . . . 132

A.2 Produção de múons em função da profundidade atmosférica . . . . . . . . . 134

A.3 Desenvolvimento longitudinal do chuveiro . . . . . . . . . . . . . 136

A.4 Número de múons no nível de observação . . . . . . . . . . . . . . . . . . 138

$\begin{array}{ll}\text { B Distribuição de pseudorapidez } & 141\end{array}$

B.1 Distribuição de múons por intervalo de pseudorapidez . . . . . . . . . . . . . 142

$\begin{array}{ll}\text { C Reconstrução dos observáveis } & 143\end{array}$

C.1 Distância radial no plano de propagação do chuveiro . . . . . . . . . . . . . . 144

C.2 Tamanho do chuveiro médio $\left(N_{19}\right) \ldots \ldots \ldots \ldots \ldots \ldots$

$\begin{array}{lr}\text { D Simulações do CORSIKA } & 147\end{array}$

D.1 Exemplo de arquivo de entrada para simulação de EAS . . . . . . . . . . . . 148

D.2 Exemplo do arquivo de partículas secundárias . . . . . . . . . . . . . 150 



\section{Capítulo 1}

\section{Introdução}

Estudos experimentais de raios cósmicos de altíssimas energias (Ultra High Energy Cosmic Ray, UHECR) são realizados usando técnicas de chuveiros atmosféricos extensos (Extensive Air Shower, EAS). As propriedades dos raios cósmicos primários são reconstruídas a partir de características das cascatas eletromagnéticas e hadrônicas induzidas pela interação do UHECR com a atmosfera. Como consequência natural, as simulações de Monte Carlo para o desenvolvimento dos EAS tornam-se importantes, particularmente a cascata de interações hadrônicas do raio cósmico primário e das partículas secundárias. Tais interações hadrônicas são uma fonte importante de incerteza nas altas energias dos UHECR. Por sua vez, os modelos de interações hadrônicas são testados até a energia máxima dos aceleradores de partículas, tais como o LHC [17](Large Hadron Collider) que atinge energias da ordem de $10^{17}$ eV no referencial do laboratório (equivalente a $14 \mathrm{TeV}$, no referencial de centro de massa para colisões próton-próton). Contudo, UHECR têm energias até três ordens de grandeza acima dos aceleradores e, consequentemente, simulações de EAS precisam extrapolar as propriedades das interações hadrônicas para essas energias.

Visto, portanto, que os modelos mais energéticos gerados pelos aceleradores ainda não são suficientes para descrever os UHECR, buscamos na literatura algum indicativo do comportamento esperado desses eventos. Dados gerados pelo Observatório Pierre Auger, sugerem que o número de múons em chuveiros produzidos por UHERC é maior do que o predito pelos principais modelos de simulação de chuveiros atmosféricos[11]. Esse estudo comparou o número de múons em eventos com alta inclinação aos principais modelos de interações hadrônicas utilizados em EAS [11]. O número de múons observado para chuveiros com energia em torno de $10^{19} \mathrm{eV}$ foi de $30 \%$ a $80 \%$ maior que o predito pelos modelos quando assumimos uma composição química para o fluxo incidente de UHECRs compatível com aquela inferida da distribuição de profundidade atmosférica de máximo desenvolvimento do chuveiro. Porém, a significância estatística da medida do excesso de múons é limitada devido 
à incerteza absoluta da calibração de energia.

Além disso, as interações hadrônicas são a principal fonte de múons em EAS. Dessa forma, a diferença entre o número de múons observados e o predito pelas simulações poderia indicar uma incerteza nos modelos de interações hadrônicas, assumindo que a composição química do primário seja bem compreendida. Essa discrepância entre os dados e resultados de simulações quanto à contribuição da componente muônica foi explorada em [12], onde um método foi desenvolvido para desacoplar os efeitos da calibração de energia da incerteza na componente hadrônica de chuveiros com energia em torno de $10^{19} \mathrm{eV}$. Os parâmetros de redimensionamento das componentes eletromagnética $R_{E}$ e hadrônica $R_{\text {had }}$ foram ajustados a uma amostra de chuveiros de alta qualidade (medidos simultaneamente pelos detectores de superfície e de fluorescência do Observatório Pierre Auger), mostrando que a discrepância mencionada aparece tão somente no fator $R_{\text {had }}$ e, portanto, não tem contribuição significativa da escala absoluta de energia associada a $R_{E}$.

Sendo assim, uma possibilidade a ser explorada para explicar o déficit de múons em simulações, pelas evidências apresentadas acima, seria a existência de alguma propriedade das interações hadrônicas a altíssimas energias ainda não completamente compreendida e corretamente implementada nos códigos utilizados atualmente. Por exemplo, novos fenômenos físicos em energias de UHECR são discutidos nas referências [18, 19, 20], enquanto estudos das propriedades incluem o aumento na produção de bárions [21], mésons vetoriais [22] e efeitos de saturação de pártons [16]. Outros trabalhos, como o discutido na referência [15], estudaram a influência dos parâmetros das interações hadrônicas, como a seção de choque, multiplicidade, elasticidade e razão de carga no desenvolvimento de EAS. Nota-se que o ponto principal aqui é o estudo da componente muônica de EAS. Os múons originam-se principalmente do decaimento de píons e káons nos primeiros estágios do desenvolvimento do chuveiro e é nesse momento que ocorrem as interações hadrônicas de altíssimas energias. Dessa forma, estudos da componente muônica podem fornecer informações importantes sobre as interações hadrônicas nessas energias.

Dentro do contexto acima, estudamos a componente muônica de EAS e as interações hadrônicas das primeiras interações de UHECR. No capítulo 4, analisamos os principais observáveis da componente muônica de EAS com diferentes modelos de interações hadrônicas. Desenvolvemos um estudo dos principais observáveis de EAS para os modelos de interações hadrônicas SIBYLL2.3 [23], EPOSLHC [13] e QGSJETII-04 [24]. A realização desse estudo foi através das análises da distribuição do número de múons ao longo do eixo da cascata, também conhecido como distribuição longitudinal de múons, da distribuição de profundidades atmosféricas de produção de múons e da densidade de múons no nível do solo e no plano transversal ao eixo da cascata. 
Após o estudo realizado no capítulo 4, onde ficará evidenciado que os modelos de interação hadrônica têm diferenças no desenvolvimento do EAS, estudamos as propriedades das interações hadrônicas. No capítulo 5, foi investigado como a multiplicidade da primeira interação de um UHECR poderia modificar os observáveis estudados no capítulo anterior. Alteramos a forma da distribuição de pseudorapidez $d N / d \eta$ para chuveiros simulados com modelo de interação hadrônica SIBYLL2.3. Tal estudo, foi motivado em entender como a região frontal de $d N / d \eta$ impacta nos observáveis de EAS. Para tal tarefa, modificou-se a distribuição $d N / d \eta$, conservou-se a energia e também o número total de partículas. Dessa forma, apenas alterou-se a distribuição de momento das partículas secundárias produzidas na primeira interação de UHECR.

Finalmente no capítulo 6, aprofundamos a análise realizada no capítulo 4 através da adição de erros sistemáticos. Inserimos os efeitos de granularidade da rede e área de detecção no processo e estudamos o número de múons $N_{19}$ para diferentes espaçamentos e área de coleção do arranjo de detectores. O processo de detecção da componente muônica foi similar a um arranjo de detectores do Observatório Pierre Auger e seu projeto de atualização AMIGA [25]. Examinamos se a diferenças entres os modelos de interação continuaria existindo e se poderíamos observá-la após o processo de reconstrução. Durante o processo de reconstrução, surgiram correções necessárias nos dados de simulação de EAS, porque é necessária a aplicação do procedimento chamado thinning [26] para realizar simulações de EAS acima de $10^{17} \mathrm{eV}$. Esse procedimento dilui a informação do chuveiro através da remoção de partículas e da aplicação de pesos estatísticos para conservação da energia total do chuveiro, reduzindo consideravelmente o custo computacional da simulação de EAS. Porém, sua aplicação dilui consideravelmente a informação da densidade de múons no solo, tornando impossível reconstruir os múons no arranjo de detectores proposto nesse trabalho. Para solucionar o problema, foi utilizado um método estatístico a fim de recriar a distribuição de densidade de múons no solo, a partir de uma distribuição suavizada no espaço de parâmetros das partículas [27]. 


\section{Capítulo 2}

\section{Raios cósmicos de altíssimas energias}

Os UHECR são as partículas mais energéticas observadas na natureza, com energias acima de aproximadamente $10^{18} \mathrm{eV}$, e continuamente chegam até à Terra vindas do espaço sideral. O fluxo é baixo, chegando a uma partícula por quilômetro quadrado por século, para energias superiores a $5 \times 10^{19} \mathrm{eV}$. Somente é possível observar os UHECR através dos EAS que são produzidos quando os raios cósmicos interagem com a atmosfera terrestre. Atualmente, as medidas de UHECR são realizadas pelo Observatório Pierre Auger [28], que se encontra no hemisfério sul, e o Telescope Array [29], que se encontra no hemisfério norte. Por causa da raridade dos UHECRs, sabemos pouco sobre suas fontes e também não sabemos como essas partículas ganham energias tão altas. Talvez possam ser amostras de material extragaláctico, evidências de uma física desconhecida ou, mais além, partículas exóticas formadas no começo do universo. 


\subsection{Contexto histórico}

Os raios cósmicos foram descobertos em 1912 por Victor Hess [30]. Ele estava tentando compreender porque corpos carregados perdiam sua carga mais rápido do que o esperado. Para excluir o efeito associado à radioatividade na Terra, ele carregou instrumentos em um balão para medir a taxa de produção de íons no ar em função da altitude. Neste experimento, Hess constatou que a taxa de ionização aumentava em função da altitude e multiplicava por um fator 3 para altitudes em torno de $5000 \mathrm{~m}$. Então, concluiu que a Terra era bombardeada por uma radiação vinda do espaço. Diversos nomes foram utilizados para caracterizar o fenômeno até que, em 1920, Millikan introduziu o termo raios cósmicos. Nas décadas de 1930 e 1940, descobriu-se que os raios cósmicos, de fato, eram partículas carregadas. Além disso, encontraram diversas partículas elementares, como o píon pelos físicos César Lattes e Cecil Powell [31], fazendo dos raios cósmicos o início dos estudos de Física de Partículas.

Já os EAS foram descobertos por Auger e seus colaboradores por volta de 1939 [32]. Auger mostrou a existência dos EAS e estudou suas propriedades usando contadores GeigerMüller e câmaras de nuvens. Uma parte dos contadores foi instalada no nível do solo e a outra parte em dois países, nas montanhas Jungfraujoch (3500 m) e Pic do Midi (2900 m). Ele mostrou que se dois ou três contadores forem separados por uma distância horizontal, um pequeno número de coincidências podem ser observadas. Contudo, ele observou que esse número diminuía rapidamente quando aumentava a separação horizontal entre os contadores em centenas de metros. Esse resultado permitiu a Auger concluir que a coincidência observada era devido a uma cascata de partículas iniciada por um raio cósmico com energia em torno de $10^{15} \mathrm{eV}$.

Estudos de EAS com contadores Geiger-Müller continuaram crescendo com adição de mais detectores, permitindo a detecção de eventos com energia maior que $10^{17} \mathrm{eV}$. Porém, esse tipo de experimento era limitado, pois não podia medir a direção de chegada dos chuveiros. Essa limitação foi superada pelo desenvolvimento da técnica de reconstrução da direção de chegada através da medida temporal de disparo de cintiladores [33]. Entre 1954 e 1957, um arranjo de 15 cintiladores, cada um com $0.9 \mathrm{~m}^{2}$, operou na estação Harvard Agassiz no Estados Unidos. A ideia de usar um arranjo de cintiladores para detecção de EAS foi usada como protótipo para os arranjos de grandes altitudes, como Chacaltaya na Bolívia [34] e Volcano Ranch no novo México [35]. O último foi o primeiro arranjo gigante que observou um UHECR com energia estimada em $10^{20} \mathrm{eV}$.

No começo dos anos 1960, antes da descoberta da radiação cósmica de fundo [36], suspeitava-se que o espectro de raios cósmicos podia se estender a energias maiores que $10^{21}$ eV, e métodos alternativos de detecção foram explorados. Um método em particular foi a 
possibilidade de usar a atmosfera como um grande cintilador. Esperava-se que as partículas carregadas do EAS, ao atravessarem a atmosfera, ionizassem seus átomos e esses, por sua vez, emitissem alguma radiação. Somente em 1968, Tanashi e seus colaboradores tiveram o primeiro sucesso ao detectar a radiação de fluorescência de um chuveiro com $10^{19} \mathrm{eV}$ na montanha Dodaira perto de Tokyo [37].

Já nos anos 1970, foram montados os primeiros arranjos híbridos, compostos por detectores de superfície e detectores de fluorescência. No ano de 1976, em Volcano Ranch, realizou-se a primeira detecção híbrida da emissão de radiação fluorescente em conjunto com um arranjo de detectores Cherenkov de superfície [38]. O sucesso desse experimento levou à construção de outros como Fly's Eye [29], Telescope Array e Observatório Pierre Auger.

Em 1992, desenvolveu-se o projeto Pierre Auger, por sugestão de Jim Cronin e Alan Watson, para construção de um arranjo gigante para detecção de EAS com uma exposição muito maior do que os anteriores. A produção, o arranjo e a estimativa de custo foi feita pelo grupo do projeto Auger hospedado pelo Fermilab, em Illinois, Estados Unidos, tornandose a base para propostas de financiamento em 17 países participantes. Essa sugestão se transformou no Observatório Pierre Auger com área de detecção de $3000 \mathrm{~km}^{2}$, localizado na província de Mendoza, Argentina, perto dos Andes [28]. Sua construção teve início em 2000, começou a operar parcialmente em 2004 e foi oficialmente terminado em 2008. Atualmente, o Observatório Pierre Auger é o maior arranjo de detectores em funcionamento, com capacidade de observar eventos com energia média de $10^{18.5} \mathrm{eV}$. Já em 2008, observou a supressão do fluxo para energias em torno de $10^{19.4} \mathrm{eV}$ que foi predito na teoria de GZK. Até a presente data, o Observatório Pierre Auger realizou diversas medidas de UHECR onde podemos destacar a medida da profundidade de máximo desenvolvimento de chuveiros com energias em torno de $10^{18.5} \mathrm{eV}$ [39], medidas de seção de choque próton-próton para energias de centro de massa de $57 \mathrm{TeV} /$ núcleon, limites para detecção de neutrinos com energia acima de $10^{18} \mathrm{eV}$, a observação de anisotropias em grandes escalas angulares e vários outros resultados [10].

Atualmente, o Observatório planeja atualizar seus sistemas de detecção e tal iniciativa é denominada AugerPrime [40]. Um dos principais objetivos dessa atualização é obter uma melhor separação entre as componentes muônica e eletromagnética dos chuveiros.

\subsection{Chuveiro atmosférico extenso}

Chuveiros atmosféricos extensos (EAS) são cascatas de partículas que se desenvolvem na atmosfera terrestre após a colisão de um UHECR com um núcleo de ar (composto principalmente de nitrogênio e oxigênio) a uma altura típica de 15 a $35 \mathrm{~km}$, em relação ao nível do mar. O EAS é um sistema complexo de produção de múltiplas partículas que pode ser 
separado nas componentes eletromagnética, muônica e hadrônica, como mostrado na figura 2.1. A componente eletromagnética é basicamente composta de fótons, elétrons e pósitrons, enquanto os múons desenvolvem a componente muônica e os prótons, píons carregados e fragmentos nucleares compõem a componente hadrônica.

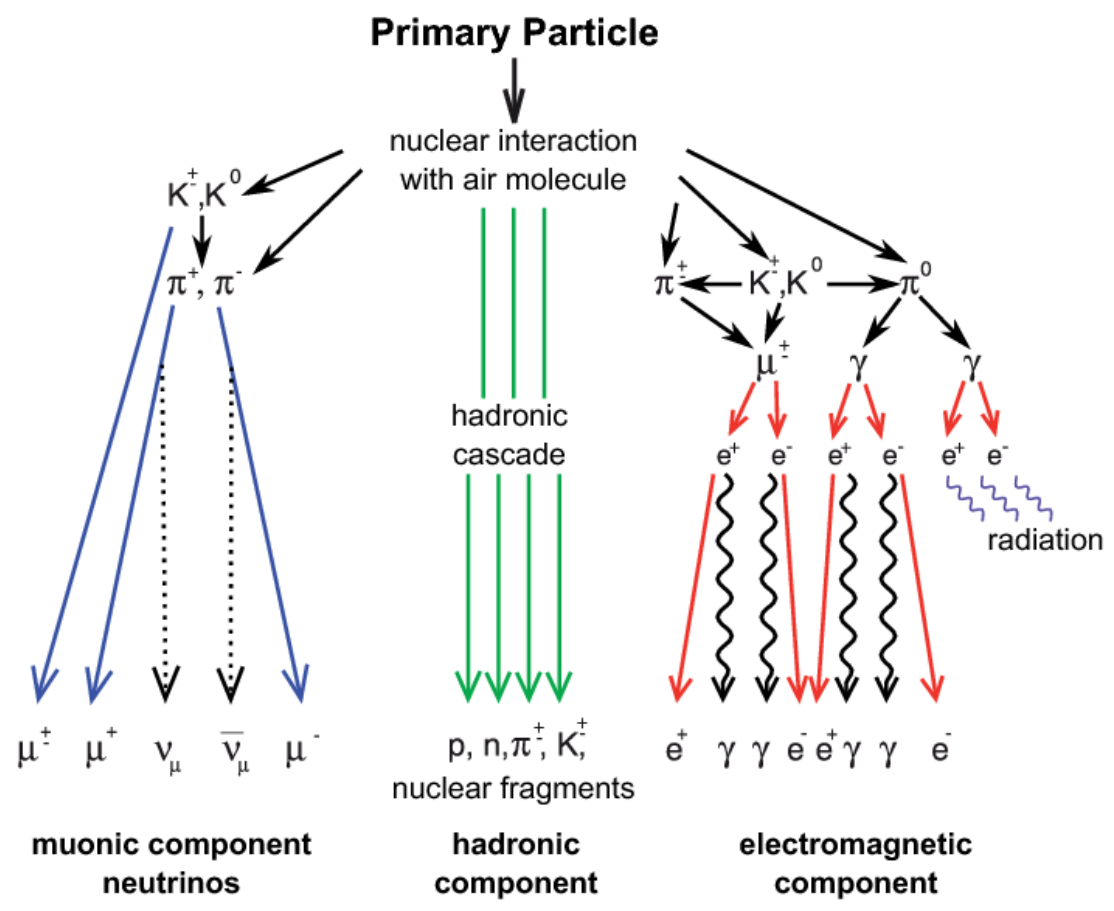

Figura 2.1: Esquema do desenvolvimento das três componentes de um chuveiro atmosférico extenso.

O EAS inicia quando um raio cósmico com altíssima energia colide com um núcleo presente na atmosfera. Desta primeira colisão são produzidas partículas altamente energéticas que continuam a penetrar na atmosfera. Essas partículas interagem novamente na atmosfera, iniciando um processo em cascata de produção de partículas. Os hádrons produzidos na cascata formam a componente hadrônica e, ao atingir o solo terrestre, se espalham por poucos metros de diâmetro em relação ao eixo do EAS* . A cada interação nuclear também são produzidos píons neutros, que carregam uma fração significativa da energia do primário, e decaem imediatamente em fótons. Os fótons de altas energias, na presença do campo eletrostático de núcleos da atmosfera, convertem-se em pares elétron-pósitron. Já os elétrons/pósitrons interagem por efeito de bremsstrahlung e irradiam fótons, produzindo um chuveiro eletromagnético. Os píons carregados $\pi^{ \pm}$, além de colidirem com os núcleos, podem também decair em múons carregados $\mu^{ \pm}$originando o chuveiro muônico. O desenvolvimento lateral da cascata ocorre devido ao efeito acumulado de sucessivos espalhamentos. O número de

${ }^{*} \mathrm{O}$ eixo do EAS é uma linha reta que o raio cósmico teria seguido até atingir o solo, caso não interagisse. 
partículas continua aumentando devido às sucessivas interações até atingir uma profundidade de máximo do chuveiro, onde a probabilidade da partícula ser absorvida por ionização ao atravessar a atmosfera passa a ser maior que a probabilidade de produzir novas partículas.

O desenvolvimento dos EAS pode ser observado sob aspectos de diferentes métodos, já que, durante seu desenvolvimento, diversos tipos de radiação são observados, como a emissão de rádio, quando partículas carregadas são defletidas pelo campo magnético terrestre (emissão coerente geomagnética [41]) e também pelo excesso de elétrons na frente do chuveiro (efeito Askarian [42]). A radiação de fluorescência é emitida quando partículas carregadas do chuveiro atravessam a atmosfera terrestre e excitam as moléculas, principalmente $\mathrm{N}_{2}$, e parte dessa energia de excitação é emitida em forma de radiação isotrópica, no espectro visível e no ultravioleta.

As medidas de desenvolvimento do EAS são feitas geralmente em função da profundidade atmosférica, que é dada por

$$
X=\int_{h}^{\infty} \rho\left(h^{\prime}\right) d h^{\prime}
$$

onde $\rho\left(h^{\prime}\right)$ é a densidade atmosférica em função da altura $h^{\prime}$. Nota-se que a grandeza $X$ é uma medida de quantidade de matéria atravessada normalmente dada em $\mathrm{g} / \mathrm{cm}^{2}$ e a integração da variável $h^{\prime}$ é realizada ao longo do caminho representado pelo eixo da cascata. A profundidade atmosférica na qual o EAS atinge o maior número de partículas é chamada de $X_{\max }$ e é um parâmetro importante no estudo de UHECR. Na figura 2.2 é mostrado um

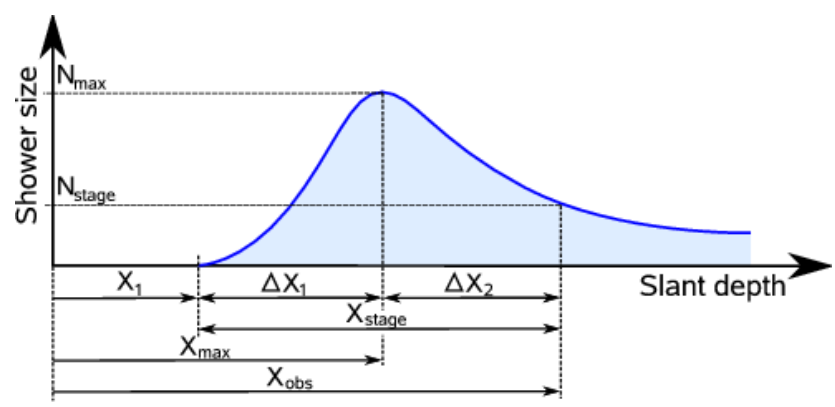

Figura 2.2: Esquema do desenvolvimento longitudinal de um EAS com destaque aos principais pontos importantes.

esquema do desenvolvimento longitudinal do chuveiro destacando pontos importantes, como a profundidade da primeira interação, $X_{1}$, a profundidade do máximo do chuveiro $X_{\max } \mathrm{e}$ o nível de observação $X_{o b s}$. Esse último parâmetro é geralmente associado ao solo onde é instalado o arranjo de detectores para observar o desenvolvimento lateral do EAS. O perfil lateral de desenvolvimento do EAS mostrado na figura 2.3, é caracterizado pela densidade de partículas que atravessam o nível de observação em função da distância do eixo do chuveiro 
$r_{\text {core }}$.

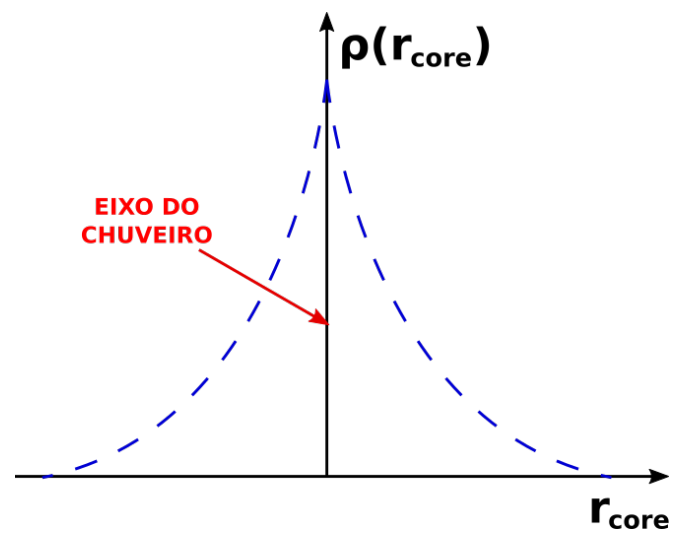

Figura 2.3: Perfil de desenvolvimento lateral de um EAS. Exemplo de espalhamento lateral da densidade de partículas, $\rho\left(r_{\text {core }}\right)$, em função da distância radial $r_{c o r e}$ do eixo do chuveiro.

\subsubsection{Componente eletromagnética}

A componente eletromagnética dos EAS é caracterizada pela produção de cascatas de partículas eletromagnéticas. Um chuveiro eletromagnético começa quando um elétron, pósitron ou fóton de alta energia interage com o meio, produzindo uma cascata. O desenvolvimento do chuveiro pode ser imaginado a partir de um fóton de altíssima energia entrando na atmosfera. Após uma distância viajada, ele desaparece pela produção de par elétron-pósitron e a energia do fóton é dividida entre o elétron e o pósitron. Por sua vez, o elétron e o pósitron viajam uma distância e radiam fótons por efeito de bremsstrahlung. Assim, sucessivamente, por efeito de produção de pares e bremsstrahlung, novas partículas vão sendo criadas durante o desenvolvimento do chuveiro. A energia vai sendo repartida entre as partículas geradas no chuveiro, e também sendo perdida por ionização, até que os elétrons, pósitrons e fótons atingem a energia crítica $E_{c}$. Abaixo dessa energia, os elétrons não radiam mais fótons com energia suficiente para produzirem pares elétron-pósitron e os fótons acabam sendo absorvidos por efeito fotoelétrico.

Os processos básicos que governam uma cascata eletromagnética são a produção de pares elétron-pósitron, a emissão de radiação de bremsstrahlung e a perda de energia devida à ionização do meio interagente por partículas eletromagnéticas. Os diagramas de Feynman, de ordem mais baixa em teoria de perturbação para a produção de pares elétron-pósitron e do efeito bremsstrahlung são mostrados na figura 2.4, e suas formulas são devido a Bethe e Heitler [43].

A probabilidade de um elétron com energia $E$ radiar um fóton com energia $W=v E$ 


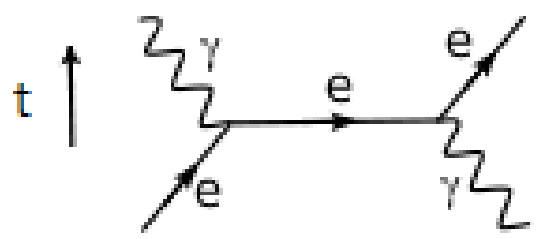

(a) Bremsstrahlung

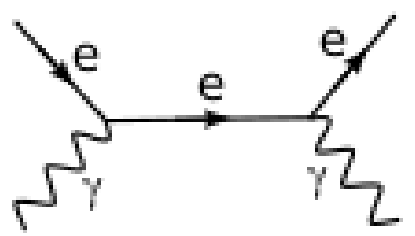

(b) Produção de Pares

Figura 2.4: Representações, em diagrama de Feynman, das principais interações eletromagnéticas. Em (a) temos o efeito bremsstrahlung, e em (b) ocorre a produção de pares elétron-pósitron.

ao atravessar uma camada $d t=d X / X_{\text {rad }}$ da atmosfera é dada por $\phi(E, v) d t d v$

$$
\phi(E, v) \underset{E \gg E_{c}}{\longrightarrow} \phi(v)=v+\frac{1-v}{v}\left(\frac{4}{3}+2 b\right),
$$

o comprimento de radiação de um elétron no ar, $X_{\text {rad }}$ é $37.1 \mathrm{~g} / \mathrm{cm}^{2}$, e $b=\left(18 \times \ln \left[183 / Z^{1 / 3}\right]\right)^{-1}$. Então, a taxa de energia perdida por bremsstrahlung é

$$
\frac{d E}{d X}=-\frac{1}{X_{r a d}} \int_{0}^{1}(v E) \phi(v) d v=-\frac{1}{X_{r a d}} E \times(1+b) \approx-\frac{E}{X_{r a d}} .
$$

A probabilidade total por unidade de comprimento de radiação para bremsstrahlung, dada por

$$
\int_{0}^{1} \phi(v) d v
$$

contém uma divergência logarítmica em $v \rightarrow 0$. Essa divergência requer um cuidado especial com a distribuição 2.2 quando usada no cálculo de Monte Carlo. Um limite inferior precisa ser introduzido na equação para evitar a divergência no infravermelho. Basicamente, precisamos escolher um corte, tal que, $v_{m i n} E_{0} \ll E_{\text {int }}$, onde $E_{\text {int }}$ é a menor energia de interesse no problema.

A expressão correspondente para produção de pares é a probabilidade $\Psi(W, u) d t d u$ de um fóton produzir um par elétron-pósitron onde a energia do pósitron é $E=u W$,

$$
\Psi(E, u) \underset{E \gg E_{c}}{\longrightarrow} \Psi(u)=\frac{2}{3}-\frac{1}{2}+\left(\frac{4}{3}+2 b\right)\left(u-\frac{1}{2}\right)^{2} .
$$

Diferente do caso do bremsstrahlung, onde existe uma divergência característica na região do infravermelho, a função de distribuição de probabilidade da produção de pares pode ser 
integrada para encontrar a probabilidade total por unidade de comprimento de radiação,

$$
\int_{0}^{1} \Psi(u) d u=\frac{7}{9}-\frac{1}{3} b \approx \frac{7}{9}
$$

Além desses processos, temos também a perda de energia por ionização que ocorre quando uma partícula carregada atravessa um meio material, neste caso a atmosfera. A partícula excita os elétrons dos núcleos atômicos, perdendo parte de sua energia por ionização. Essa perda de energia pode ser escrita como

$$
d E / d X=-\alpha(E)-E / X_{r a d}
$$

onde $\alpha(E)$ é a energia perdida por unidade de comprimento devido à ionização e $d E / d X$ é a energia perdida na atmosfera pela partícula ao atravessar uma distância $X$ até $X+d X$. Na referência [44], a equação de perda de energia por ionização para elétrons, com energia $\gamma m c^{2}$, é dada por

$$
-\frac{d E}{d x}=\frac{e^{4} N_{e}}{8 \pi \varepsilon_{0}^{2} m_{e} v^{2}}\left[\ln \frac{\gamma m_{e} v^{2} E_{\max }}{2 \bar{I}^{2}}-\left(\frac{2}{\gamma}-\frac{1}{\gamma^{2}}\right) \ln (2)+\frac{1}{\gamma^{2}}+\frac{1}{8}\left(1-\frac{1}{\gamma}\right)^{2}\right]
$$

onde $N_{e}$ é o número de elétrons, $\varepsilon_{0}$ é a constante de permissividade do vácuo, $\bar{I}$ é a energia média de excitação e $E_{\max }$ é a energia máxima transferida em uma única colisão. A perda de energia por colisão, ou espalhamento Compton, pode ser desprezada na cascata eletromagnética, pois enquanto a cascata mantiver uma energia muito maior que a energia crítica $E_{c}$, estaremos em uma situação completa de blindagem.

\subsubsection{Modelo de Heitler para cascatas eletromagnéticas}

O modelo semi empírico de Heitler [45] é usado para descrever o desenvolvimento de chuveiros eletromagnéticos e prediz com precisão aceitável as propriedades mais importantes desses chuveiros. Esse modelo é composto de fótons e elétrons/pósitrons ${ }^{\dagger}$ que repetidamente interagem e produzem duas partículas. Após viajar uma distância fixa $X$, definida pelo comprimento de radiação $\lambda_{\text {rad }}$, os elétrons interagem por bremsstrahlung e os fótons por produção de par elétron-pósitron. Depois de $n$ interações, haverá um total de $2^{n}$ partículas no chuveiro. A multiplicação é interrompida quando a energia individual de cada partícula estiver abaixo da energia crítica $\xi_{c}$. Nesse ponto a perda média de energia por colisão torna-se maior que a perda por radiação. Desse cenário, duas propriedades muito importante são bem

\footnotetext{
${ }^{\dagger}$ No modelo de Heitler não há distinção entre elétrons e pósitrons
} 
reproduzidas: (i) o número final de partículas $N_{\max }$ é simplesmente proporcional à energia inicial $E_{0}$ e (ii) a profundidade máxima do desenvolvimento do chuveiro é proporcional ao logarítmo de $E_{0}$.

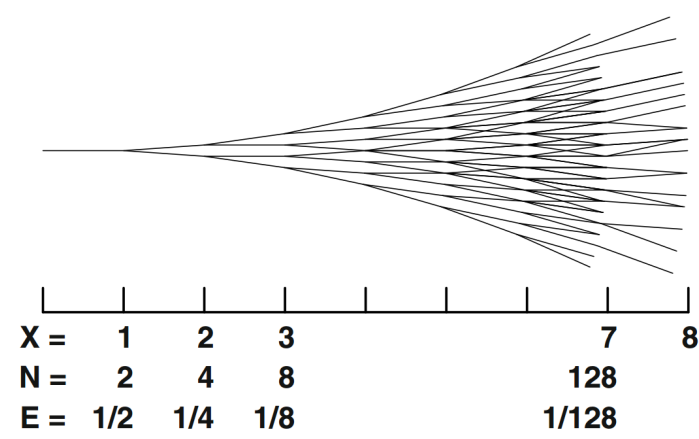

Figura 2.5: Visão esquemática do modelo de Heitler para chuveiros eletromagnético. O chuveiro inicia com uma partícula que viaja por uma distância fixa $X$, definida pelo comprimento de radiação $\lambda_{\text {rad }}$, e interage produzindo duas partículas. Esse processo se repete $n$ vezes até atingir o número máximo de partículas.

Como visto na figura 2.5, um elétron, com energia $E_{0}$, radia um fóton após viajar um comprimento de radiação ${ }^{\ddagger}$

$$
d=\lambda_{\text {rad }} \ln 2 .
$$

e um fóton se desintegra em um par elétron-pósitron, ao viajar a mesma distância. Nesse instante, assume-se que a energia da partícula inicial (elétron ou fóton) é igualmente dividida entre as duas partículas finais. Então, após $n$ interações, a profundidade do chuveiro é

$$
X=n \lambda_{\text {rad }} \ln 2
$$

e o tamanho total do chuveiro é dado por $N=2^{n}=e^{X / \lambda_{\text {rad }}}$. A multiplicação acaba quando a energia se torna menor que a energia crítica $\xi_{c}$. A energia crítica $\xi_{c}$ para chuveiros eletromagnéticos no ar é $85 \mathrm{MeV}$. Quando o chuveiro atinge o seu tamanho máximo $N=N_{\max }$, todas as partículas terão a energia $\xi_{c}$ e a energia total $E_{0}$ pode ser descrita como

$$
E_{0}=\xi_{c} N_{\max }
$$

A profundidade de penetração máxima $X_{\max }$, na qual o chuveiro atinge o seu tamanho máximo, é obtida pela determinação do número $n_{c}$ de divisões requerida para que a energia por partícula seja reduzida para $\xi_{c}$. Então, sabendo que $N_{\max }=2^{n_{c}}$, obtemos da equação

\footnotetext{
${ }^{\ddagger}$ Note que $d$ é de fato a distância em que o elétron perde, na média, metade de sua energia por radiação
} 
2.11 que

$$
n_{c}=\ln \left(\frac{E_{0}}{\xi_{c}}\right) \text {, }
$$

e, consequentemente,

$$
X_{\text {max }}=n_{c} \lambda_{\text {rad }} \ln 2=\lambda_{\text {rad }} \ln \left(\frac{E_{0}}{\xi_{c}}\right) .
$$

A taxa de elongação $\Lambda$ é o crescimento de $X_{\max }$ em relação ao logaritmo da energia $E_{0}$, definida como

$$
\Lambda \equiv \frac{d X_{\max }}{d \log _{10} E_{0}}
$$

Se usarmos $X_{\max }$ da equação 2.13 ,temos $\Lambda=2.3 \lambda_{\text {rad }}=85 \mathrm{~g} / \mathrm{cm}^{2}$ por década de energia do primário para chuveiros eletromagnéticos no ar. A figura 2.6 mostra uma simulação detalhada de chuveiro eletromagnético no ferro $\left(\lambda_{\text {rad }}=13.8 \mathrm{~g} / \mathrm{cm}^{2}\right.$ e $\left.\xi_{c}=22.4 \mathrm{MeV}\right)$. A profundidade máxima, prevista pela equação 2.13 de $X_{\max }=7.4 \lambda_{\text {rad }}$, está muito próxima do valor da simulação. O modelo superestima o número de fótons e elétrons: ele prediz que

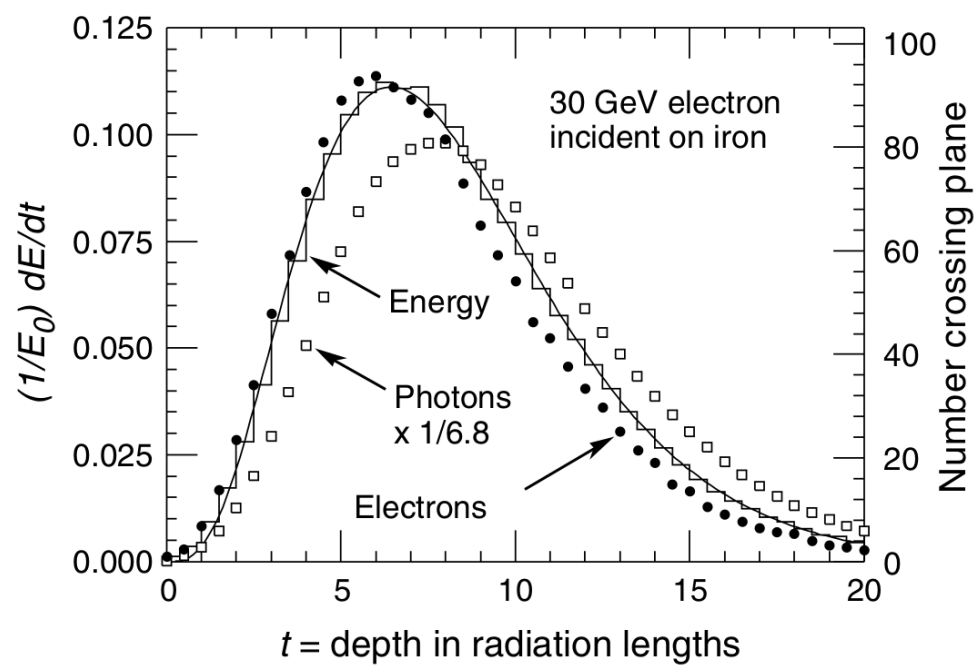

Figura 2.6: Simulação de chuveiro eletromagnético no meio Ferro. Os pontos são elétrons e fótons, e a curva mostra a energia depositada por comprimento de interação. Extraída da referência [1]

após algumas gerações, o número de elétrons $N_{e} \approx(2 / 3) N_{\max }$. Esse valor é muito alto por diversas razões e a principal é que múltiplos fótons podem ser radiados durante emissão de bremsstrahlung. Simulações mostram que o número de fótons é muito maior que o número de elétrons durante o desenvolvimento do chuveiro, como visto na figura 2.6. Para extrair o número correto de elétrons $N_{e}$ do modelo Heitler, temos que adotar um fator de correção:

$$
N_{e}=N / g
$$


onde o valor da constante $g=10$. Desconsiderando suas limitações, o modelo de Heitler consegue reproduzir o tamanho máximo do chuveiro, proporcional a $E_{0}$, e a profundidade máxima que aumenta com o logaritmo da energia, com a taxa de $85 \mathrm{~g} / \mathrm{cm}^{2}$ por década de energia.

\subsubsection{Componente hadrônica}

Chuveiros hadrônicos são cascatas iniciadas por interações hadrônicas de um ou mais núcleons. Na primeira interação, uma fração da energia do núcleon é transferida para os mésons e bárions secundários. O resto da energia permanece com o núcleon que irá interagir novamente após atravessar um comprimento de interação $\lambda_{\text {air }}$. Enquanto isso, alguns mésons secundários também podem interagir produzindo a segunda geração de hádrons da cascata. Esse processo continua até que o núcleon tenha energia abaixo do limite mínimo para produção de hádrons.

Os principais processos que ocorrem durante o desenvolvimento da cascata hadrônica são:

1. Produção de píons, com altas energias, devido à interação do hádron.

2. Os hádrons secundários e píons carregados têm energia suficiente para continuar se multiplicando em sucessivas gerações até que a energia não seja suficiente para produção de píons.

3. A perda de energia por ionização da atmosfera devido aos hádrons carregados;

4. Os píons neutros $\pi^{0}$ têm tempo de vida muito curto $\left(1.78 \times 10^{-16} \mathrm{~s}\right)$ antes de decair em dois fótons $\gamma\left(\pi^{0} \rightarrow 2 \gamma\right)$ e cada $\gamma$ inicia um chuveiro eletromagnético;

5. Muitos dos píons carregados decaem em múons via as interações

$$
\begin{aligned}
& \pi^{+} \rightarrow \mu^{+}+\nu_{\mu}, \\
& \pi^{-} \rightarrow \mu^{-}+\bar{\nu}_{\mu},
\end{aligned}
$$

pois o tempo de vida média desses píons é de $2.603 \times 10^{-8} \mathrm{~s}$.

6. Devido aos múons não interagirem fortemente, eles atravessam a atmosfera perdendo pouca energia por efeito de ionização. Às vezes podem decair, pois tempo de vida média dos múons é $2.196 \times 10^{-6} \mathrm{~s}$ :

$$
\mu^{+} \rightarrow e^{+}+\nu_{e}+\overline{\nu_{\mu}},
$$




$$
\mu^{-} \rightarrow e^{-}+\overline{\nu_{e}}+\nu_{\mu}
$$

Diferentemente dos chuveiros eletromagnéticos que podem ser descritos de maneira bem direta por uma única teoria (QED), a produção de partículas em interações hadrônicas é fortemente dependente da energia e diferentes mecanismos de interações tornam-se importantes para cada região de energia estudada. Porém ainda podemos utilizar o modelo de HeitlerMatthews [1], que será discutido mais à frente, para compreender as principais características do desenvolvimento de EAS.

Em torno de $\sqrt{s} \sim 1-2 \mathrm{GeV}$, a produção de partículas pode ser descrita por modelos isobáricos [46]. A amplitude das ondas parciais de todos os diagramas para a troca de uma única partícula ou fusão de partícula-ressonância, incluindo todas as possíveis excitações de hádrons, são adicionadas com pesos, e a fase relativa é determinada por simetria e comparações com medidas. Dois exemplos desses processos são mostrados na figura 2.7. Píons positivos interagem com prótons e formam uma ressonância $\Delta^{++}(1232)$ que decai na sequência em $\pi^{+}$e $p$. Situação similar ocorre no caso da absorção de fóton exceto pelos diferentes canais de decaimento.
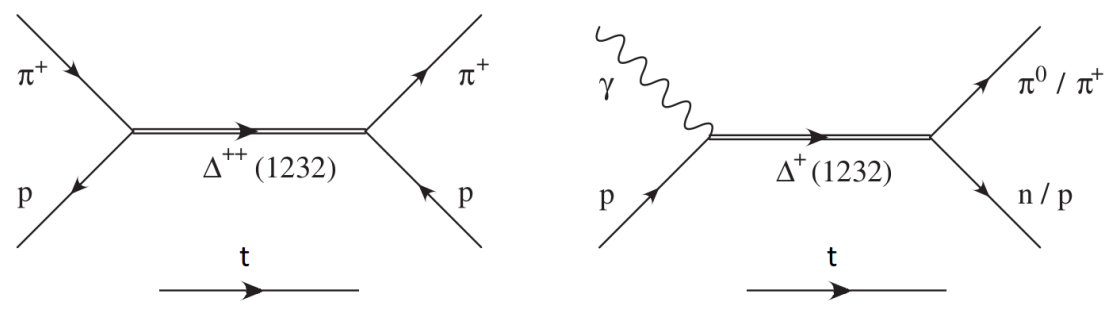

Figura 2.7: Produção de ressonância $\Delta^{++}$(1232) em interações de píons (esquerda) e fótons (direita) com prótons. Retirado da referência [2].

A produção de partículas cresce em função da energia até valores da ordem $\sqrt{s} \sim 100$ $\mathrm{GeV}$. Esse crescimento é descrito satisfatoriamente, de forma fenomenológica, pela teoria de Regge, onde a amplitude de espalhamento é descrita como uma função analítica do momento angular. Em geral, nessa teoria o momento angular não é restrito a número inteiros e pode assumir valores complexos. Dessa forma, a amplitude é considerada uma função complexa que descreve um caminho no plano complexo chamado trajetória de Regge. Essa generalização descreve que as forças de interação forte são originárias da troca de composições de partículas, ou polos de Regge, como mostrado na figura 2.8. Diversos modelos, como párton duplo (DPM) [47] e corda de quark-gluon (QGS) [48] foram desenvolvidos usando a teoria fenomenológica de Regge.

A produção de mini-jatos começa a ocorrer para energias maiores que $\sqrt{s}>100 \mathrm{GeV}$ e é descrita com sucesso pela QCD perturbativa, a qual descreve a produção de partículas em 


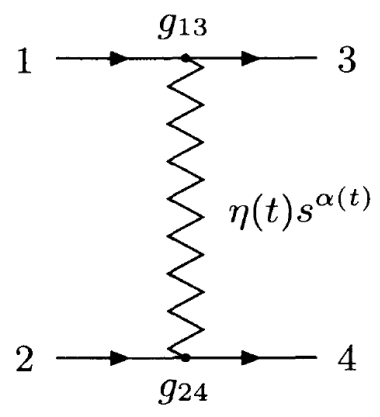

Figura 2.8: Descrição da interação inelástica $1+2 \rightarrow 3+4$ mediada por reggeon. Retirado da referência [3].

termos de pártons livres. Nesse cenário, o hádron é visto como um mar de pártons que são continuamente gerados e reabsorvidos. Durante o processo de colisão hadrônica, a interação é considerada sobre uma configuração independente, como mostrado na figura 2.9.

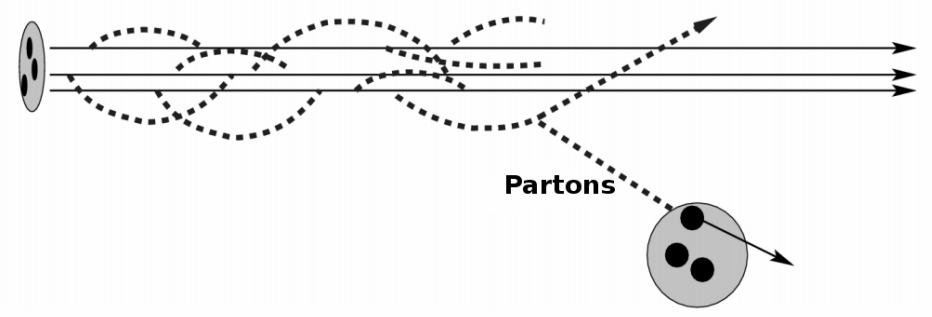

Figura 2.9: Ilustração da interação intermediada por pártons para produção de mini-jatos.

\subsubsection{Modelo de Matthews para cascatas hadrônicas}

O modelo de Matthews [1] para EAS descreve as interações hadrônicas de modo similar ao modelo de Heitler, como mostrado na figura 2.10. Podemos imaginar um hádron interagindo após atravessar uma camada $\lambda_{I}$, produzindo $N_{c h}$ píons carregados e $0.5 N_{c h}$ de píons neutros. Os píons neutros decaem em fótons imediatamente, produzindo sub-chuveiros eletromagnéticos. Já os píons carregados viajam uma distância fixa e interagem produzindo uma nova geração de píons. A multiplicação continua até que a energia individual dos píons esteja abaixo da energia crítica $\xi_{c}^{\pi} \approx 20 \mathrm{GeV}$, momento no qual a probabilidade do píon decair se torna maior que a probabilidade de interação. Todas as interações são perfeitamente inelásticas, com toda a energia indo para a produção de novos píons. A multiplicidade $N_{c h}$ de colisões píons-núcleo é muito similar à interação hadrônica de colisões próton-próton [49]. A produção de partículas cresce muito lentamente com a energia de laboratório, $E^{1 / 5}$, em dados de colisões pp [50]. Desta forma, o modelo de Matthews adota a constante $N_{c h}=10$, 
um valor aceitável para o fator de produção de píons com energia cinética em torno de $1 \mathrm{GeV}$ a $10 \mathrm{TeV}$.

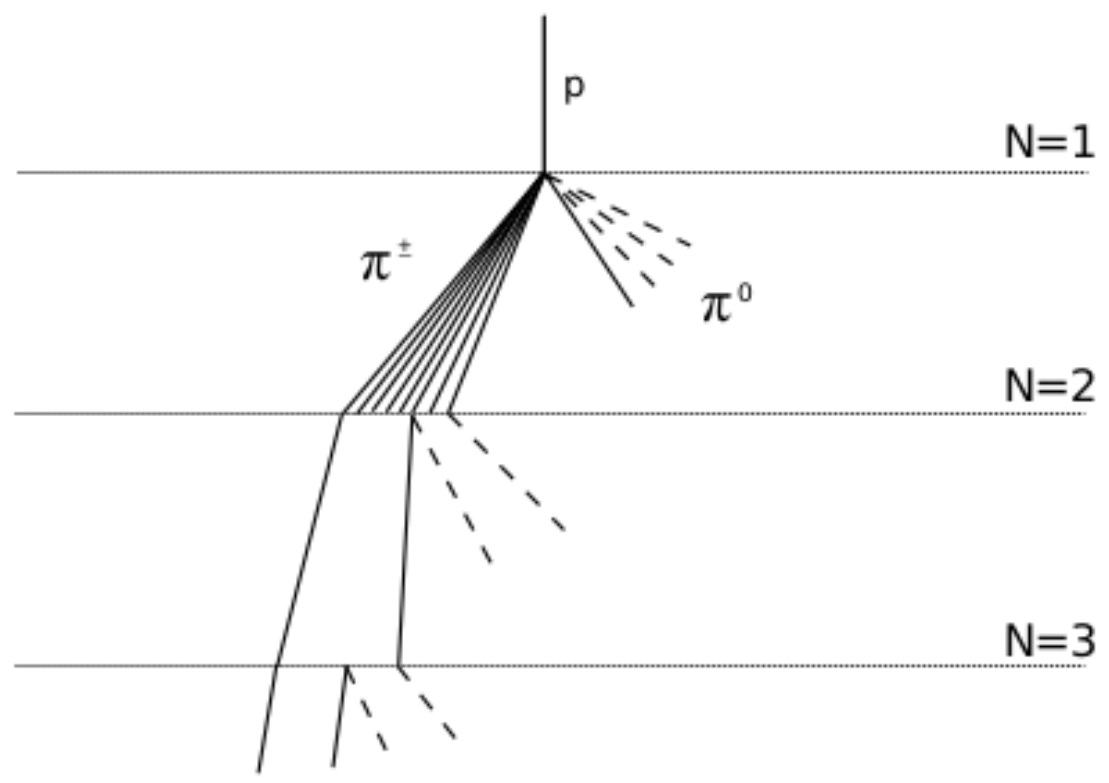

Figura 2.10: Visão esquemática do chuveiro hadrônico.

Considerando um raio cósmico entrando na atmosfera com energia $E_{0}$, teremos após $n$ interações $N_{\pi}=\left(N_{c h}\right)^{n}$ píons carregados. Assumindo divisão igual de energia durante a produção de partículas, esses píons carregam uma energia total de $(2 / 3) E_{0}$. O restante da energia irá para os chuveiros eletromagnéticos que são iniciados pelo decaimento de $\pi^{0}$. Logo, a energia por píon carregado após $n$ interações é dada por

$$
E_{\pi}=\frac{E_{0}}{\left(1.5 N_{c h}\right)^{n}}
$$

e o número de interações $n_{c}$ necessárias para chegar na energia crítica é

$$
n_{c}=\frac{\ln \left(E_{0} / \xi_{c}^{\pi}\right)}{\ln \left(1.5 N_{c h}\right)}=0.85 \log _{10}\left(E_{0} / \xi_{c}^{\pi}\right)
$$

Nesse modelo, o número de múons é dado por $N_{\pi}=N_{\mu}$, e a energia total

$$
E_{0}=\xi_{c} N_{e}+\xi_{c}^{\pi} N_{\mu} \approx 0.85 \mathrm{GeV}\left(N_{e}+24 N_{\mu}\right)
$$

mostra a contribuição relativa por múons e elétrons. Podemos determinar o número total de 
múons usando a equação 2.21 da seguinte forma

$$
\ln N_{\mu}=n_{c} \ln N_{c h}=\beta \ln \left(E_{0} / \xi_{c}^{\pi}\right),
$$

onde $\beta=\ln \left(N_{c h}\right) / \ln \left(1.5 N_{c h}\right)=0.85$. Já a profundidade de máximo desenvolvimento $X_{\max }$ é dada por

$$
X_{\text {max }}=X_{0}+\lambda_{\text {rad }} \ln \left(E_{0} /\left(3 N_{c h} \xi_{c}\right)\right)
$$

onde $X_{0}=\lambda_{I} \ln 2$ é a profundidade da primeira interação. Por último, a taxa de elongação para um chuveiro de próton é dada por

$$
\Lambda^{p}=\Lambda+\frac{d}{d \log _{10} E_{0}}\left(X_{0}-\lambda_{\text {rad }} \ln \left(3 N_{c h}\right)\right)=58 \mathrm{~g} / \mathrm{cm}^{2} \text { por década. }
$$

Um modelo básico de EAS, similar ao modelo de Heitler para cascatas eletromagnéticas, nos permite predizer vários parâmetros razoavelmente bem quando comparado a simulações e dados. A energia primária é proporcional a uma combinação do número de múons e elétrons. O peso relativo depende principalmente das características da escala de energia na qual as interações hadrônicas e eletromagnéticas param de ocorrer. O crescimento do número de múons é lento e proporcional $\sim E_{0}^{\beta}$. O expoente é dependente da fração de energia dada aos píons carregados em cada interação. A taxa de elongação para EAS está em acordo com as simulações.

\subsubsection{Modelo de superposição para núcleos}

A ideia geral do modelo de superposição é reduzir a colisão núcleo-núcleo a um conjunto de colisões núcleon-núcleon. Ou seja, um núcleo com número de massa $A$ e energia $E_{0}$ é considerado composto de $A$ núcleons independentes com energia $E_{h}=E_{0} / A$, pois a energia de ligação, de $\approx 5 \mathrm{MeV}$ por núcleon, começa a ser menor que a energia típica de interação. Nesse cenário, os núcleos são compostos por núcleons e durante o processo de colisão existe a probabilidade dos núcleons do projétil e do alvo interagirem. Os núcleons que interagem durante o processo de colisão são chamados de "núcleons feridos". Podemos determinar o número médio de núcleons feridos no alvo através de um modelo simplificado construído sobre a representação do parâmetro de impacto para seção de choque inelástica

$$
\sigma_{\text {ine }}^{h A}=\sum_{i=1}^{N} \int d^{2} b\left\{1-e^{-\sigma_{i, i n e}^{h h} T(b)}\right\} .
$$


Essa equação mostra que a seção de choque para colisões núcleo-núcleo $\left(\sigma_{\text {ine }}^{h A}\right)$ é composta pelas somas parciais de $N$ seções de choque núcleon-núcleon $\sigma_{i n e}^{h h}$ e os núcleons estão distribuídos sobre o espaço de parâmetro de impacto $b$ com uma probabilidade $T(b)$. Se considerarmos que todos os núcleons são iguais, a equação 2.26 reduz para

$$
\sigma^{h A}=\sum_{i=1}^{N} \int d^{2} b \frac{[\sigma T(b)]^{N}}{N !} e^{-\sigma T(b)} .
$$

O número de núcleons feridos durante o processo de colisão agora é dado por

$$
\langle N\rangle_{p A}=\frac{A \sigma_{p p}}{\sigma_{h A}}
$$

A generalização do número médio de núcleons feridos por projétil nuclear com número de massa $A$ incidente em um núcleo alvo com núemro de massa $B$, é dada por

$$
\langle N\rangle_{A B}=\frac{A \sigma_{h B}}{\sigma_{A B}}+\frac{B \sigma_{h A}}{\sigma_{A B}}
$$

onde o primeiro termo descreve o número de núcleons feridos no projétil e o segundo termo, o número de núcleons feridos no alvo.

O modelo de superposição para núcleos descreve razoavelmente bem EAS iniciados por núcleos. Por exemplo, um chuveiro iniciado por um raio cósmico com número de massa $A$ e energia $E_{0}$ seria equivalente a $A$ chuveiros iniciados por prótons com energia de $E_{0} / A$. Dessa forma, a fração de energia que é transferida para a componente eletromagnética é dada por

$$
N_{e m, \max }^{A}\left(E_{0}\right)=A \cdot N_{e m, \max }^{h}\left(E_{h} / E_{c}\right) \approx N_{e m, \max }\left(E_{0}\right)
$$

onde $N_{e m, \max }^{h}$ é número máximo de partículas por núcleon. Outro resultado é a dependência da composição química na medida do número de múons $\left(N_{\mu}^{A}\right)$, dada por

$$
N_{\mu}^{A}\left(E_{0}\right)=A \cdot\left(\frac{E_{0} / A}{\xi^{\pi}}\right)^{\alpha}=A^{1-\alpha}\left(\frac{E_{0}}{\xi^{\pi}}\right)^{\alpha}
$$

e na profundidade máxima $\left(X_{\max }^{A}\left(E_{0}\right)\right)$ que equivalente a um chuveiro iniciado por um núcleon com energia $E_{0} / A$. 


\subsection{Observatório Pierre Auger}

O Observatório Pierre Auger é um experimento para detecção de UHECR localizado na região de Pampa Amarilla, na Argentina. Esse experimento foi o primeiro a combinar as duas principais técnicas de detecção de chuveiros atmosféricos extensos: telescópios de fluorescência e detectores de superfície de luz Cherenkov. A figura 2.11, mostra o arranjo do Observatório Pierre Auger, os pontos azuis representam os detectores de superfície de luz Cherenkov e os traços verdes mostram esquematicamente a cobertura em azimute do campo de visão de cada um dos seis telescópios de fluorescência presentes em cada uma das quatro estações de observação. O uso de ambas as técnicas simultaneamente torna o experimento um detector híbrido que resulta na redução de erros sistemáticos de medida e possibilita calibrações cruzadas entre as distintas técnicas. Graças, principalmente, a uma área estável de detecção oferecida pelos detectores de superfície e uma medida calorimétrica da energia feita com os telescópios, o Observatório Pierre Auger tem uma capacidade diferenciada no que compete ao campo UHECR.

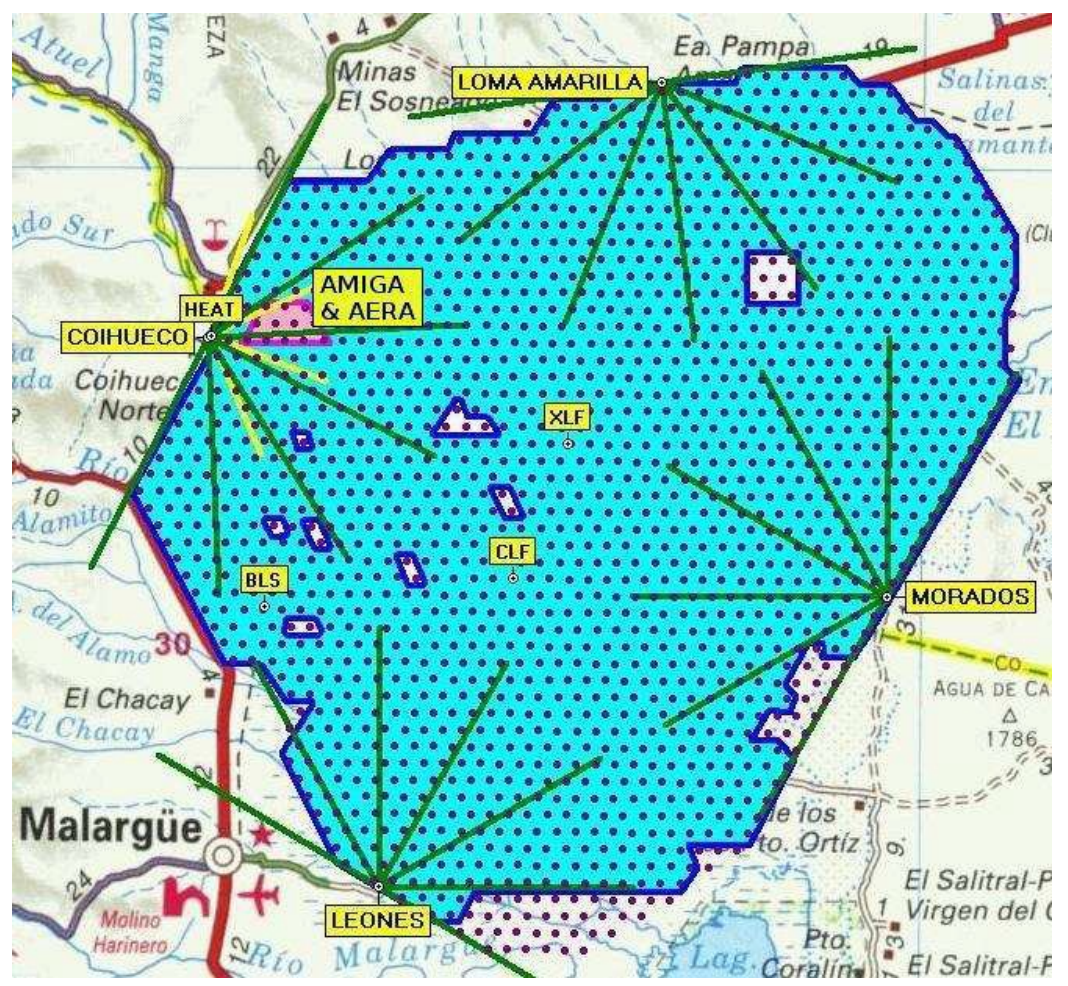

Figura 2.11: Representação do Observatório Pierre Auger, os pontos azuis representam os detectores de superfície de luz Cherenkov e as linhas verdes representam esquematicamente a cobertura em azimute do campo de visão de cada um dos 6 telescópios de fluorescência presentes em cada uma das quatro estações de observação. 


\subsubsection{Detectores de superfície}

Os detectores de superfície são compostos por um tanque preenchido com água purificada, dispondo de três fotomultiplicadoras no seu topo, como mostrado na figura 2.12. Esses detectores medem a radiação Cherenkov emitida pelas partículas carregadas provenientes do EAS ao atravessarem a água do tanque.

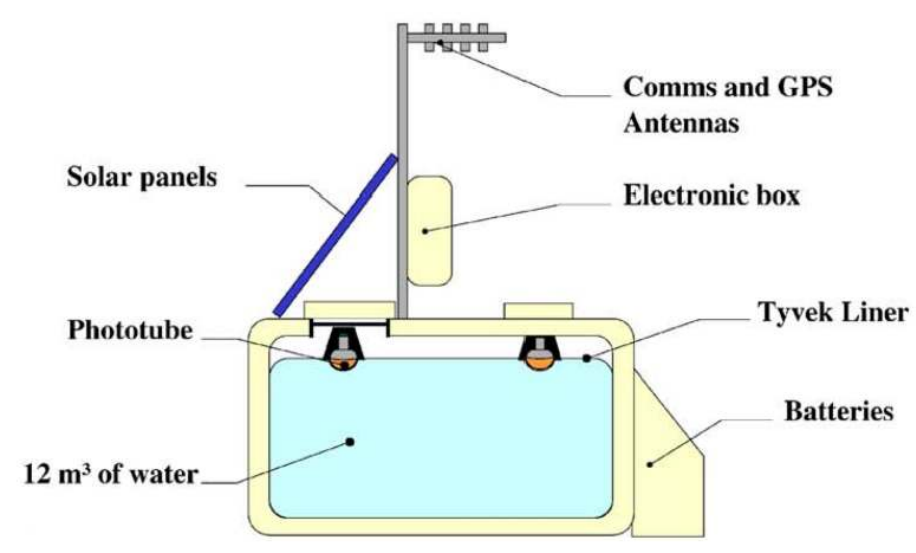

Figura 2.12: Esquema mostrando os principais componentes do detector de luz Cherenkov utilizado no Auger.

No Observatório Pierre Auger, cada tanque possui a forma de um cilindro opaco, com 3.6 metros de diâmetro e 1.6 metro de altura. Dentro do tanque há um material para refletir a radiação Cherenkov e maximizar a coleta de fótons. De acordo com [28], no interior do tanque as fotomultiplicadoras coletam a radiação Cherenkov produzida pelas partículas que o atravessaram. A parte eletrônica do tanque é alimentada por duas baterias que são carregadas por energia solar. O arranjo detector de superfície do Observatório Pierre Auger é composto por 1600 tanques de água espalhados em uma rede triangular com espaçamento de $1.5 \mathrm{~km}$ (como mostrado na figura 2.11) que medem a luz Cherenkov produzida pela passagem das partículas geradas pelo chuveiro atmosférico extenso. Os dados são enviados de cada tanque para uma central de aquisição através de uma conexão sem fio.

\subsubsection{Telescópios de fluorescência}

Os telescópios de fluorescência [51] são equipados com um espelho segmentado de 11 $\mathrm{m}^{2}$, com raio de curvatura de $3.4 \mathrm{~m}$ e diafragma com $2.2 \mathrm{~m}$ de diâmetro e um exemplo é mostrado na figura 2.13. A abertura do telescópio é coberta por um filtro que seleciona o 
intervalo de frequência correspondente à emissão fluorescente das moléculas de nitrogênio (300 - $400 \mathrm{~nm}$ ). Uma abertura de $2.2 \mathrm{~m}$ de diâmetro só é possível graças ao uso de um anel corretor acoplado ao diafragma do telescópio. Tal anel possibilitou o aumento da área de exposição do telescópio em aproximadamente $60 \%$ sem comprometer a qualidade óptica do experimento. Finalmente, depois de passar por esse arranjo experimental, a luz produzida pelo chuveiro atmosférico é captada por um conjunto de 440 fotomultiplicadoras.

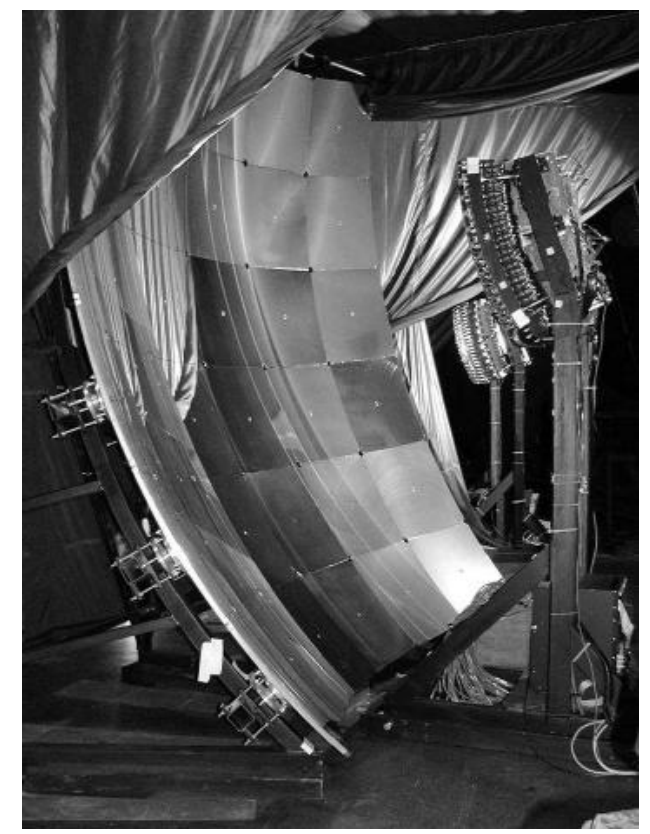

Figura 2.13: Detector de luz fluorecente do Observatório Pierre Auger.

Todo esse aparato é usado para medir a luz ultravioleta emitida pelos EAS quando passam na atmosfera terrestre. As partículas carregadas geradas durante o desenvolvimento do EAS excitam as moléculas de nidrogênio presentes na atmosfera terrestre, e os mesmos emitem luz ultravioleta via processo de fluorescência. O número de fótons emitido é proporcional à energia depositada na atmosfera devido a perdas eletromagnéticas pelas partículas carregadas. Os telescópios de fluorescência do Observatório Pierre Auger observam o rastro de fluorescência do nitrogênio e seguem o desenvolvimento do chuveiro medindo a intensidade da radiação emitida. Ao total são 27 telescópios espalhados em quatro prédios e cada telescópio observa uma faixa de $30^{\circ}$ de elevação e $30^{\circ}$ de azimute. Além desses, existem mais três telescópios do experimento HEAT [52] que observam a região do céu entre $30^{\circ}-60^{\circ}$ de elevação. 


\subsubsection{Projeto AMIGA}

O projeto AMIGA [25] (Auger Muons and Infill for the Ground Array) tem como objetivo estender o alcance de detecção do Auger e medir diretamente a componente muônica de EAS. Enquanto o Observatório Pierre Auger estuda UHECR com energias acima de $3 \times 10^{18}$ $\mathrm{eV}$, AMIGA foi desenvolvido para detectar chuveiros em torno de $3 \times 10^{17} \mathrm{eV}$. Esse projeto consiste de um conjunto de detectores de superfície de radiação Cherenkov, separados por 750 $\mathrm{m}$, cobrindo uma área de $23.5 \mathrm{~km}^{2}$. Cada estação é acompanhada por $30 \mathrm{~m}^{2}$ de cintiladores que estão enterrados a $2.3 \mathrm{~m}$ (correspondente a $540 \mathrm{~g} / \mathrm{cm}^{2}$ ) para proteger das partículas eletromagnéticas e contar apenas múons, como mostrado na figura 2.14. Os contadores, são compostos de quatro módulos independentes, dois com $5 \mathrm{~m}^{2}$ e dois com $10 \mathrm{~m}^{2}$. Cada módulo é segmentado por 64 tiras de cintiladores plásticos e os fótons são guiados para uma fotomultiplicadora por uma coleção de cabos de fibra ótica. O projeto AMIGA terá um

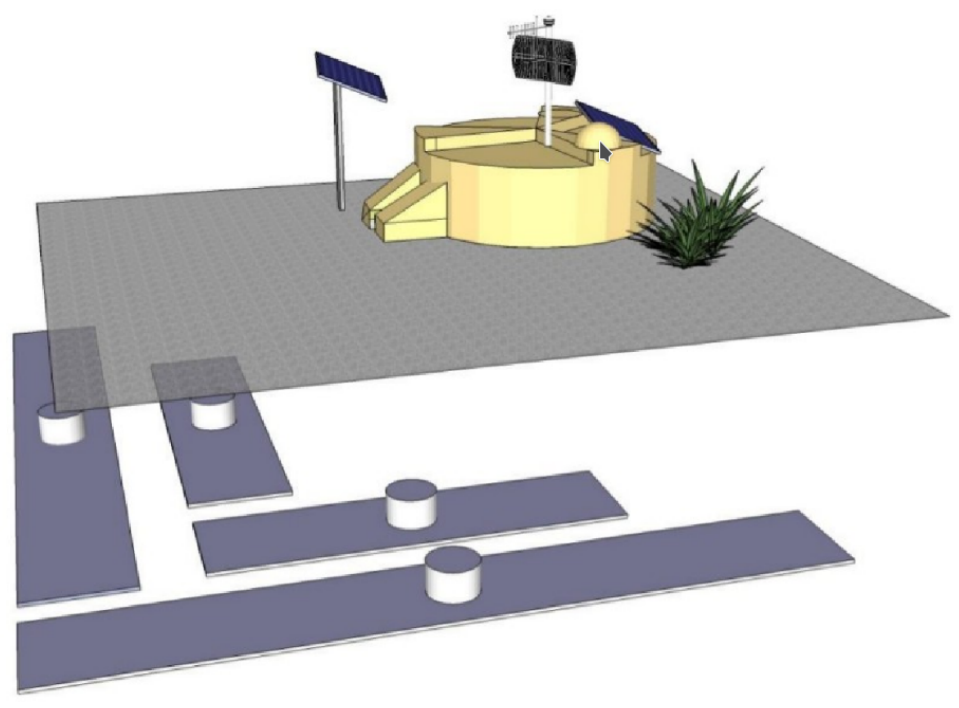

Figura 2.14: Configuração das estações do AMIGA, com os detectores de superfície e os módulos de cintiladores enterrados.

papel importante na atualização do Observatório Pierre Auger, o AugerPrime mencionado anteriormente. Fornecerá medidas diretas da componente muônica de EAS, podendo ser utilizada para realizar um ajuste melhor da componente muônica que hoje é obtida pelos detectores de superfície. 


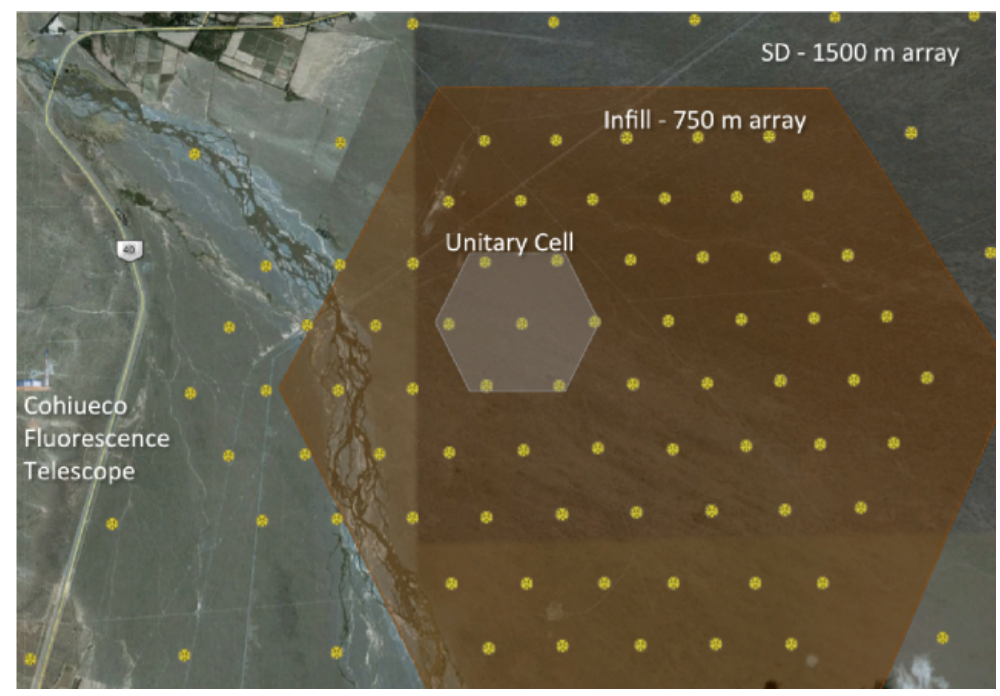

Figura 2.15: Disposição dos detectores utilizados no projeto AMIGA. Detectores de superfície distribuídos por uma rede triangular, com separação de $750 \mathrm{~m}$, e cobrindo uma área de $23.5 \mathrm{~km}^{2}$.

\subsection{Principais resultados de raios cósmicos}

\subsubsection{Espectro de energia}

O fluxo de raios cósmicos acima de $100 \mathrm{TeV}$ é extremamente raro e sua detecção direta, com balões ou satélites, é muito difícil. Porém, ao entrar na atmosfera, os UHECR produzem uma cascata de partículas secundárias que são detectadas pelos experimentos de EAS. Sendo assim, todos os dados de espectro de energia para UHECR vêm de experimentos de EAS. Empiricamente, podemos dizer que o fluxo de raios cósmicos $N(E) d E$ segue uma distribuição do tipo lei de potência da seguinte forma

$$
N(E) d E \propto E^{-\gamma} d E
$$

onde $E$ é a energia, $N(E)$ é o número de partículas com energia entre $E$ e $E+d E$ e $\gamma$ é chamado de índice espectral de fluxo. Dependendo do intervalo de energia dos raios cósmicos, podemos ter diferentes valores de índices espectrais. Na compilação do fluxo de vários experimentos de raios cósmicos, mostrado na figura 2.16, podemos ver claramente três mudanças no índice espectral $\gamma$ :

1. Uma mudança chamada de segundo joelho para energias em torno de $10^{17} \mathrm{eV}$;

2. Outra mudança chamada tornozelo em aproximadamente $10^{18.4} \mathrm{eV}$;

3. E uma forte supressão do espectro de energia em $10^{19.5} \mathrm{eV}$. 


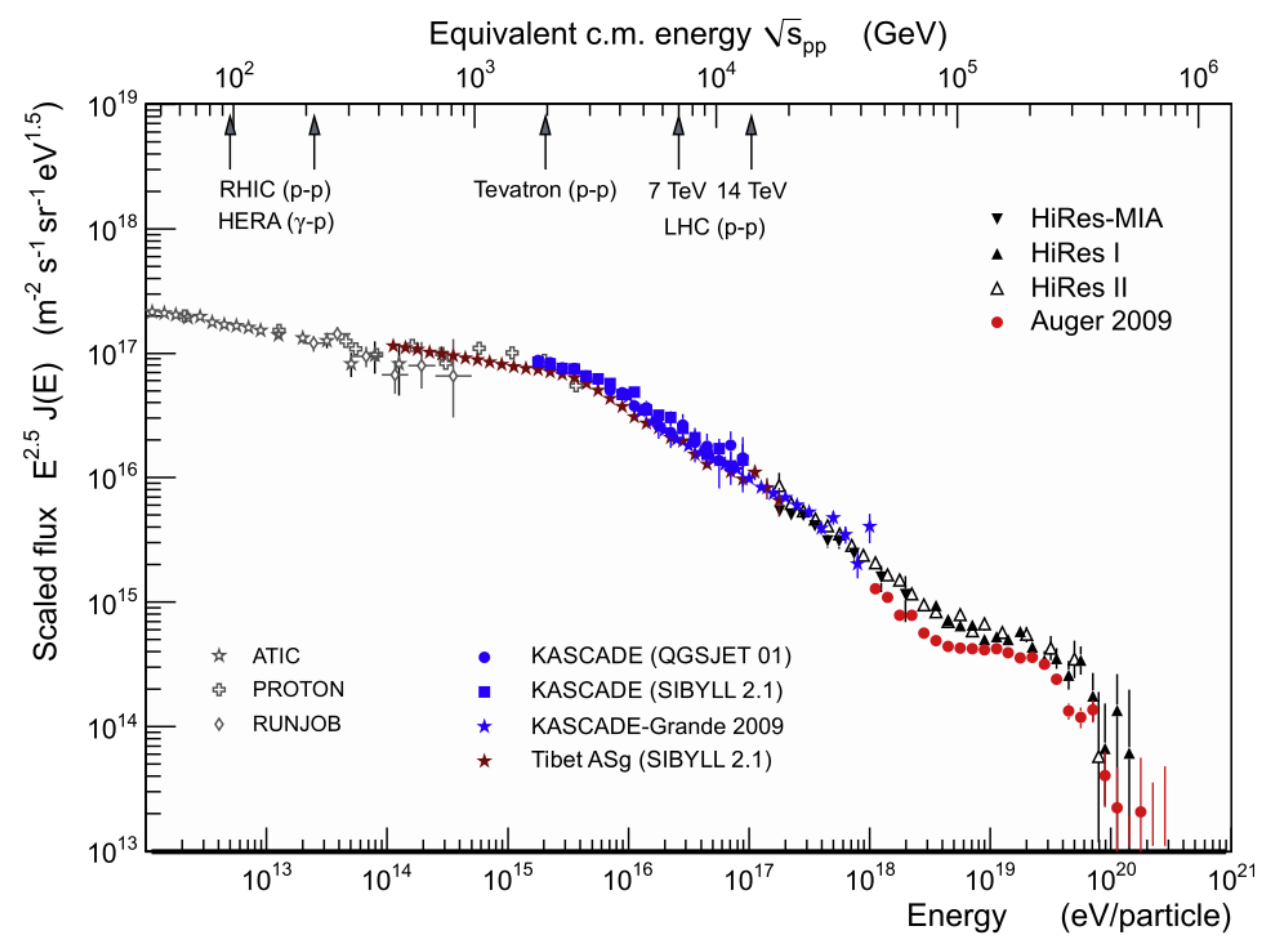

Figura 2.16: Compilação de fluxo de vários experimentos de raios cósmicos. O fluxo foi reescalado por $E^{2,5}$ para que as características se tornem claramente visíveis. Retirado da referência [4]

Variações no comportamento do fluxo de raios cósmicos podem ocorrer devido a mudanças no mecanismo de produção e aceleração, mudanças nas fontes astrofísicas com contribuição majoritária ao fluxo, novas interações no meio interestelar e evolução cosmológica. Por exemplo, nas energias acessíveis ao Observatório Pierre Auger que é mostrado na figura 2.17, as medidas de fluxo apresentam duas mudanças espectrais bem pronunciadas, o tornozelo em torno de $10^{18.4} \mathrm{eV}$ e a forte supressão no fluxo em torno de $10^{19.5} \mathrm{eV}$ [53], essa última provavelmente associada à interação ressonante dos UHECR com a radiação cósmica de fundo (CMB).

Resultados recentes publicados pelo experimento KASCADE-Grande [54] mostram que a mudança no índice espectral observada em torno de $10^{17} \mathrm{eV}$ no fluxo total de partículas, e comumente denominada de segundo joelho, é determinada por um amolecimento ${ }^{\S}$ da componente pesada (elementos mais pesados que He). Observa-se também, no mesmo conjunto de dados, um endurecimento " da componente mais leve (H e He) na mesma região do espectro. Ambas as mudanças espectrais podem ser uma indicação da transição entre as componentes galáctica e extragaláctica dos UHECR [55].

No tornozelo, existem dois cenários possíveis, um cenário de composição mista e outro

\footnotetext{
$\S$ espectro mole é aquele com índice espectral grande, ou seja fortemente atenuado.

『 espectro duro é aquele com índice espectral pequeno, ou seja, o espectro se estende até altas energias.
} 


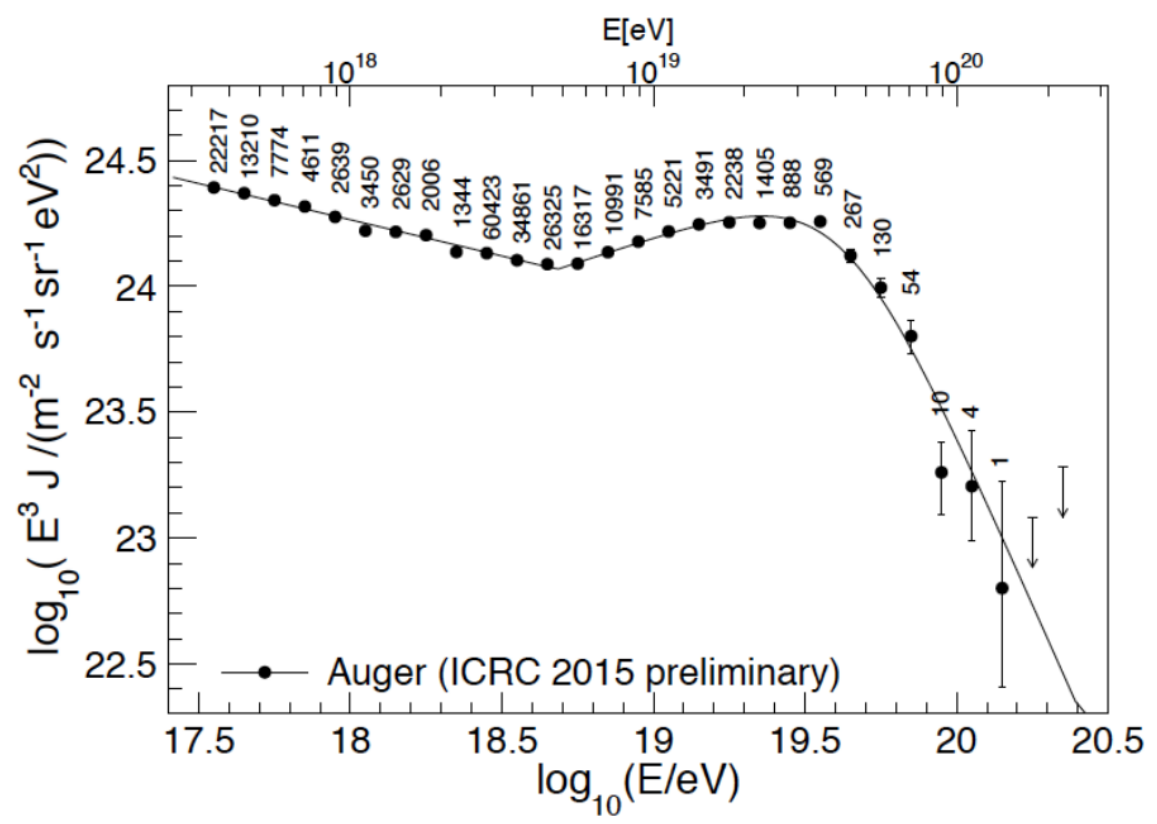

Figura 2.17: O espectro de energia obtido pelo OPA por combinação de medidas hibridas usando telescópio de fluorescência e detectores de superfície. Retirado da referência [5].

chamado modelo dip. No cenário de composição mista [6] o tornozelo é descrito como uma transição da componente galática para extragaláctica em torno de $10^{18} \mathrm{eV}$. Nesse modelo, assume-se uma composição de partículas pesadas nas fontes astrofísicas e o processo de fotodesintegração nuclear por interação com CMB dá origem a uma composição mista na Terra, como mostrado na figura 2.18. No modelo do dip [7] supõe-se que o fluxo seja puramente de prótons e o tornozelo seria devido à perda de energia por produção de pares devido às sucessivas interações com o CMB e a transição extragaláctica ocorreria em torno de $10^{17} \mathrm{eV}$. O fator de modificaçãoll nesse cenário é mostrado na figura 2.19 .

A supressão possivelmente ocorre devido à interação de raios cósmicos com a CMB, chamado de corte Greisen-Zatsepin-Kuzmin (GZK) [56, 57]. Nesse corte, um dos processos esperado é que um próton de altíssima energia interaja com o fóton do CMB $\gamma_{C M B}$, criando uma ressonância que consequetemente decai, através do processo de foto-produção de píons, em nêutron e píons carregados

$$
p+\gamma_{C M B} \rightarrow \pi^{+}+n
$$

ou em próton e píon neutro

$$
p+\gamma_{C M B} \rightarrow \pi^{0}+p
$$

A energia mínima do próton para que ocorra o efeito GZK pode ser facilmente calculada uti-

\footnotetext{
"Fator de modificação é a razão entre o espectro calculado com todas as perdas de energias e o espectro somente com perdas adiabáticas.
} 


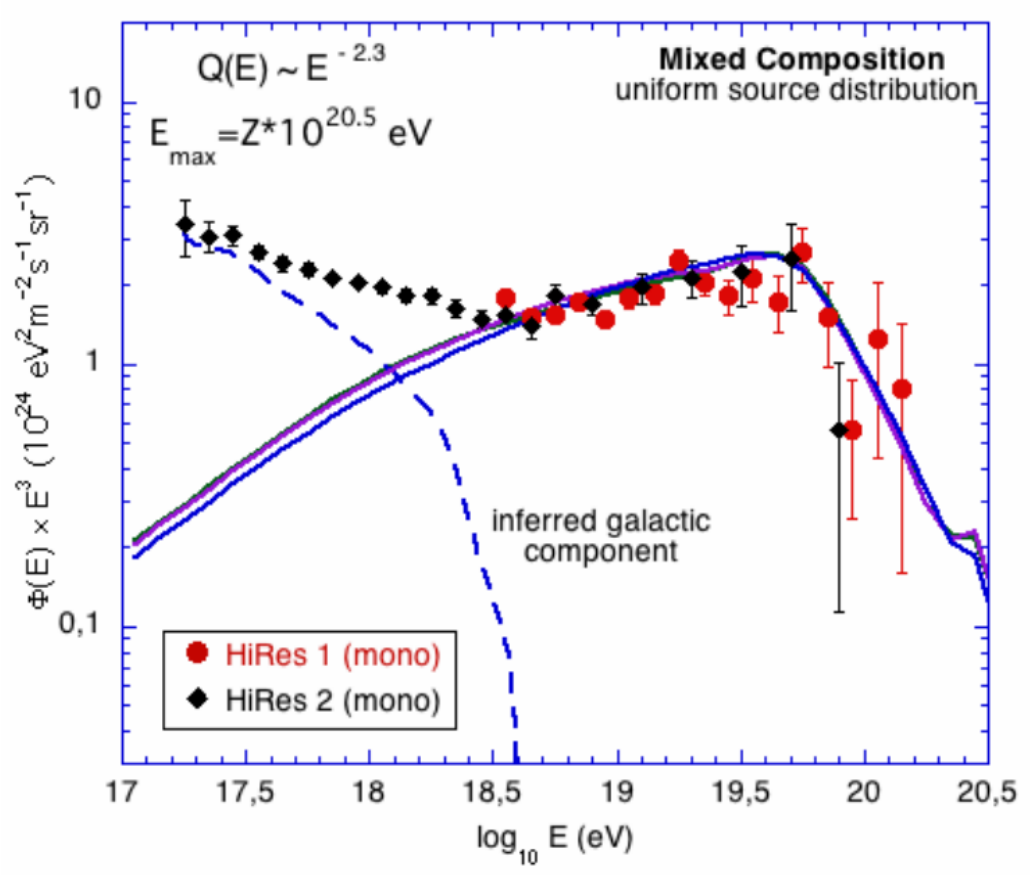

Figura 2.18: Fator de modificação do espectro de energia para o cenário de composição mista, indicando que o tornozelo seria devido à transição de componente galáctica para extragaláctica. Retirado da referência [6].

lizando a física relativística e a conservação do quadrimomento. Aplicando-se a conservação do quadrimomento $P$ ao sistema antes e depois da interação, que é dada por

$$
\left(P_{p}+P_{\gamma}\right)^{2}=\left(P_{n}+P_{\pi}\right)^{2}
$$

podemos determinar a energia mínima do próton fazendo as seguintes considerações: (i) o nêutron e píon são criados em repouso $\left(P_{n}=M_{n}^{2} c^{2}\right.$ e $\left.P_{\pi}=M_{\pi}^{2} c^{2}\right)$, (ii) a colisão próton-fóton é frontal e em direções opostas maximizando a energia da interação e (iii) consideraremos que a energia térmica mais provável do fóton do CMB é $E_{\gamma}=3 \times k_{B} T=7.89 \times 10^{-10} \mathrm{MeV}$. Resolvendo a equação de conservação 2.35 a menor energia do próton para esse processo é

$$
E_{p}=\frac{\left(M_{n} c^{2}+M_{\pi} c^{2}\right)^{2}-\left(M_{p} c^{2}\right)^{2}}{4 E_{\gamma}}
$$

e substituindo alguns números como a massa do nêutron $M_{n}=939.6 \mathrm{MeV} / \mathrm{c}^{2}$, a massa do próton $M_{p}=938.3 \mathrm{MeV} / \mathrm{c}^{2}$ e a massa do píon $M_{\pi}=139.6 \mathrm{MeV} / \mathrm{c}^{2}$, determinamos que a energia mínima para que ocorra a interação $\left(p+\gamma_{C M B} \rightarrow n+\pi\right)$ é

$$
E_{p} \approx 10^{20} \mathrm{eV}
$$




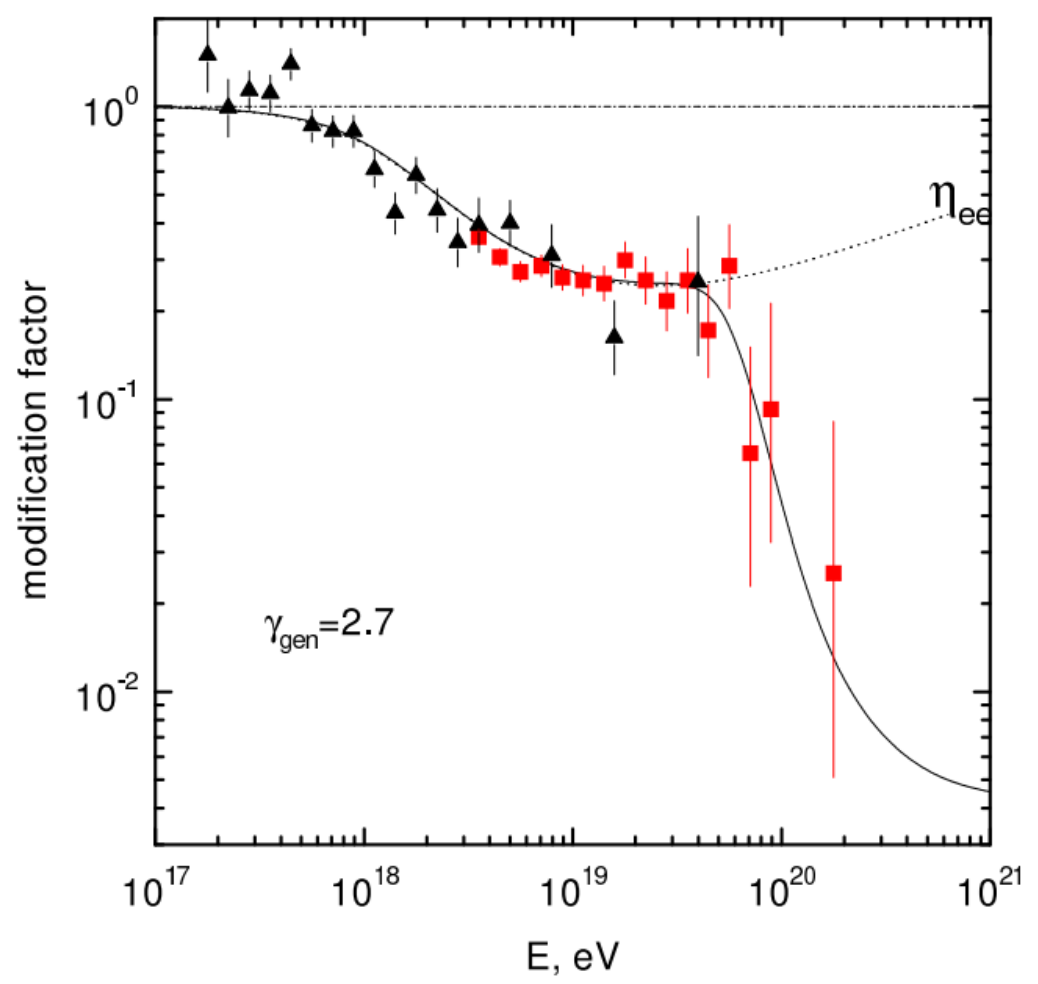

Figura 2.19: Fator de modificação do espectro de energia para o cenário do modelo do dip, indicando que o tornozelo é devido à perda de energia por produção de par. Retirado da referência [7].

Esse limiar do corte GZK é uma aproximação, pois existe um apreciável número de fótons do CMB mais energéticos na cauda da distribuição de Planck. Considerando esse detalhe, a energia de supressão GZK começaria em torno de $3 \times 10^{19} \mathrm{eV}$.

A produção de píons não é o único processo de interação esperado do próton com o CMB. Em particular, é esperado que também ocorra a produção de pares da seguinte forma

$$
p+\gamma_{C M B} \rightarrow e^{+}+e^{-}+p
$$

Esse processo pode ser tratado como perda contínua de energia, já que a energia do par $e^{+} / e^{-}$ criado é muito pequena (um infinitésimo) comparada à energia do próton. Então, espera-se que os prótons com altíssimas energias percam parte de sua energia ao se propagarem pelo meio interestelar, limitando a distância máxima da fonte para UHECR [58].

No caso de núcleos em altíssimas energias, a situação se altera ligeiramente, pois, além do $\mathrm{CMB}$, espera-se que o núcleo interaja também com a luz extragaláctica de fundo (EBL) [59]. O núcleo propagando-se no meio interestelar pode interagir via produção de par e fotodesintegração, sendo este último um processo no qual o núcleo interage com o CMB ou 
EBL e perde um ou mais núcleons, da seguinte forma

$$
A+\gamma_{C M B, E B L} \rightarrow(A-n N)+n N
$$

ou seja, um núcleo de número de massa $A$ que foi emitido na fonte de raios cósmicos pode interagir com o $\mathrm{CMB} / \mathrm{EBL}$ e perder um ou mais núcleons e, quando chegar na Terra, sua massa será descrita por $(A-n N)$. A fotodesintegração também pode ser responsável pela supressão no espectro observado de UHECR.

\subsubsection{Composição}

A composição de UHECR pode ser inferida a partir de observações de EAS. Por exemplo, podemos utilizar o parâmetro $X_{\max }$ para determinar a composição do raio cósmico primário que iniciou o chuveiro, pois estão correlacionados. Essa correlação pode ser generalizada através do modelo de Heitler-Matthews para chuveiros atmosféricos extensos com um UHECR primário de número de massa $A$. A profundidade máxima média do chuveiro $\left\langle X_{\max }\right\rangle$ para uma dada energia $E$ é esperada ser a seguinte

$$
\left\langle X_{\max }\right\rangle=\alpha(\ln E-\langle\ln A\rangle)+\beta
$$

onde $\langle\ln A\rangle$ é o valor médio num dado intervalo de energia do primário e os coeficientes $\alpha$ e $\beta$ dependem da natureza das interações hadrônicas para altíssimas energias. A variação $\Lambda$ da energia por década é chamada de taxa de elongação dada por

$$
\Lambda=\frac{\left\langle X_{\max }\right\rangle}{d \log E} \approx \alpha\left(1-\frac{d\langle\ln A\rangle}{d \ln E}\right),
$$

é sensível a mudanças na composição química.

Atualmente, os resultados de composição para UHECR são obtidos através de medidas realizadas pelo Observatório Pierre Auger e Telescope Array. Na figura 2.20 podemos observar uma tendência quase monotônica do número de massa média $\langle A\rangle$, inferida a partir de variáveis sensíveis à composição química, como $\left\langle X_{\max }\right\rangle$, indo de uma composição com acentuada contribuição protônica a "baixas" energias para um cenário de composição mista [39] a altas energias. Tal interpretação, no entanto, deve ser feita com ressalva devido às simulações das primeiras interações no topo da atmosfera utilizadas para interpretar o resultado.

Uma outra medida complementar da composição é a flutuação chuveiro a chuveiro da profundidade máxima RMS $\left(X_{\max }\right)$. Espera-se que a flutuação diminua em função do número de massa $A$, pois a multiplicidade aumenta em função de $A$ e, consequentemente, diminuem 


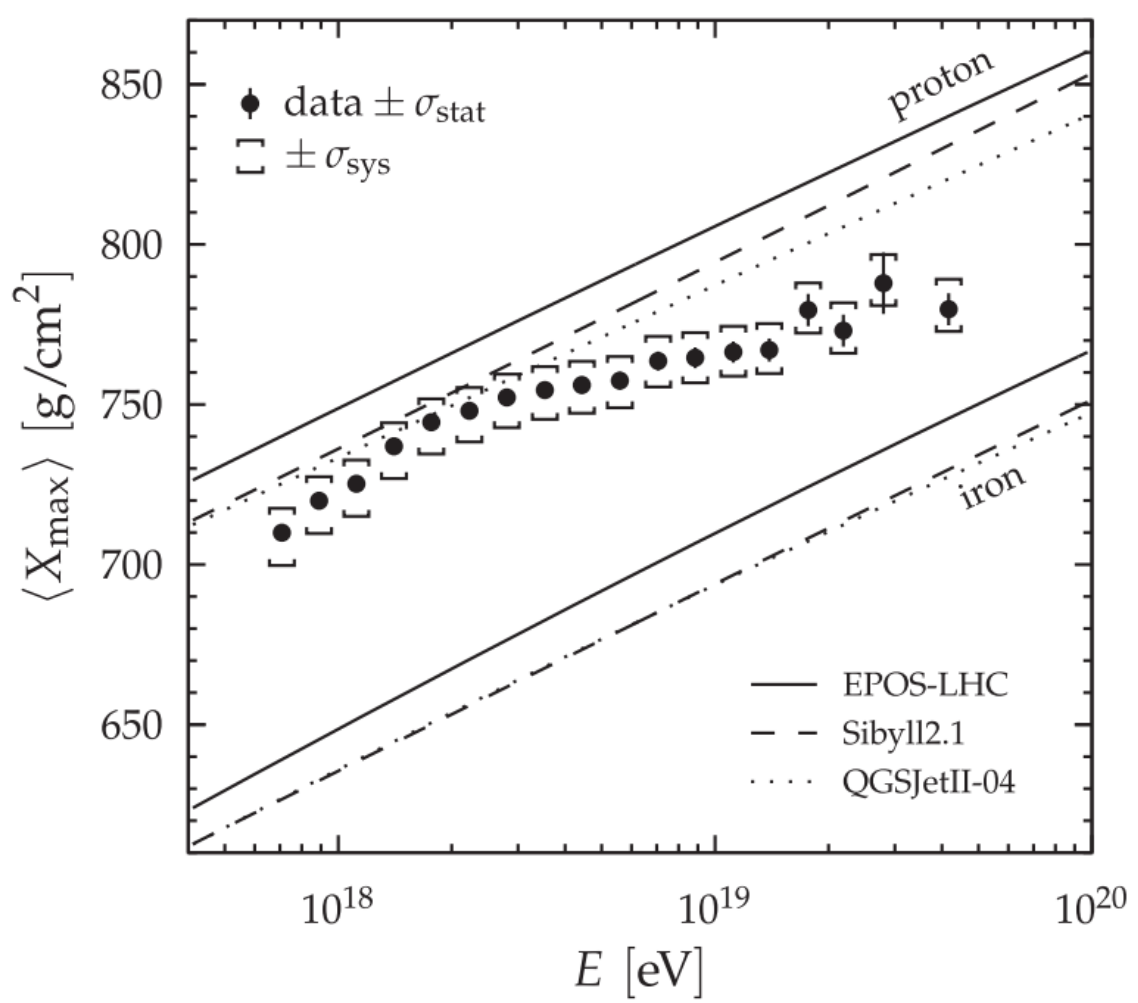

Figura 2.20: Medida de $\left\langle X_{\max }\right\rangle$, realizada pelo Observatório Pierre Auger, comparado com simulações de chuveiros atmosféricos usando diferentes modelos de interações hadrônicas. Retirado da referência [8]

as possíveis flutuações do parâmetro $X_{\max }$. Na figura 2.21 são mostradas as medidas de RMS $\left(X_{\max }\right)$ e, novamente, encontramos uma tendência monotônica indo de partículas leves para partículas pesadas conforme a energia aumenta.

Os resultados de composição para o experimento TA, mostrados na figura 2.22 indicam uma composição de UHECR de partículas leves, como prótons. O resultado encontrado pelo TA é compatível com a medida de composição do Observatório Pierre Auger. Entretanto, um grupo de trabalho conjunto envolvendo membros de ambas as colaborações chegou, recentemente, à conclusão de que o TA não tem resolução em $X_{\max }$ suficiente para distinguir populações de chuveiros iniciados por diferentes tipos de primário [9].

\subsubsection{Anisotropia}

Acima da energia do corte GZK, a contribuição do universo para o fluxo observado de raios cósmicos é confinada dentro de um círculo de aproximadamente $200 \mathrm{Mpc}^{* *}$ em volta da

${ }^{* *}$ Parsec (pc) é uma unidade astronômica para medida de distâncias, 1 pc $\approx 3.26$ anos luz ou $3.08 \times 10^{16}$ m. 


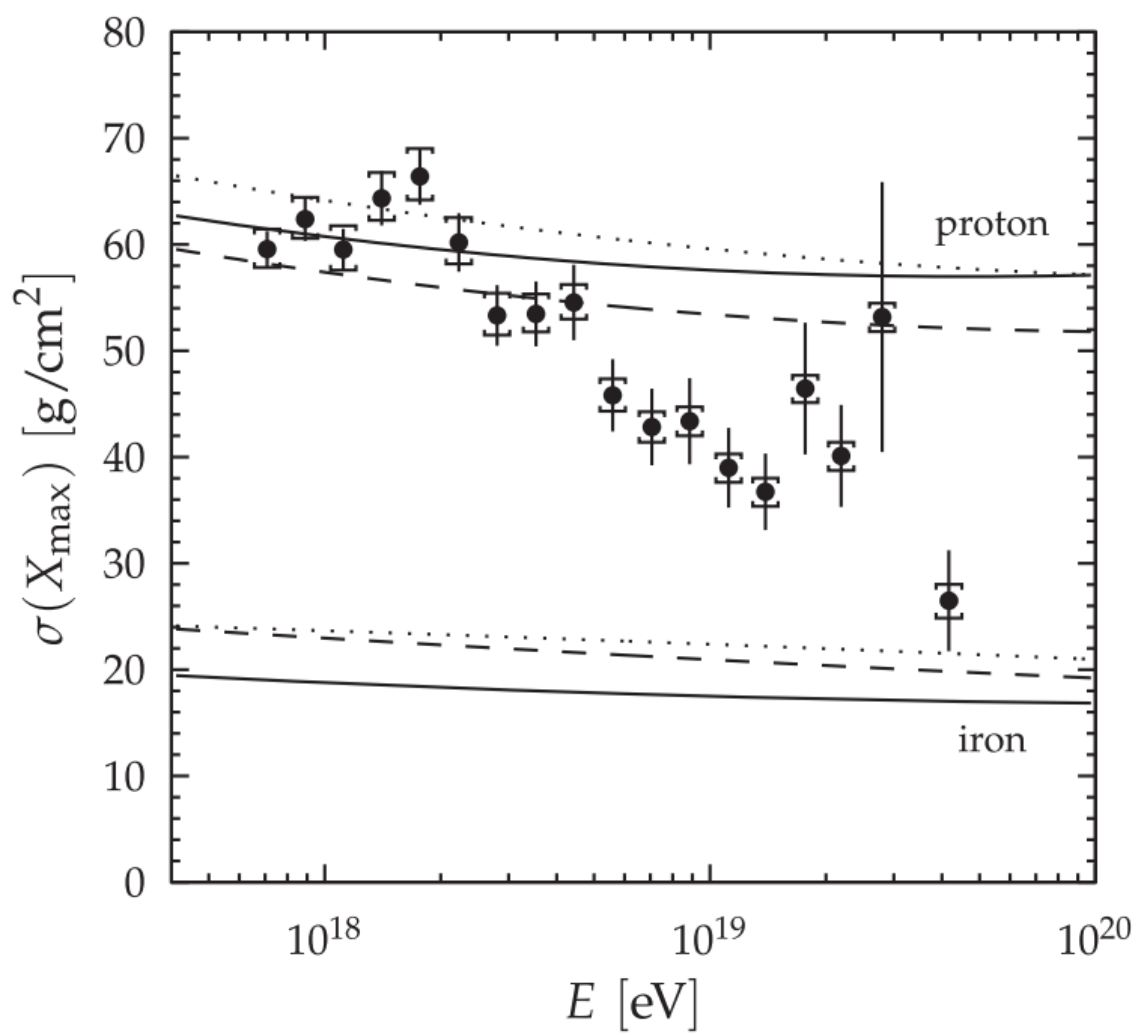

Figura 2.21: Medida de RMS $\left(X_{\max }\right)$, realizada pelo Observatório Pierre Auger, comparado com simulações de chuveiros atmosféricos usando diferentes modelos de interações hadrônicas. Retirado da referência [8]

Terra. Em particular, se o fluxo de UHECR for composto principalmente de prótons, eles devem interagir com o CMB por produção de píons, levando à conhecida supressão GZK no fluxo. Por outro lado, se o fluxo de UHECR for principalmente composto de núcleos, devem ocorrer processos de fotodesintegração no meio extragaláctico e uma forte diminuição também deve ser observada no espectro. Portanto, é esperado que para energias maiores que $5 \times 10^{19} \mathrm{eV}$, o universo visível para UHECR passe de Gpc para centenas de Mpc.

No caso em que fontes próximas de UHECR não forem uniformemente distribuídas, a direção de chegada dos UHECR pode refletir uma anisotropia. Esta hipótese depende principalmente da carga elétrica do UHECR, pois o efeito dos campos magnéticos galácticos pode eliminar a anisotropia. No caso de prótons se propagando pela distância de kpc pelo meio galáctico, a deflexão angular devido ao campo magnético galáctico ( $\mu$-Gauss) é da ordem de poucos graus para partículas com energia $E>50 \mathrm{EeV}$. Aumentando-se a carga elétrica, por exemplo Hélio $(Z=2)$, a deflexão começa a chegar em torno de $10^{\circ}$ e para Ferro $(Z=26)$ é maior que $50^{\circ}$. Portanto, seria difícil observar sinais de correlação entre as direções de chegada de UHECR e as suas fontes astrofísicas de produção. 


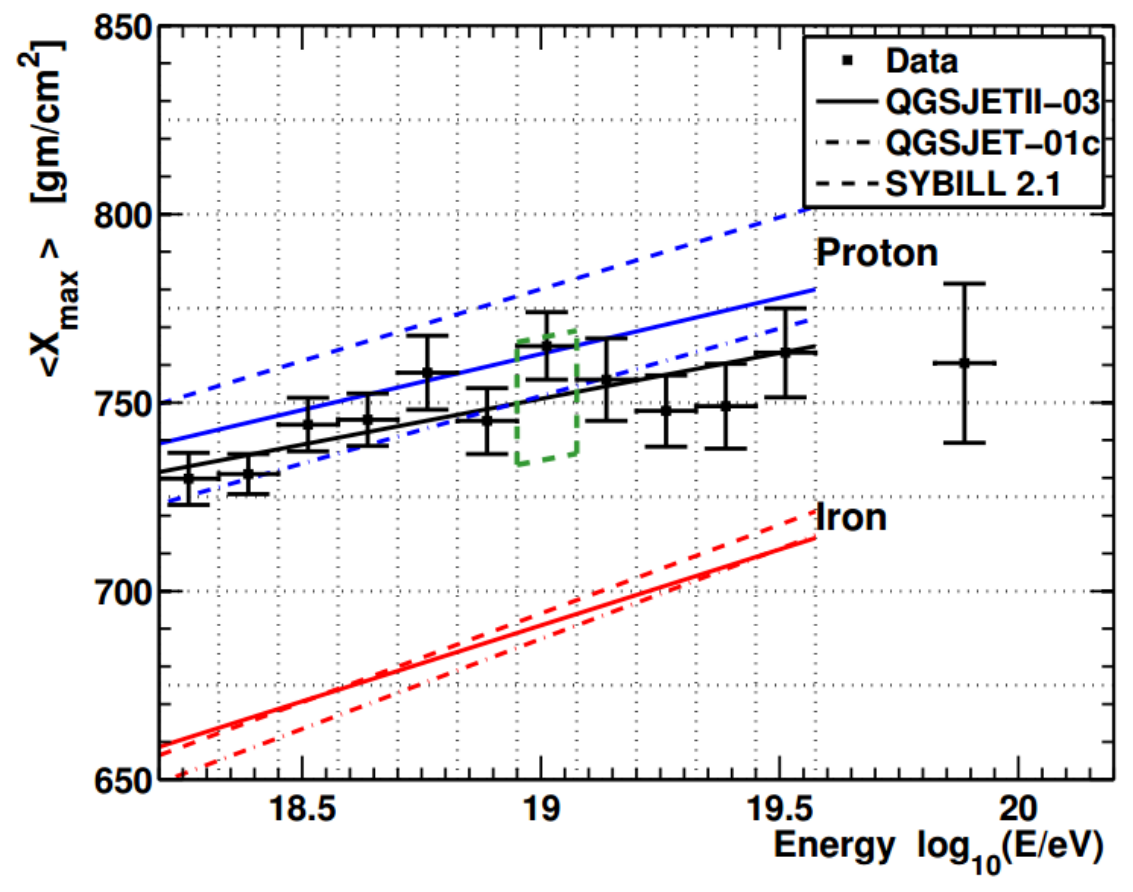

Figura 2.22: Medida de $\left\langle X_{\max }\right\rangle$, realizada pelo experimento Telescope Array, comparada com simulações de chuveiros atmosféricos usando diferentes modelos de interações hadrônicas. Retirado da referência [9].

Resultados mais recentes da distribuição de chegada dos UHECR [10] detectaram uma anisotropia, em eventos de UHECR com energia acima de $8 \times 10^{18} \mathrm{eV}$. Neste trabalho, analisaram-se dados coletados pelo Observatório Pierre Auger de 2004 até 2016 alcançando uma exposição total de $76800 \mathrm{~km}^{2}$ sr ano. Usou-se o arranjo de superfície do Auger e eventos com um grande alcance zenital $\theta<80^{\circ}$ e declinação $-90^{\circ}<\delta<45^{\circ}$, cobrindo $85 \%$ do céu. Usando método padrão para o estudo de anisotropia em grandes escalas, a análise de Rayleigh em ascensão reta, determinou-se a existência de uma amplitude dipolar de $\sim 6.5 \%$ apontando para a direção em coordenadas equatoriais $\left(\alpha_{d}, \delta_{d}\right)=\left(100^{\circ},-24^{\circ}\right)$. Esse padrão dipolar pode ser visto claramente no mapa de fluxo na figura 2.23 e a grande distância angular entre a direção do eixo do dipolo e o centro galáctico torna difícil acomodar este resultado com uma hipótese de origem galáctica para os UHECRs da amostra utilizada.

\subsubsection{Excesso de múons}

O número de múons em chuveiros atmosféricos é outra importante variável para determinar a composição química de UHECR. Recentemente, o Observatório Pierre Auger comparou o número de múons em eventos com alta inclinação aos principais modelos de interações hadrônicas utilizados em EAS [11], como mostrado na figura 2.24. O número de 


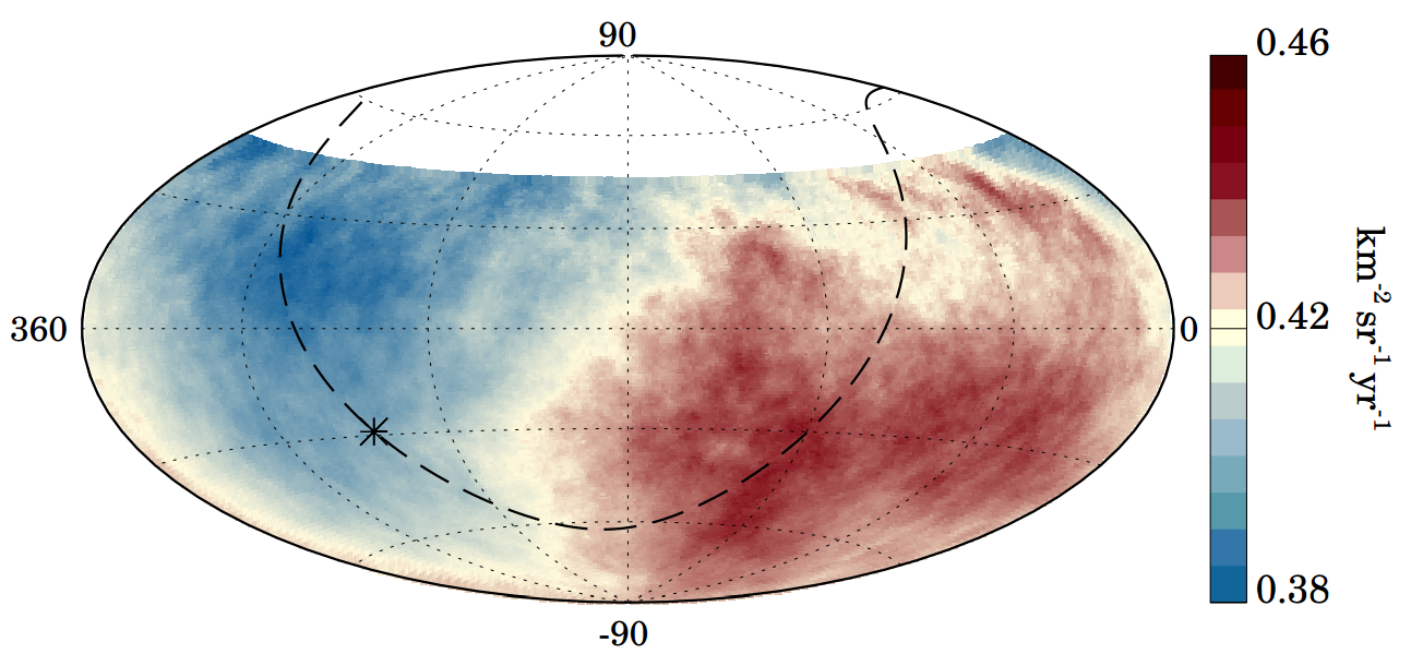

Figura 2.23: Mapa do fluxo de partículas em coordenadas equatoriais, usando a projeção de Hammer. O gráfico mostra o fluxo de raios cósmicos para energias maiores que $8 \mathrm{EeV}$ suavizado com uma função "top-hat" de $45^{\circ}$. O centro galáctico está marcado com um asterisco e o plano galáctico é mostrado pela linha pontilhada. Retirado da referência [10]

múons observado para chuveiros com energia em torno de $10^{19} \mathrm{eV}$ foi de $30 \%$ a $80 \%$ maior que o predito pelos modelos quando assumida uma composição química para o fluxo incidente de UHECRs compatível com aquela inferida da distribuição de profundidade atmosférica de máximo desenvolvimento do chuveiro.

Além disso, um outro estudo[12], publicou que essa diferença seria devido as incertezas nos modelos de interações hadrônicas, assumindo que a composição química do primário seja bem compreendida. Nesta análise desenvolveram um método para desacoplar os efeitos da calibração de energia da incerteza na componente hadrônica de chuveiros com energia em torno de $10^{19} \mathrm{eV}$. Os parâmetros de redimensionamento das componentes eletromagnética $R_{E}$ e hadrônica $R_{\text {had }}$ foram ajustados a uma amostra de chuveiros de alta qualidade (medidos simultaneamente pelos detectores de superfície e de fluorescência do Observatório Pierre Auger), mostrando que a discrepância mencionada aparece tão somente no fator $R_{\text {had }}$ e, portanto, não tem contribuição significativa da escala absoluta de energia associada a $R_{E}$. O resultado, mostrado na figura 2.25, indica que a diferença de múons observada pelo Observatório Pierre Auger e as simulações de EAS poderia ser explicada por uma recalibração do sinal proveniente das interações hadrônicas. 


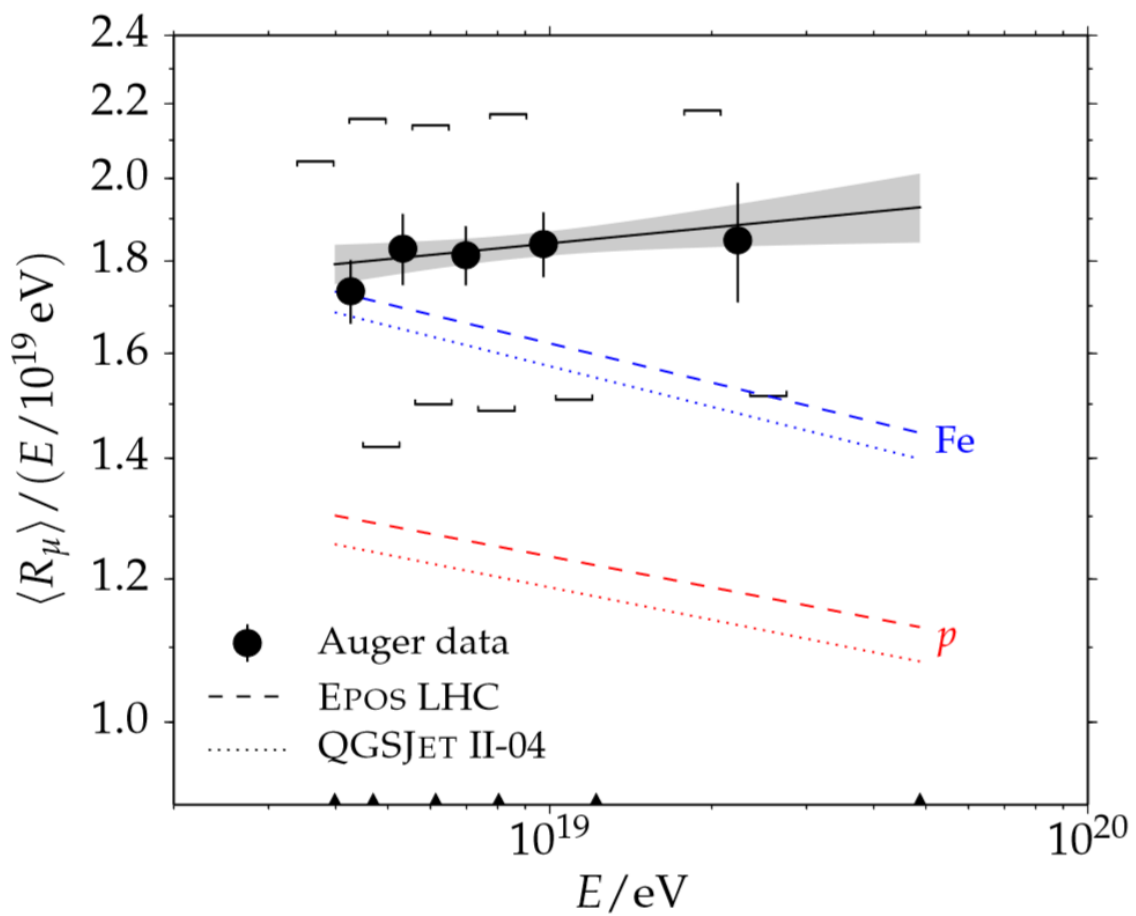

Figura 2.24: Número médio de múons $R_{\mu}$ por energia $E$ do chuveiro como função da energia do chuveiro em escala logarítmica. Retirado da referência [11].

\begin{tabular}{lcc}
\hline \hline Model & $R_{E}$ & $R_{\text {had }}$ \\
\hline QII-04 p & $1.09 \pm 0.08 \pm 0.09$ & $1.59 \pm 0.17 \pm 0.09$ \\
QII-04 Mixed & $1.00 \pm 0.08 \pm 0.11$ & $1.61 \pm 0.18 \pm 0.11$ \\
EPOS p & $1.04 \pm 0.08 \pm 0.08$ & $1.45 \pm 0.16 \pm 0.08$ \\
EPOS Mixed & $1.00 \pm 0.07 \pm 0.08$ & $1.33 \pm 0.13 \pm 0.09$ \\
\hline
\end{tabular}

Figura 2.25: Valores de $R_{E}$ e $R_{\text {had }}$ com as incertezas estatísticas e sistemáticas, para os modelos QGSJETII-04 e EPOSLHC. Retirado da referência [12]. 


\section{Capítulo 3}

\section{Interações hadrônicas em chuveiros atmosféricos}

As interpretações realizadas dos dados experimentais de EAS são fortemente dependentes das simulações de cascata, em especial, dos modelos de interações hadrônicas utilizados. Devido à operação de experimentos em grandes escalas, como o Observatório Pierre Auger, os modelos de interações hadrônicas foram extrapolados para além dos limites testados em aceleradores de partículas. Consequentemente, as interações hadrônicas tornaram-se as fontes importantes de incertezas sistemáticas em medidas de EAS, como mostrado em [15]. Por sua vez, os aceleradores estão se desenvolvendo e alcançando energias cada vez maiores. Por exemplo, o LHC (Large Hadron Collider, LHC) alcança a energia de centro de massa em torno de $14 \mathrm{TeV}$ para colisões próton-próton e seus dados estão ajudando a melhorar os modelos de interações hadrônicas usados em EAS [4]. Precisamos dos dados de aceleradores para criar modelos de interações hadrônicas mais realistas, ou mesmo descobrir novos processos físicos em altas energias que não foram modelados.

Como veremos neste capítulo, precisamos conhecer os modelos de interações hadrônicas para estudar as medidas de EAS. Discutiremos então as variáveis comumente utilizadas no estudo de interações hadrônicas e os modelos desenvolvidos para simulação de EAS, além de comparar os últimos modelos, ajustados aos dados do LHC, e suas consequências nos observáveis de EAS. 


\subsection{Variáveis de trabalho}

As variáveis comumente utilizadas no estudo de produção de hádrons são a rapidez ( $y$ ), a pseudorapidez $(\eta)$ e a variável de Feynman $\left(x_{F}\right)$. Além disso, a rapidez tem relações úteis que a conectam às componentes do momento $\vec{p}$. Entretanto, a pseudorapidez é mais utilizada em experimentos de colisões de partículas, pois para determiná-la somente é necessário conhecer o ângulo da partícula em relação ao feixe de colisão. Já a variável de Feynman é muito útil para descrever colisões difrativas.

\subsubsection{Rapidez}

A rapidez $y$ de uma partícula viajando ao longo do eixo $z$ é uma quantidade adimensional, podendo ser positiva ou negativa, e é dada pela seguinte equação

$$
y=\frac{1}{2} \ln \left(\frac{E+p_{z}}{E-p_{z}}\right)
$$

onde está definida em termos da energia $E$ e $p_{z}$ é o momento longitudinal da partícula. A rapidez, no limite não-relativístico, coincide com a velocidade da partícula em unidades da velocidade da luz. Por exemplo, no regime relativístico, a energia de uma partícula no sistema natural de unidades é dada por

$$
E=\gamma m
$$

onde $m$ é a massa de repouso da partícula. O momento longitudinal é dado por

$$
p_{z}=\gamma \beta m
$$

Substituindo o $p_{z}$ e $E$ na equação 3.1 encontramos a rapidez de uma partícula viajando com velocidade $\beta$ na direção $z$ positiva

$$
y=\frac{1}{2} \ln \left(\frac{1+\beta}{1-\beta}\right) .
$$

No regime não relativístico, sabemos que $\beta \ll 1$ e a equação da rapidez torna-se

$$
y=\beta+O\left(\beta^{3}\right),
$$

que é aproximadamente a velocidade da partícula não relativística em unidade da velocidade da luz.

Para mudar de um referencial $S^{\prime}$ para $S$, com velocidade relativa $\beta$, aplicamos a trans- 
formação de Lorentz no quadrivetor energia-momento $\left(E^{\prime}, \vec{p}^{\prime}\right)$ dado por

$$
E^{\prime}=\gamma\left(E-\beta p_{z}\right), p_{z}^{\prime}=\gamma\left(p_{z}-\beta E\right)
$$

sobre a rapidez $y^{\prime}$, dada no referencial $S^{\prime}$ por

$$
y^{\prime}=\frac{1}{2} \ln \left(\frac{E^{\prime}+p_{z}^{\prime}}{E^{\prime}-p_{z}^{\prime}}\right) .
$$

Então, substituindo a equação 3.6 em 3.7 temos

$$
y^{\prime}=y-\frac{1}{2} \ln \left(\frac{1+\beta}{1-\beta}\right) .
$$

onde $y$ é a rapidez da partícula no referencial $S$. Expressando a rapidez neste formato podemos ver claramente que a transformação de Lorentz se reduz à soma de uma constante.

Para qualquer partícula livre podemos encontrar uma transformação do quadrivetor energia-momento $(E, \vec{p})$ para o espaço da rapidez e momento transverso $\left(y, \vec{p}_{T}\right)$. Exponenciando a equação 3.1 , temos duas novas equações

$$
e^{y}=\sqrt{\frac{E+p_{z}}{E-p_{z}}},
$$

e

$$
e^{-y}=\sqrt{\frac{E-p_{z}}{E+p_{z}}} .
$$

A relação entre energia $E$ e rapidez $y$ da partícula pode ser encontrada somando as equações 3.9 e 3.10 ,

$$
E=m_{T} \cosh y,
$$

onde $m_{T}$ é a massa transversa da partícula

$$
m_{T}^{2}=m^{2}+\vec{p}_{T}^{2}
$$

Subtraindo as equações 3.10 e 3.9, obtemos a relação entre o momento longitudinal $p_{z}$ e a rapidez da partícula

$$
p_{z}=m_{T} \sinh y .
$$

A rapidez y é uma escolha apropriada para descrever a dinâmica de partículas relativísticas, pois se transforma de maneira simples sob boosts de Lorentz e as equações $3.11 \mathrm{e}$ 3.13 são relações úteis que conectam as componentes do momento com a variável rapidez. 


\subsubsection{Pseudorapidez}

A pseudorapidez $\eta$ é uma variável de fácil acesso experimental e podemos determiná-la conhecendo apenas o ângulo entre a partícula e o feixe pela relação

$$
\eta=-\ln [\tan (\theta / 2)]
$$

onde $\theta$ é o ângulo entre a partícula com momento $\vec{p}$ e o eixo do feixe (tomado aqui como o eixo $z$ do sistema de coordenadas), como mostrado na figura 3.1. Em termos do momento, a

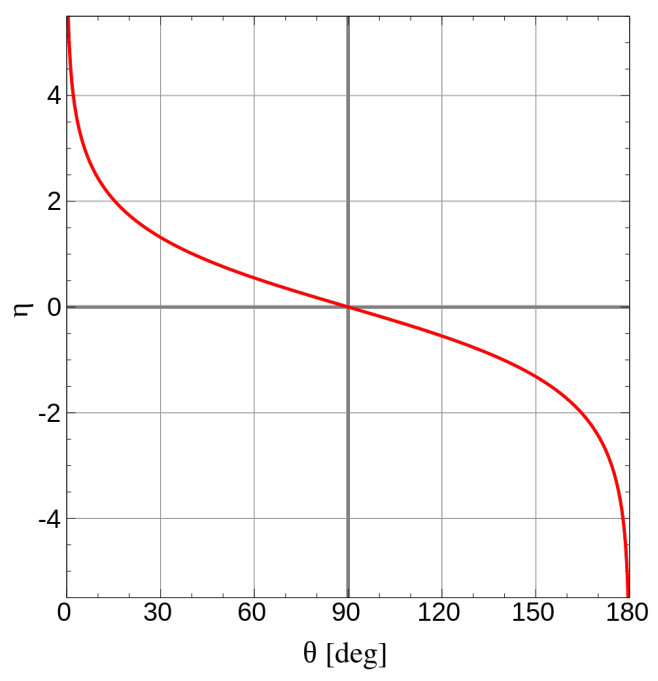

Figura 3.1: Gráfico mostrando a relação entre o ângulo da partícula em relação ao feixe e a variável $\eta$.

pseudorapidez pode ser escrita como

$$
\eta=\frac{1}{2} \ln \left(\frac{|\vec{p}|+p_{z}}{|\vec{p}|-p_{z}}\right) .
$$

Comparando as equações 3.1 e 3.15, podemos ver que a pseudorapidez coincide com a rapidez quando o momento é grande, ou seja, quando $|\vec{p}| \approx E$.

Tal como na rapidez, podemos encontrar as equações que levam do espaço de momento $(E, \vec{p})$ para representação de pseudorapidez e momento transverso $\left(\eta, p_{T}\right)$ e vice-versa. A partir da equação 3.15 , podemos expressar $\eta$ em função do momento $\vec{p}$ da seguinte forma

$$
e^{\eta}=\sqrt{\frac{|\vec{p}|+p_{z}}{|\vec{p}|-p_{z}}}
$$


e

$$
e^{-\eta}=\sqrt{\frac{|\vec{p}|-p_{z}}{|\vec{p}|+p_{z}}} .
$$

Adicionando as equações 3.16 e 3.17, obtemos a relação para o momento total

$$
|\vec{p}|=p_{T} \cosh \eta
$$

onde $p_{T}$ é a magnitude do momento transverso, dado por

$$
p_{T}=\sqrt{p^{2}-p_{z}^{2}}
$$

Subtraindo a equação 3.17 de 3.16, obtemos a magnitude do momento longitudinal em função da pseudorapidez

$$
p_{z}=p_{T} \sinh \eta
$$

Também podemos expressar a rapidez $y$ em função de $\eta$ como

$$
y=\frac{1}{2} \ln \left[\frac{\sqrt{p_{T}^{2} \cosh ^{2} \eta+m^{2}}+p_{T} \sinh \eta}{\sqrt{p_{T}^{2} \cosh ^{2} \eta+m^{2}}-p_{T} \sinh \eta}\right],
$$

onde $m$ é a massa de repouso da partícula. Analogamente, a pseudorapidez $\eta$ pode ser escrita em função da rapidez $y$ por

$$
\eta=\frac{1}{2} \ln \left[\frac{\sqrt{m_{T}^{2} \cosh ^{2} y+m^{2}}-m_{T} \sinh y}{\sqrt{m_{T}^{2} \cosh ^{2} y-m^{2}}-m_{T} \sinh y}\right]
$$

e se a partícula tem distribuição $d^{3} N / d y d \vec{p}_{T}$ em termos da rapidez $y$, então a distribuição em pseudorapidez $\eta$ é dada por

$$
\frac{d^{3} N}{d \eta d \vec{p}_{T}}=\sqrt{1-\frac{m^{2}}{m_{T}^{2} \cosh ^{2} y}} \frac{d^{3} N}{d y d \vec{p}_{T}} .
$$

Assim como na rapidez, a pseudorapidez é uma escolha apropriada para estudar experimentos de partículas relativísticas e ainda existem relações simples que a conectam com a rapidez. 


\subsubsection{A variável de Feynman $x_{F}$}

A variável de Feynman $x_{F}$ é uma variável de escala definida para descrever a produção de hádrons em colisões núcleon-núcleon. Em processos de colisões inclusivos como $p+p \rightarrow$ $A+X$, em que a colisão próton-próton produz uma partícula $A$ e partículas adicionais, denotadas simplesmente por $X$, podemos definir a variável de Feynman $x_{F}$ como

$$
x_{F}=\frac{P_{z}^{A}}{P_{z, \text { max }}^{A}},
$$

onde $P_{z}^{A}$ é o momento longitudinal da partícula $A$ no referencial de centro de massa e $P_{z, \max }^{A}$ é o máximo de momento que a partícula $A$ poderia carregar, baseado na energia da colisão próton-próton. Claramente $x_{F}$ varia entre -1 e 1 e é um invariante de Lorentz. No cenário de pártons, a variável $x_{F}$ está relacionada com a fração de momento carregada pelos pártons $x_{i}$ que interagiram durante o processo de colisões inclusivas e produziram a partícula $A$. Nesse cenário, $x_{F}$ é definida como

$$
x_{F}=\frac{P_{z}^{A}}{P_{z, \max }^{A}}=x_{1}-x_{2},
$$

onde $x_{1}$ e $x_{2}$ é a fração de momento dos pártons envolvidos na produção de $A$.

\subsection{Modelos de interações hadrônicas}

Nessa seção, será apresentado um resumo geral dos modelos de interação hadrônica frequentemente utilizados em simulações de EAS e que podem ser extrapolados para as altíssimas energias dos raios cósmicos de $10^{20} \mathrm{eV}$, correspondente a aproximadamente $\sqrt{S_{N N}}=$ $400 \mathrm{TeV}$ no referencial de centro de massa. Esses modelos são SIBYLL2.3 [60], EPOSLHC [13] e QGSJETII-04 [24]. Todos os modelos são baseados na associação simples do párton com aproximação de múltiplos espalhamentos de Gribov-Regge*. Os modelos diferem na sua filosofia, por exemplo, efeitos não lineares, efeitos nucleares, partícula líder para diferentes extrapolações, entre outros. O modelo EPOS é um gerador de evento hadrônico usado para interações de íons pesados e raios cósmicos. O diferencial desse modelo está na descrição da produção de partículas soft para qualquer sistema e energia com muito detalhes. O modelo QGSJETII é um modelo hadrônico ajustado para descrever interações nucleares e otimizado para simulações de EAS. O conjunto mínimo de parâmetros livres, no QGSJETII-04, reduz a incerteza devido à extrapolação para altas energias e, consequentemente, o modelo possui uma descrição menos detalhada do estágio final da interação. O modelo SIBYLL2.3, assim

\footnotetext{
*Nesse cenário, a interação é descrita pela troca de pártons líderes entre o projétil e o alvo.
} 
como o QGSJETII, é um modelo hadrônico ajustado para descrever interações nucleares, descrevendo as interações dos núcleos leves pelo modelo de superposição e sendo otimizado para simulações de EAS.

\subsubsection{EPOSLHC}

EPOS é um gerador, baseado em Monte Carlo, de interações hadrônicas para eventos do tipo minimum bias ${ }^{\dagger}$, usado para interações de íons pesados e simulações de raios cósmicos. Esse gerador considera o modelo de párton simples para interações hadrônicas, que pode ser visto como uma troca de pártons em um processo de escada entre hádrons [61]. A escada de pártons evolui a partir do projétil e do alvo, como representado esquematicamente na figura 3.2, e tal evolução é governada no caso mais simples pelas equações de DokshitzerGribov-Lipatov-Altarelli-Parisi (DGLAP). Atualmente a escada de pártons consiste de uma parte hard, descrita pela QCD, e uma parte soft, puramente fenomenológica, parametrizada pela teoria de Regge [62]. Além disso, há outra fonte de produção de partículas vinda dos remanescentes do processo de espalhamento.

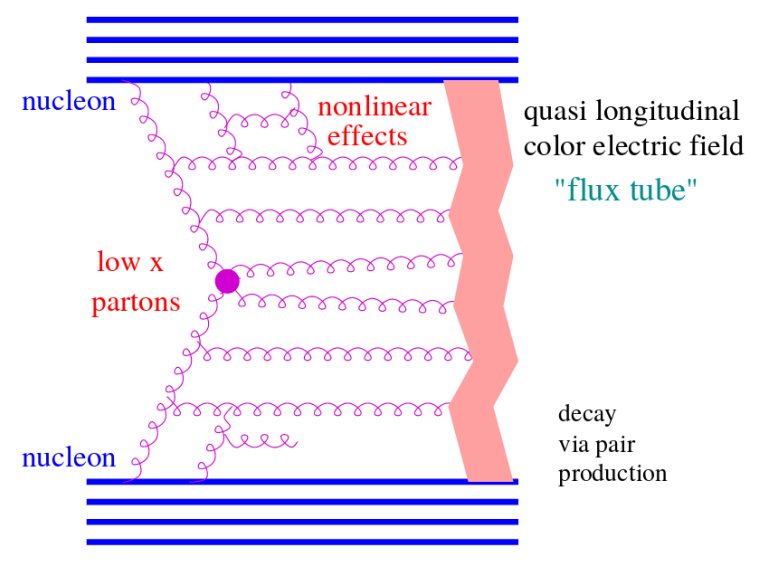

Figura 3.2: . Extraído da referência [13].

Também foram introduzidos no EPOS efeitos nucleares, saturação de pártons, blindagem e efeitos de altas densidades no comportamento coletivo em colisões de íons pesados. O compartilhamento de energia e momento e o tratamento dos remanescentes da colisão também são incorporados e são pontos chaves para o desenvolvimento de simulações EAS, pois influenciam diretamente a multiplicidade e a inelasticidade do modelo. A versão mais recente do EPOS é a chamada EPOSLHC, ajustada para reproduzir qualquer tipo de interação de hádrons-núcleon até núcleo-núcleo. Neste gerador, o intervalo de energias de

\footnotetext{
${ }^{\dagger}$ Eventos do tipo minimum bias são aqueles selecionados por um nível de trigger bastante relaxado em colisores de altas energias. Tais eventos incluem tanto processos difrativos quanto processos do tipo hard.
} 
centro de massa para a colisão primária vai de $40 \mathrm{GeV}$ até mais de $1000 \mathrm{TeV}$ (equivalente a aproximadamente $10^{21} \mathrm{eV}$ no referencial de laboratório). O modelo foi modificado seguindo os novos dados do LHC, em particular os efeitos de hadronização coletiva em espalhamentos próton-próton [63].

\subsubsection{QGSJETII-04}

O QGSJETII-04 é um modelo similar ao EPOSLHC, porém difere ligeiramente no tratamento da colisão. Ele usa a abordagem dos reggeons de Gribov para descrever as interações hadrônicas. A teoria de Regge é um estudo das propriedades analíticas da amplitude de espalhamento como uma função do momento angular que não fica restrito a múltiplos inteiros de $\hbar$, mas permite-se que assuma valores complexos. Nessa teoria, a interação hadrônica seria intermediada por partículas virtuais chamadas reggeons, caracterizadas por altos valores de spin e massa maior que ou similar às massas das partículas convencionais.

No QGSJETII-04, os processos de múltiplos espalhamentos são tratados como contribuições individuais e são descritos fenomenologicamente por troca de pomerons, tipos de partículas virtuais derivadas de reggeons para explicar as interações soft. O QGSJETII [64] foi implementado a partir do modelo de cordas de quarks e glúons, e generalizado para descrever interações núcleo-núcleo e processos semihard. Em sua versão mais recente QGSJETII-04-II04, o modelo foi estendido, adicionando novas interações não lineares ${ }^{\ddagger}$ para descrever melhor as interações nas energias de UHECR.

\subsubsection{SIBYLL2.3}

O SIBYLL2.3 é um dos modelos de interação hadrônica padrão para geradores de eventos baseados em Monte Carlos que são usados em simulações de EAS. Ele foi criado para descrever características gerais da produção de partículas hadrônicas, como o efeito da partícula líder ${ }^{\S}$, a formação de jatos com alto momento transverso preditos pela QCD, produções difrativas de estados excitados dos projéteis e alvos e escalonamento da distribuição da partícula líder com a energia da interação. O foco do SIBYLL2.3 é incorporar os aspectos físicos mais importantes para o desenvolvimento de EAS, como fluxo de energia e produção de partículas na região frontal do espaço de fase. Enquanto o modelo é criado de forma mais

\footnotetext{
${ }^{\ddagger}$ Efeitos não lineares em interações hadrônicas acontecem quando a energias dos pomerons que fazem a intermediação da interação é muito alta. Nesse cenário, os pomerons passam a ter um pequeno parâmetro de impacto e pode ocorrer interações pomeron-pomeron.

${ }^{\S}$ Em algumas colisões existe a probabilidade do projétil primário sobreviver carregando uma fração significativa da energia. Essa partícula é chamada de líder e contém os mesmos número quânticos do projétil original.
} 
simples possível, conceitos físicos microscópicos e princípios gerais da teoria de espalhamento e unitariedade são implementados para permitir a extrapolação para altas energias além das alcançadas por colisores.

Recentemente, foi lançada uma nova versão do SIBYLL2.3 [60] que estendeu e atualizou o cenário de interações hadrônicas já implementadas. As principais mudanças foram:

- Novas seções de choque inelásticas ajustadas aos dados do LHC.

- Melhor tratamento na descrição da partícula líder.

- Produção melhorada do ressonâncias vetoriais na região de fragmentação de mésons.

- Implementação da difração dissociativa na interação de hádrons com núcleons, similar ao modelo de difração Good-Walker [65].

- Implementação de um modelo fenomenológico para descrever a produção de partículas com charme.

\subsection{Comparação entre os modelos hadrônicos}

Através dos modelos de interações hadrônicas podemos estudar qualitativamente a dependência dos observáveis de EAS em função dos parâmetros, como seção de choque, elasticidade, multiplicidade e razão de carga. Até o funcionamento do LHC, os modelos de interações hadrônicas não tinham restrições bem definidas para as energias de UHECR. As previsões dos modelos eram relativamente diferentes dependendo da extrapolação realizada [66]. Atualmente, as extrapolações são menos divergentes para as energias de UHECR devido aos dados do LHC criarem restrições para a energia de $10^{17} \mathrm{eV}$ em colisões próton-próton [67].

A seção de choque está fortemente relacionada com a profundidade máxima do chuveiro, $X_{\text {max }}$, principalmente porque ela define o livre caminho médio da interação. Dessa forma, a seção de choque inelástica é muito importante para o desenvolvimento do chuveiro. Por exemplo, a seção de choque inelástica para colisões próton-próton é usada como parâmetro para os modelos de interações hadrônicas. Atualmente, esse parâmetro é bem descrito por todos os principais modelos até as energias do LHC, como podemos ver na figura 3.3. Entretanto, vemos que as previsões para a seção de choque inelástica de colisões próton-ar têm diferenças significativas. Esse resultado geralmente é associado à falta de dados experimentais para colisões hádron-núcleo, e além disso, os dados que existem são para colisões com energias menores que as colisões próton-próton. Consequentemente, o desenvolvimento de 
EAS para diferentes seções de choque próton-ar pode levar a diferentes interpretações dos observáveis de EAS.
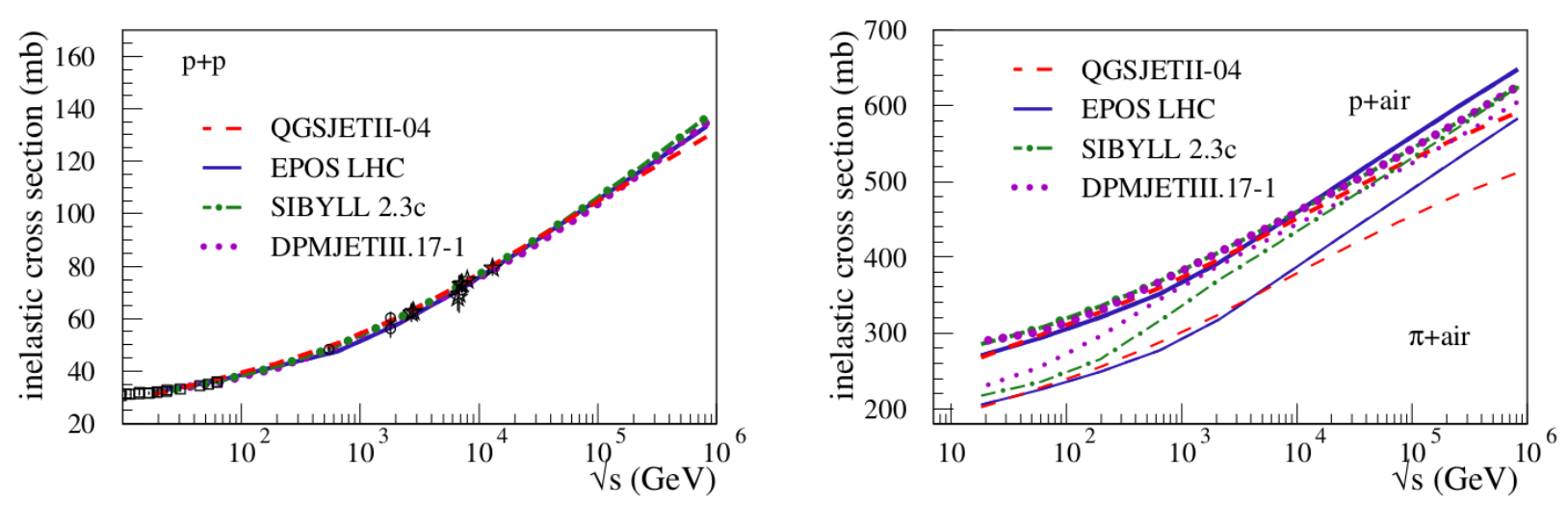

Figura 3.3: Seção de choque inelástica para colisões próton-próton (esquerda), colisão próton-ar (linhas grossas à direita) e colisões píons-ar (linhas finas à direita). Na figura, o modelo QGSJETII é representado por linha tracejada vermelha, EPOSLHC por linha tracejada azul e o SIBYLL2.3 por linha tracejada verde. Figura extraída de [14].

A multiplicidade atua de maneira similar à seção de choque inelástica, porém com uma intensidade menor (veja seção 2.2.4). Por outro lado, a predição dos modelos para a multiplicidade é relativamente bem diferente e insere mais incertezas sistemáticas nas medidas do que a seção de choque. Um exemplo é a distribuição de pseudorapidez $d N / d \eta$ para colisões próton-próton provenientes dos modelos, mostrada na figura 3.4. Os modelos são divergentes e o mais próximo dos dados do LHC é EPOSLHC, enquanto QGSJETII e SIBYLL2.3 não reproduzem os dados com a mesma precisão. Esse cenário torna-se pior quando olhamos a distribuição para colisões próton-ar, mostrado na figura 3.5 pois as diferenças tornam-se ainda maiores à medida que a energia aumenta. Assim como a seção de choque, mudanças na multiplicidade influenciam no desenvolvimento do EAS.

Outro observável importante no desenvolvimento de EAS é a fração de energia carregada por "uma partícula secundária" chamada de partícula líder. Essa fração é chamada de elasticidade, e define a energia que não foi perdida durante o processo de colisão. Devido ao difícil acesso experimental à região frontal do espaço de fase do processo de colisão em experimentos com colisores, há poucos vínculos experimentais sobre a elasticidade nessa região em comparação com a região central,. Esse resultado gera comportamentos opostos nos modelos, por exemplo, o SIBYLL2.3 tem a maior elasticidade quando comparado ao EPOSLHC e QGSJETII, como mostrado na figura 3.6. Esse resultado está relacionado com o fato de ele ter a menor multiplicidade, logo a partícula líder perde menos energia, em média, durante o processo de colisão.

Por sua vez, resultados obtidos pela Colaboração Auger encontraram uma diferença en- 

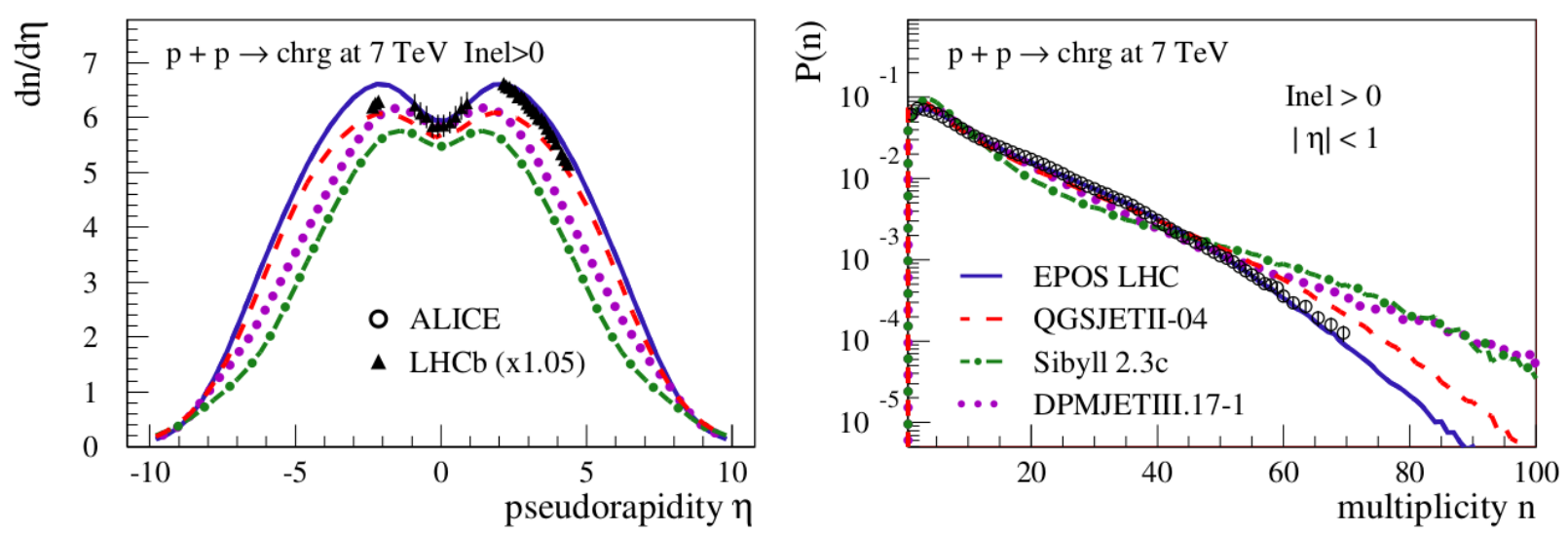

Figura 3.4: Distribuição de pseudorapidez $d N / d \eta$ para eventos com ao menos uma partícula com $|\eta|<1$ (esquerda) e a distribuição correspondente de multiplicidade (direita) para interações prótonpróton com energia $7 \mathrm{TeV}$. Na figura, os resultados do modelo QGSJETII são representado por linha tracejada vermelha, EPOSLHC por linha tracejada azul e o SIBYLL2.3 por linha tracejada verde. Figura extraída de [14].

tre o número de múons produzidos na simulação em relação ao observado experimentalmente[11]. Essa diferença pode ser atribuída aos modelos de interações hadrônicas, pois os múons são em grande parte produzidos pelos decaimentos de píons e káons gerados na componente hadrônica do chuveiro. Diferentes trabalhos já tentaram explicar essa diferença. Por exemplo, em [68] a contribuição da produção de bárions/antibárions, assim como a produção de $\rho^{0}$ ao longo da cascata foi estudada no tocante à produção final de múons. Outro trabalho mais recente [69] mostrou que a produção de $\rho^{0}$ em interações píon-carbono pode estar subestimada por um fator que contribuiria com aumento na produção de múons.

Alguns estudos recentes, como [15], mostram a influência dos principais parâmetros de interações hadrônicas sobre o desenvolvimento dos EAS. Através de mudanças sistemáticas nos valores de tais variáveis, aferiu-se que os parâmetros mais usados para inferir a composição química são sensíveis a diferentes extrapolações. Na figura 3.7 vemos que mudanças na seção de choque, multiplicidade, elasticidade e razão de carga podem mudar a profundidade do máximo do chuveiro, $X_{\max }$, em cerca de $20 \mathrm{~g} / \mathrm{cm}^{2}$. Esse resultado levaria a outras interpretações sobre a composição química dos UHECR.

Outros estudos como [16], tomando por base um modelo devido a L. Portugal e T. Kodama [70], mostram que o efeito de saturação de pártons pode influenciar na evolução subsequente dos EAS. A altíssimas energias, a seção de choque inelástica deve ser dominada pela interação com pártons de baixo momento (regime pequeno $x$ ) levando a uma saturação e, consequentemente, a seção de choque inelástica tem um aumento mais rápido quando comparado ao modelo de Glauber. Na figura 3.8 é mostrado o número de massa médio em 

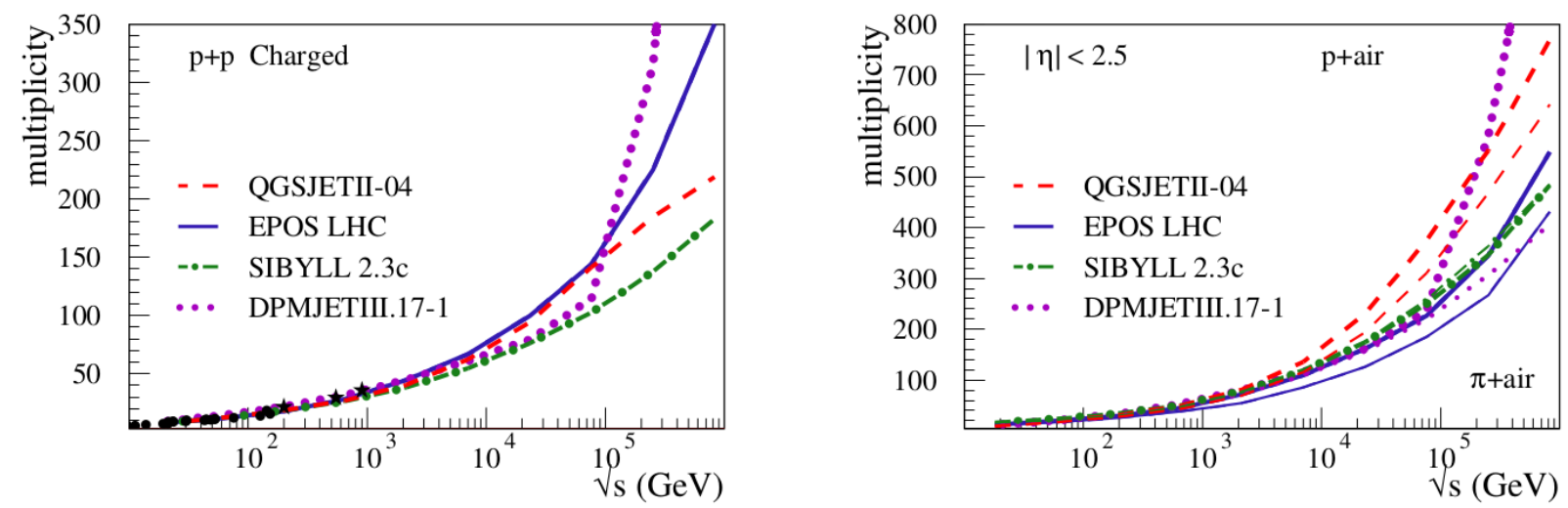

Figura 3.5: Multiplicidade em função da energia para eventos próton-próton (esquerda) e próton-ar a direita. Na figura, o modelo QGSJETII é representado por linha tracejada vermelha, EPOSLHC por linha tracejada azul e o SIBYLL2.3 por linha tracejada verde. Figura extraída de [14].

uma escala logarítmica como função da energia. Nota-se que, ao inserir o efeito de saturação de pártons (Gaussiana, Woods-Saxon) na seção de choque resultou em uma redução do número de massa média observado nos dados do Observatório Pierre Auger indicando uma composição química mais leve.

『Nomes utilizados pelo autor para diferenciar os modelos gerados por uma distribuição de perfil Gaussiana, ou Woods-Saxon para os pártons dentro do núcleo. 

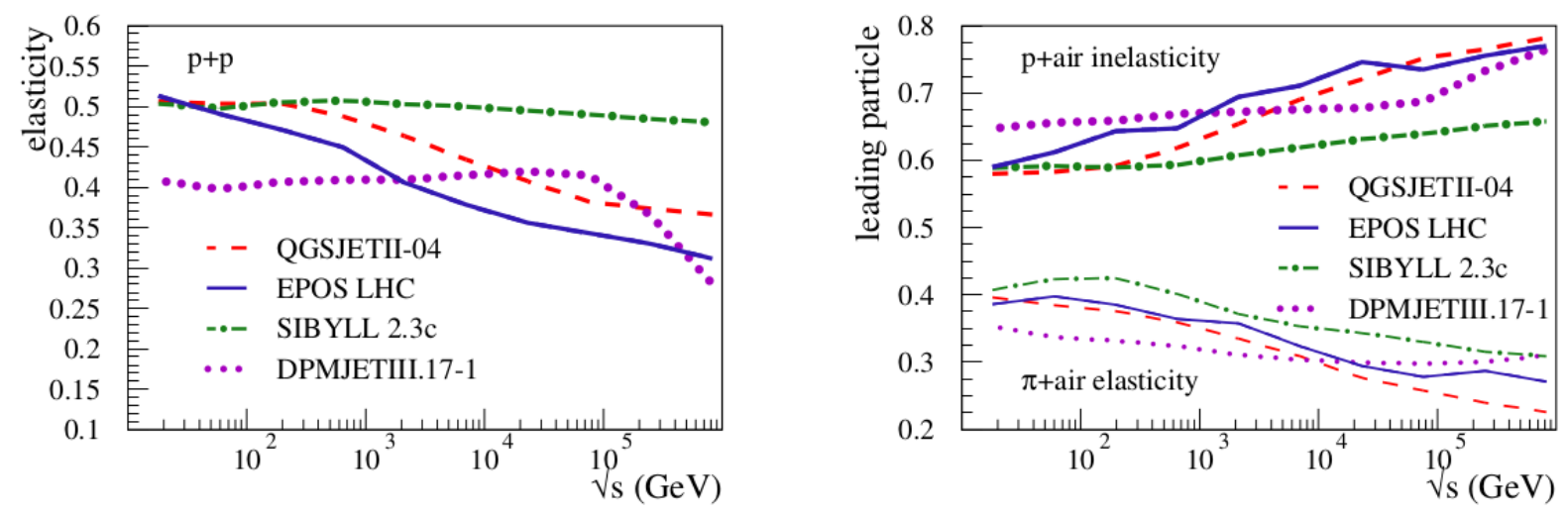

Figura 3.6: Elasticidade (fração de energia da partícula líder) para colisões próton-próton (a esquerda) e colisões píon-ar (linhas finas na figura a direita) e a inelasticidade próton-ar (linhas fortes na figura a esquerda) em função da energia de centro demassa. Simulações foram feitas com EPOSLHC(azul), DPMJETIII, (roxo) QGSJETII-04 (vermelho) e SIBYLL2.3 (verde). Figura extraída de [14].
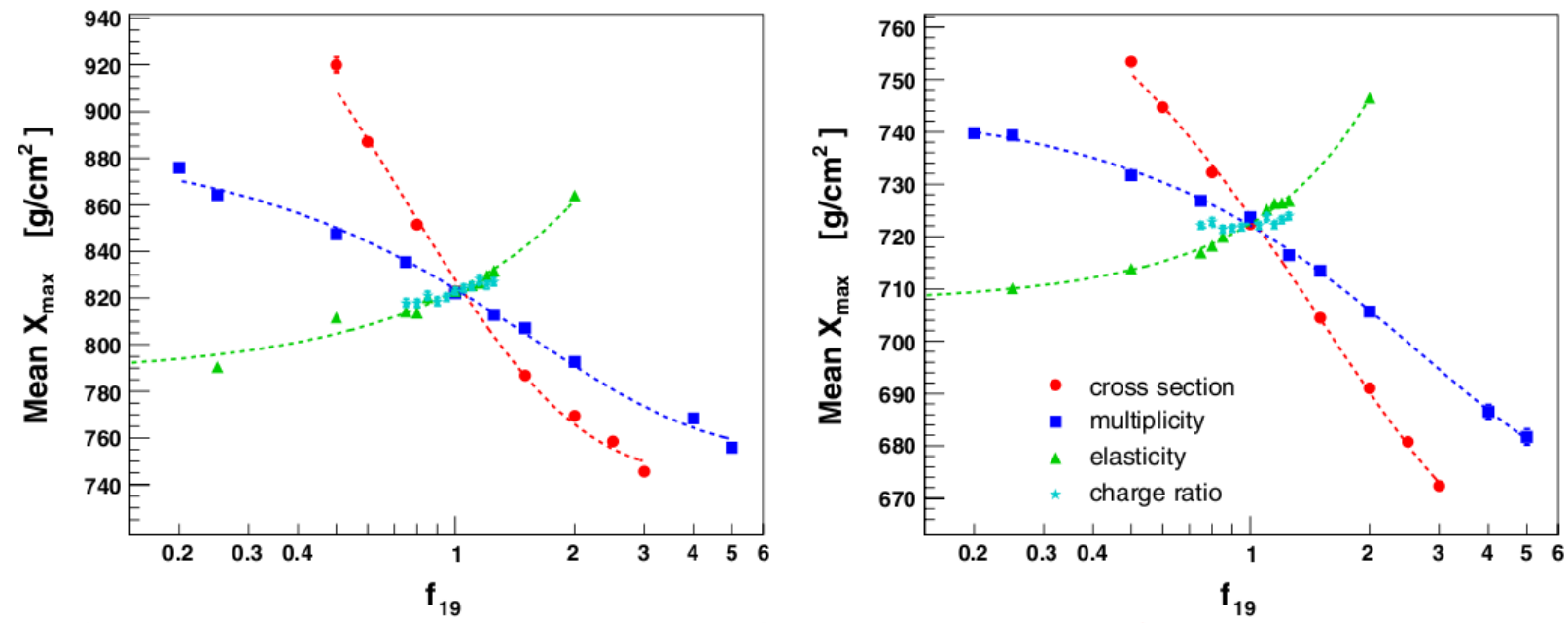

Figura 3.7: Mudança do parâmetro $X_{\max }$ dos EAS devido a modificações sistemáticas na seção de choque, multiplicidade, elasticidade e razão de carga por meio de uma constante multiplicativa $f_{19}$ aplicada aos valores de tais parâmetros em $E=10^{19} \mathrm{eV}$. Extraído da referência [15]. 


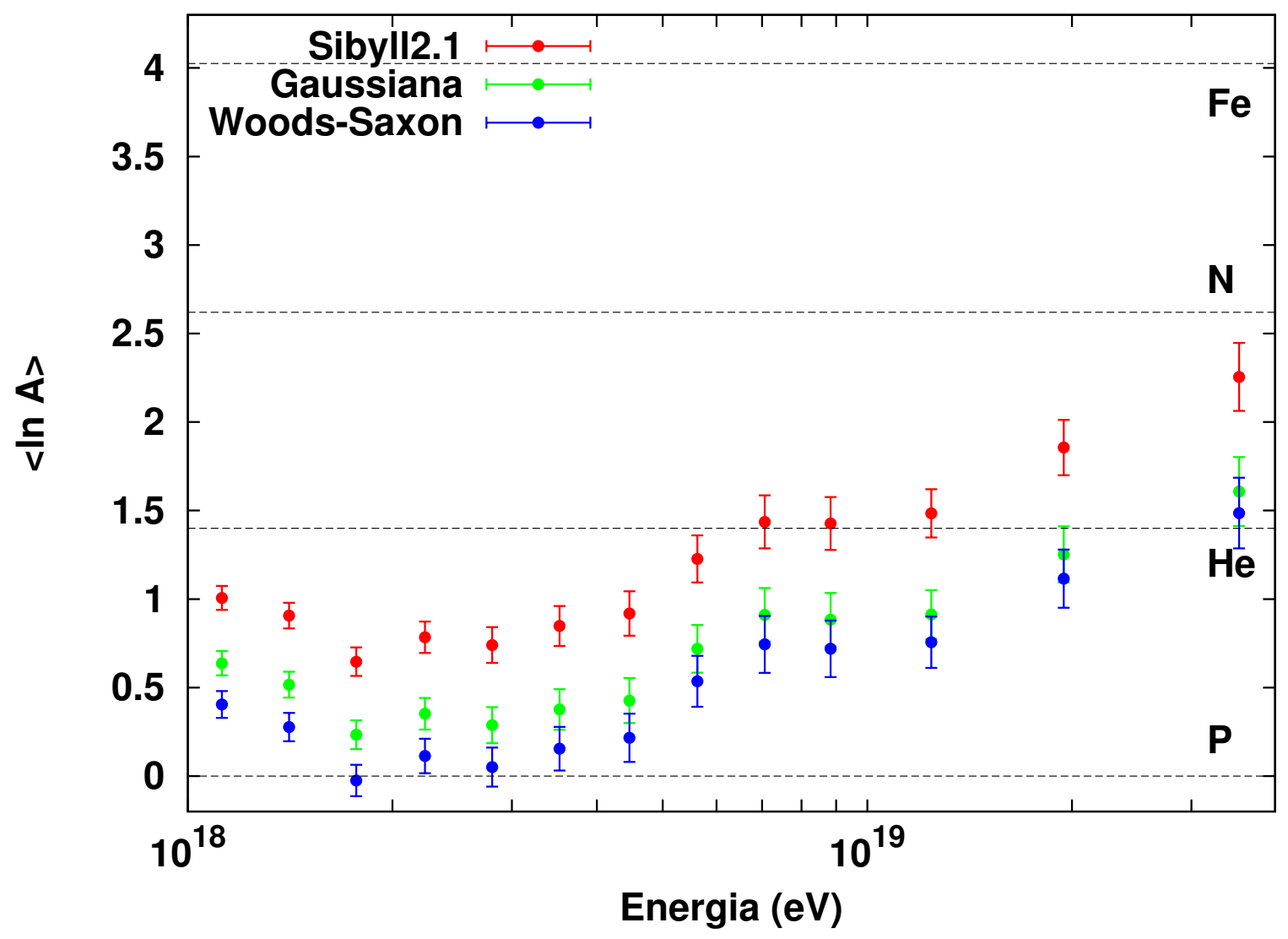

Figura 3.8: Número de massa médio em uma escala logarítmica como função da energia. Em verde e azul, temos os resultados da composição para os dois modelos da saturação de glúons. Quando comparados ao resultado do modelo do Glauber (SIBYLL), vemos que a composição para o modelo de saturação de glúons é de partículas mais leves do que o SIBYLL2.3. Retirado da referência [16]. 


\section{Capítulo 4}

\section{Análise dos observáveis de chuveiros atmosféricos}

Neste capítulo, realizou-se uma análise dos principais observáveis de EAS para diferentes modelos de interações hadrônicas. A realização deste estudo foi através das análises da distribuição do número de múons ao longo do eixo da cascata, também conhecido com distribuição longitudinal de múons, da distribuição de profundidades atmosféricas de produção de múons e da densidade de múons no nível do solo e no plano transversal ao eixo da cascata. A análise foi realizada para chuveiros iniciados por próton e ferro com energia de $10^{19} \mathrm{eV}$ e depois estendemos para energias entre $10^{18.5}$ e $10^{19.5} \mathrm{eV}$. A direção de entrada do UHECR foi fixada em $\left(\theta=60^{\circ}, \phi=0^{\circ}\right)$ onde $\theta$ é o angulo zenital e $\phi$ é o ângulo azimutal. Para a realização da simulação dos EAS utilizamos o programa CORSIKA

Ao todo, estudamos três modelos de interações hadrônicas, sendo eles EPOSLHC, SIBYLL2.3 e QGSJETII-04, todos em suas versões mais recentes. Para cada combinação de variável possível (modelo, composição química e energia) foram simulados 1000 chuveiros e, ao final, foram simulados 30000 chuveiros com um custo computacional de aproximadamente 45000 CPU-horas, ou 1875 CPU-dias. Somente foi possível realizar essa análise graças ao uso de dois clusters de computadores: CENAPAD [71] e SDUMONT [72].

\subsection{Densidade lateral de múons}

Espera-se que a distribuição lateral de múons (Lateral Distribution Function, LDF) seja sensível à composição química do UHECR, visto que os múons se originam a partir do decaimento dos píons e káons e que partículas primárias de naturezas químicas diferentes sofrem processos hadrônicos diferentes. Para observar essas influências dos modelos de interações hadrônicas e da composição química, analisamos a distribuição lateral dos múons 
no nível do solo do Observatório Pierre Auger (1400 m acima do nível do mar), para os três principais modelos utilizados em simulações de EAS. Encontramos o perfil lateral da densidade de múons, caracterizamos a densidade de múons a $1000 \mathrm{~m}$ do ponto de impacto do chuveiro $\left(\rho_{1000}\right)$ e também quantificamos a diferença entre os modelos para o intervalo de energia de $10^{18.5}$ até $10^{19.5} \mathrm{eV}$. Na fase de design do Auger se determinou, a partir de simulações, que nas energias em torno de $10^{18} \mathrm{eV}$, a flutuação chuveiro-a-chuveiro é mínima em torno de $1000 \mathrm{~m}$ do eixo da cascata. Por isso, essa é a distância de referência usada para se estimar o "tamanho" de uma cascata medida pelo Auger.

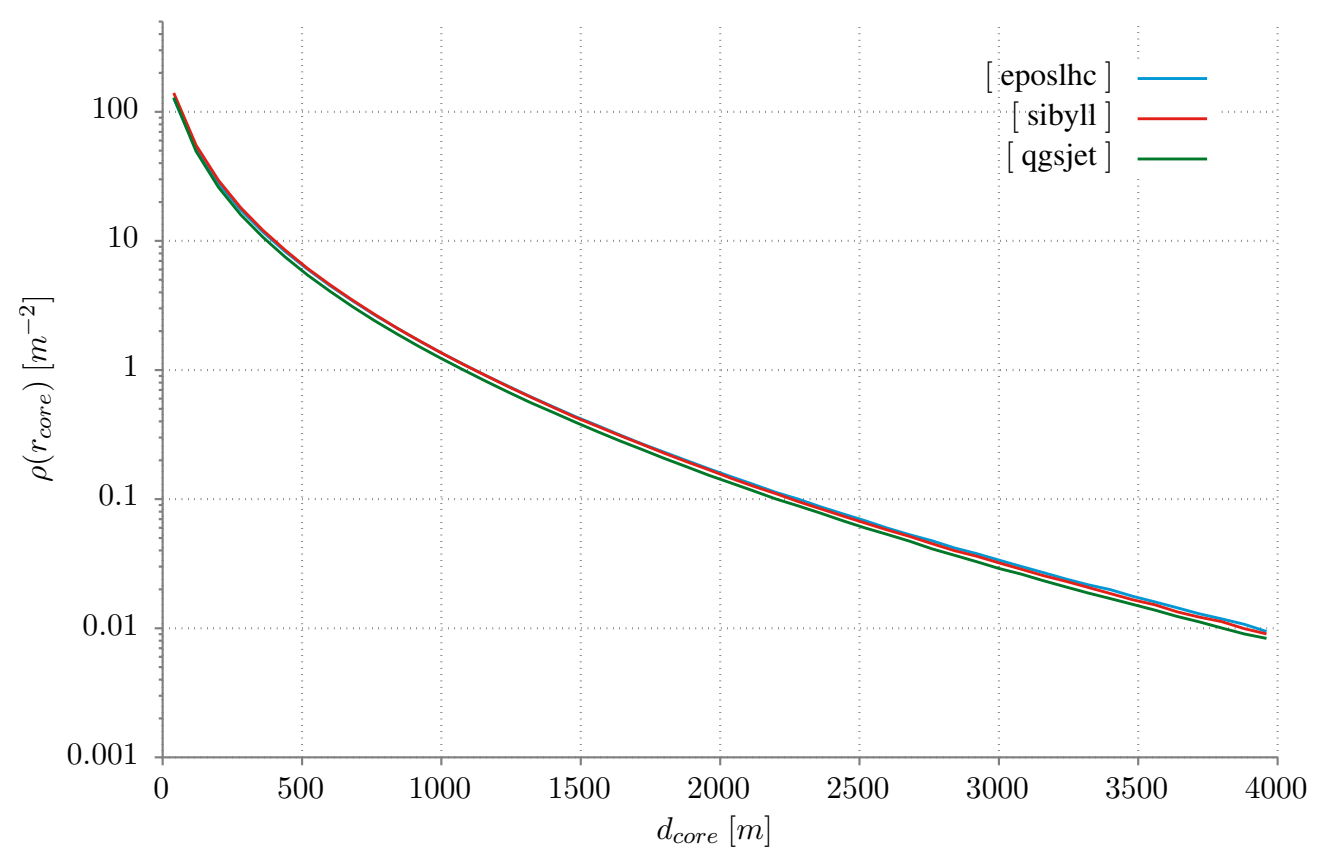

Figura 4.1: Comparação entre os modelos EPOSLHC, SIBYLL2.3 e QGSJETII-04 sobre a distribuição lateral (LDF) média para 1000 chuveiros iniciados por próton com energia de $10^{19} \mathrm{eV}$ e ângulo $\theta=60^{\circ}$ e $\phi=0^{\circ}$.

Na figura 4.1 é mostrado o perfil lateral da densidade de múons $\left(\rho\left(r_{\text {core }}\right)\right)$ em função da distância do ponto de impacto do chuveiro. Para esse perfil, foram simulados EAS iniciados por prótons com energias de $10^{19} \mathrm{eV}$ e inclinação zenital de $60^{\circ}$ e azimutal de $0^{\circ}$. A linha de cor azul representa o modelo SIBYLL2.3, a linha vermelha o EPOSLHC e a linha verde o QGSJETII-04. Para os três modelos, o perfil da densidade de múons é semelhante, não apresentando nenhuma característica distinta, e $\rho_{1000}$ é da ordem de uma partícula por metro quadrado. Para poder apreciar a diferença entre os modelos, é melhor analisar a diferença relativa

$$
\Delta \%=\frac{\rho_{1}-\rho_{2}}{\rho_{2}} .
$$

Na figura 4.2 é mostrada a diferença relativa entre as previsões dos três modelos de interação 
hadrônica. Em azul, SIBYLL2.3 e EPOSLHC apresenta uma diferença de aproximamente $\sim 10 \%$ próxima ao ponto de impacto e essa diferença diminui até que, em torno $1000 \mathrm{~m}$, ela seja praticamente nula. A diferença entre SIBYLL2.3 e QGSJETII-04, em verde, próxima ao ponto de impacto é aproximadamente $\sim 5 \%$ e aumenta para $\sim 10 \%$ rapidamente ao afastar-se do ponto de impacto. Por último, em vermelho, a diferença entre EPOSLHC e QGSJETII-04 é de $\sim 7 \%$ para regiões perto do ponto de impacto e aumenta para $\sim 10 \%$ para mais longe do centro. Outra análise realizada sobre a densidade lateral de múons, foi a

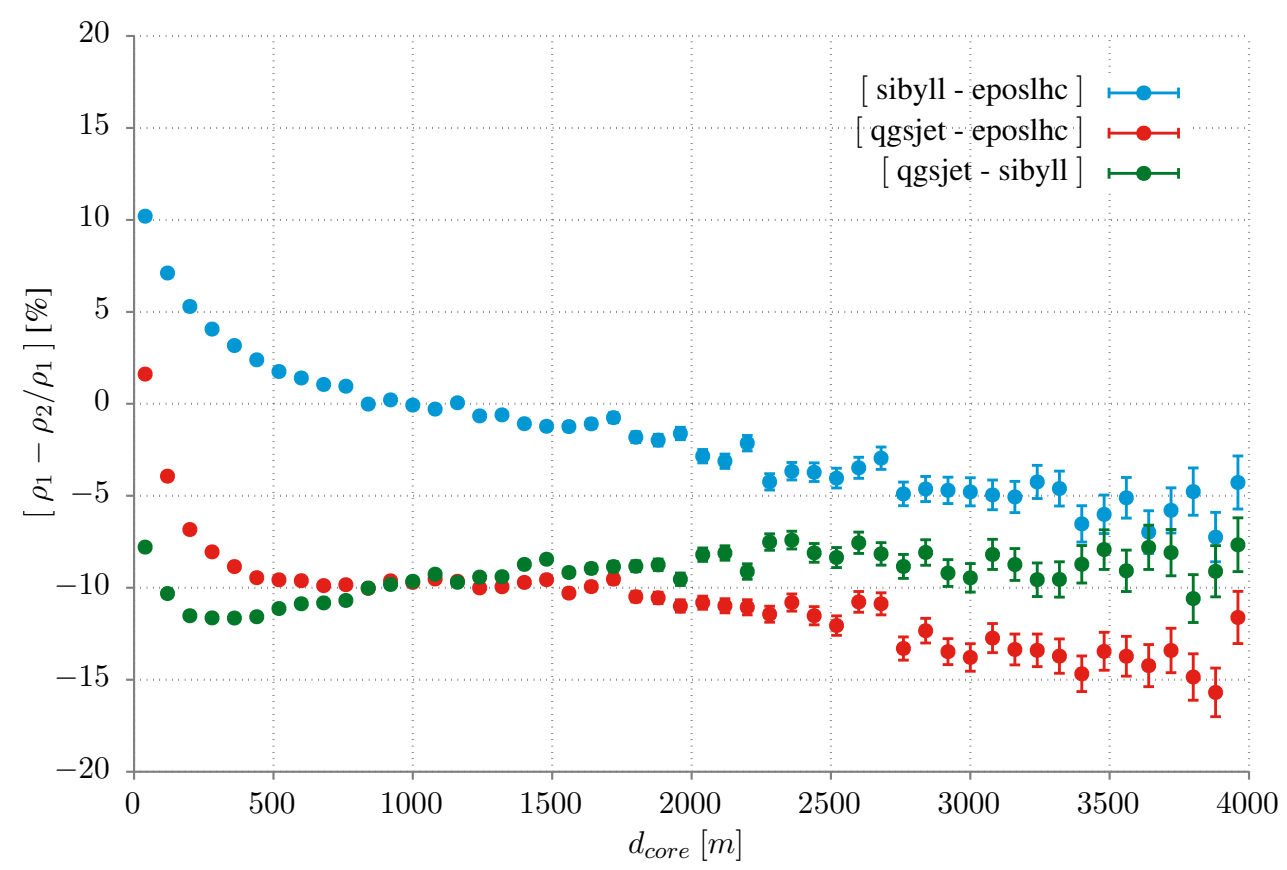

Figura 4.2: Diferença entre os modelos EPOSLHC, SIBYLL2.3 e QGSJETII-04 sobre a distribuição lateral $(\mathrm{LDF})$.

distribuição de $\rho_{1000}$ chuveiro a chuveiro. Na figura 4.3 é mostrada a distribuição de $\rho_{1000}$ para 1000 chuveiros iniciados por prótons com energia de $10^{19} \mathrm{eV}$. O modelo SIBYLL2.3 apresenta a maior densidade média entre os modelos, $\left\langle\rho_{1000}\right\rangle=1.49 \pm 0.25_{R M S}$, o modelo EPOSLHC preve um valor muito próximo do SIBYLL2.3 com $\left\langle\rho_{1000}\right\rangle=1.47 \pm 0.24_{R M S}$ e, por último, o QGSJETII-04 difere dos outros dois com $\left\langle\rho_{1000}\right\rangle=1.32 \pm 0.20_{R M S}$. A principal observação que podemos tirar desse resultado é que o modelo QGSJETII-04 tem uma densidade lateral de múons relativamente diferente dos modelos EPOSLHC e SIBYLL2.3 para chuveiro com energia de $10^{19} \mathrm{eV}$. Além do valor médio, as flutuações chuveiro a chuveiro de $\rho_{1000}$ são diferentes. O modelo QGSJETII-04 apresenta uma distribuição simétrica em torno do valor médio, enquanto as distribuições para os outros dois modelos possuem caudas assimétricas. Essa característica observada para o valor médio de $\rho_{1000}$ ocorre para todo o intervalo de energia estudado nesse trabalho, como mostrado na figura 4.4. Para o intervalo de energia de 


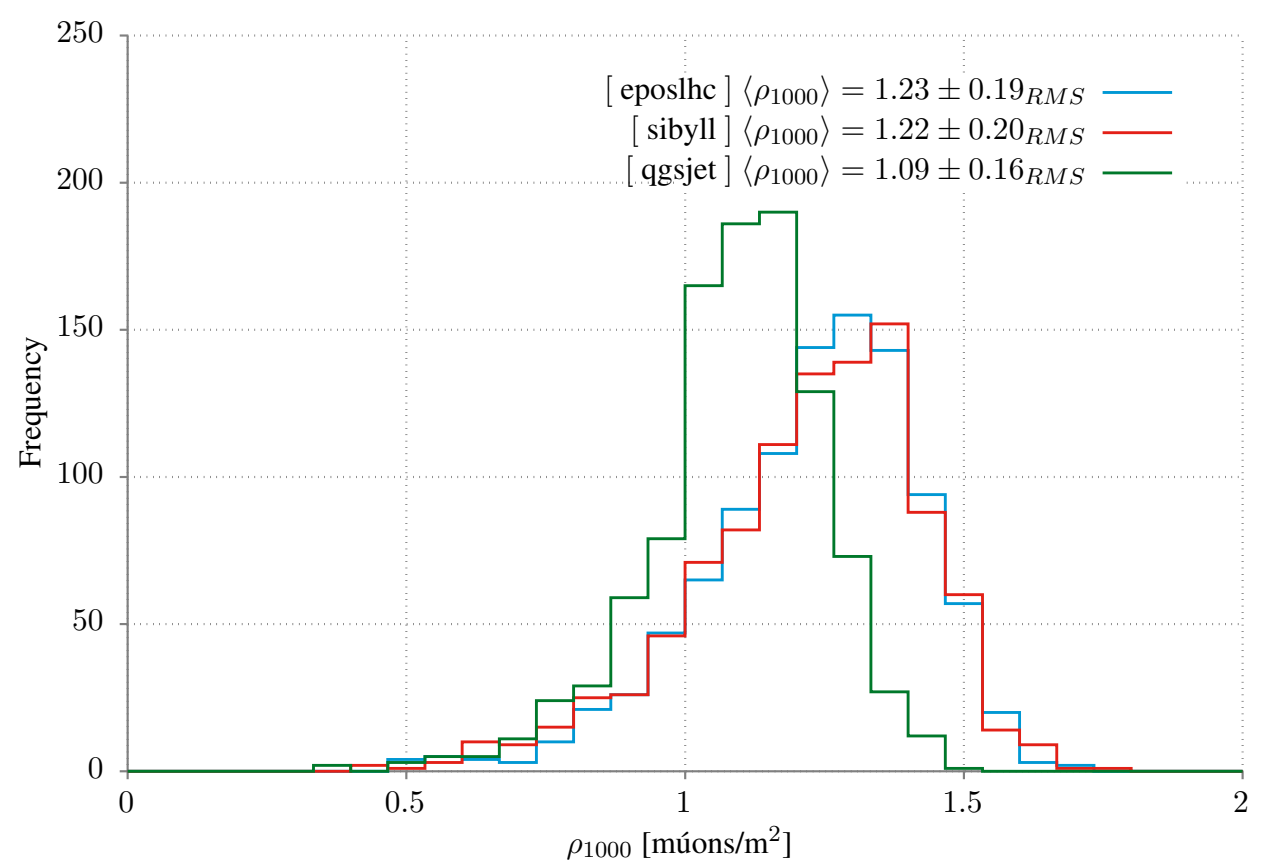

Figura 4.3: Distribuição de $\rho_{1000}$ entre os modelos EPOSLHC, SIBYLL2.3 e QGSJETII-04 para 1000 chuveiros iniciados por próton com energia de $10^{19} \mathrm{eV}$ e ângulo $\theta=60^{\circ}$ e $\phi=0^{\circ}$.

$10^{18.5}$ até $10^{19} \mathrm{eV}$, os modelos SIBYLL2.3 e EPOSLHC são relativamente próximos, enquanto o modelo QGSJETII-04 apresenta uma densidade de múons menor que os outros dois. A diferença dos modelos em função da energia é constante. Todas as figuras que foram usadas para construir a figura de evolução de $\rho_{1000}$ em função da energia encontram-se no apêndice.

\subsection{Desenvolvimento longitudinal}

A medida do desenvolvimento longitudinal de EAS possibilita o estudo da composição química do UHECR que iniciou o EAS, principalmente através da determinação do $X_{\max }$. Espera-se que o núcleo de massa $A$ tenha a primeira interação a uma profundidade $\left\langle X_{0}\right\rangle$ com comprimento de interação menor que de um próton $\left(\lambda_{A}<\lambda_{p}\right)$. Além disso, a flutuação do valor de $X_{\max }$ é menor para os núcleos quando a comparamos com a flutuação do valor de $X_{\max }$ de prótons. Esse resultado pode ser mostrado a partir do modelo de Matthews para o desenvolvimento de EAS. A profundidade $X_{\max }$ neste modelo é dada pela equação 2.24. Nela, podemos ver claramente que $X_{\max }$ depende do comprimento de interação $\lambda_{p}$ e da energia da partícula inicial. Se aplicarmos o modelo de superposição, descrito na seção 2.2.5, podemos 


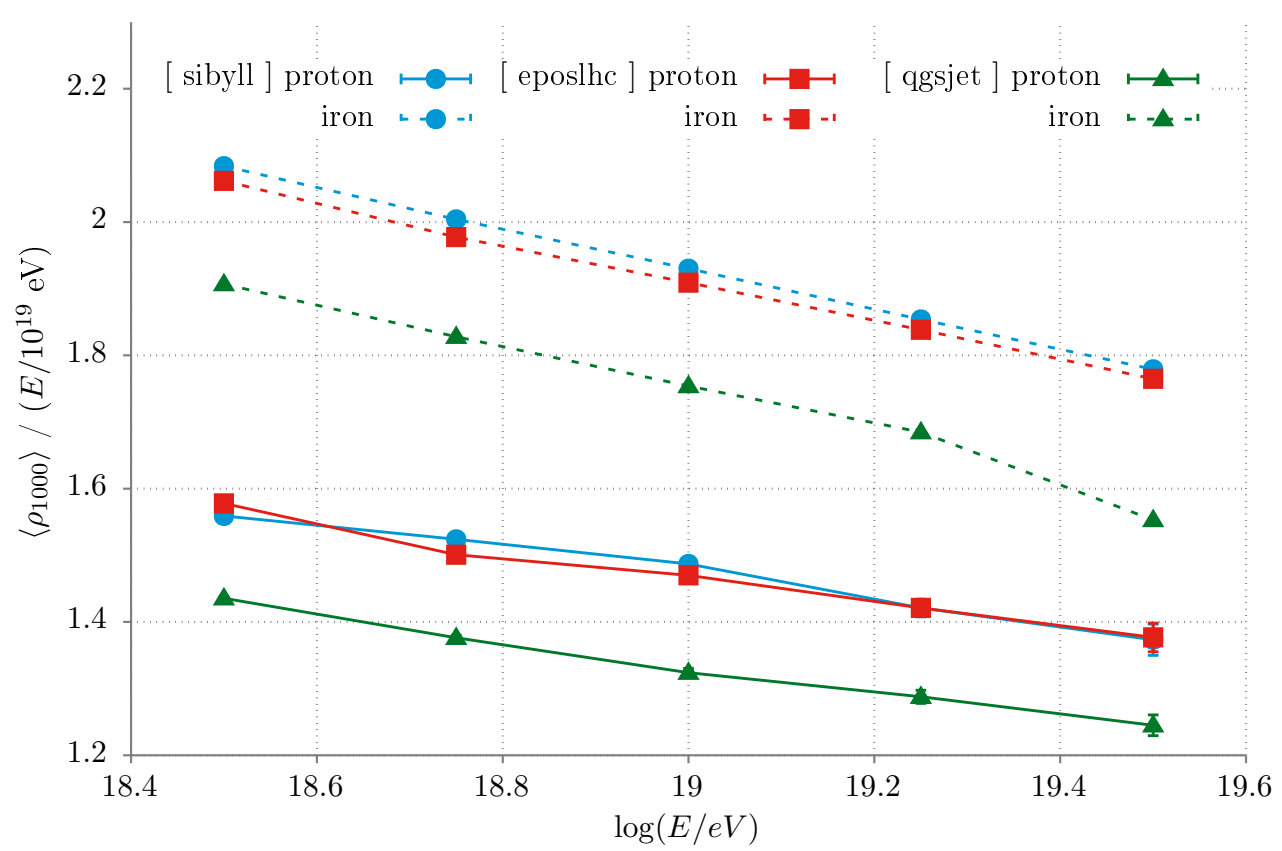

Figura 4.4: Evolução do $\left\langle\rho_{1000}\right\rangle$ em função da energia para os modelos EPOSLHC, SIBYLL2.3 e QGSJETII-04 para chuveiros com energia entre $10^{18.5}$ e $10^{19.5} \mathrm{eV}$ e ângulo $\theta=60^{\circ}$ e $\phi=0^{\circ}$. Ao todo, foram simulados 1000 chuveiros para cada ponto do gráfico.

obter a equação da profundidade máxima

$$
\left\langle X_{\text {max }}^{A}\right\rangle=\left\langle X_{\max }^{p}\left(E^{\prime}=E / A\right)\right\rangle=\left\langle C+D_{p} \ln (E / A)\right\rangle=\left\langle X_{\max }^{p}\right\rangle-D_{p}\langle\ln A\rangle
$$

que demonstra explicitamente a relação de $X_{\max }$ com a composição química do UHECR que iniciou a cascata.

Em vista disso, analisamos o desenvolvimento longitudinal de EAS utilizando simulações com diferentes modelos de interações hadrônicas. Nessa análise, estudamos o número de partículas (múons, fótons e elétrons) em função da profundidade $X$, dada em $\mathrm{g} / \mathrm{cm}^{2}$, mostrado na figura 4.5. Na figura (a) é mostrado o perfil médio do desenvolvimento longitudinal de chuveiros iniciados por prótons com energia de $10^{19} \mathrm{eV}$ usando os modelos de interação hadrônica SIBYLL2.3 (linha azul), EPOSLHC (linha vermelha) e QGSJETII-04(linha verde). Aqui, é mostrado que o perfil médio de desenvolvimento longitudinal difere ligeiramente entre os modelos, mas essa diferença não é clara nesse tipo de gráfico. Contudo, quando se observa a figura (b), fica evidenciado que no início do chuveiro, onde ocorrem as primeiras interações, a diferença é da ordem de $60 \%$, depois, chega a ser inexistente perto da região do máximo e volta a aumentar para $\sim 20 \%$ para grandes profundidades. A diferença no início do chuveiro é claramente uma consequência do modelo de interação hadrônica, pois é nesse estágio que ocorrem as interações hadrônicas de altas energias. As medidas experimentais 


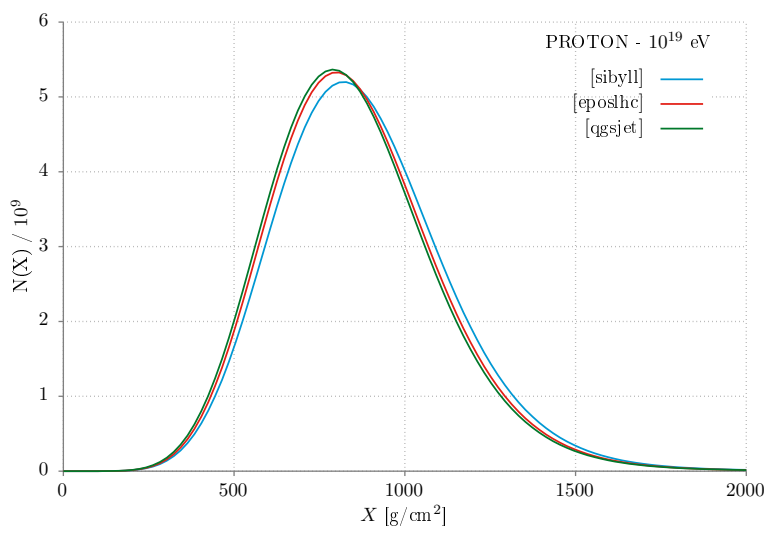

(a) Perfil médio

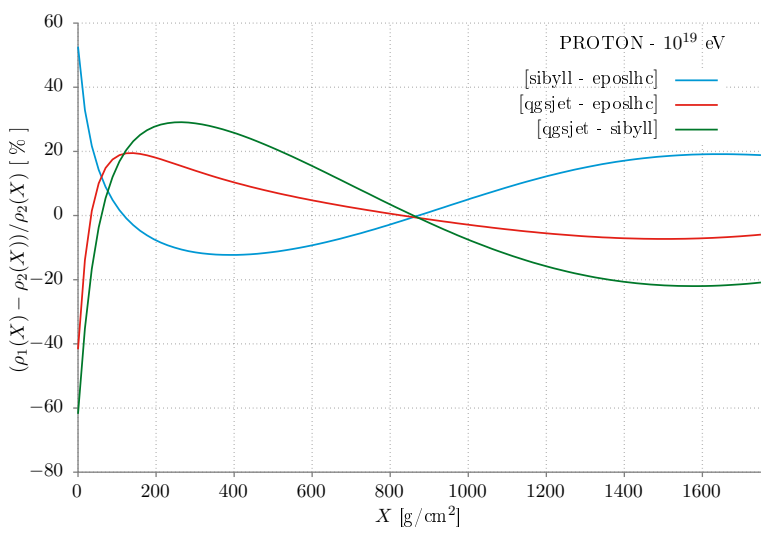

(b) Diferença

Figura 4.5: Comparação do desenvolvimento longitudinal de chuveiros atmosféricos iniciados por próton com energia de $10^{19} \mathrm{eV}$ e inclinação $\theta=60^{\circ}$. Na figura (a) estão representados os perfis médios de 1000 EAS para os modelos EPOSLHC (linha vermelha), SIBYLL2.3 (linha azul), QGSJETII-04 (linha verde) e na figura (b) é mostrada a diferença entre os modelos.

do desenvolvimento longitudinal de EAS no Observatório Pierre Auger são realizadas com os telescópios de fluorescência através da taxa de emissão fluorescente $d E / d X$ em função da profundidade atmosférica. O perfil dessa emissão pode ser descrito por meio da função de Gaisser-Hillas [28], dada por

$$
f_{G H}=\left(\frac{d E}{d X}\right)_{\max }\left(\frac{X-X_{0}}{X_{\max }-X_{0}}\right)^{\left(X_{\max }-X_{0}\right) / \lambda} e^{\left(X_{\max }-X\right) / \lambda}
$$

A profundidade do número máximo de partículas chuveiro $\left(X_{\max }\right)$ é outro observável interessante dado pelo perfil longitudinal de EAS. Assim como o perfil do EAS, o $X_{\max }$ também é estimado através do ajuste da equação 4.3. Na figura 4.6 é mostrada a distribuição de $X_{\max }$ para chuveiros iniciados por próton com energia de $10^{19} \mathrm{eV}$. Para o modelo SIBYLL2.3 foi encontrado $\left\langle X_{\max }\right\rangle=820 \pm 65_{R M S} \mathrm{~g} / \mathrm{cm}^{2}$, enquanto o EPOSLHC foi encontrado $\left\langle X_{\max }\right\rangle=800 \pm 56_{R M S} \mathrm{~g} / \mathrm{cm}^{2}$ e para o QGSJETII-04 $\left\langle X_{\max }\right\rangle=790 \pm 64_{R M S} \mathrm{~g} / \mathrm{cm}^{2}$. Quando estudamos outra composição como ferro ou outros intervalos de energia, a diferença entre os modelos se mostrou constante. O modelo SIBYLL2.3 sempre atingiu a maior profundidade, independente da massa ou energia, e em seguida EPOSLHC e QGSJETII-04, como mostrado na figura 4.7. Ou seja, o $\left\langle X_{\max }\right\rangle$ é uma função monotonamente crescente da energia com uma taxa de elongação de $\sim 60 \mathrm{~g} / \mathrm{cm}^{2}$ por década de energia para todos os modelos. Como esperado, o desenvolvimento longitudinal para chuveiros iniciados por ferro e próton são diferentes e, além disso, os modelos de interações hadrônicas resultam em perfil médio e profundidades máximas diferentes. 


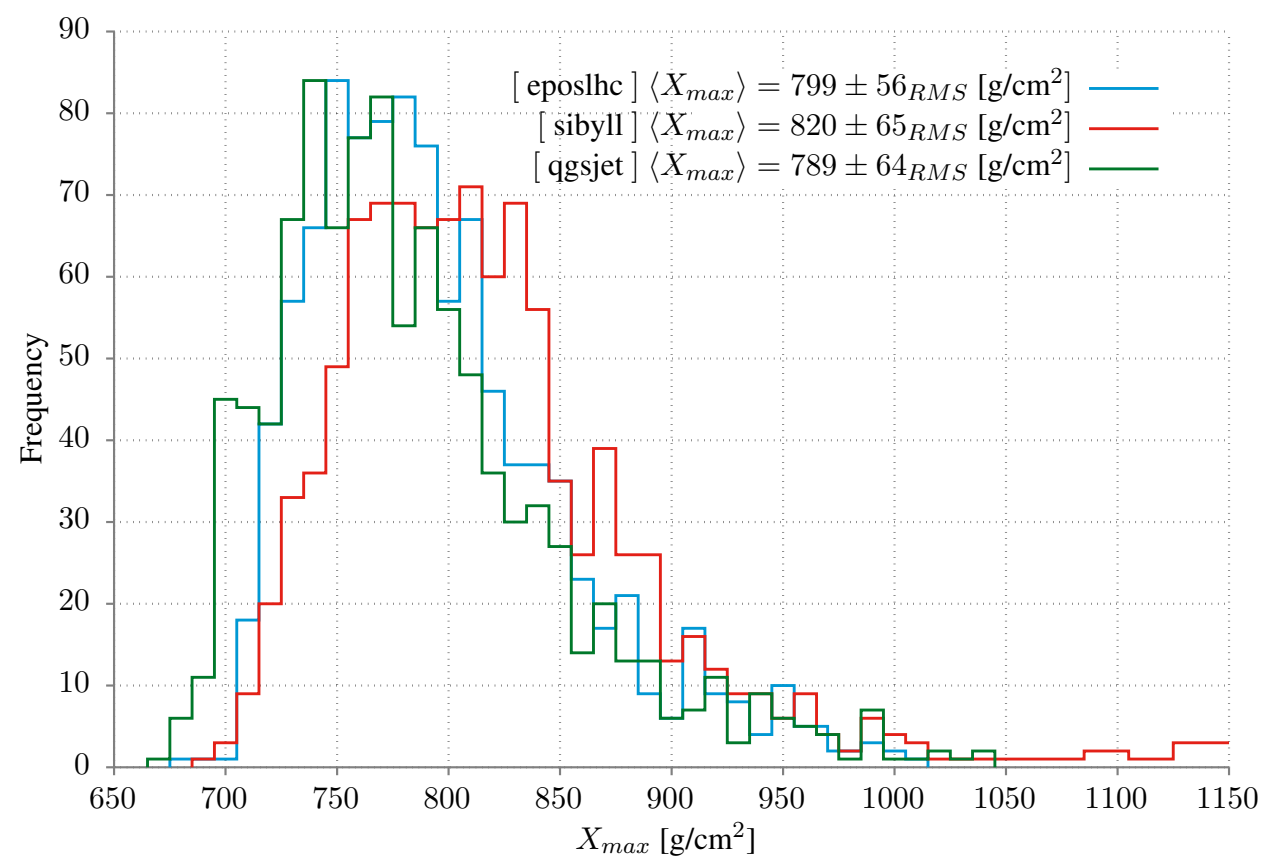

Figura 4.6: Distribuição de $X_{\text {max }}^{\mu}$ entre os modelos EPOSLHC, e QGSJETII-04 para 1000 chuveiros iniciados por próton com energia de $10^{19} \mathrm{eV}$ e ângulo $\theta=60^{\circ}$ e $\phi=0^{\circ}$.

\subsection{Número de múons no nível de observação}

O número de múons $\left(N_{\mu}\right)$ produzidos no desenvolvimento de EAS também é sensível à composição do UHECR que iniciou o chuveiro. Simulações mostram que o número de múons cresce quase que linearmente em função da energia $(E)$ e também cresce com uma potência pequena da composição química $(A)$ do UHECR. Este caso também pode ser deduzido a partir do modelo de Matthews, que prediz

$$
N_{\mu}=A\left(\frac{E / A}{\xi_{c}}\right)^{\beta}
$$

para o número de múons. Aplicando o logaritmo na equação 4.4 e calculando a derivada com respeito ao logaritmo da energia, obtemos a seguinte equação

$$
\frac{d \ln N_{\mu}}{d \ln E}=\beta+(1-\beta) \frac{d \ln A}{d \ln E} .
$$

Esse resultado mostra o ganho de múons em função do logaritmo da energia e carrega a informação adicional da mudança de composição química e também a mudança de composição química é invariante sobre a escala de energia.

Desta maneira, podemos analisar o número de múons produzidos no EAS que chegam ao nível de observação. Para tal tarefa, utilizamos a variável $N_{19}$ que é definida como a razão 


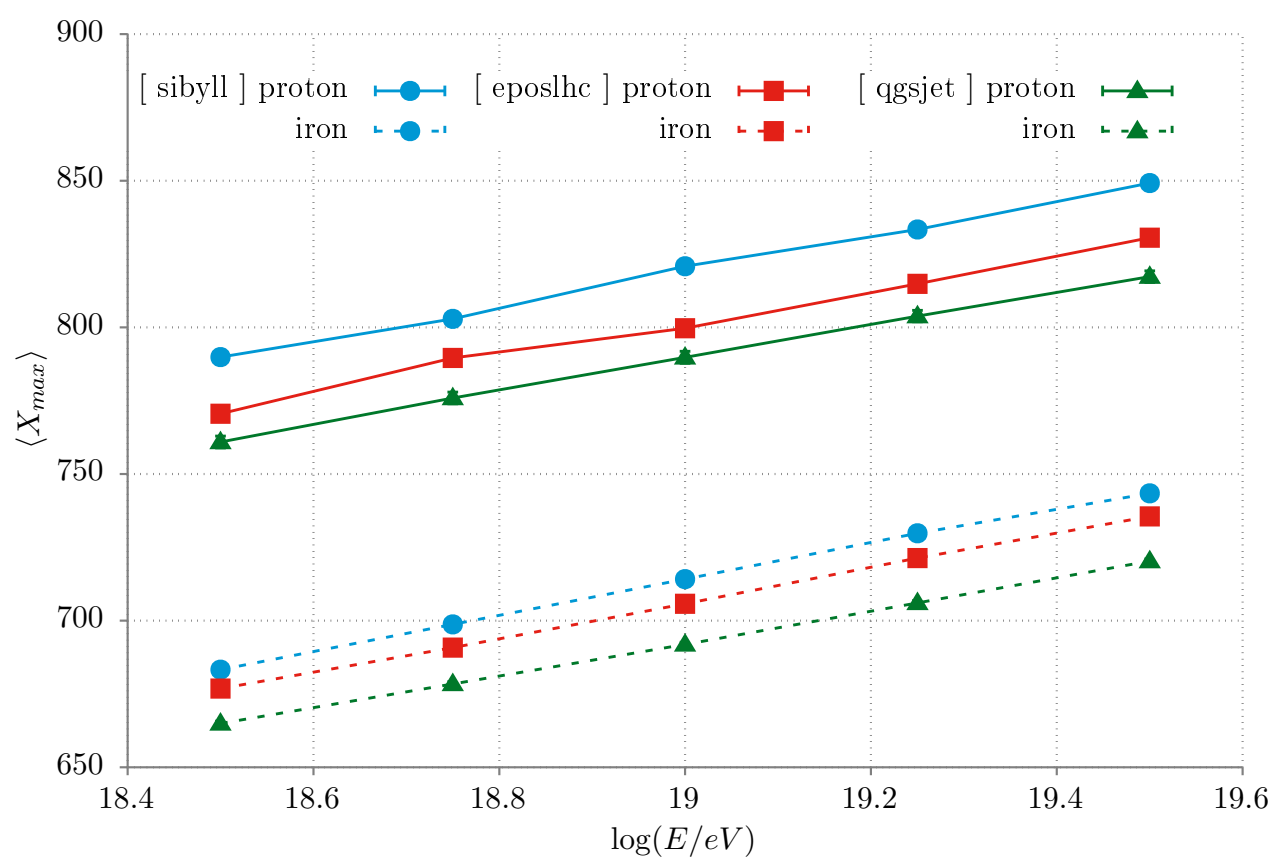

Figura 4.7: Evolução do $X_{\max }$ em função da energia para os modelos EPOSLHC, SIBYLL2.3 e QGSJETII-04 para chuveiros com energia entre $10^{18.5}$ e $10^{19.5} \mathrm{eV}$ e ângulo $\theta=60^{\circ}$ e $\phi=0^{\circ}$.

do número de múons $N_{\mu}$ por um valor de referência.

IMPORTANTE: Chamamos a atenção para o fato de que, a rigor, $N_{19}$ utilizado nesta tese difere daquele utilizado pelo Observatório Pierre Auger. Os detectores de superfície do

Auger não têm acesso direto ao número de múons, mas simplesmente ao sinal total depositado na forma de luz Cherenkov nos tanques. Este sinal é medido em uma unidade especial, denominada VEM (Vertical Equivalent Muon), e corresponde ao sinal depositado por um único múon atravessando o tanque na direção vertical ao longo do seu eixo de simetria.

Neste caso, usamos o número de múons médio de 1000 chuveiros de próton com energia de $10^{19} \mathrm{eV}$ e simulados com EPOSLHC, dado por $2.82 \times 10^{7}$ múons. O número de múons de um chuveiro foi obtido através da contagem direta de partículas que chegam ao solo, com energia maior que $0.3 \mathrm{GeV}$, sem nenhuma restrição de raio de integração.

Na figura 4.8 é mostrado o número de múons que chegaram ao solo para 1000 chuveiros iniciados por prótons com energia de $10^{19} \mathrm{eV}$. Os resultados indicam que o modelo SIBYLL2.3 tem o valor médio de múons $\left\langle N_{19}\right\rangle=1.03 \pm 0.19_{R M S}$, enquanto o EPOSLHC tem $\left\langle N_{19}\right\rangle=$ $1.00 \pm 0.17_{R M S}$ e o QGSJETII-04 $\left\langle N_{19}\right\rangle=0.92 \pm 0.14_{R M S}$. Analogamente ao caso do $X_{\max }$, o maior número de múons foi obtido com o modelo SIBYLL2.3, enquanto o modelo QGSJETII04 apresenta o menor número. No caso do EPOSLHC, vemos que ele apresenta o $N_{19}$ médio igual a 1. Isso acontece porque ele foi usado como referência para o cálculo de $N_{19}$. No final, 


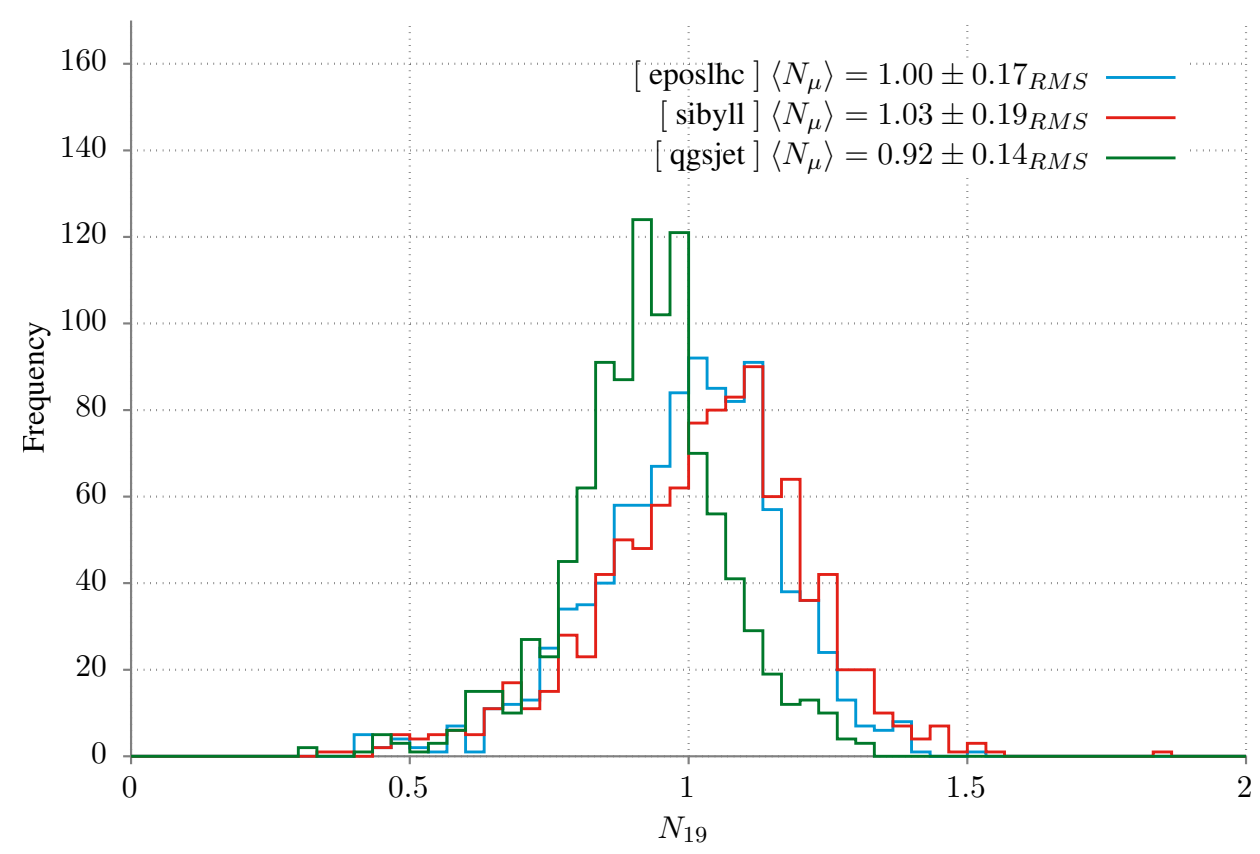

Figura 4.8: Distribuição do número de múons para chuveiros iniciados por próton com energia de $10^{19} \mathrm{eV}$ e ângulo $\theta=60^{\circ}$ e $\phi=0^{\circ}$. Em vermelho é mostrado o modelo interações hadrônicas EPOSLHC, em azul SIBYLL2.3 e em verde QGSJETII.

analisamos o comportamento do $N_{19}$ em função da energia. Na figura 4.9 é mostrado o $\left\langle N_{19}\right\rangle$, para o intervalo de energia entre $10^{18.5}$ e $10^{19.5} \mathrm{eV}$, para chuveiros iniciados por prótons e ferros. Da mesma maneira, vemos que os modelos SIBYLL2.3 e EPOSLHC possuem um número de múons próximo, já o QGSJETII-04 apresenta um número menor de múons em todo intervalo.

Assim como no caso de $\rho_{1000}$, o observável $N_{19}$ apresentou uma distribuição simétrica em torno do valor médio para o QGSJETII-04, enquanto as distribuições para os outros dois modelos possuem caudas assimétricas.

\subsection{Produção de múons em função da profundidade at- mosférica}

A função que descreve a distribuição de profundidades atmosféricas de produção de múons (Muon Production Depth, MPD) representa outro observável de EAS. Sabemos que os múons são criados a partir do decaimento principalmente de píons e káons, de forma que a MPD contém informação sobre a evolução da cascata. Também sabemos que raios cósmicos de natureza química distintas têm processos hadrônicos distintos, consequentemente, teríamos diferentes perfis longitudinais da MPD. Portanto, é natural pensar que a 


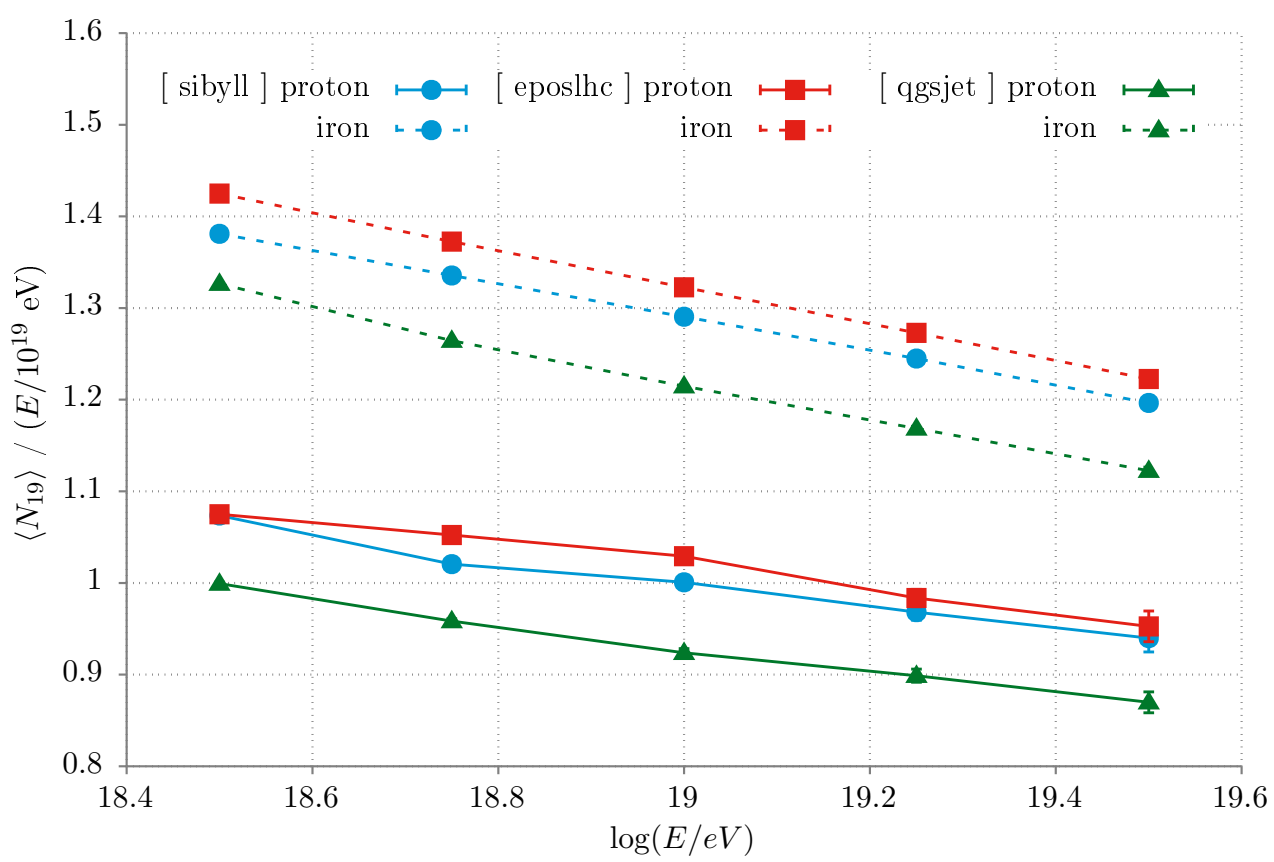

Figura 4.9: Evolução do número de múons para chuveiros com energia entre $10^{18.5}$ até $10^{19.5} \mathrm{eV}$ e ângulo $\theta=60^{\circ}$ e $\phi=0^{\circ}$. Em vermelho é mostrado o resultado com o modelo interações hadrônicas EPOSLHC, em azul com o SIBYLL2.3 e em verde com o QGSJETII-04.

MPD seja sensível à composição química do primário do UHECR que iniciou a cascata.

A profundidade de produção de múons $X^{\mu}$ é obtida da integração da densidade atmosférica $\rho$ ao longo do eixo da cascata até a altura de origem do múon

$$
X^{\mu}=\int_{z}^{\infty} \rho\left(z^{\prime}\right) d z^{\prime}
$$

A forma da distribuição depende do ponto de observação no solo e do ângulo zenital do EAS. Além disso, ela depende da distribuição de energia dos múons, pois isso dita o tempo de vida médio dessas partículas. Sobre a distribuição de $X^{\mu}$ é ajustado a função de Gaisser-Hillas 4.3. A partir desse ajuste, podemos determinar o perfil e a profundidade de máxima produção de múons $X_{\text {max }}^{\mu}$.

Para permitir comparações com a literatura, aplicamos um corte na distância ao ponto de impacto da cascata. Apenas os múons com mais de $1700 \mathrm{~m}$ de distância são considerados na distribuição de profundidade de produção de múons. Esse é o melhor valor encontrado na referência [73], onde se mostrou que incertezas no tempo de chegada para os múons próximo ao ponto de impacto são grandes e por isso devem ser descartados.

Para a análise da MPD, simularam-se 1000 chuveiros com energia de $10^{19} \mathrm{eV}$ iniciados por próton com inclinação zenital de $60^{\circ}$ e azimutal $0^{\circ}$. A partir de cada chuveiro foi extraída uma MPD e sobre ela ajustada a função Gaisser-Hillas como mostrado na figura 4.10. Aqui, 
os pontos pretos mostram os dados da MPD para um chuveiro iniciado por próton com energia de $10^{19} \mathrm{eV}$ utilizando o modelo EPOSLHC, enquanto que a linha em vermelho é o melhor ajuste por minimização pelo método máxima verossimilhança.

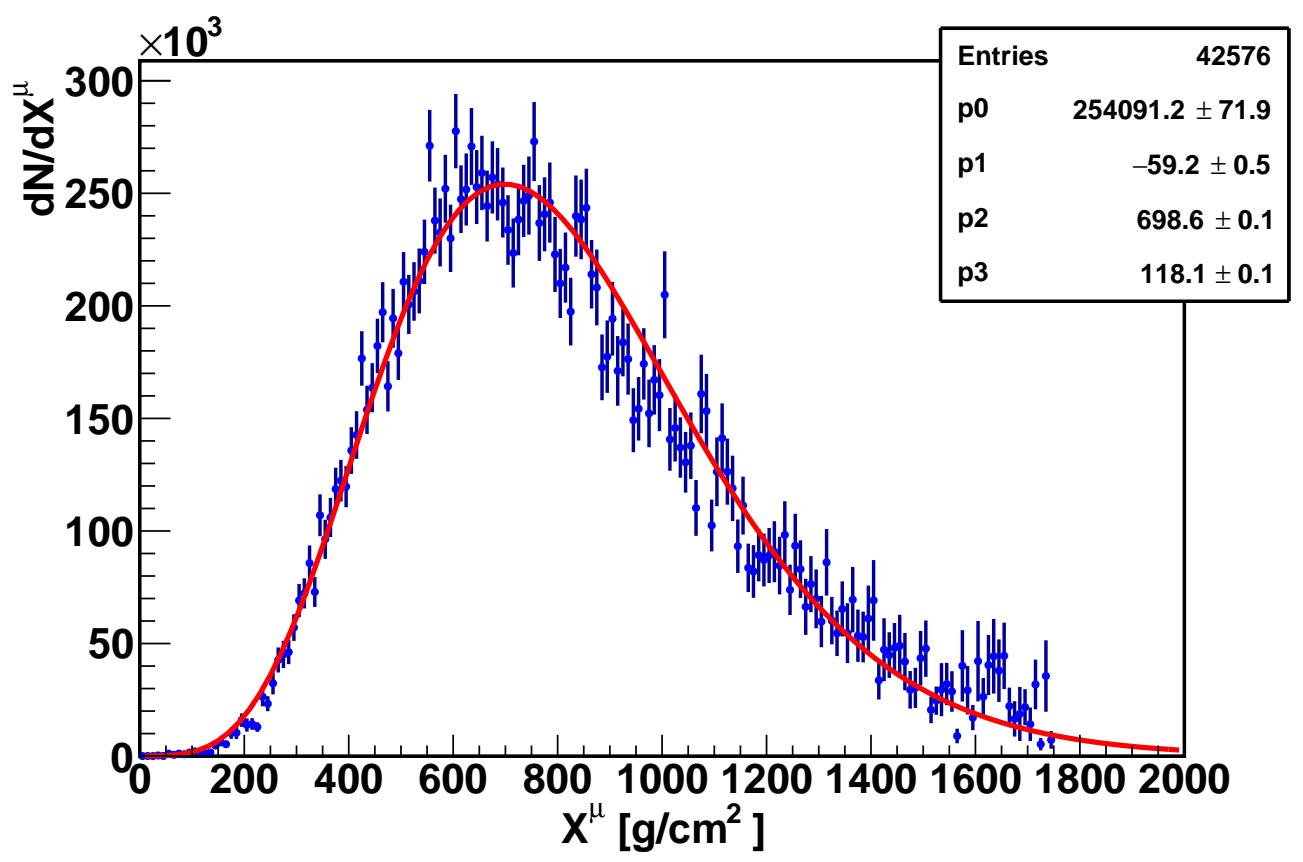

Figura 4.10: Distribuição de $X^{\mu}$ em função da profundidade atmosférica de um EAS iniciado por um próton com energia de $10^{19} \mathrm{eV}$. Sobre os dados foi aplicado um corte, $r_{c u t}>1700 \mathrm{~m}$, na distância ao ponto de impacto do chuveiro. Além disso, a linha vermelha representa o melhor ajuste da função Gaisser-Hillas através da minimização de máxima verossimilhança.

Na figura 4.11 é mostrado o perfil médio de desenvolvimento da produção de múons e a diferença entre os modelos estudados. Os modelos EPOSLHC (linha vermelha) e SIBYLL2.3 (linha azul) apresentam um perfil semelhante, enquanto o QGSJETII-04 (linha verde) tem uma produção menor. Nos primeiros estágios de desenvolvimento do chuveiro, o modelo QGSJETII-04 apresenta uma taxa de 70\% a 80\% maior de produção de múons em relação aos outros modelos. Porém, durante o desenvolvimento, a taxa de produção diminui e a diferença se inverte e o modelo QGSJETII-04 passa a produzir $\sim 40 \%$ a menos múons.

Assim como no perfil longitudinal, podemos estudar a profundidade de máxima produção de múons $X_{m a x}^{\mu}$. Essa profundidade é obtida através do ajuste da equação 4.3. Na figura 4.12 é mostrada a distribuição de $X_{\max }^{\mu}$ para chuveiros iniciados por próton com energia de $10^{19} \mathrm{eV}$. Podemos ver na figura o valor médio de $X_{\max }^{\mu}$ para o modelo SIBYLL2.3 é $\left\langle X_{\text {max }}^{\mu}\right\rangle=629 \pm 81_{R M S}$, para o EPOSLHC $\left\langle X_{\max }^{\mu}\right\rangle=625 \pm 81_{R M S}$ e QGSJETII-04 $\left\langle X_{\max }^{\mu}\right\rangle=591 \pm 81_{R M S}$.

A evolução de $\left\langle X_{\max }^{\mu}\right\rangle$ em função da energia é mostrada na figura 4.13. Os dados da 


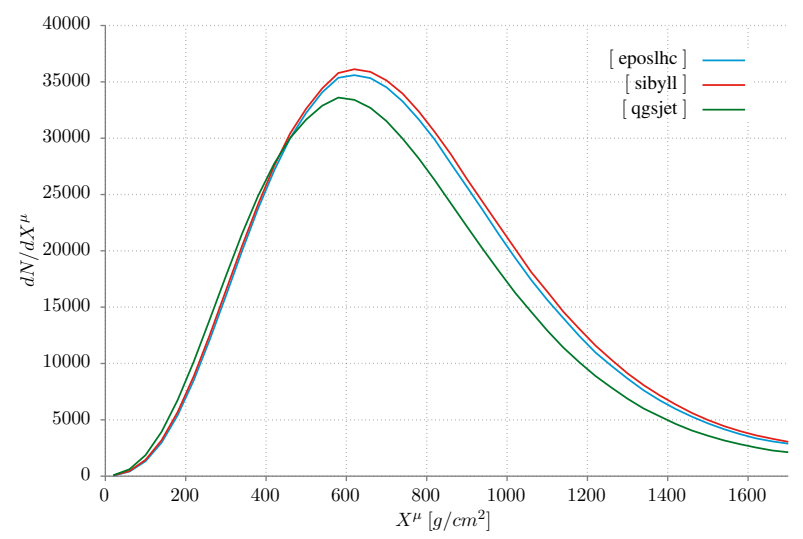

(a) Perfil médio

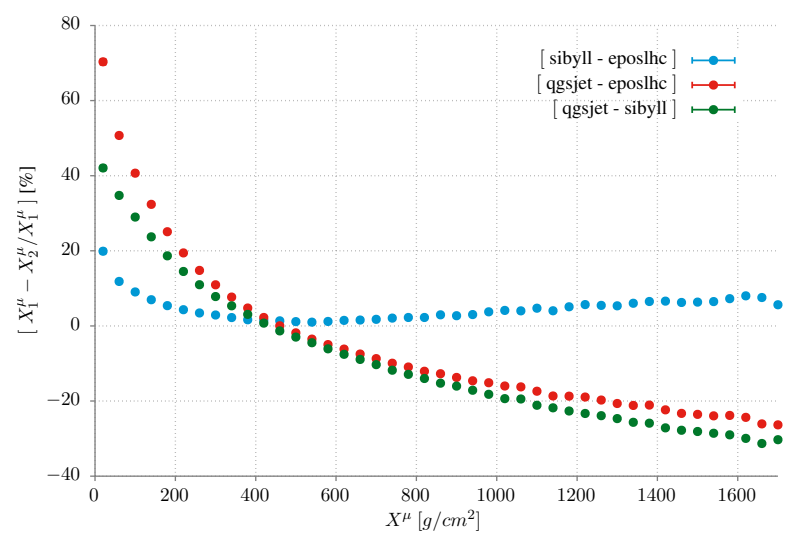

(b) Diferença

Figura 4.11: Comparação da MPD de chuveiros atmosféricos iniciados por próton com energia de $10^{19,5} \mathrm{eV}$ e inclinação $\theta=60^{\circ}$. Na figura (a) é mostrado o perfil médio de 1000 chuveiros e na figura (b) está representada a diferença em porcentagem entre os modelos.

figura mostram que a evolução da MPD é constante para todos os modelos e cresce a uma taxa de $\sim 38 \mathrm{~g} / \mathrm{cm}^{2}$ por década de energia. Entre todos os observáveis que foram estudados nessa seção, a MPD foi a que apresentou a maior taxa de variação no valor médio. Também é importante notar que o $X_{\max }^{\mu}$ é sistematicamente menor que $X_{\max }$ da parte eletromagnética. 


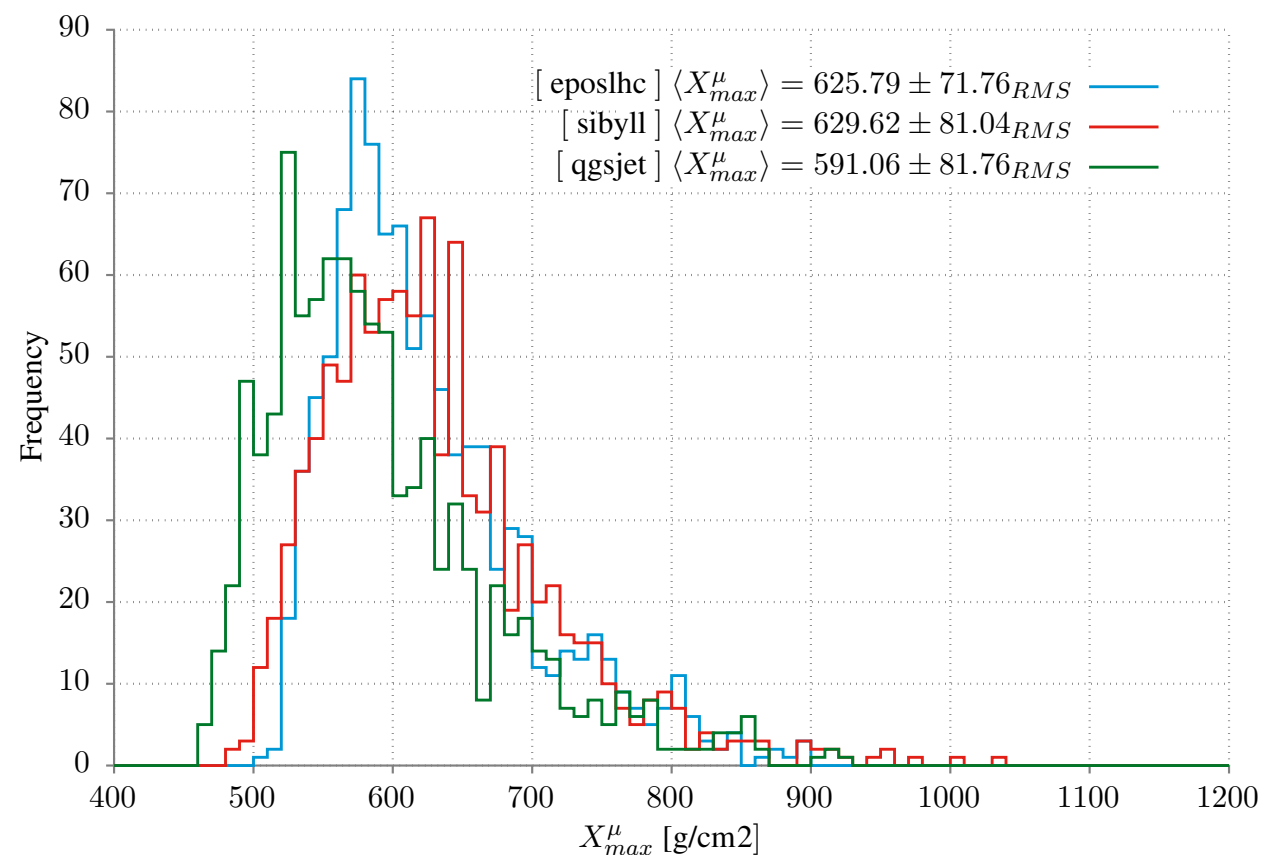

Figura 4.12: Distribuição de $X_{\max }^{\mu}$ entre os modelos EPOSLHC, SIBYLL2.3 e QGSJETII-04 para 1000 chuveiros iniciados por próton com energia de $10^{19} \mathrm{eV}$ e ângulo $\theta=60^{\circ}$ e $\phi=0^{\circ}$.

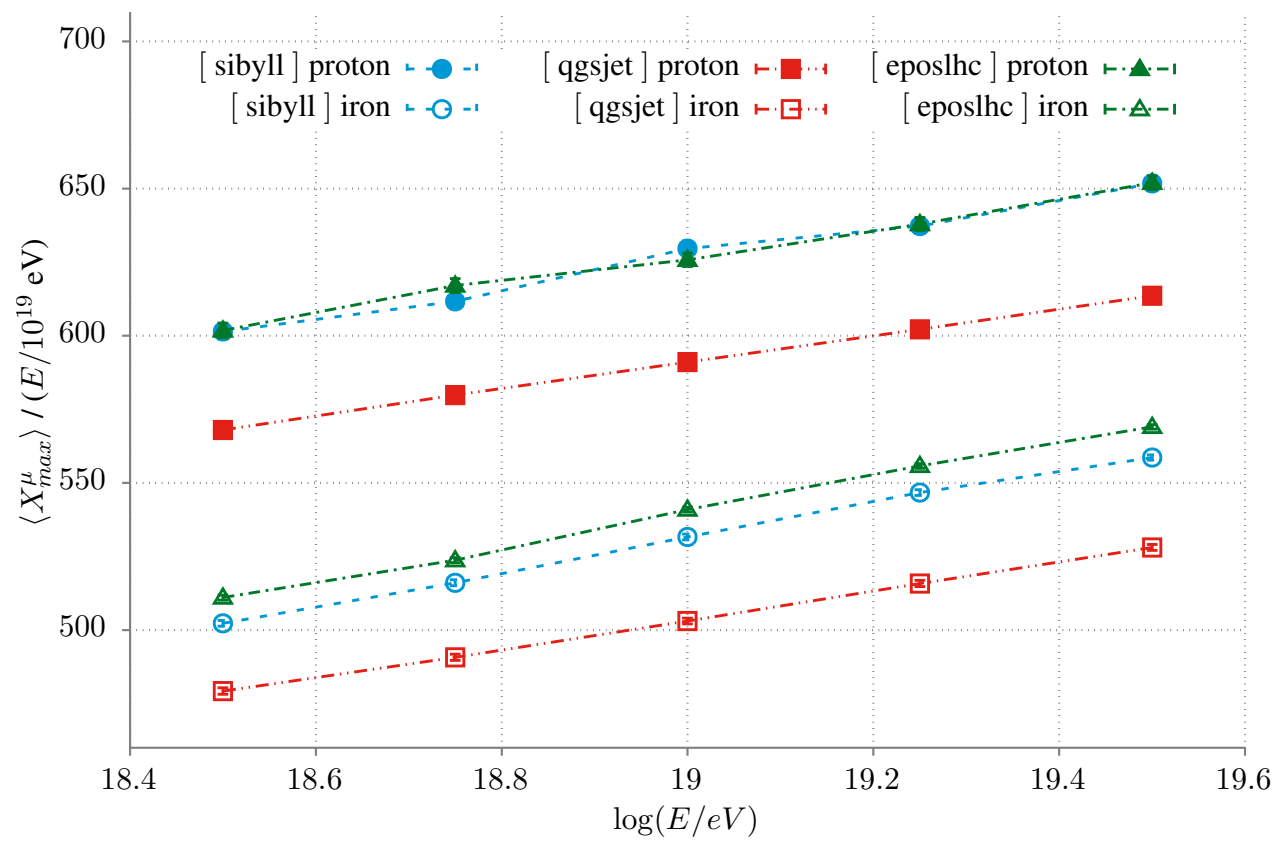

Figura 4.13: Evolução do $X_{\max }^{\mu}$ em função da energia para os modelos EPOSLHC, SIBYLL2.3 e QGSJETII-04 para chuveiros com energia entre $10^{18,5}$ e $10^{19,5} \mathrm{eV}$ e ângulo $\theta=60^{\circ}$ e $\phi=0^{\circ}$. 
90 CAPÍTULO 4. ANÁLISE DOS OBSERVÁVEIS DE CHUVEIROS ATMOSFÉRICOS 


\section{Capítulo 5}

\section{Distribuição de pseudorapidez e EAS}

A distribuição de pseudorapidez, $d N / d \eta$, é importante para o estudo da física de produção de hádrons e para o desenvolvimento de EAS. Sua medida é necessária para ajustar os geradores de colisões, por Monte Carlo, e entender quais processos de colisões, "soft" ou "hard", estão sendo mais importantes durante a colisão. Atualmente, os ajustes sobre $d N / d \eta$ são feitos utilizando dados de aceleradores de partículas até a energia de $10^{17} \mathrm{eV}$ para colisões próton-próton. Essa energia pode ser algumas ordens de grandeza menor do que aqueles eventos de mais alta energia medidos pelo Observatório Pierre Auger, como os UHECRs em torno de $10^{20} \mathrm{eV}$.

Neste capítulo, elucidamos como a distribuição de pseudorapidez $d N / d \eta$ das partículas produzidas a partir da primeira colisão hadrônica no topo da atmosfera se relaciona com a distribuição de partículas de um EAS que chegam ao solo. Em seguida, nos concentramos na chamada região frontal e estudamos o impacto de modificações nessa região no desenvolvimento posterior da cascata. A região frontal é, sabidamente, de difícil acesso do ponto de vista experimental em aceleradores, devido ao fato de que partículas emitidas nessa região viajarem muito próximas ao feixe incidente. Apesar de importante para o processo de desenvolvimento da cascata, mostramos aqui que alterações na região frontal da distribuição de pseudorapidez, realizadas de modo a manter a energia total da cascata e o número de secundários da primeira geração inalterados, são rapidamente atenuadas à medida que a cascata se desenvolve. Dessa forma, tanto observáveis associados ao desenvolvimento longitudinal quanto lateral se mostram insensíveis a essas variações. 


\subsection{Distribuição de pseudorapidez no desenvolvimento de um EAS}

Antes de estudar novas extrapolações, procuramos entender a importância da distribuição $d N / d \eta$ no desenvolvimento de EAS. Esse estudo permite que encontremos informações que possam auxiliar no desenvolvimento das extrapolações de $d N / d \eta$ de forma mais coerente. Resumidamente, buscamos entender qual região de $d N / d \eta$ é mais importante para a geração dos sinais que podem ser observados em EAS. Sabemos que a distribuição $d N / d \eta$ é, atualmente, medida experimentalmente com o LHC e os dados são preferencialmente na região central, pois a região frontal tem momento transverso $p_{T}$ muito baixo, tornando-a de difícil acesso experimental, como mostrado esquematicamente na figura 5.1.

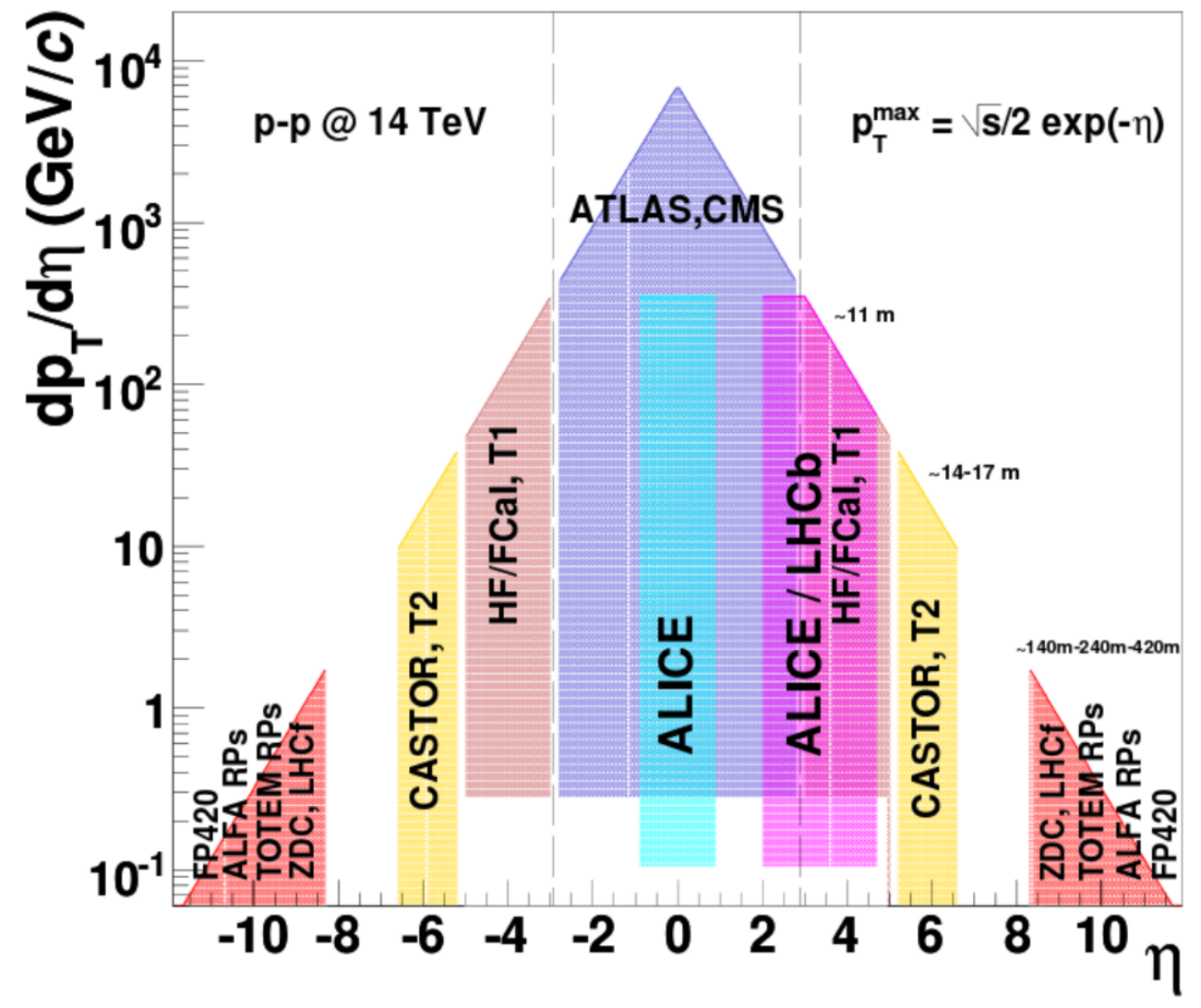

Figura 5.1: Cobertura experimental de diversos experimentos, no LHC, em função da pseudorapidez $\eta$.

No desenvolvimento de um EAS, esperamos que partículas mais energéticas sejam aquelas mais interagentes e, portanto, as que dominam o processo de produção de partículas novas na cascata. Logo após a colisão primária, se olharmos para a distribuição de número de partículas e energias dos secundários para colisões próton-ar, vemos que a produção de 
partículas é maior na região central $(|\eta| \lesssim 5)$, porém a distribuição de energia se concentra na região frontal $(|\eta| \gtrsim 8)$, figura 5.2. Esse resultado é uma indicação de que a região frontal é responsável pela maior produção de partículas e, portanto, a mais importante para o desenvolvimento de EAS. Para verificar essa hipótese, criamos um procedimento que permitisse sepa-

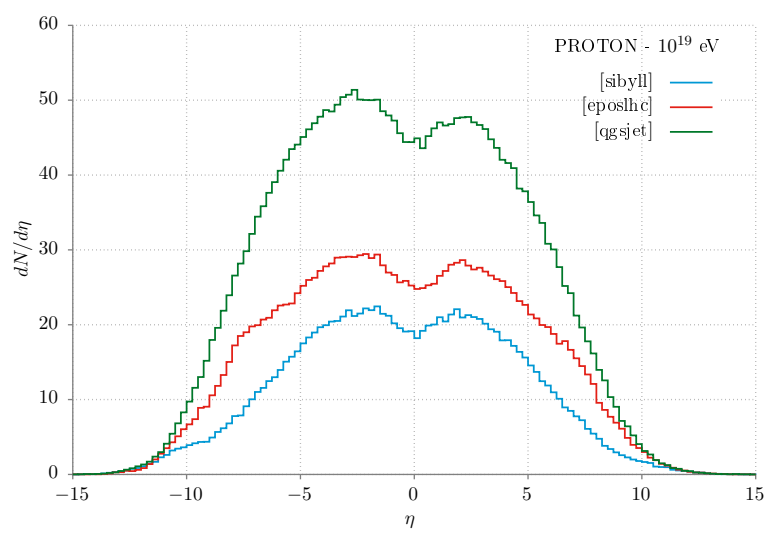

(a) Distribuição de partículas

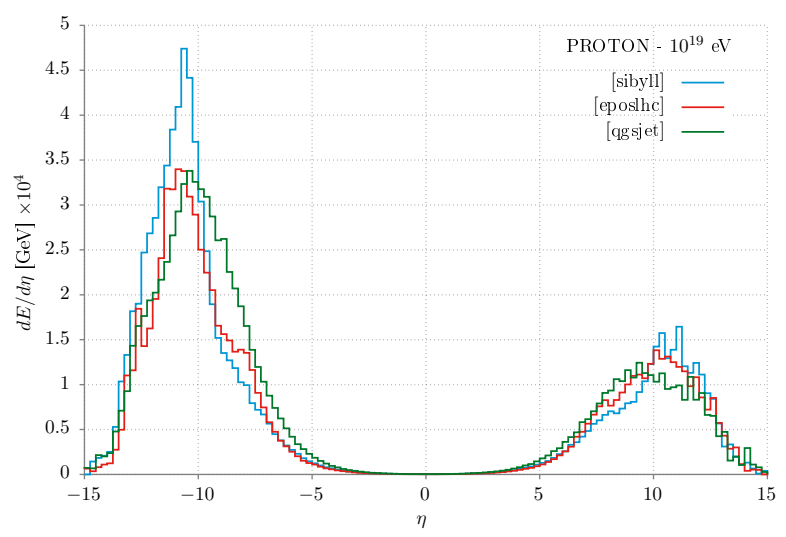

(b) Distribuição de energia

Figura 5.2: Distribuição de partículas em (a) e energia em (b) em função da pseudorapidez para chuveiros atmosféricos iniciados por próton com energia de $10^{19} \mathrm{eV}$ e inclinação $\theta=60^{\circ}$. Nesta figura foi utilizado o modelo de interação hadrônica EPOSLHC.

rar o EAS por intervalo de pseudorapidez. Para isso, interrompemos os EAS após a primeira interação e dividimos as partículas secundárias em intervalos de $\eta(-\infty,-8,-6, \ldots, 6,8,+\infty)$ e inserimos cada conjunto de partículas em um novo chuveiro e o desenvolvemos separadamente. Ao final, as saídas produzidas pelas simulações de cada chuveiro representam um intervalo de pseudorapidez do chuveiro original. Desta forma, pudemos quantificar qual região da pseudorapidez, de fato, está contribuindo para as medidas dos EAS.

Após a simulação de um chuveiro iniciado por próton com energia de $10^{17} \mathrm{eV}$ utilizando o modelo EPOSLHC, extraímos os observáveis do EAS e mostramos a intensidade de cada intervalo de $\eta$. Olhando a densidade lateral, mostrada na figura 5.3, destacamos que valores $\eta \gtrsim 6$ são responsáveis por quase todo o sinal observado. Esse resultado torna-se bem claro quando vemos a distribuição espacial de múons no nível de observação, mostrado nas figuras que se encontram no apêndice B.1.

\subsubsection{Modelando a distribuição de pseudorapidez}

Como vimos na seção anterior, a região frontal da distribuição $d N / d \eta$ é responsável por grande parte das partículas que são observadas no desenvolvimento do chuveiro, em ambas componentes eletromagnética e muônica. Com base nisso, procuramos por uma função analítica que pudesse descrever a distribuição $d N / d \eta$ e que permitisse uma modificação na 


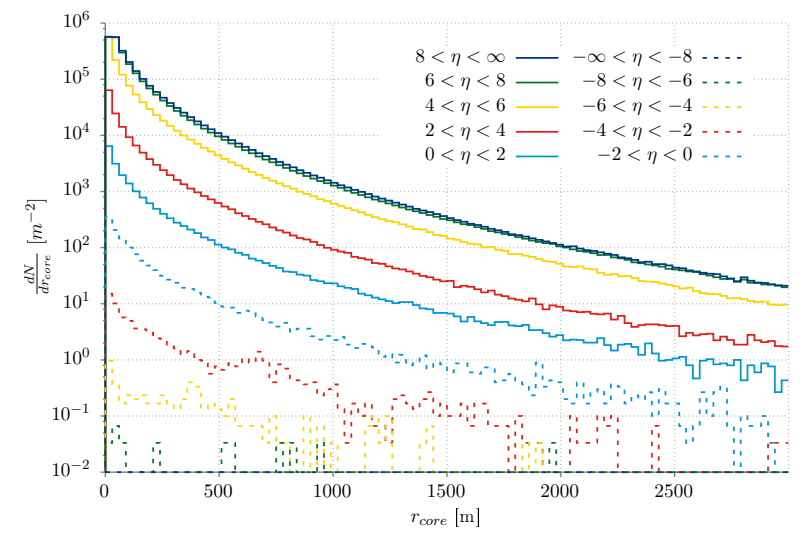

(a) Perfil

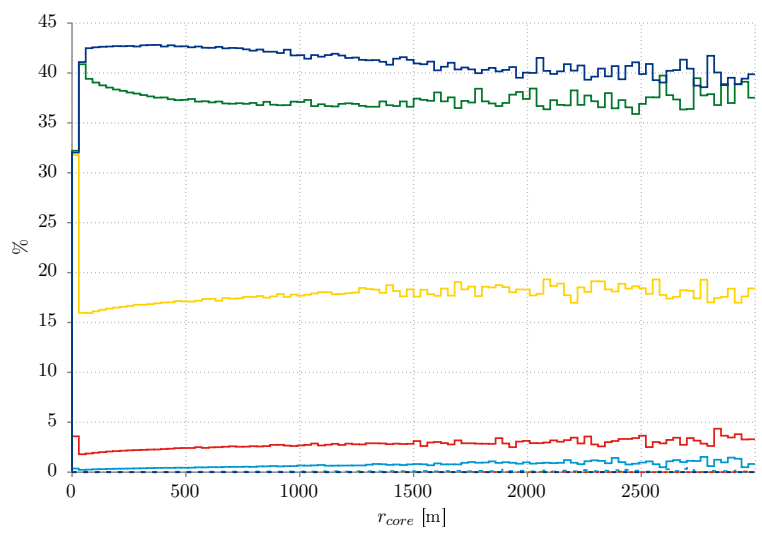

(b) Diferença [\%]

Figura 5.3: Medida de densidade lateral para diferentes intervalos de $\eta$ para EAS iniciados por prótons com energia de $10^{17} \mathrm{eV}$, usando o modelo hadrônico EPOSLHC. Em (a) é mostrado o perfil da densidade lateral e em (b) a porcentagem de contribuição para cada intervalo.

região frontal. Optamos por uma função que descrevesse corretamente a região frontal e não alterasse de forma significativa a região central. Para esse fim, utilizamos a distribuição normal generalizada, dada pela seguinte equação

$$
g(\eta)=\frac{C}{\Gamma(1 / \beta)} e^{-(|x-\mu| / \alpha)^{\beta}} .
$$

Essa função inclui a distribuição normal quando $\beta=2$ (com média $\mu$ e variância $\left.\alpha^{2} / 2\right)$ e também a distribuição de Laplace quando $\beta=1$. O parâmetro $\beta$ permite uma modificação na forma da distribuição, por exemplo $\beta<2$, descreve caudas que tendem a 0 mais devagar e $\beta>2$, caudas que tendem a 0 mais rápido.

A figura 5.4, mostra o ajuste, realizado pelo método de máxima verossimilhança, de $g(\eta)$ para uma colisão próton-ar com energia de $10^{19} \mathrm{eV}$. A função $g(\eta)$ se ajusta razoavelmente bem à região frontal e também permite realizar ajustes nessa região, modificando o parâmetro de escala $\alpha$. Na região central, a gaussiana generalizada deve ser tomada apenas como uma primeira aproximação para a distribuição de partículas nessa região. Na figura 5.4 é mostrado o ajuste da gaussiana generalizada sobre a distribuição de pseudorapidez para colisões prótonar.

Pode-se notar na figura $5.4 \mathrm{um}$ pequeno excesso em torno de $\eta=-10$ devido às partículas líderes. Após a colisão, uma parte da energia de centro de massa $\sqrt{s}$ não é usada para produção de partículas secundárias, e em vez disso, uma fração significativa é carregada pela partícula líder. A partícula líder é caracterizada por possuir os mesmos números quânticos da partícula original e carregar grande valor do momento longitudinal $\left(P_{z}\right)$. Esse excesso também aparece para valores negativos da pseudorapidez e tais partículas 


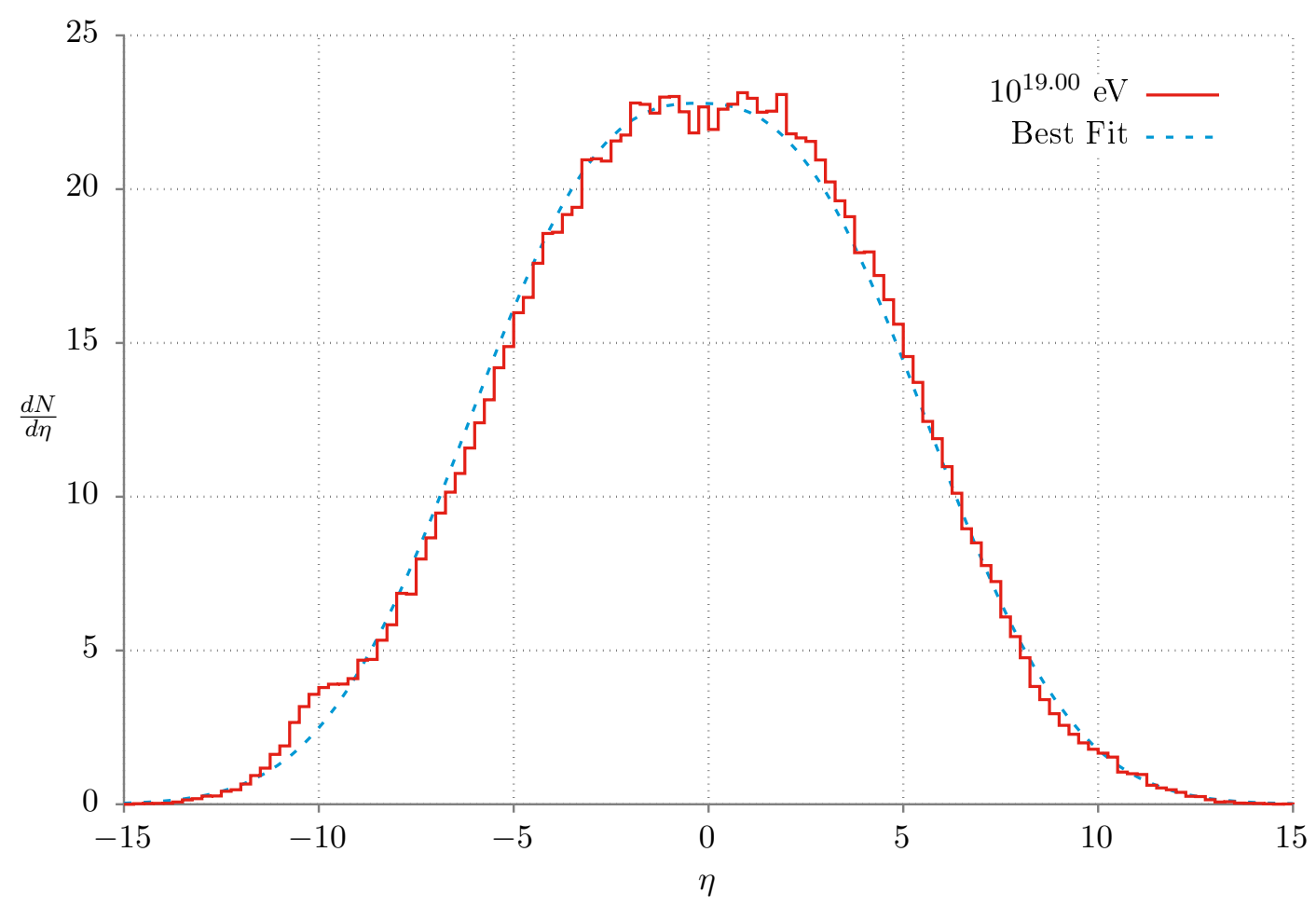

Figura 5.4: Ajuste para distribuição de $d N / d \eta$ para 1000 interações próton-ar, simuladas com SIBYLL2.3, com energia de centro de massa núcleon-núcleon, $\sqrt{S_{N N}} \approx 140 \mathrm{TeV}$ equivalente a $10^{19}$ eV no referencial do laboratório.

correspondem a núcleos de átomos de elementos presentes na atmosfera. Essas partículas não devem ser modificadas, pois não participam do processo de produção de partículas após a interação.

Desse ponto em diante, sempre falaremos de duas modificações na distribuição $d N / d \eta$ : cauda curta e cauda longa. A primeira, cauda curta, é dada por uma diminuição do fator de escala da função $g(\eta)$, dada por $\alpha^{\prime}=\alpha-1$ e, analogamente, a modificação cauda longa é dada por $\alpha^{\prime}=\alpha+1$. A figura 5.5 mostra como ficam as duas distribuições (curta e longa) quando comparamos com a distribuição original. Como esperado, a região central, não sofre modificação e a região frontal, agora, tem diferentes formas para cada modelo.

As mudanças aqui adotadas têm caráter puramente fenomenológico, além de terem sido escolhidas de forma a representarem situações extremas, provavelmente além dos vínculos atuais na região frontal e na própria região central. 


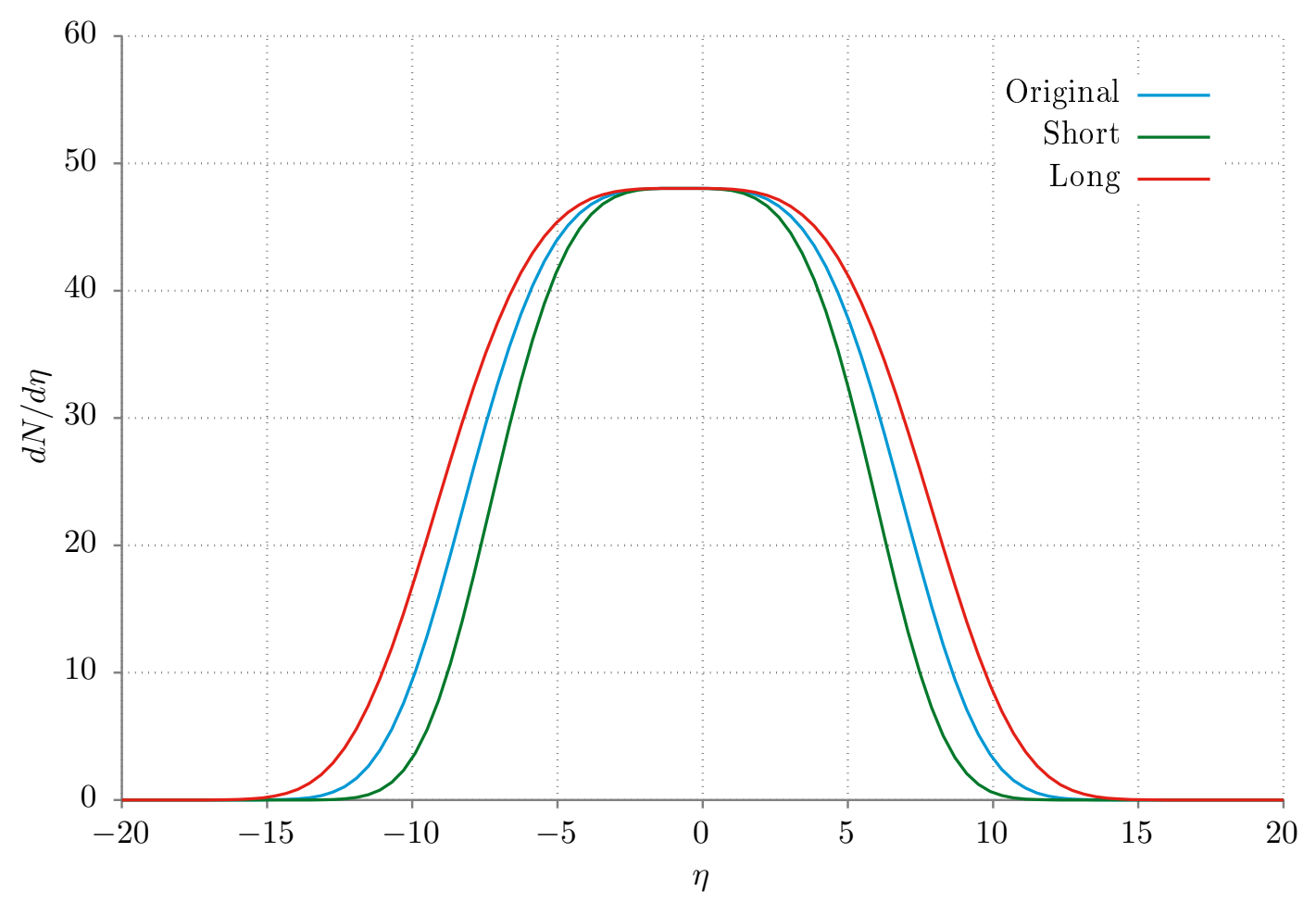

Figura 5.5: Exemplo de modificações da distribuição $d N / d \eta$ para colisões próton-ar, cauda curta em verde e cauda longa em vermelho.

\subsubsection{Remodelando a distribuição de pseudorapidez}

A distribuição $d N / d \eta$ pode ser obtida usando o próprio simulador de chuveiro CORSIKA, através da opção OUTFILE*, que salva as partículas secundárias produzidas após a primeira interação. A figura 5.2 mostra a distribuição $d N / d \eta$ para 1000 colisões próton-ar com energia $10^{19} \mathrm{eV}$ usando os principais modelos de interação hadrônica de EAS. Para alterar a distribuição original $d N / d \eta$ para os modelos de cauda curta ou longa, usamos o processo de Monte Carlo que leva de uma distribuição a outra através da conservação da probabilidade total, dada pela seguinte equação

$$
\int_{-\infty}^{x^{\prime}} g(x) d x=\int_{-\infty}^{y^{\prime}} f(y) d y
$$

A probabilidade total de encontrar um valor $x$ entre $-\infty$ e $x^{\prime}$ tem que ser igual à probabilidade de encontrar um valor $y$ entre $-\infty$ e $y^{\prime}$. Ou seja, se soubermos a pseudorapidez da partícula $\eta$ e a distribuição $g(\eta)$ (original) e $g^{\prime}\left(\eta^{\prime}\right)$ (modificada), podemos encontrar $\eta^{\prime}$ na nova distribuição, usando a equação 5.2. Usando esse método, o número total de partículas é

* Mais detalhes sobre a opção OUTFILE pode ser encontrada na referência [74] e no apêndice D.2 há um exemplo desse arquivo. 
conservado, assim como a energia e momento total de cada partícula no referencial do centro de massa. Sabemos que $\eta$ está associado com o ângulo $\theta$ entre o eixo da colisão e a direção da partícula e uma alteração de $\eta$ determinaria uma nova direção para a partícula produzida. A partir da relação 3.14 podemos encontrar a nova direção $\theta^{\prime}$ e determinar a intensidade de cada componente do momento $\vec{p}$ na nova distribuição, lembrando que devemos conservar a energia e o momento de cada uma.

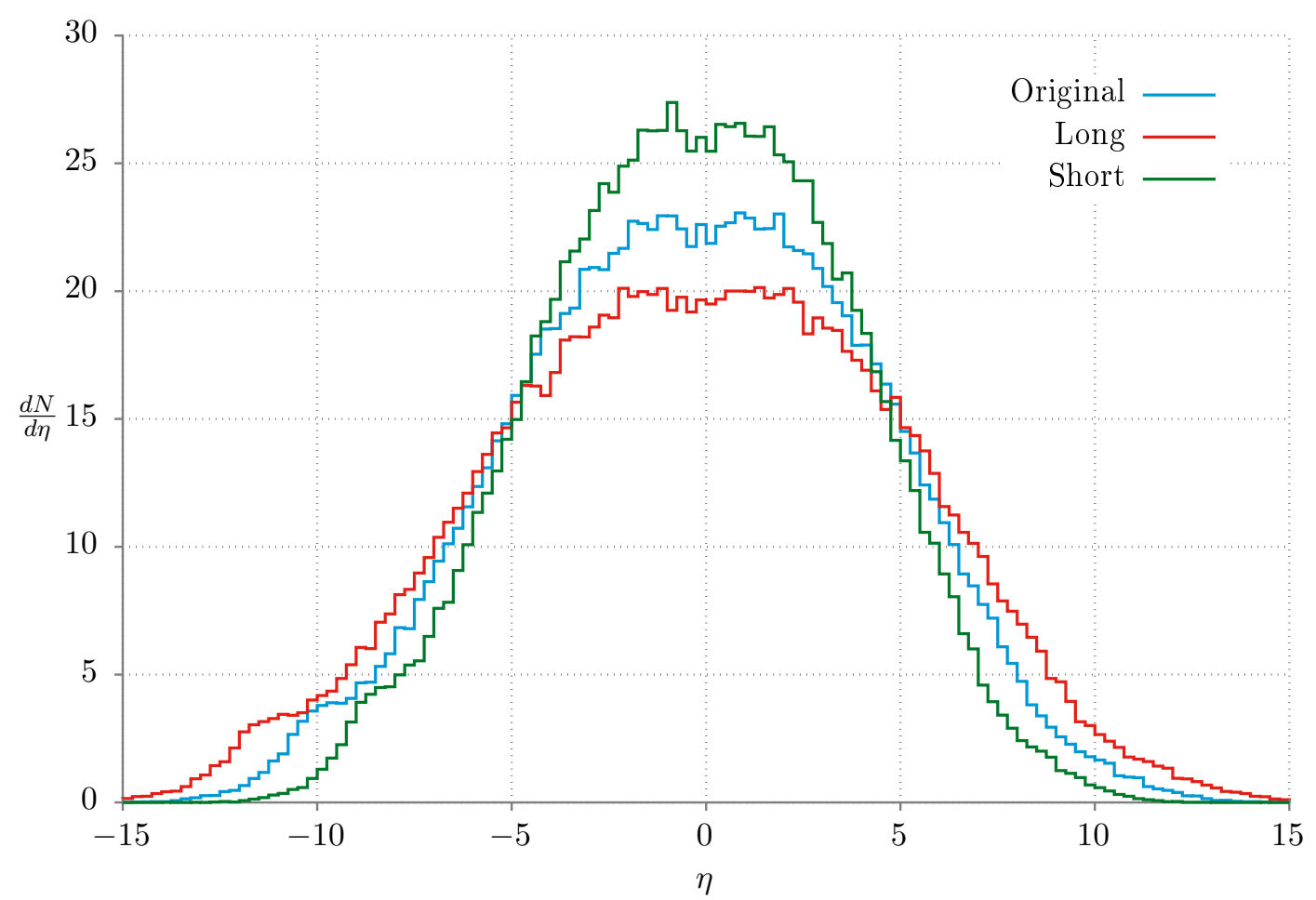

Figura 5.6: Comparação entre os modelos de distribuição $d N / d \eta$ para 1000 interações próton-ar com energia de $10^{19} \mathrm{eV}$ no referencial do laboratório, usando o modelo de interação hadrônica QGSJETII.

Aplicamos então esse método sobre a distribuição $d N / d \eta$ para 1000 colisões próton-ar com energia $10^{19} \mathrm{eV}$, como mostrado na figura 5.6. Como esperado, as partículas seguem o perfil da nova distribuição (cauda curta em azul e cauda longa em verde) e mantêm a região central com formato inalterado. Lembramos que todo o processo ocorre excluindo a partícula líder de interações difrativas simples. Agora, temos três conjuntos de partículas produzidos após a primeira interação de um EAS. Podemos simular chuveiros para cada conjunto e verificar o impacto da distribuição $d N / d \eta$ no desenvolvimento do chuveiro através dos observáveis mensuráveis dos chuveiros. 


\subsection{Resultado sobre observáveis de EAS}

Após construir novos modelos de distribuições de pseudorapidez, simulamos uma amostra de chuveiros atmosféricos para estudar a influência das distribuições sobre os observáveis $X_{\text {max }}, X_{\text {max }}^{\mu}, \rho_{1000}$ e $N_{19}$. Para isso, simulamos amostras de chuveiros atmosféricos extensos e utilizamos o modelo de interação hadrônica SIBYLL2.3, que será chamado de original e será representado pela cor azul. A partir desses chuveiros, alteramos a distribuição da primeira interação, seguindo os passos descritos nesta seção. Esse processo resultou em duas novas amostras de chuveiros, que chamaremos de cauda longa, em verde, e o outro de cauda curta, em vermelho, conforme os modelos de distribuições utilizados nos mesmos. A altura, o número de partículas secundárias e a energia total da cascata após a primeira interação é a mesma para todos os modelos. Analisamos os chuveiros iniciados por próton com energia de $10^{19} \mathrm{eV}$, ângulo de incidência $\theta=60^{\circ} \mathrm{e} \phi=0^{\circ}$. Também estudamos a influência das novas distribuições de pseudorapidez sobre o intervalo de energia de $10^{18.5}$ até $10^{19.5} \mathrm{eV}$ e utilizamos duas composições química: próton e ferro.

\subsubsection{Desenvolvimento longitudinal}

Começamos pela análise do desenvolvimento longitudinal dos chuveiros atmosféricos. Comparamos o perfil de desenvolvimento do número de partículas em função da profundidade atmosférica, dado em $\mathrm{g} / \mathrm{cm}^{2}$, mostrado na figura 5.7a. Ambos os modelos de cauda curta e longa mostraram um perfil muito semelhante ao perfil original. Esse resultado é mais claro quando olhamos a razão entre os modelos, mostrada na figura 5.7b. Aqui vemos que existe inicialmente uma diferença da ordem $\pm 20 \%$ que vai diminuindo em função da profundidade, até chegar a $\pm 1 \%$ para o modelo de cauda curta, enquanto o modelo de cauda longa mostra um pequeno aumento no início do desenvolvimento, atingindo $\pm 5 \%$ e, depois, diminui até atingir a diferença de $\pm 1 \%$ como no outro modelo. Esse resultado já mostra que o observável $X_{\max }$ não é sensível a variações na cauda da distribuição de pseudorapidez. Por completeza, analisamos e comparamos a distribuição de $X_{\text {max }}$, mostrada na figura 5.8 para os três modelos. A distribuição original atinge o máximo em $\left\langle X_{\max }\right\rangle=821 \pm 2 \mathrm{~g} / \mathrm{cm}^{2}$,. Enquanto isso obtivemos os valores $\left\langle X_{\max }\right\rangle=820 \pm 2 \mathrm{~g} / \mathrm{cm}^{2}$ e $\left\langle X_{\max }\right\rangle=820 \pm 2 \mathrm{~g} / \mathrm{cm}^{2}$ para as distribuições de cauda curta e longa, respectivamente (neste caso os erros são sobre a média e não sobre o RMS como na seção anterior). Logo, o resultado indica que não há diferença significativa entre os modelos, pois a diferença do $\left\langle X_{\max }\right\rangle$ foi da mesma ordem do erro estatístico da amostra. Essa diferença não poderia ser observada experimentalmente, pois a resolução do observável $X_{\max }$ para experimentos como o Observatório Pierre Auger é da ordem de $20 \mathrm{~g} / \mathrm{cm}^{2}$ [39]. Por fim, analisamos o comportamento do $X_{\max }$ para o intervalo 


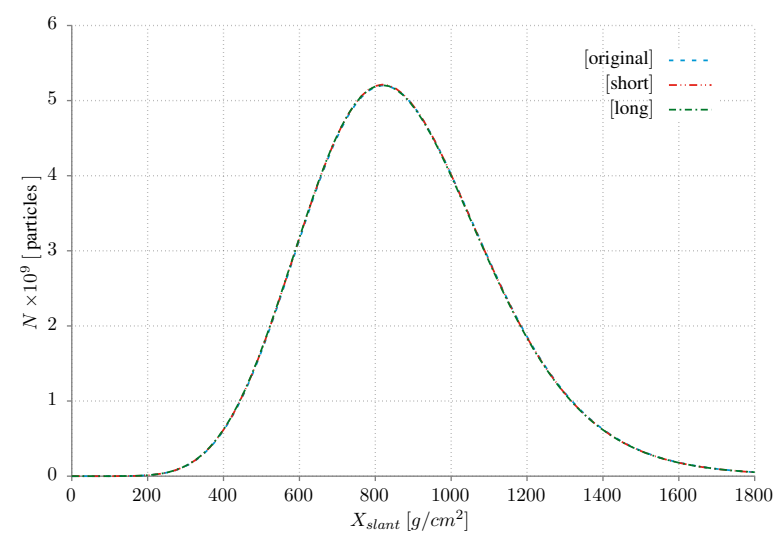

(a) Perfil médio

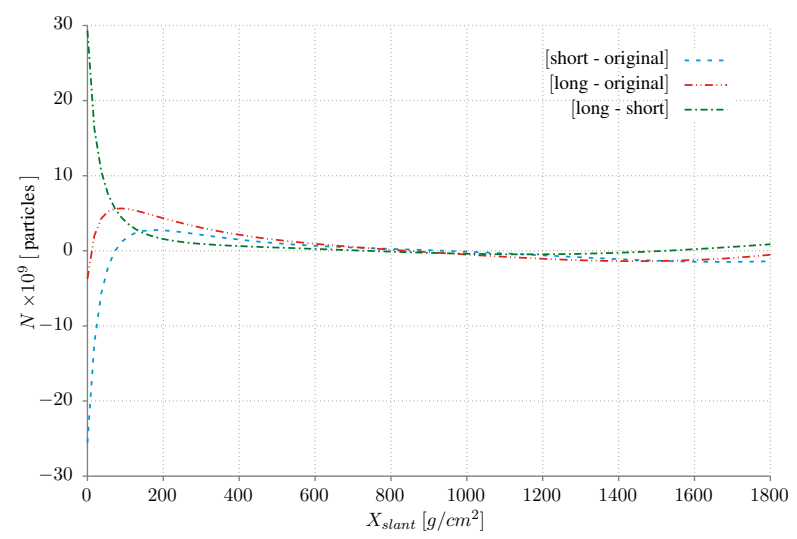

(b) Diferença

Figura 5.7: Comparação do desenvolvimento longitudinal de chuveiros atmosféricos iniciados por próton com energia de $10^{19} \mathrm{eV}$ e inclinação $\theta=60^{\circ}$. Na figura (a) é mostrado o perfil médio de 1000 chuveiros e na figura (b) está representado a diferença em porcentagem entre os modelos.

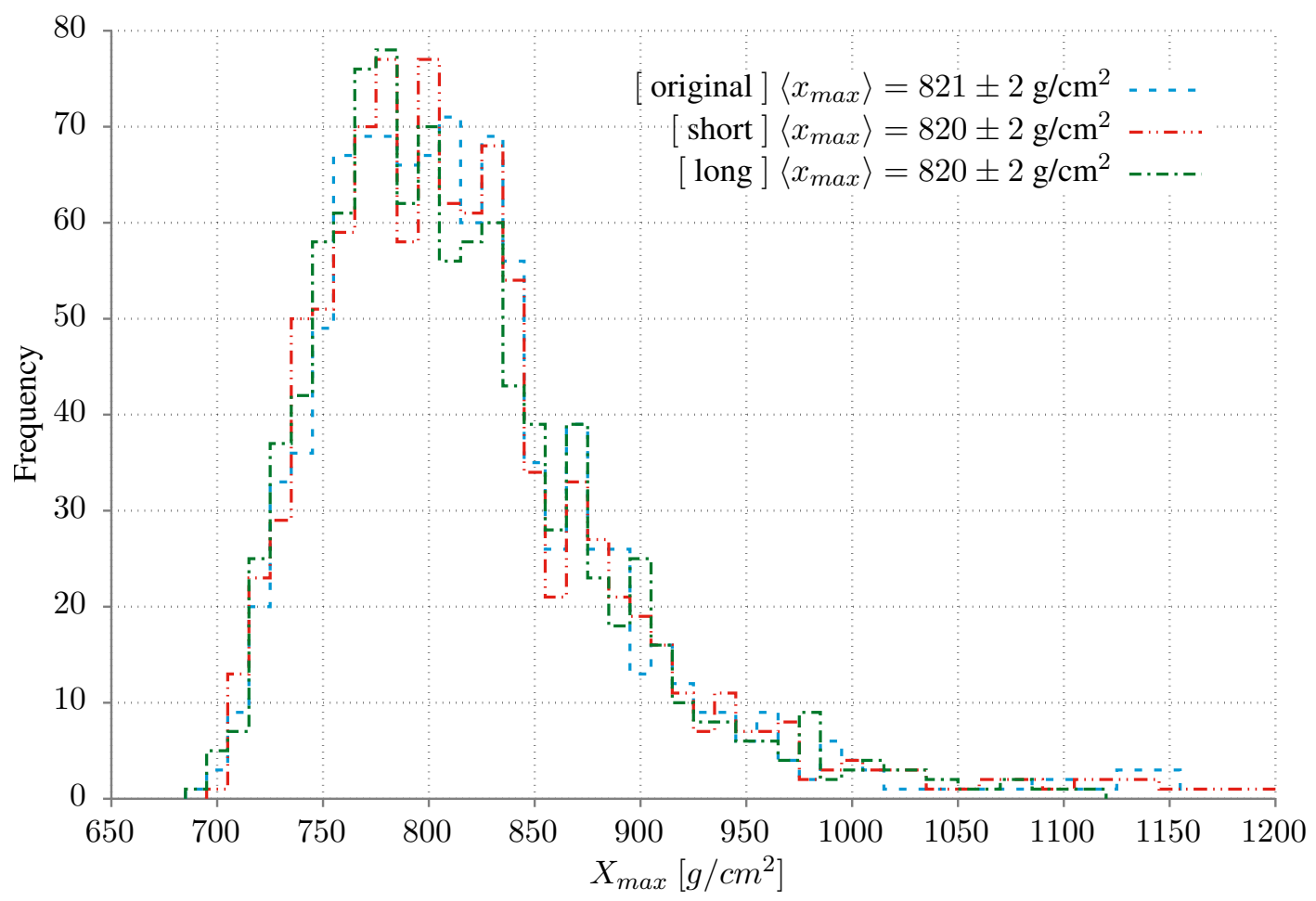

Figura 5.8: Comparação da distribuição de $X_{\max }$ para as distribuições de pseudorapidez original, cauda curta e cauda longa. Foram usados 1000 chuveiros iniciados por próton com energia de $10^{19}$ $\mathrm{eV}$ e ângulo $\theta=60^{\circ}$ e $\phi=0^{\circ}$. O modelo SIBYLL2.3, de interação hadrônica, foi utilizado nas simulações dos chuveiros.

de energia de $10^{18.5}$ e $10^{19.5} \mathrm{eV}$ e chuveiros iniciados por próton ou ferro, mostrado na figura 5.9. Para todos os modelos, dentro do intervalo de energia estudado, não houve diferença significativa de $\left\langle X_{\max }\right\rangle$ em relação ao original. Mudanças de distribuição de pseudorapidez, 
que conservem o número de partículas e a distribuição de energia na primeira interação não influenciam o observável $X_{m a x}$. No mesmo caminho, obtivemos uma diferença da ordem de $\pm 20 \%$ no início do desenvolvimento longitudinal que também é da ordem de flutuação estatística da amostra.

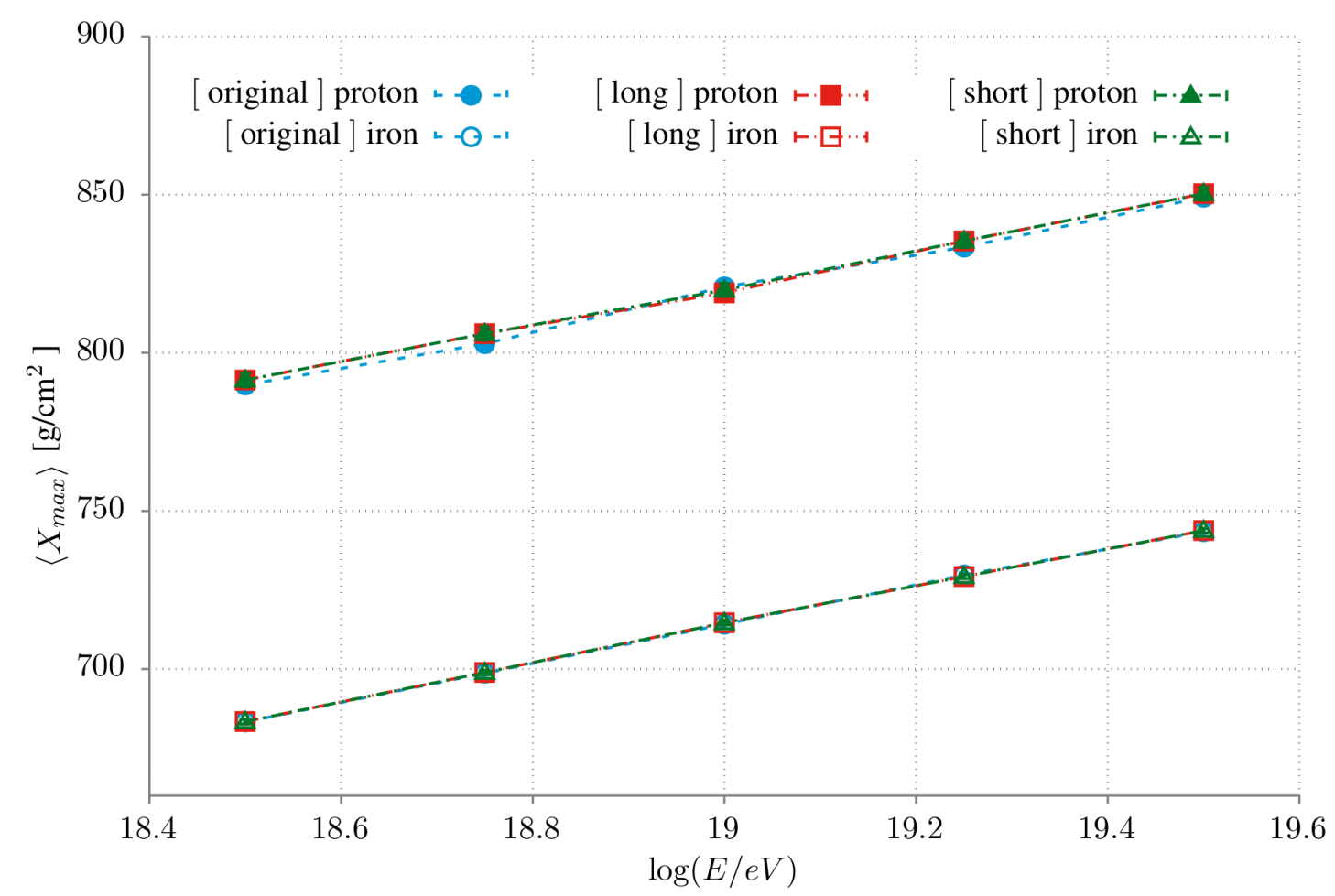

Figura 5.9: Evolução do $\left\langle X_{\max }\right\rangle$ em função da energia para as distribuições de pseudorapidez original (azul), cauda curta (vermelho) e cauda longa (verde).

\subsubsection{Número de múons no nível de observação}

Comparamos o número de múons que chegam ao nível de observação, ou nesse caso, a uma altura de aproximadamente $1420 \mathrm{~m}$ acima do nível do $\operatorname{mar}^{\dagger}$. Na figura 5.10 é mostrada a distribuição do observável $N_{19}$ para os modelos original, cauda curta e cauda longa. Em azul, é mostrada a distribuição original de $N_{19}$ e o valor médio é $\left\langle N_{19}\right\rangle=1.029 \pm 0.006$. Em vermelho, é mostrado a distribuição de cauda curta com $\left\langle N_{19}\right\rangle=1.019 \pm 0.006 \mathrm{e}$, em verde, a distribuição de cauda longa com valor $\left\langle N_{19}\right\rangle=1.025 \pm 0.006$. Os resultados mostram que a diferença entre os modelos é pequena e tem a mesma ordem de grandeza do erro estatístico da amostra. Medidas experimentais de $N_{19}$ alcançam uma resolução da ordem de $10 \%$, por exemplo em [11], mostrando que essa diferença não é significativa. O mesmo comportamento

\footnotetext{
${ }^{\dagger}$ Essa é a altura em que se encontra o Observatório Pierre Auger
} 


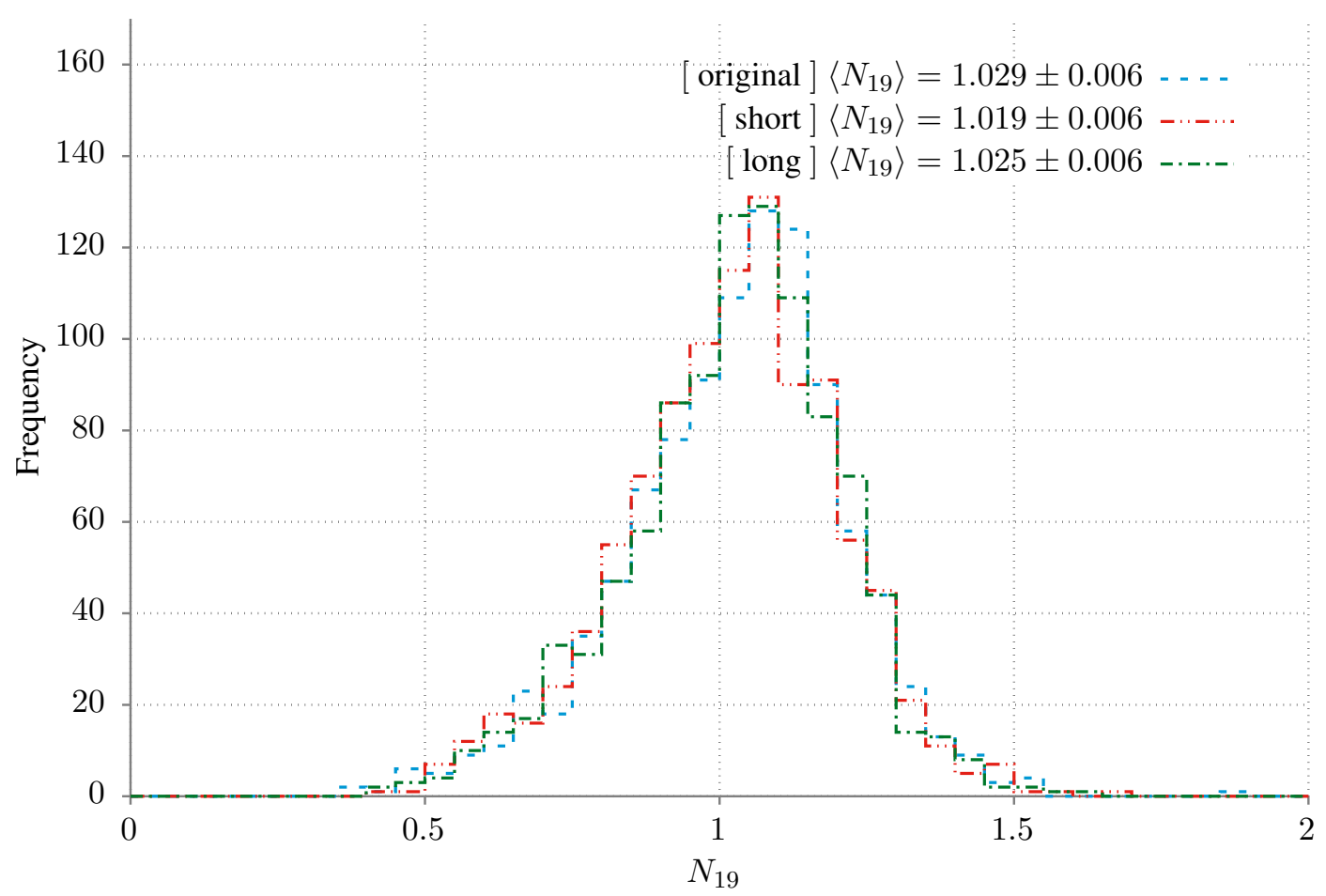

Figura 5.10: Comparação da distribuição de $N_{19}$ para as distribuições de pseudorapidez original(azul), cauda curta(vermelho) e cauda longa(verde). Foram usados 1000 chuveiros iniciados por próton com energia de $10^{19} \mathrm{eV}$ e ângulo $\theta=60^{\circ}$ e $\phi=0^{\circ}$. Foi utilizado o modelo de interações SIBYLL2.3 nas simulações do chuveiro.

foi observado quando estudamos $\left\langle N_{19}\right\rangle$ em função da energia, mostrado na figura 5.11. Para o intervalo de energia de $10^{18.5}$ até $10^{19.5} \mathrm{eV}$ não houve diferenças significativas entre os modelos de cauda curta e longa em relação ao original. Esse resultado é observado para diferentes composições químicas do primário, como próton e ferro.

Assim como no caso de $X_{\max }$, mudanças na distribuição de pseudorapidez da primeira interação não influenciam no observável $N_{19}$ para o intervalo de energia estudado e para as composições químicas de primário consideradas.

\subsubsection{Profundidade máxima de produção de múons}

Analisamos a produção de múons em função da profundidade e a profundidade do máximo $X_{\max }^{\mu}$. Na figura 5.12a, é mostrado o perfil da produção de múons em função da profundidade atmosférica para os três modelos de cauda. Como no caso do desenvolvimento longitudinal do chuveiro, os perfis dos três modelos são semelhantes e precisamos olhar a razão entre os modelos, mostrada na figura5.12b, para poder quantificar a diferença. A razão oscila entre $\pm 10 \%$ no início do chuveiro, diminui para em torno de $\pm 2 \%$ próxima da 


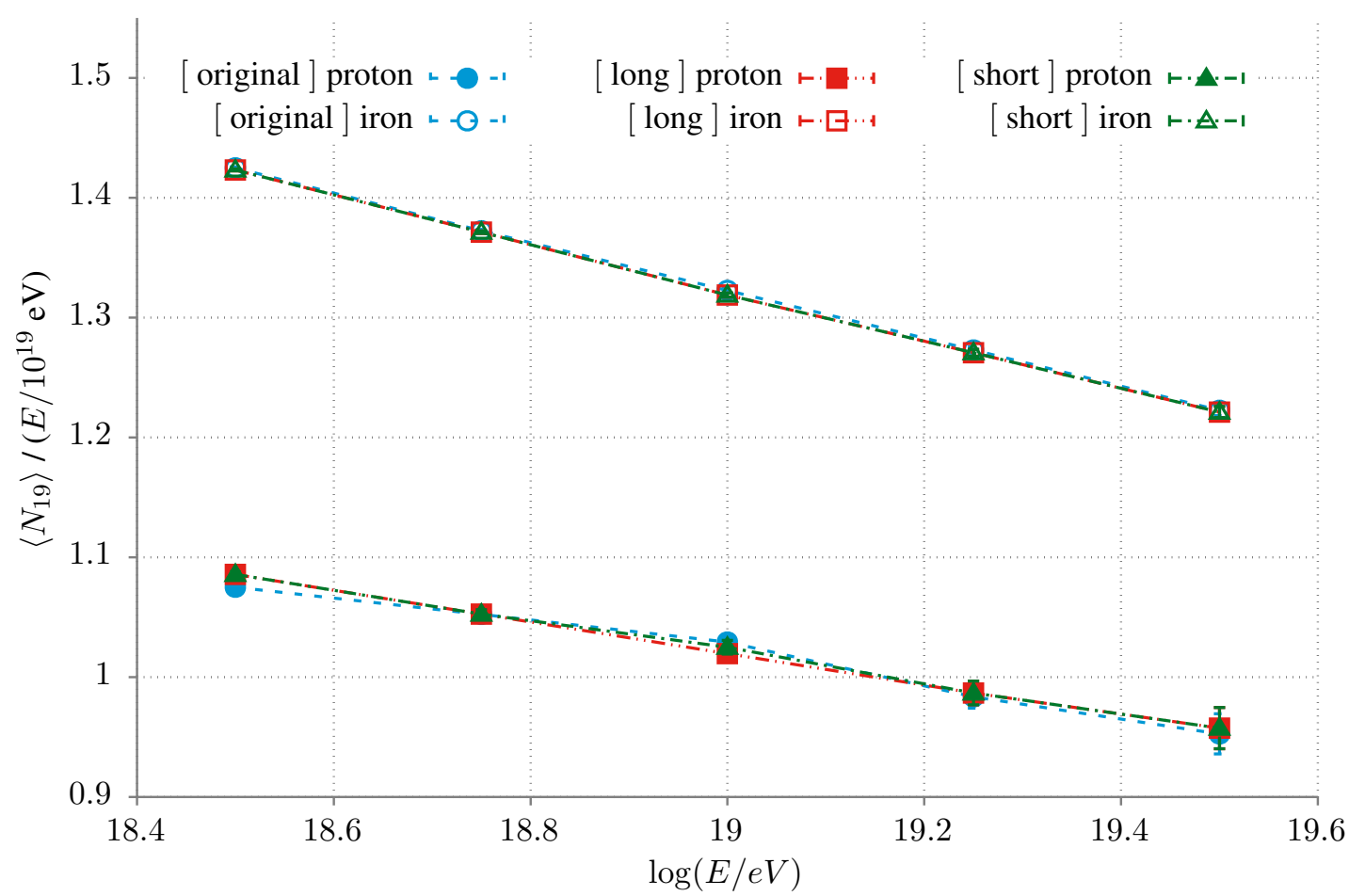

Figura 5.11: Evolução do $\left\langle X_{\max }\right\rangle$ em função da energia para as distribuições de pseudorapidez original, cauda curta e cauda longa.

região de $1000 \mathrm{~g} / \mathrm{cm}^{2}$ e volta a aumentar em profundidade maiores. O resultado disso é da ordem das flutuações estatísticas da amostra. Os chuveiros em média contêm menos múons na região inicial e no final do desenvolvimento, e essa observação explica a maior flutuação nessas regiões. Dessa forma, não há alteração significativa no perfil de produção de múons. Esse resultado fica mais claro quando analisamos o observável $X_{\max }^{\mu}$, mostrado na figura 5.13. O modelo original (azul) tem $\left\langle X_{\max }^{\mu}\right\rangle=593 \pm 2 \mathrm{~g} / \mathrm{cm}^{2}$, enquanto isso para os outros modelos obtivemos $\left\langle X_{m a x}^{\mu}\right\rangle=591 \pm 2 \mathrm{~g} / \mathrm{cm}^{2}$, para o distribuição de cauda curta (vermelho), $\mathrm{e}\left\langle X_{\text {max }}^{\mu}\right\rangle=591 \pm 2 \mathrm{~g} / \mathrm{cm}^{2}$ para a distribuição de cauda longa (verde). A diferença é da mesma ordem do erro estatístico indicando que se houver alguma diferença entre os modelos de cauda curta e cauda longa em relação ao original, a diferença deve ser menor que 2 $\mathrm{g} / \mathrm{cm}^{2}$. Resultados publicados de $X_{m a x}^{\mu}$, como [73], mostram que essa diferença não pode ser observada experimentalmente. Além disso, também não há diferenças significativas de $\left\langle X_{m a x}^{\mu}\right\rangle$ em função da energia, como mostrado na figura 5.14. Mudanças na distribuição de pseudorapidez não impactam no observável $\left\langle X_{m a x}^{\mu}\right\rangle$ para o intervalo de energia $10^{18.5}$ até $10^{19.5} \mathrm{eV}$ e para diferentes composições químicas do primário. 


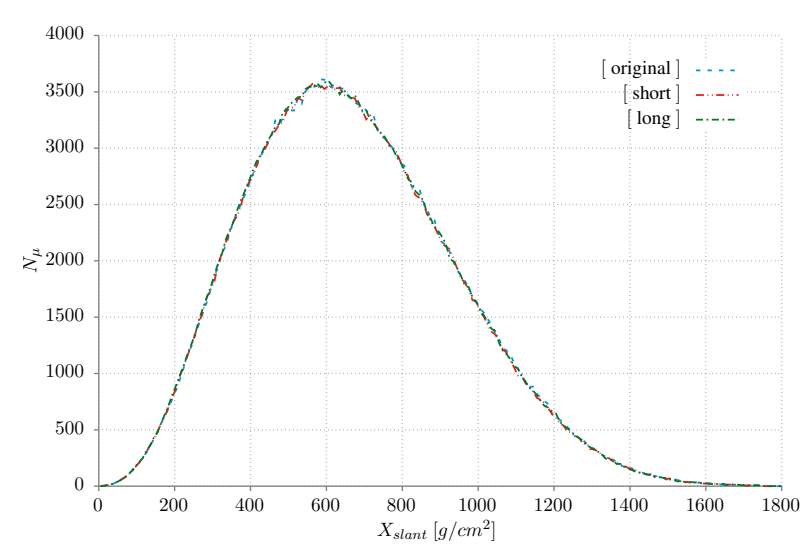

(a) Perfil médio

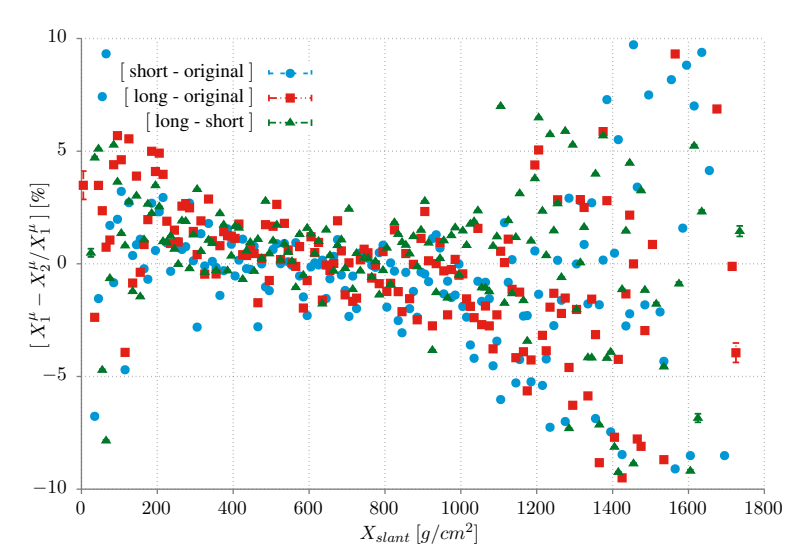

(b) Razão

Figura 5.12: Comparação da produção de múons em função da profundidade para chuveiros atmosféricos iniciados por próton com energia de $10^{19} \mathrm{eV}$ e inclinação $\theta=60^{\circ}$. Na figura (a) é mostrado o perfil médio de 1000 chuveiros e na figura (b) está representada a diferença em porcentagem entre os modelos.

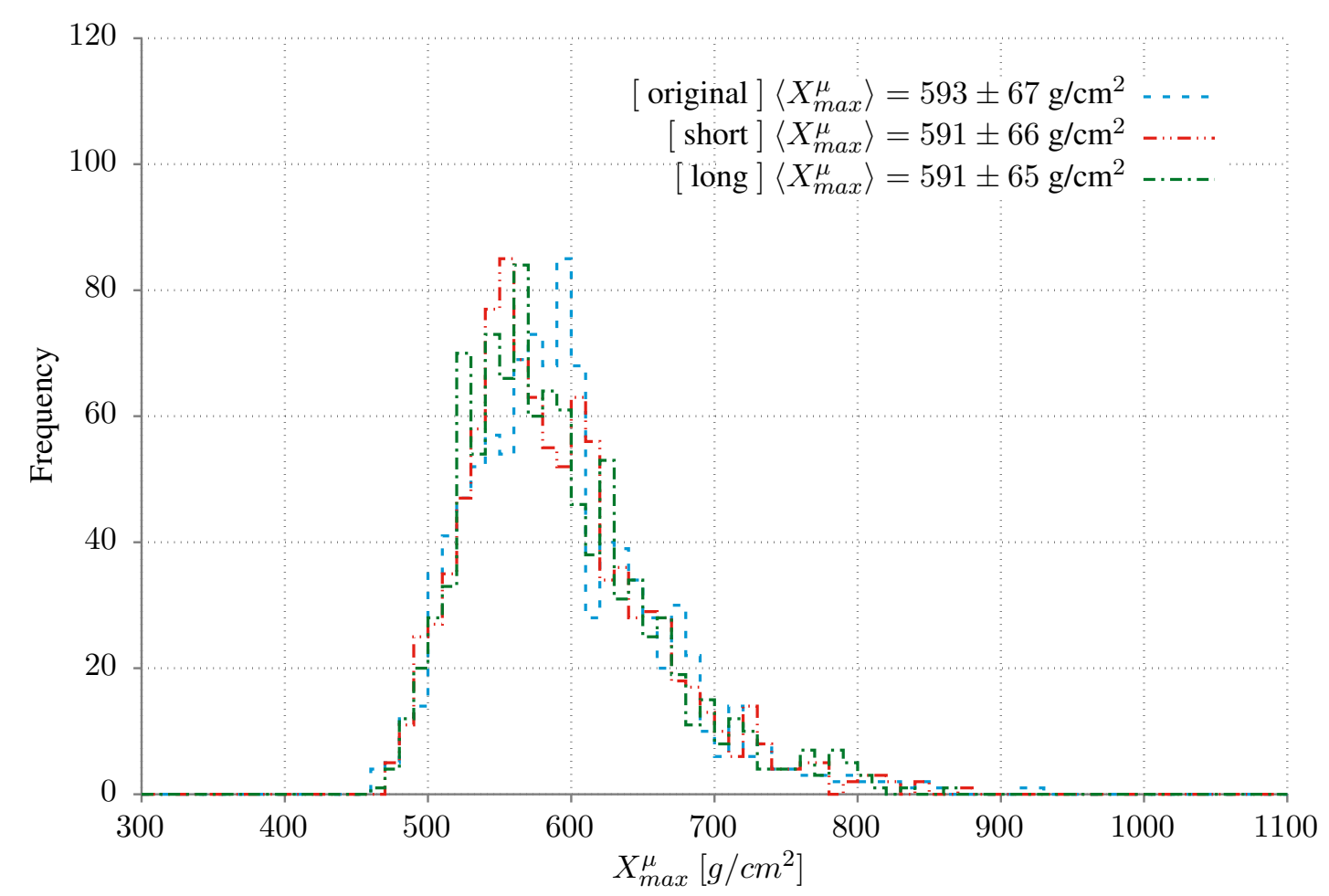

Figura 5.13: Comparação da distribuição de $X_{\max }^{\mu}$ para as distribuições de pseudorapidez original, cauda curta e cauda longa. Foram usados 1000 chuveiros iniciados por próton com energia de $10^{19}$ $\mathrm{eV}$ e ângulo $\theta=60^{\circ}$ e $\phi=0^{\circ}$. O modelo SIBYLL2.3, de interação hadrônica, foi utilizado nas simulações dos chuveiros.

\subsubsection{Densidade lateral de múons}

Por último, analisamos a densidade lateral de múons e o observável $\rho_{1000}$. Na figura 5.15a é mostrada a densidade lateral de múons em função da distância ao eixo do chuveiro. 


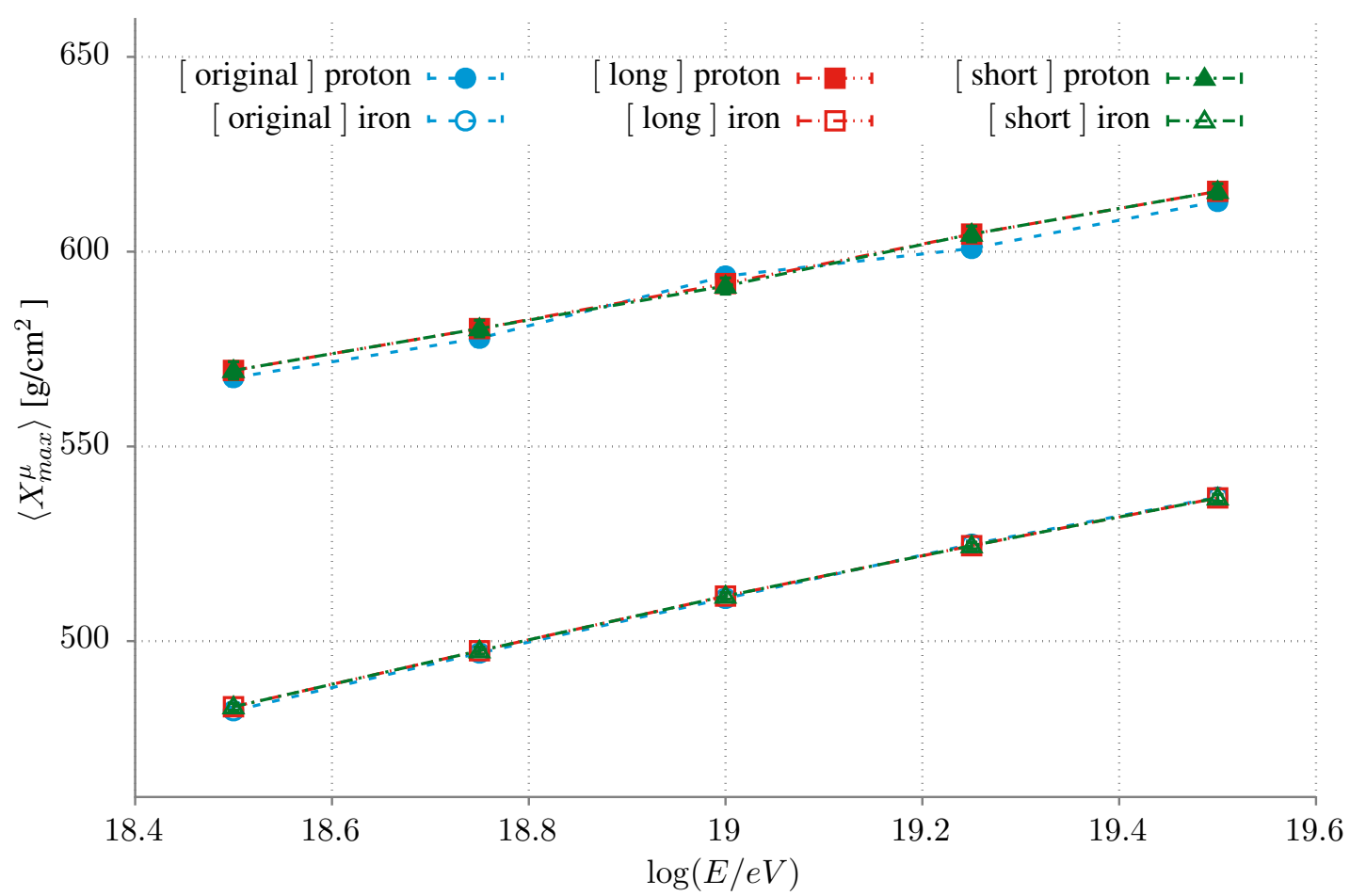

Figura 5.14: Evolução do $\left\langle X_{\max }^{\mu}\right\rangle$ em função da energia para as distribuições de pseudorapidez original (azul), cauda curta (vermelha) e cauda longa (verde).

Em azul é mostrado o perfil para chuveiros com a distribuição original, em vermelho, chuveiros com distribuição de cauda longa e em verde, chuveiros com distribuição de cauda curta. Os três modelos apresentam um perfil lateral de múons semelhante e quantificamos a razão entre eles, mostrada na figura 5.15b. Essa razão, mostrou diferenças pequenas em regiões próximas ao eixo do chuveiro, da ordem de $\pm 1 \%$ e cresce em função da distância radial, atingindo $\pm 5 \%$ para distâncias maiores que $1500 \mathrm{~m}$, sujeita, nessa região, a consideráveis flutuações. O observável $\rho_{1000}$ também não apresentou diferenças significativas ou maiores que a flutuação estatística. Para a distribuição original $\left\langle\rho_{1000}\right\rangle=1.22 \pm 0.20$. Enquanto isso, encontramos $\left\langle\rho_{1000}\right\rangle=1.21 \pm 0.20$ para a distribuição de cauda curta e $\left\langle\rho_{1000}\right\rangle=1.22 \pm 0.20$ para a distribuição de cauda longa, mostrado na figura 5.16. A variação da densidade de múons a 1000 metros do eixo do chuveiro foi muito pequena e não observável experimentalmente, pois o erro estatístico é da mesma ordem da diferença observada. Assim como os demais observáveis, estudamos a evolução do $\left\langle\rho_{1000}\right\rangle$ em função da energia, mostrado na figura 5.17. O resultado foi que a observável $\rho_{1000}$ não é influenciado pela distribuição de pseudorapidez da primeira interação. 


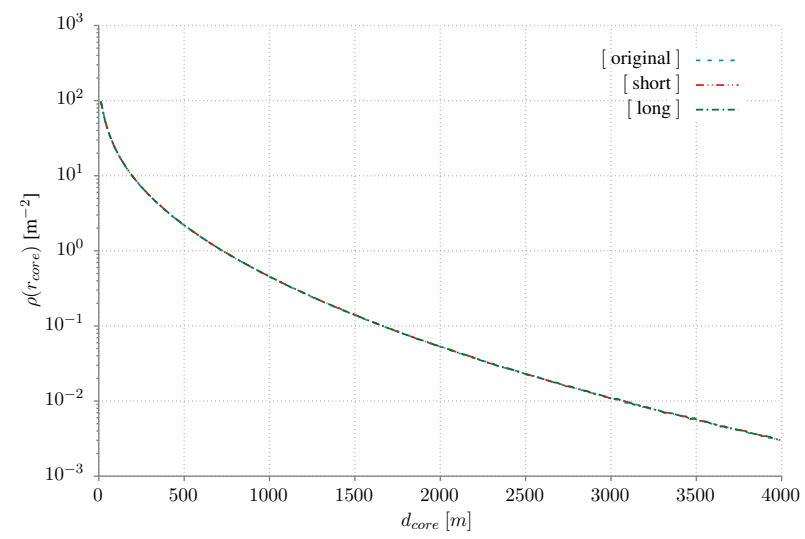

(a) Perfil médio

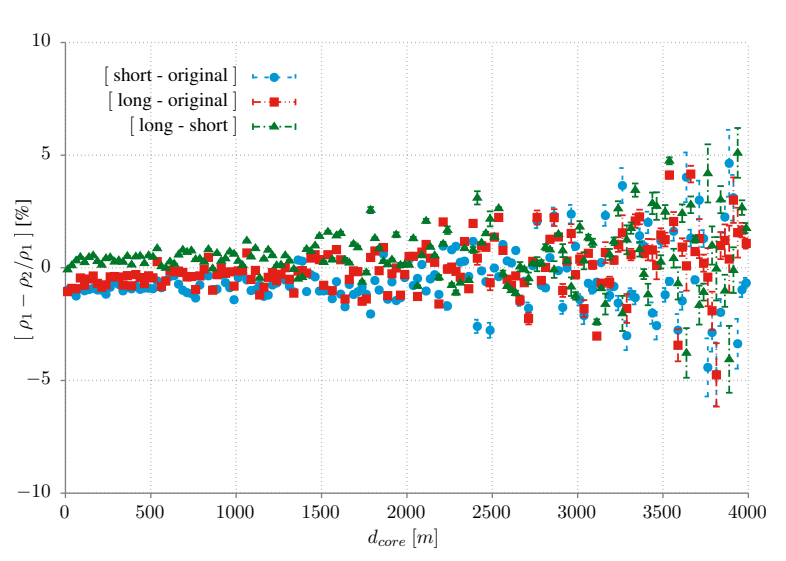

(b) Razão

Figura 5.15: Comparação da densidade lateral de múons em função da distância ao ponto de impacto do chuveiro. Dados simulados são de chuveiros atmosféricos iniciados por próton com energia de $10^{19} \mathrm{eV}$ e inclinação $\theta=60^{\circ}$. Na figura (a) é mostrado o perfil médio de 1000 chuveiros e na figura (b) está representado a diferença da densidade lateral de múons em porcentagem entre os modelos.

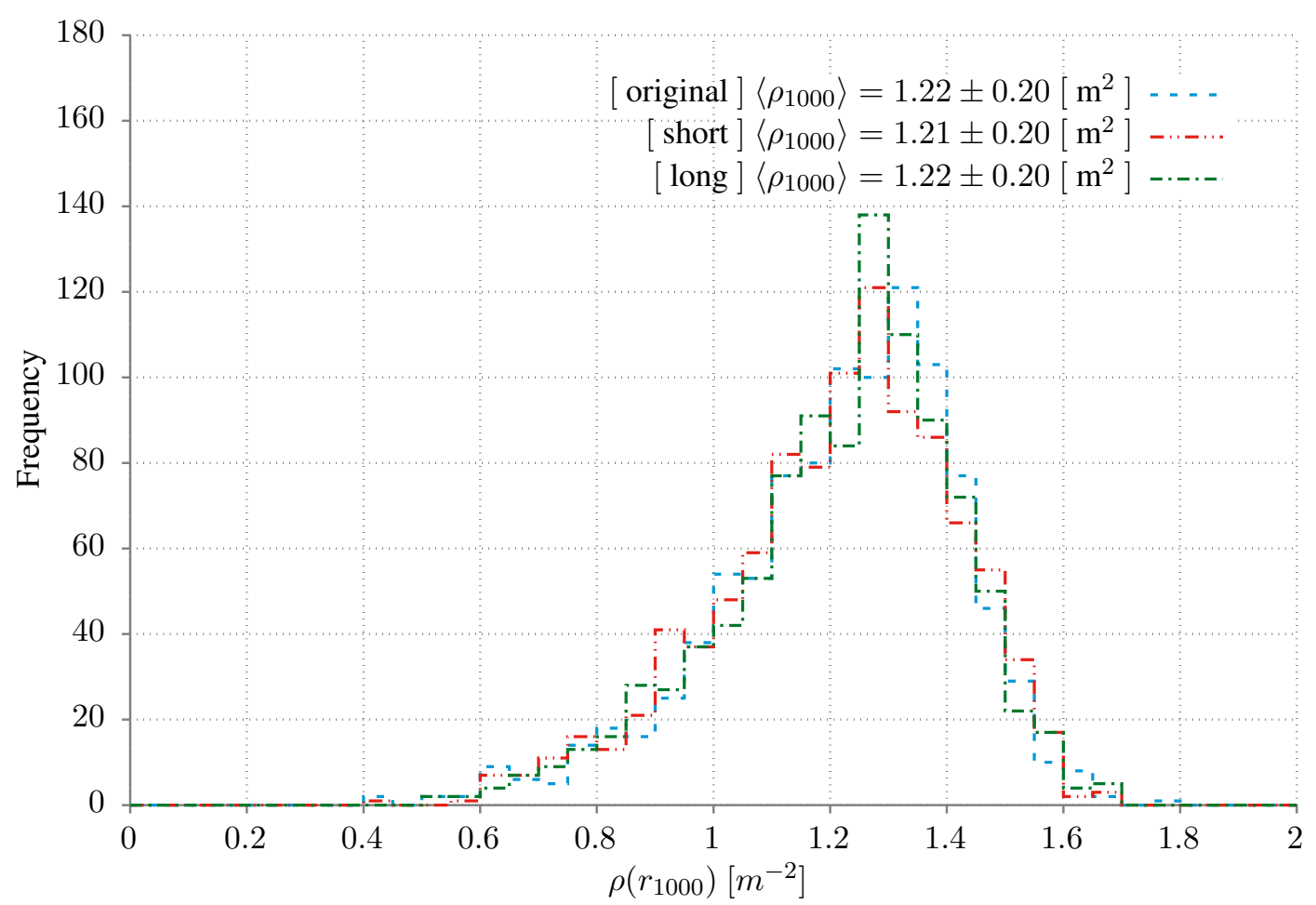

Figura 5.16: Comparação da distribuição de $\rho_{1000}$ para as distribuições de pseudorapidez original, cauda curta e cauda longa. Foram usados 1000 chuveiros iniciados por próton com energia de $10^{19}$ $\mathrm{eV}$ e ângulo $\theta=60^{\circ}$ e $\phi=0^{\circ}$. O modelo SIBYLL2.3, de interação hadrônica, foi utilizado nas simulações dos chuveiros.

\subsection{Consequência da distribuição nos observáveis}

Mostramos nas seções anteriores que variáveis comumente utilizadas para caracterizar o chuveiros atmosférico extenso, e associadas às distribuições longitudinal e lateral de 


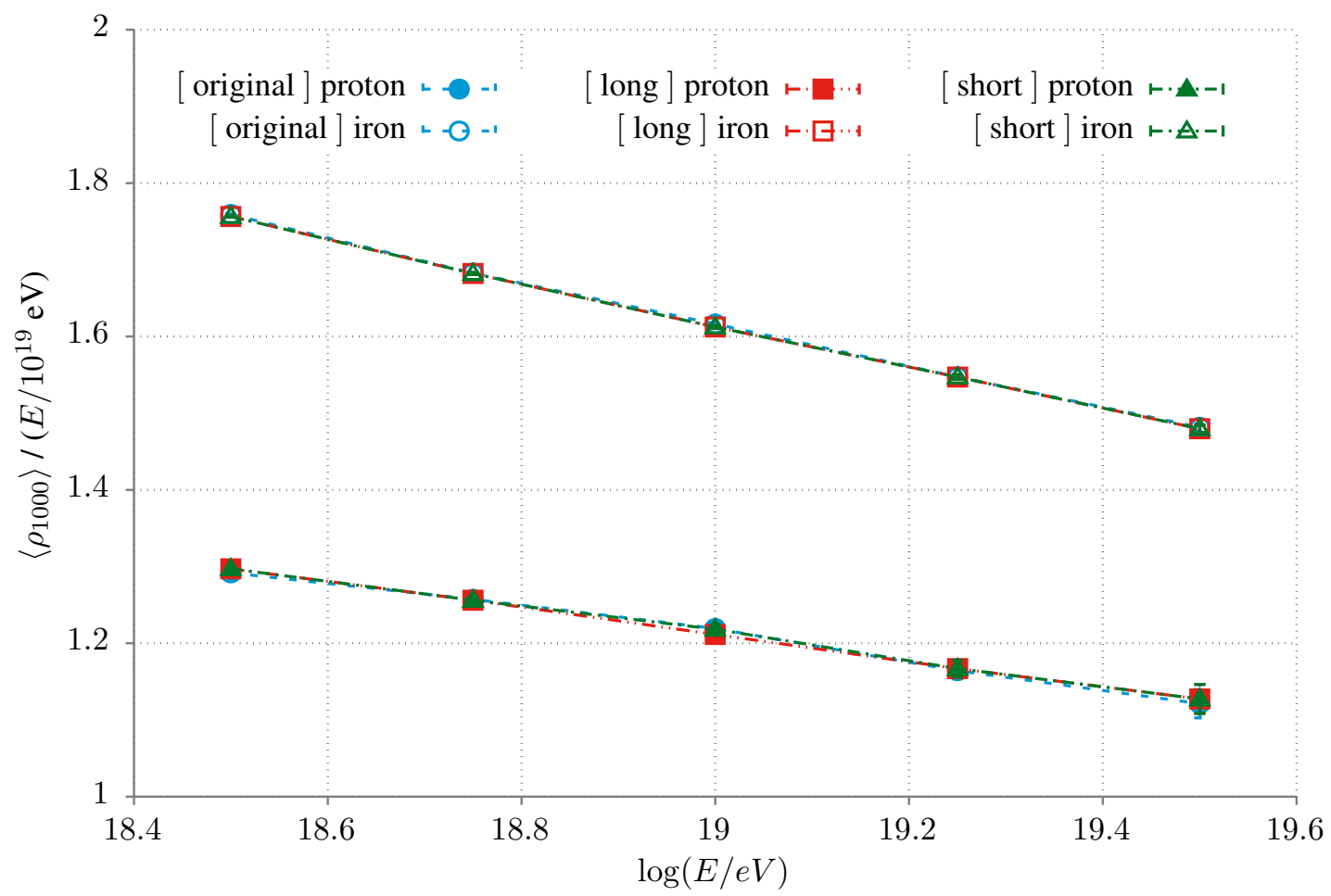

Figura 5.17: Evolução do $\left\langle\rho_{1000}\right\rangle$ em função da energia para as distribuições de pseudorapidez original (azul), cauda curta (vermelha) e cauda longa (verde).

partículas, são completamente insensíveis a variações nas caudas da distribuição de pseudorapidez de partículas secundárias produzidas na primeira interação. Quando a energia total da cascata permanece inalterada, bem como o número total de secundários produzidos, o desenvolvimento subsequente da cascata atenua rapidamente as variações introduzidas na sua primeira geração de partículas. 


\section{Capítulo 6}

\section{Inclusão de efeitos do detector}

O próximo passo da análise foi a inclusão de alguns efeitos de detector. Para tal tarefa, desenvolvemos um programa de computador para simular o funcionamento de um arranjo de detectores espalhados por uma rede triangular semelhante à do Observatório Pierre Auger. Para a simulação desenvolvemos métodos computacionais para reconstruir a direção de chegada do evento e o número de múons. A cadeia de simulação é simplificada, já que não compreende a reprodução completa da resposta dos detectores como em programas como GEANT4 [75]. Entretanto, nos permitiu construir uma análise mais próxima do mundo real ao introduzir a primeira camada de incerteza às variáveis experimentais, a saber, aquelas advindas da natureza esparsa da rede de detecção e área finita de coleção de detectores individuais. As flutuações introduzidas por essas incertezas, por sua vez, permitiram um melhor entendimento acerca dos erros estatísticos e sistemáticos.

\subsection{Simulação do arranjo de detectores}

Construímos uma simulação de arranjo de detectores para EAS baseados no Observatório Pierre Auger e fundamentamos a construção no projeto de atualização AMIGA [25]. Esse projeto consiste de um arranjo de cintiladores que detectam a componente muônica de EAS através da contagem dos múons que chegam ao nível de observação (1420 m em relação ao nível do mar). Deste modo, simulamos um arranjo de detectores que cobre uma área de 25 $\mathrm{km}^{2}$, composto de 61 detectores com área de detecção de $A_{\text {det }}=10.18 \mathrm{~m}^{2}$ e espalhados sobre uma rede triangular com separações de $1500 \mathrm{~m}$ e $750 \mathrm{~m}$ (correspondendo ao espaçamento observado na região da sub-rede INFILL) e um terceiro espaçamento de $350 \mathrm{~m}$ para efeitos de estudo da evolução das incertezas, como mostrado na figura 6.1.

O funcionamento da simulação consiste em definir uma posição para o ponto de impacto do chuveiro no solo aleatoriamente dentro do hexágono central representado pela área em 


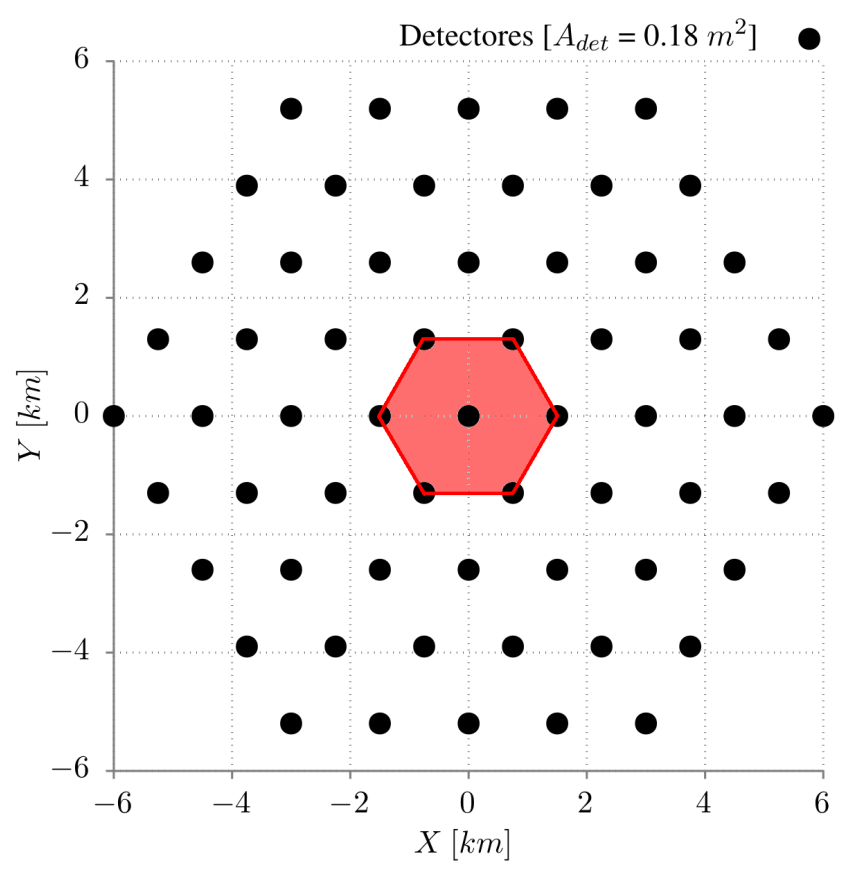

Figura 6.1: Representação gráfica do arranjo de detectores.

vermelho. Após isso, utilizou-se o arquivo binário do programa CORSIKA que contém todas as partículas que chegaram no nível de observação. Desse arquivo, retirou-se a posição dos múons, depois verificou-se quais passaram pelo arranjo de detectores e armazenou-se o tempo da passagem dos que atravessaram os detectores. Ao final da simulação, cada detector $i$ terá armazenado o número de múons $n_{i}$ e um lista do tempo* $t_{i}^{n}$ de quando ocorreu a detecção do múon.

A simulação gera um arquivo final de saída em formato "json", como mostrado abaixo

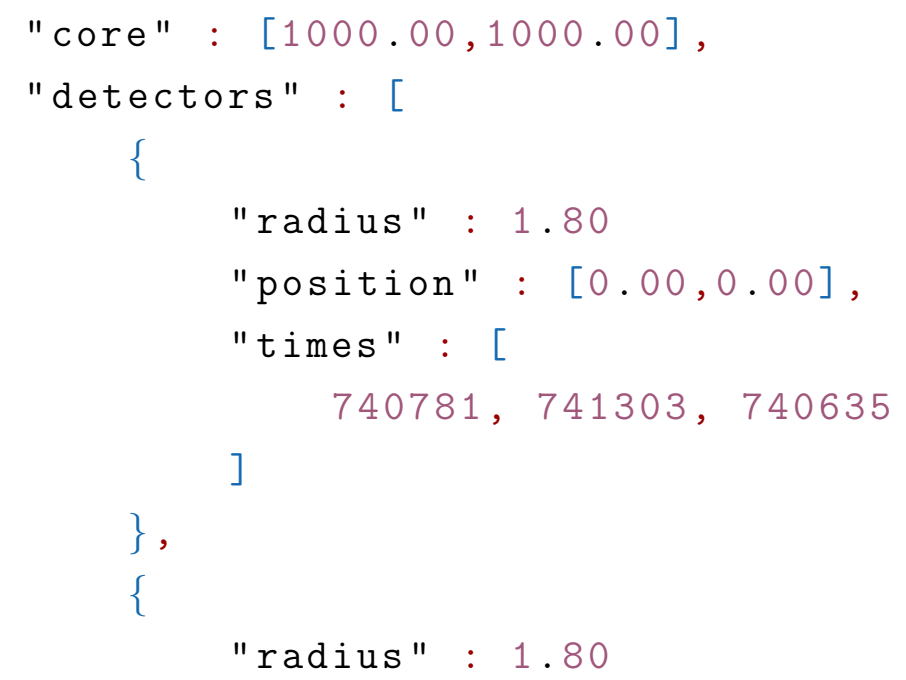

* Os tempos de detecção foram obtidos através dos dados gerados pelo programa CORSIKA. 
onde "core" é a posição de impacto do chuveiro e "detectors" é a lista de detectores da simulação. As unidades de distância e tempo são dadas em metros e nanosegundos, respectivamente. Essa lista contém o raio do detector "radius", sua localização "position" e, por fim, uma lista do tempo de disparo, "times", de cada múon que atravessou o detector. Também podemos representar graficamente o evento, como mostrado na figura 6.2, onde cada detector foi representado por um ponto, o número de múons que atravessaram o detector é proporcional ao raio do círculo nele centrado e a escala de cores mostra o tempo de disparo do primeiro múon que atingiu o detector.

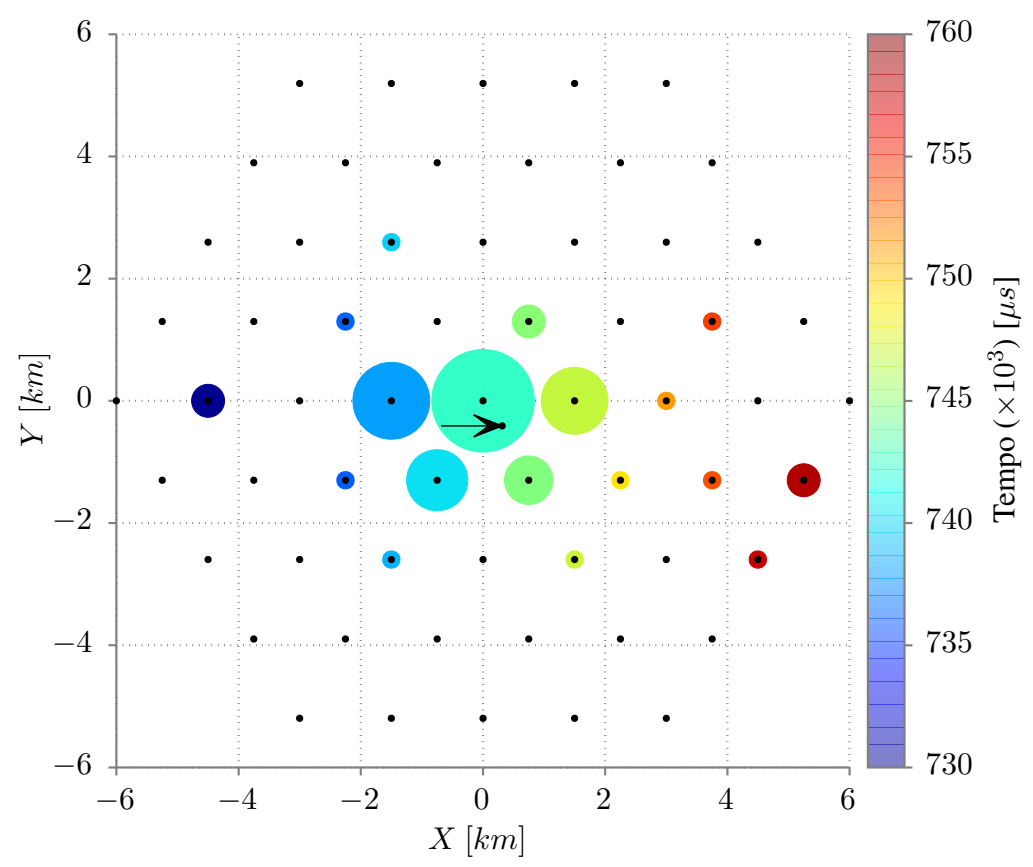

Figura 6.2: Representação gráfica do funcionamento do conjunto de detectores. Cada detector foi representado por um ponto preto, o número de múons que atravessaram o detector é proporcional a largura do ponto, a escala de cores mostra o tempo de disparo do primeiro múon que atingiu o detector e a seta indica a direção de entrada do chuveiro com sua ponta apontando para o ponto de impacto no solo. 


\subsection{Direção de chegada}

Através dos tempos observados no processo de detecção, podemos determinar a direção de chegada do UHECR primário que iniciou o chuveiro. A direção pode ser reconstruída a partir dos tempos de chegada das partículas do chuveiro que cruzam os detectores, que se encontram na posições $\left(x_{i}, y_{i}\right)$. Em primeira aproximação, podemos considerar a frente do chuveiro sendo plana e propagando-se à velocidade da luz c. Essa aproximação é válida para detectores com distância menor que $\sim 2000 \mathrm{~m}$ do eixo do chuveiro. Os tempos de disparo dos detectores, para uma frente de chuveiro plana, podem ser descritos como

$$
t_{i}=T_{0}-\left[\frac{u\left(x_{i}-x_{c}\right)+v\left(y_{i}-y_{c}\right)}{c}\right],
$$

onde $T_{0}$ é o instante em que o centro do chuveiro atinge a posição $\left(x_{c}, y_{c}\right)$. As variáveis $u$ e $v$ são chamadas de cossenos diretores e são dadas por $u=\sin \theta \cos \phi$ e $v=\sin \theta \sin \phi$. Contudo, sabemos que a aproximação de frente do chuveiro plana não deve ser válida para detectores muito distantes do eixo do chuveiro. Dessa forma, devemos propor correções à equação 6.1 de modo a usar todos os detectores disponíveis. Como dados experimentais mostram que há uma curvatura na frente do chuveiro devido às características do desenvolvimento do mesmo, podemos corrigir a equação 6.1 com a adição de um termo $\Delta / c$. Por exemplo, para frente de chuveiros esférica ou parabólica devemos adicionar, respectivamente, ao lado direito de 6.1 um dos seguintes termos

$$
\frac{\Delta}{c}=\frac{\left(\sqrt{R^{2}+r_{i}^{2}}-R\right)}{c}, \quad \frac{\Delta}{c} \approx \frac{r_{i}^{2}}{2 R c}
$$

onde $R$ é o raio de curvatura da frente do chuveiro e $r_{i}$ é a distância da posição do detector $r_{i}^{\prime}$ projetada no plano do chuveiro. Para calcular o termo da curvatura $\Delta / c$, precisamos conhecer a distância do detector $\left(r_{i}\right)$. Ou seja, dada a posição do detector $\left(x_{i}, y_{i}\right)$ e as coordenadas polares da direção de entrada da cascata $(\theta, \phi)$ podemos usar relações de geometria e determinar $r_{i}$ (Os detalhes para determinação de $r_{i}$ encontram-se no apêndice C.1).

Para determinar a direção de chegada do EAS, faremos um processo de minimização de $\chi^{2}$ em duas etapas: uma primeira estimativa dos parâmetros será obtida por meio da aproximação de frente de chuveiro plana e, em seguida, essa estimativa inicial é utilizada para a determinação dos valores finais incluindo o efeito da curvatura. A estimativa inicial, envolve a minimização do $\chi^{2}$ :

$$
\chi^{2}=\sum_{i=1}^{N}\left(\frac{t_{i}^{m}-t_{i}}{\sigma_{i}}\right)^{2}
$$


onde $t_{i}^{m}$ são os tempos medidos pela detecção com incertezas correspondentes $\sigma_{i}$ e $N$ é o número total de detectores atravessados por pelo menos uma partícula. O mínimo do $\chi^{2}$ deve corresponder a um ponto no espaço de parâmetros $\left(T_{0}, u\right.$ e $\left.v\right)$ tal que $\partial \chi^{2} / \partial T_{0}=0$, $\partial \chi^{2} / \partial u=0$ e $\partial \chi^{2} / \partial v=0$. Essas três equações podem ser postas na forma de uma única equação matricial da forma $A x=b$ e esse sistema pode ser resolvido encontrando a inversa da matriz $3 \times 3$, de modo que $x=A^{-1} b$. Logo, cada inversão matricial irá fornecer o tempo $T_{0}$ e os cossenos diretores $u$ e $v$, e por consequência, as direções reconstruídas $\left(\theta_{r}, \phi_{r}\right)$, já que

$$
\theta_{r}=\operatorname{asin}\left(\sqrt{u^{2}+v^{2}}\right) \text { e } \phi_{r}=\operatorname{atan}(v / u) .
$$

Em seguida, devemos minimizar a equação da frente do chuveiro 6.1 com a adição do termo de curvatura 6.2. O mínimo do novo $\chi^{2}$ não leva mais a um sistema de equações lineares e será necessário utilizar um método de minimização não linear para encontrar a solução. Neste caso, realizamos a minimização do $\chi^{2}$ com a biblioteca "TMinuit" fornecida pelo framework ROOT [76] e utilizamos como valores iniciais os resultados obtidos através da aproximação de frente plana.

Por fim, podemos determinar a precisão da reconstrução através da resolução angular, evento a evento, a partir das incertezas de $\theta$ e $\phi$ obtidos no processo de reconstrução, usando a relação:

$$
A R=1.5 \sqrt{\frac{1}{2}\left(\sigma_{\theta}^{2}+\sin ^{2}(\theta) \sigma_{\phi}^{2}\right)}
$$

onde $\sigma_{\theta}$ e $\sigma_{\phi}$ são as incertezas de ajuste em $\theta$ e $\phi$ respectivamente ${ }^{\dagger}$.

\subsection{Número de múons}

Uma vez estabelecida a direção de chegada, podemos modelar a densidade de múons $\rho_{\mu}$, em uma posição $\vec{r}$, como

$$
\rho_{\mu}(\vec{r})=N_{19} \rho_{\mu, 19}(\vec{r} ; \theta, \phi),
$$

onde $N_{19}$ é o parâmetro de tamanho do chuveiro e $\rho_{\mu, 19}$ é a densidade no solo parametrizada para um chuveiro iniciado por próton, simulado com energia de $10^{19} \mathrm{eV}$ e utilizando o modelo de interações hadrônicas EPOSLHC,conforme mostrado na figura 6.3. Estudos mais detalhados [78] mostram que a forma de $\rho_{\mu, 19}$ depende muito fracamente da energia $E$ e da composição química, representada pelo número de massa $A$ do raio cósmico para chuveiros com ângulo zenital $\theta>60^{\circ}$, então a separação proposta na equação 6.6 é uma boa aproximação para chuveiros inclinados acima de $10^{18} \mathrm{eV}$. Também foi mostrado que a

\footnotetext{
${ }^{\dagger}$ Essa relação foi extraída da referência [77].
} 
distribuição lateral $\rho_{\mu, 19}$ é consistentemente reproduzida por diferentes modelos de interações hadrônicas e simuladores de chuveiros.

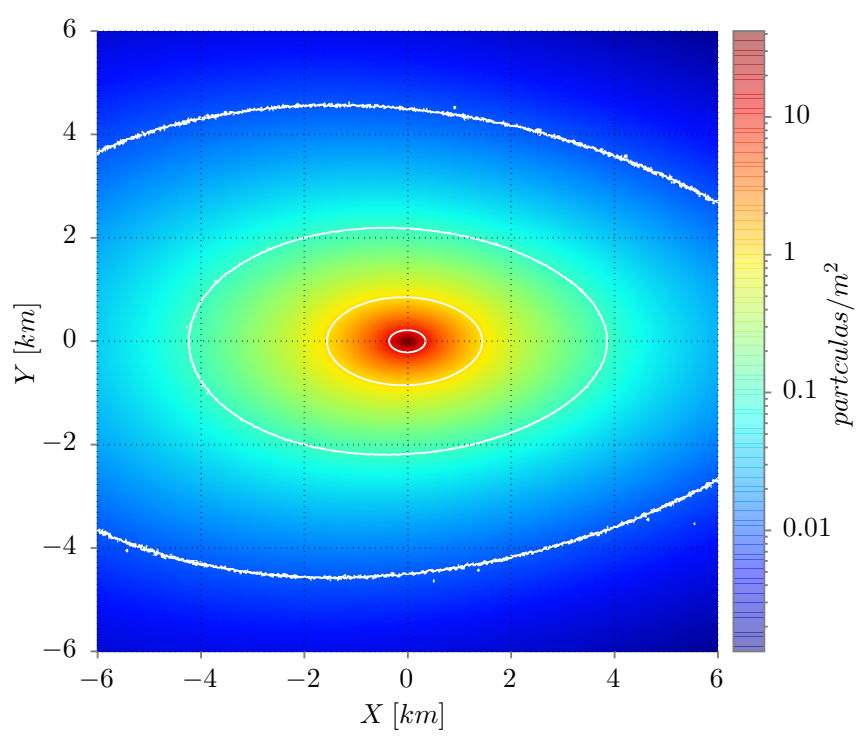

Figura 6.3: Mapa bidimensional de densidade de múons para EAS iniciados por próton com energia de $10^{19} \mathrm{eV}$ e inclinação $\left(\theta=60^{\circ}, \phi=0^{\circ}\right)$, utilizando o modelo EPOSLHC.

O parâmetro de tamanho do chuveiro $N_{19}$ pode ser obtido através do sinal gerado pelo número de múons observados durante a simulação do arranjo de detectores. Sobre os sinais, ajustamos a função $N_{\mu}(\vec{r})$, que descreve o número de múons com uma função de verossimilhança $L$ dada por

$$
L\left(N_{\mu}, k_{1}, \ldots, k_{n}\right)=\prod_{i=1}^{n} f\left(k_{i} \mid N_{\mu}\right)
$$

onde $N_{\mu}=\rho_{\mu} A_{\text {det }}$ (área do detector) é o número de múons esperados e $k_{i}$ é o número de múons observados para cada detector $i$ com área de coleção $A_{d e t}$. A função $f\left(k_{i} \mid N_{\mu}\right)$ descreve a distribuição de probabilidade de medida de um número de múons $k_{i}$ quando o valor esperado é $N_{\mu}$ e no nosso caso será tomada como uma distribuição de Poisson, dada por

$$
f\left(k_{i} \mid N_{\mu}\right)=\frac{e^{-N_{\mu}} N_{\mu}^{k_{i}}}{k_{i} !} .
$$

Ao final, devemos minimizar o logaritmo negativo da verossimilhança, com $N_{19}$ como parâmetro livre

$$
-\sum_{i=1}^{n} \ln f\left(k_{i} \mid N_{\mu}\right)=-\sum_{i=1}^{n}\left[k_{i} \ln \left[N_{19} \rho_{19}\left(r_{i}\right) A_{d e t}\right]+N_{19} \rho_{19}\left(r_{i}\right) A_{d e t}+\ln \left(k_{i} !\right)\right] .
$$

Lembramos que nessa somatória foram incluídas todas as estações do arranjo de detecção 
até as estações com contagem nula de múons. Pois ao excluir estações com zero múons, estamos introduzindo um viés no ajuste, porque para uma distribuição de Poisson, existe uma probabilidade não nula de medir zero múons, mesmo quando o valor esperado é maior do que zero.

\subsection{O problema do "thinning" em EAS}

O número de partículas em um EAS é proporcional à energia do raio cósmico primário. Para energias acima de $10^{17} \mathrm{eV}$, torna-se inviável realizar a simulação completa, pois esta exige um alto custo computacional. O tempo de processamento vira um problema, pois pode chegar a dias ou meses para simular um chuveiro. Além disso, o armazenamento das partículas que chegam ao solo transforma-se em outro problema e exige grandes quantidades de memória.

\subsubsection{O método "thinning"}

A solução para esse problema foi a aplicação de um método estatístico de diluição chamado "thinning". No caso de EAS, esse método é aplicado através do descarte de partículas e da aplicação de um peso estatístico às demais partículas que não foram descartadas. Por exemplo, no programa CORSIKA, todas as partículas secundárias que têm energia abaixo do nível de "thinning" $\left(\varepsilon_{t h}=E / E_{0}\right)$, serão expostas a esse procedimento. Ou seja, se a soma da energia de todas as $j$ partículas secundárias estiver abaixo da energia de "thinning"

$$
\varepsilon_{t h} E_{0}>\sum_{j} E_{j},
$$

apenas uma das partículas secundárias será seguida. Ela será selecionada aleatoriamente de acordo com a sua energia $E_{i}$ com probabilidade

$$
p_{i}=E_{i} / \sum_{j} E_{j} .
$$

e todas as outras serão descartadas. Um peso apropriado $w_{i}=1 / p_{i}$ é atribuído à partícula sobrevivente, a fim de conservar a energia. No caso de apenas algumas partículas secundárias terem energia abaixo do nível de "thinning", a partícula correspondente sobrevive com probabilidade $p_{i}$ dada por

$$
p_{i}=E_{i} /\left(\varepsilon_{t h} E_{0}\right) .
$$

e, no caso em que sobreviva, é atribuído um peso estatístico $w_{i}=1 / p_{i}$. 


\subsubsection{Consequências em EAS}

Quando aplicamos o método de "thinning" no desenvolvimento dos EAS devemos ter cuidado com os dados produzidos pela simulação. A aplicação do método dilui a informação presente no chuveiro removendo partículas e atribuindo o valor dela a outras partículas. Para os detectores de fluorescência, o "thinning" não gera problemas significativos, porque o peso estatístico é muito menor que a densidade de partículas observada no detector. Por outro lado, os detectores de superfície estão a quilômetros de distância do eixo do chuveiro onde a densidade de partícula é baixa, e chega a ser menor do que uma partícula $/ \mathrm{m}^{2}$.

Todas as simulações usadas nesse estudo utilizaram o nível de "thinning" $\varepsilon_{t h}=10^{-6}$. Dessa forma, cada múon produzido na simulação de EAS possui um peso estatístico médio alto de 100. Ou seja, cada múon representa ao todo 100 outros múons. No final, para distâncias maiores do que $1000 \mathrm{~m}$ do ponto de impacto do chuveiro a distribuição de partículas se torna esparsa, como mostrado na figura 6.5a. Logo, o processo de "thinning" está causando perda significativa na distribuição espacial dos múons que atingem o nível de observação para distâncias maiores do que $1000 \mathrm{~m}$ do ponto de impacto do chuveiro.

\subsubsection{Processo de "dethinning"}

Uma vez determinada a causa do problema gerado pelo processo de "thinning", procuramos um método para recuperar a informação perdida. Na literatura existem dois métodos mais conhecidos para recriar o conjunto de partículas no nível de observação: (i) a partir das propriedades dos sinais gerados em detectores de superfície [79] e (ii) construir uma distribuição suavizada no espaço de parâmetros da partícula [27]. Ambos os métodos recuperam razoavelmente bem a distribuição de partículas no nível de observação. Porém nessa tese nos limitamos ao uso da opção (ii) conhecida também pelo nome de "dethinning". Esse modelo elimina os pesos estatísticos das partículas convertendo esses pesos em novas partículas. A saída do simulador CORSIKA consiste de uma lista com informações de tipo, energia, momento, posição, ângulos e tempo de chegada das partículas ao solo. O processo de "dethinnig" consiste em adicionar partículas a essa lista até que o peso estatístico $w$ da partícula se torne 1. Para se inserir novas partículas, deve-se seguir a geometria definida na figura 6.4 e deve-se também executar o seguinte procedimento:

1. Escolher um vértice aleatório sobre a trajetória da partícula com peso;

2. Definir um cone centrado na trajetória da partícula com peso;

3. Sortear um ponto dentro desse cone seguindo uma distribuição gaussiana em duas dimensões. Essa será a trajetória da nova partícula; 


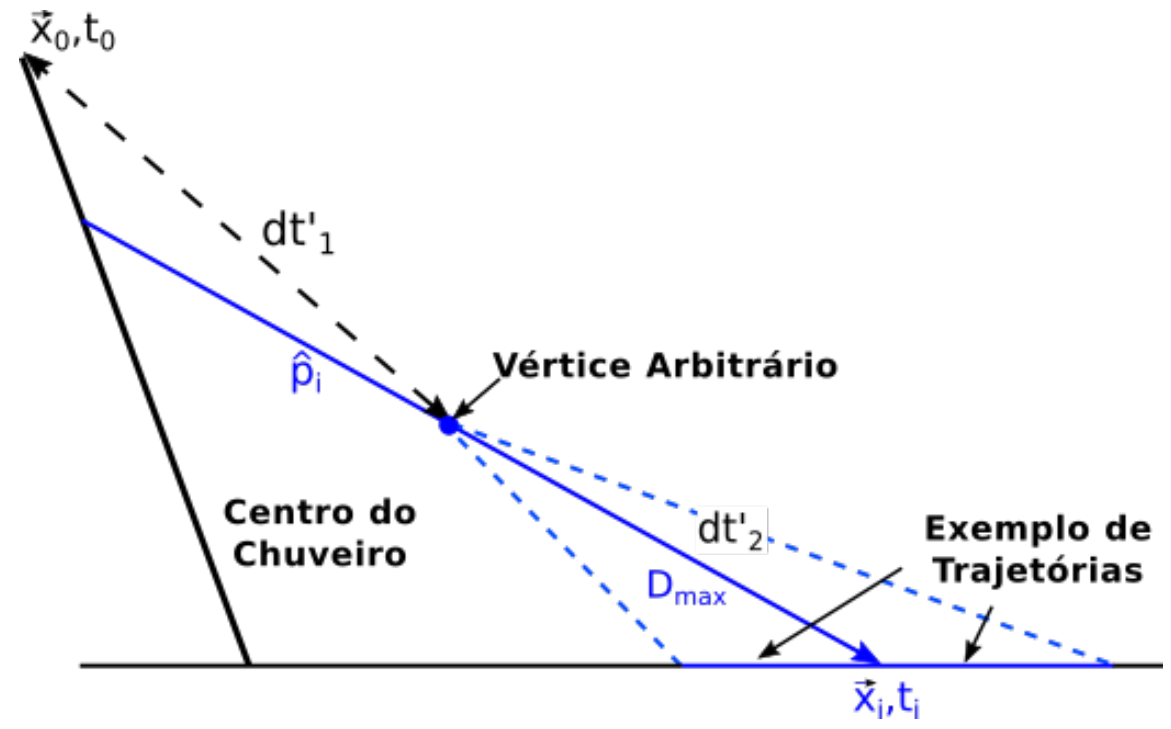

Figura 6.4: Representação da geometria utilizada para reconstruir a informação do chuveiro por "dethinning".

4. Projetar a nova partícula até o nível do solo, adicionando-se o tempo e a energia;

5. Realizar todos os passos $w-1$ vezes. Para o caso em que o peso $w$ não seja um número inteiro, adicionar aleatoriamente uma outra partícula, para a qual a probabilidade é dada pela parte decimal de $w$.

Como nenhuma partícula pode chegar no solo antes da frente do chuveiro, teremos uma distância máxima $\left(D_{\max }\right)$ do solo para escolher o vértice. Essa escolha será definida pelo tempo de chegada da partícula ao solo e é dada por

$$
D_{\text {max }}=\frac{c^{2}\left(t_{i}-t_{0}\right)^{2}-\left|\overrightarrow{x_{i}}-\overrightarrow{x_{0}}\right|^{2}}{2\left[c\left(t_{i}-t_{0}\right)-\left(\overrightarrow{x_{i}}-\overrightarrow{x_{0}}\right) \cdot \hat{p_{i}}\right]},
$$

onde $\overrightarrow{x_{i}}$ e $\overrightarrow{x_{0}}$ é a posição da partícula com peso e a posição da primeira interação, respectivamente. Devemos enfatizar que $D_{\max }$ é a separação máxima entre o vértice e o solo. Os parâmetros utilizados nesse processo são os seguintes:

1. O ângulo do cone gaussiano é definido por $\beta d$ onde $d$ é a distância lateral do ponto de impacto do chuveiro em relação à partícula com peso, $\beta=3^{\circ} / \mathrm{km}$ para partículas eletromagnéticas e $\beta=1^{\circ} / \mathrm{km}$ para múons e hádrons.

2. A distribuição de energia para as novas partículas é proporcional a uma distribuição gaussiana centrada no valor de energia da partícula original com desvio padrão de $10 \%$.

3. Foi introduzida uma aceitação para as partículas seguindo a probabilidade $P=e^{\Delta \chi / \epsilon}$, 
onde $\Delta \chi$ é a diferença do comprimento das trajetórias da partícula nova em relação à partícula com peso e $\epsilon=50 \mathrm{~g} / \mathrm{cm}^{2}$.

4. Os múons são criados mais tarde no desenvolvimento do chuveiro e, como consequência, a distância do vértice é menor que $D_{\max }$, logo

$$
D=\left|\overrightarrow{x_{i}}-\overrightarrow{x_{0}}\right|-X^{-1}\left(\overrightarrow{x_{i}}, \overrightarrow{x_{0}}, \alpha h\right)
$$

Aplicamos esse procedimento a todos os chuveiros estudados nesse capítulo e o resultado é mostrado na figura 6.5. Aqui, temos a distribuição espacial dos múons que chegaram ao solo para um chuveiro simulado com o CORSIKA com energia de $10^{19} \mathrm{eV}$ iniciado por um próton com ângulo zenital de $60^{\circ}$ e azimutal $0^{\circ}$. A figura da esquerda é a simulação original, enquanto a figura da direita mostra o resultado após a aplicação do processo de "dethinning"e a escala de cores indica a densidade de múons no local.

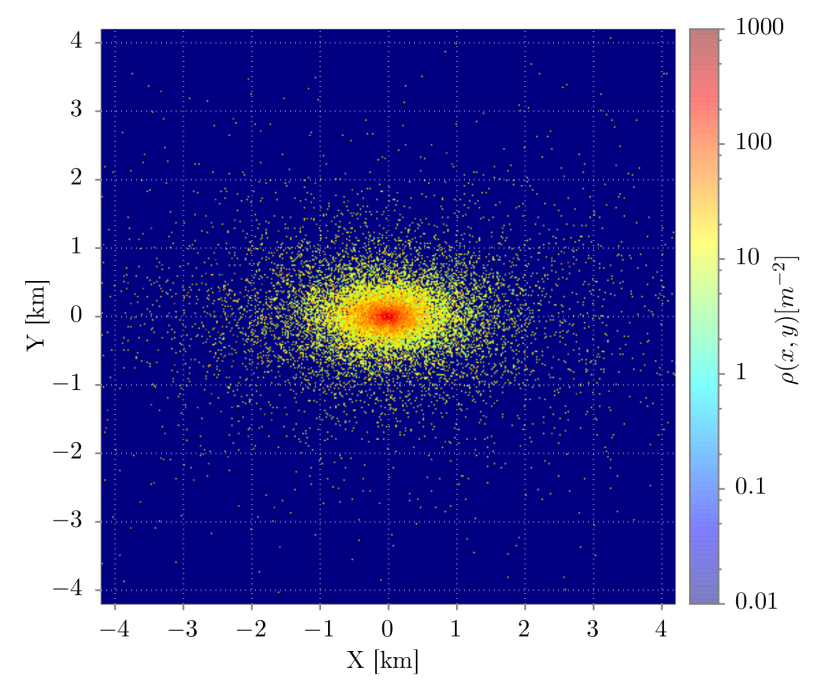

(a) ("thinning")

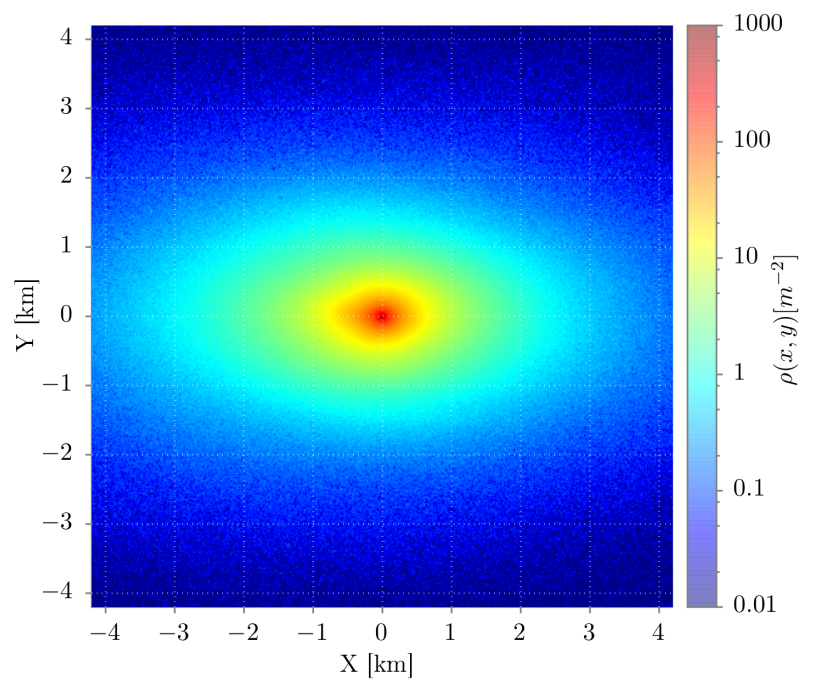

(b) ("dethinning")

Figura 6.5: Comparação da distribuição bidimensional de distribuição de partículas no solo para EAS iniciados por próton com energia de $10^{19} \mathrm{eV}$ e inclinação zenital de $60^{\circ}$ e azimutal $0^{\circ}$. Em (a) temos o mapa original sem aplicação de "dethinning"e em (b) temos o mapa após a aplicação do algoritmo de "dethinning".

\subsection{Cenário de teste da reconstrução}

Criamos um cenário para testar a reconstrução da direção de chegada e o parâmetro de tamanho do chuveiro $N_{19}$ a partir de dados extraídos da simulação do arranjo de detectores. Nesse cenário, utilizamos o mapa médio da densidade de múons para chuveiros iniciados 
por próton com energia de $10^{19} \mathrm{eV}$, com inclinação de $\theta=60^{\circ}$ e utilizando o modelo de interação hadrônica EPOSLHC, que é mostrado na figura 6.3. Para cada detector, localizado na posição $(x, y)$, extraímos a densidade de múons e geramos flutuações estatísticas através de uma distribuição de Poisson, dada por

$$
f(n ; \lambda)=\frac{\lambda^{n} e^{-\lambda}}{n !}
$$

onde $\lambda=A_{\text {det }} \rho_{19}(x, y ; \theta, \phi)$ é o número de múons dado pelo mapa de referência e $A_{\text {det }}$ é a área do detector. Os tempos de disparos dos detectores foram gerados pela equação equação 6.1 adicionando o termo de curvatura parabólica 6.2 e as flutuações estatísticas foram geradas a partir de um modelo, publicado em [80], em que a variância $V\left[T_{s}\right]$ no tempo de chegada da primeira partícula ao detector é dada por

$$
V\left[T_{s}\right]=a^{2}\left(\frac{2 T_{50}}{n}\right)^{2} \frac{n-1}{n+1}+b^{2}
$$

onde $a^{2}=1, b^{2}=144 \mathrm{~ns}^{2}, n$ é o número de partículas observado pelo detector e $T_{50}$ é tempo necessário para atingir $50 \%$ do sinal do detector.

Para esse teste, geramos 1000 simulações e reconstruímos a direção de chegada com o método descrito na seção 6.2. Essa reconstrução tem quatro parâmetros livres: o tempo do impacto no solo do centro do chuveiro $\left(T_{0}\right)$, a inclinação do chuveiro em relação ao solo $(\theta$ e $\phi$ ) e a curvatura do chuveiro $R_{c}$. A figura 6.9 , mostra a diferença do valor reconstruído ao original de $T_{0}$. O valor de $T_{0}$ utilizado na simulação foi de $740 \mu \mathrm{s}$ e o reconstruído pelo método de minimização da frente do chuveiro $\left\langle T_{0}\right\rangle=740 \pm 200_{R M S} \mu s$ onde o erro na média é de aproximadamente 200 ns. No mesmo processo de reconstrução também determinamos os ângulos $\theta$ e $\phi$ do chuveiro, que são mostrados respectivamente nas figuras 6.7 e 6.7. Como mencionado anteriormente, a inclinação dos chuveiros utilizados no teste era de $\theta=60^{\circ} \mathrm{e}$ $\phi=0^{\circ}$ e no processo de reconstrução encontramos o valor médio de $\langle\theta\rangle=59.90 \pm 1.44_{R M S}^{\circ} \mathrm{e}$ $\langle\phi\rangle=0.02 \pm 1.42_{R M S}^{\circ}$. Esse resultados levam a uma resolução angular de $1.76^{\circ}$ para o cenário de teste. Além dos parâmetros $T_{0}, \theta$ e $\phi$, a reconstrução também estima a curvatura da frente do chuveiro, $R_{c}$. Utilizamos o valor de $R_{c}=10000 \mathrm{~m}$ na simulação do cenário de teste e a reconstrução encontrou $\left\langle R_{c}\right\rangle=10540 \pm 1328_{R M S} \mathrm{~m}$. A curvatura do chuveiro foi próxima do valor esperado, porém entre todos os parâmetros é para o qual obtivemos mais flutuações durante a reconstrução da direção de chegada.

\footnotetext{
${ }^{\ddagger}$ Esse modelo trata as diferenças de tempo dos múons com respeito à frente de onda da cascata como um processo de Poisson, bem como inclui às flutuações contribuições do detector devido à taxa finita de amostragem da eletrônica de aquisição. Os números adotados em 6.16 são consistentes com a eletrônica de aquisição do detector de superfície do Observatório Pierre Auger.
} 


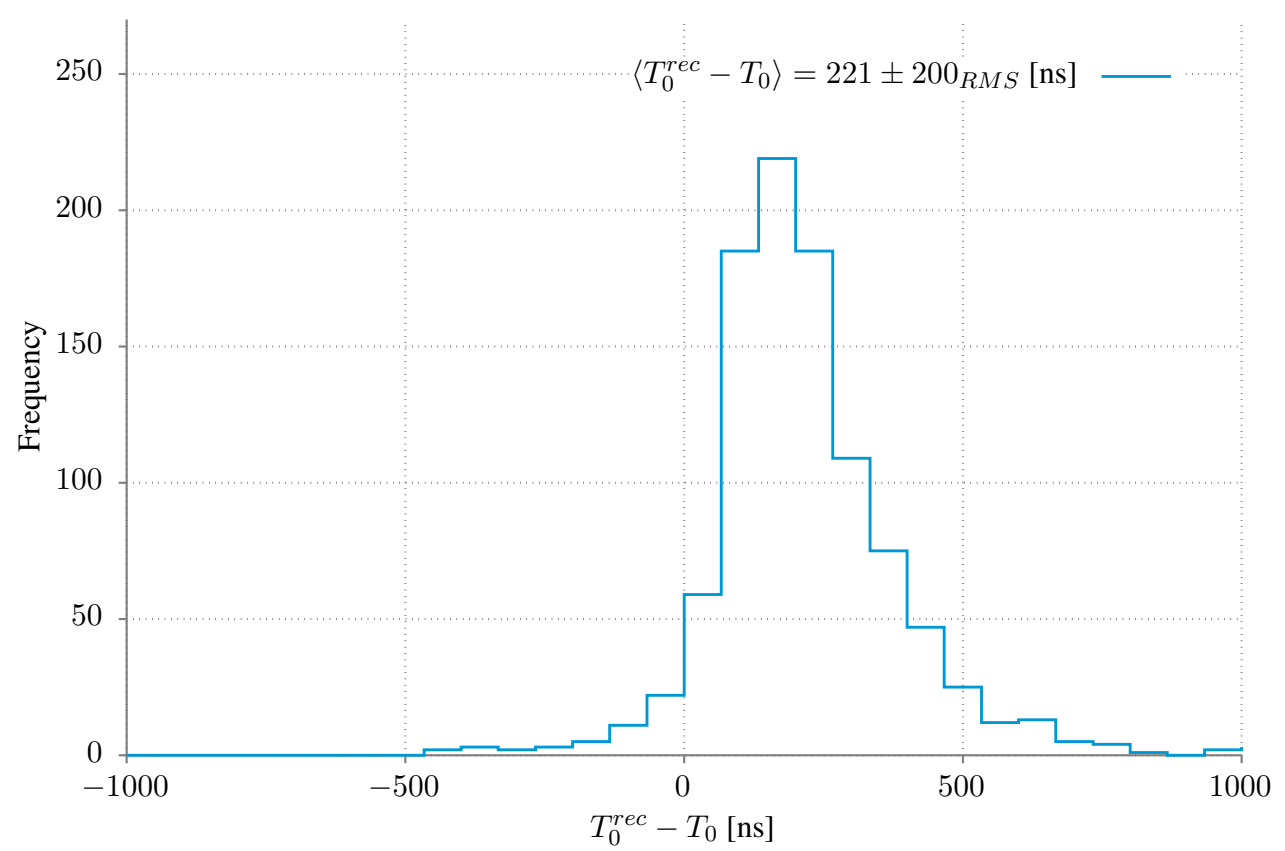

Figura 6.6: Reconstrução do parâmetro livre $T_{0}$ usando o método de minimização da frente de propagação curva.

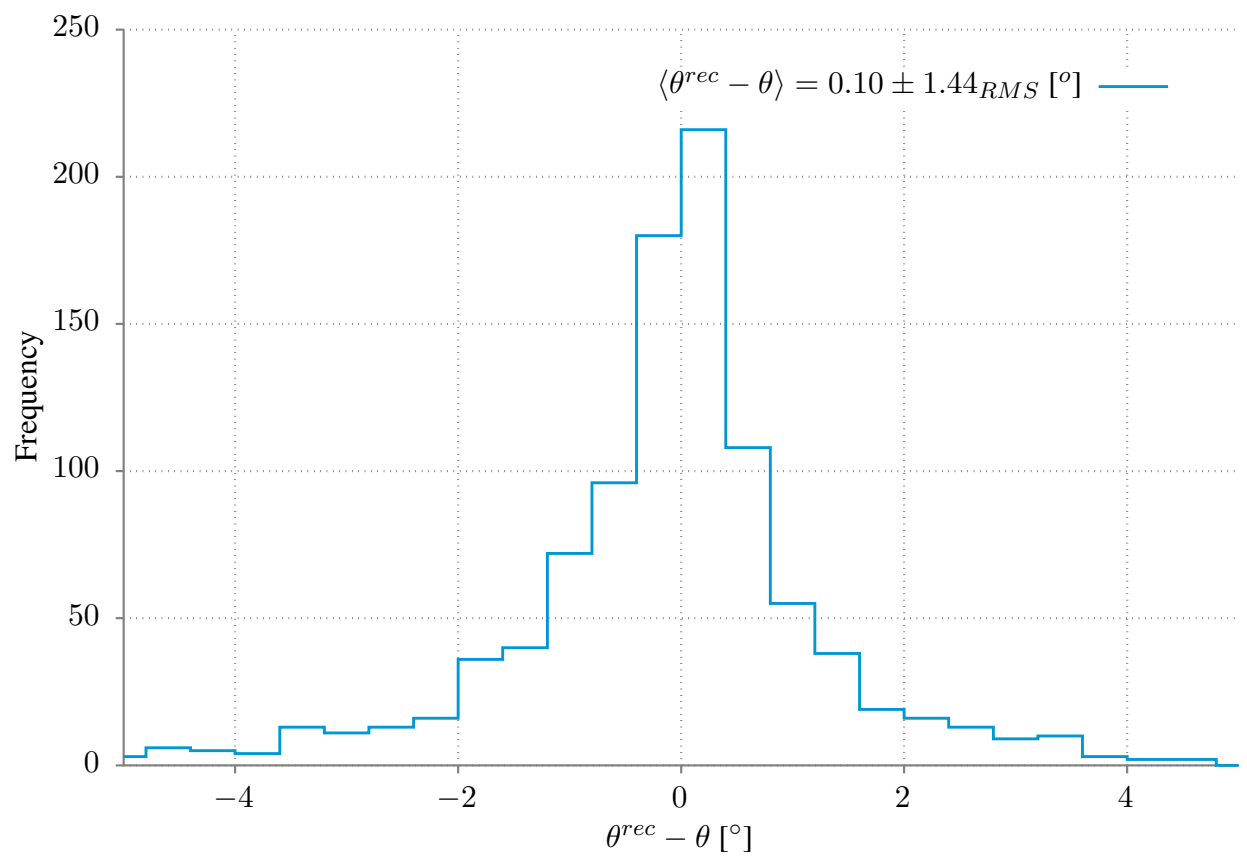

Figura 6.7: Reconstrução do parâmetro livre $\theta$ usando o método de minimização da frente de propagação curva.

Como mencionado anteriormente, $N_{19}$ é reconstruído normalizando um mapa de densidade de múons, dado por $\rho_{19}(x, y ; \theta, \phi)$, dependente da direção de chegada. Ou seja, dada a direção de chegada, podemos reconstruir o número de múons através do método de máxima 


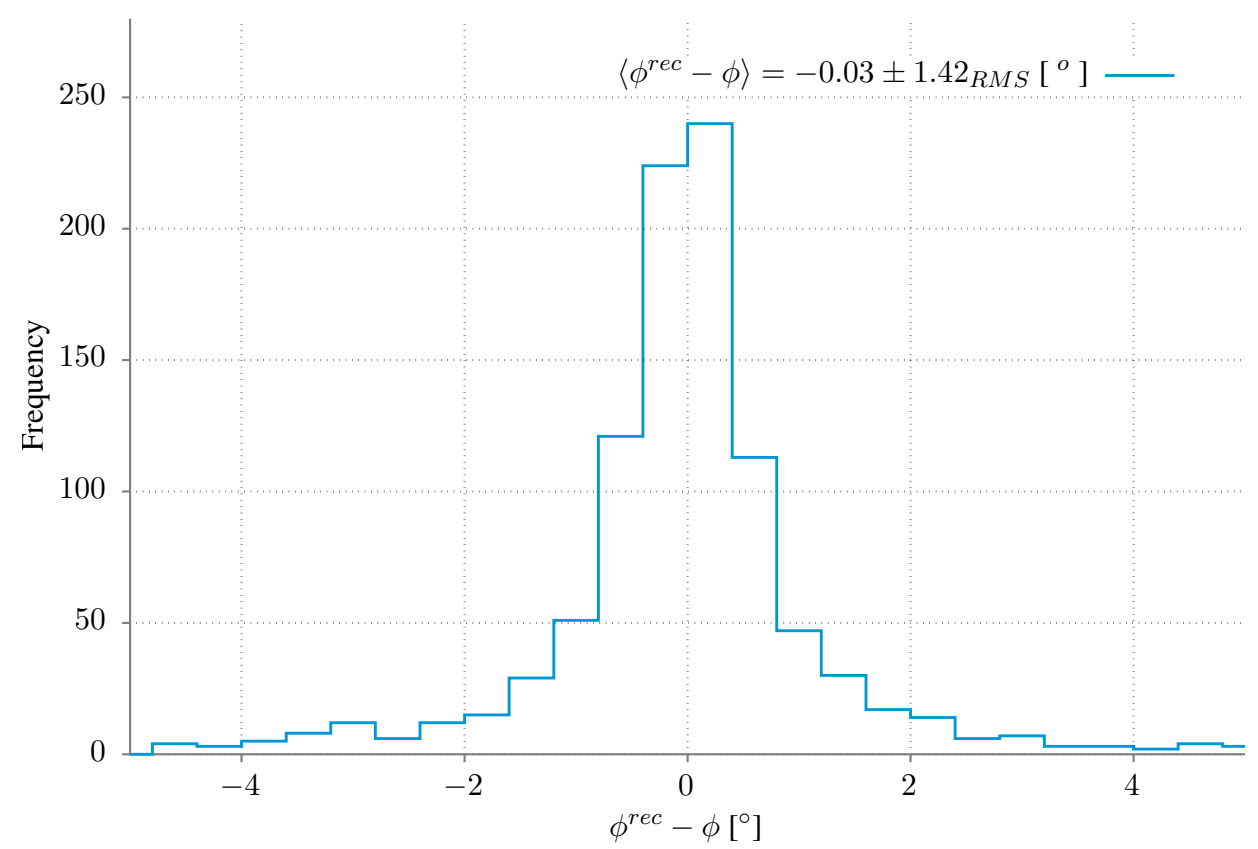

Figura 6.8: Reconstrução do parâmetro livre $\phi$ usando o método de minimização da frente de propagação curva.

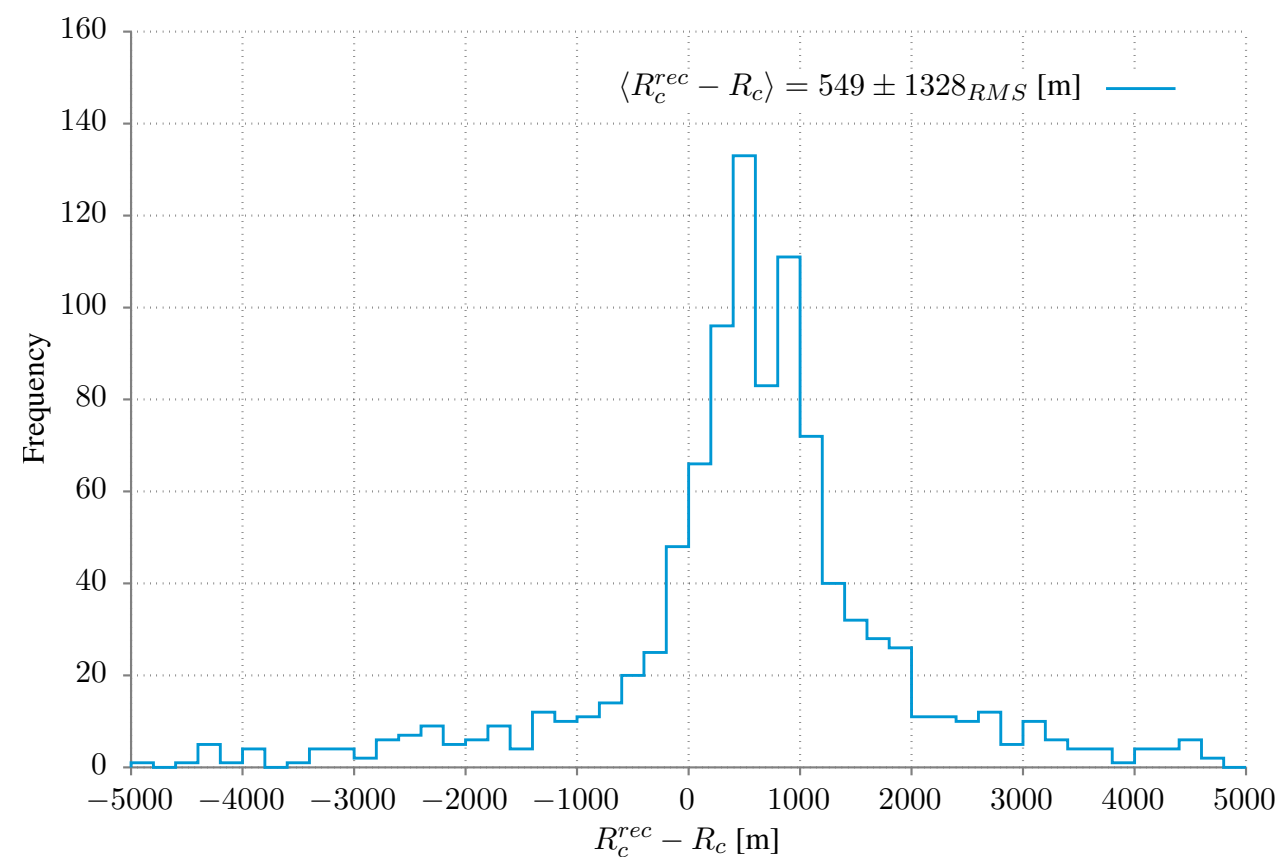

Figura 6.9: Reconstrução do parâmetro livre $R_{c}$ usando o método de minimização da frente de propagação curva.

verossimilhança usando uma distribuição de Poisson como estimador para a flutuação. A reconstrução de $N_{19}$, mostrada na figura 6.10 , encontrou $\left\langle N_{19}\right\rangle=1.00 \pm 0.10$, valor consistente com o esperado $N_{19}=1$. 


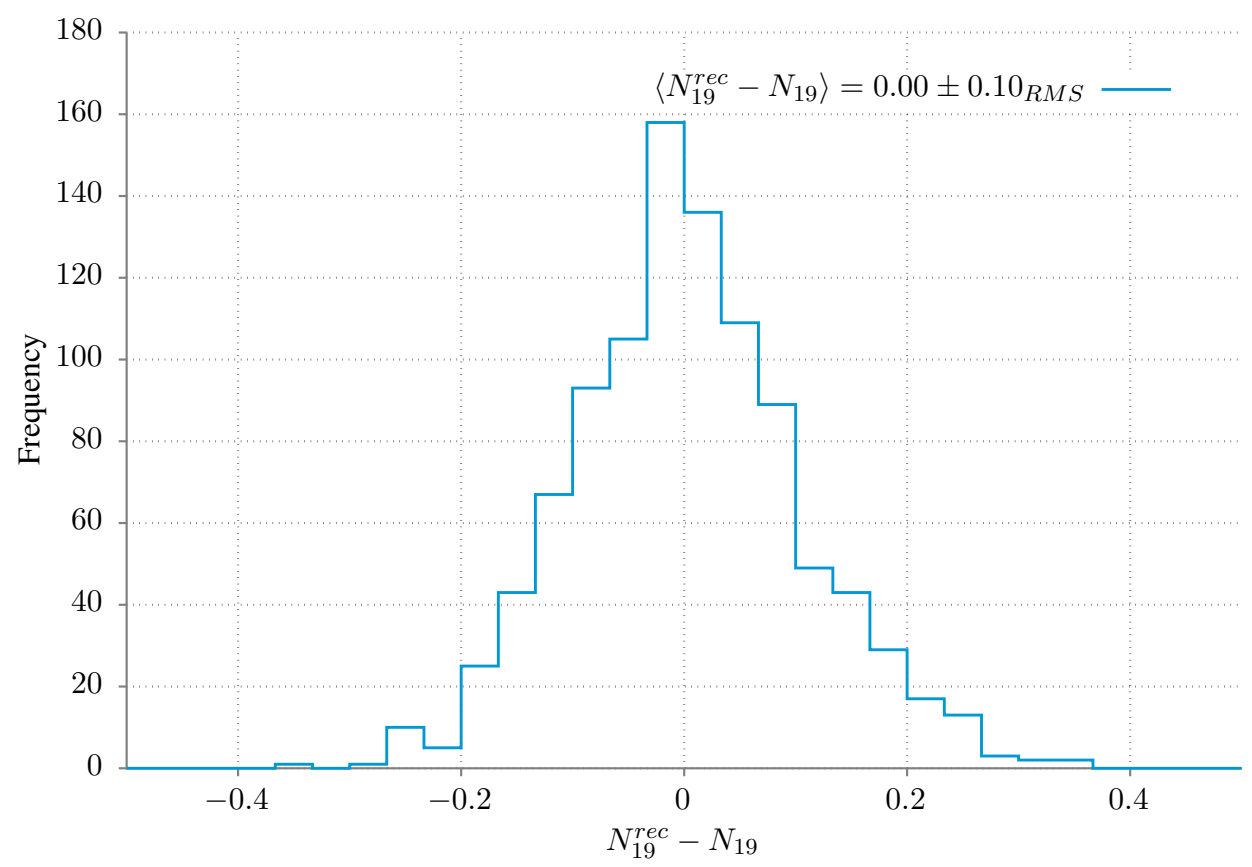

Figura 6.10: Reconstrução do parâmetro livre $N_{19}$ usando o método máxima verossimilhança.

Sabemos que a reconstrução nunca será exata, pois reconstruímos com uma informação limitada à área de detecção. Para melhorar a reconstrução seria necessário aumentar a área de coleção através do aumento da área dos detectores, ou diminuir o espaçamento entre as células de detecção. Por exemplo, na figura 6.11, é mostrado a reconstrução do parâmetro $N_{19}$ para diferentes distâncias entre os detectores. Em verde, para os detectores separados por uma distância de $1500 \mathrm{~m}$, a reconstrução de $N_{19}$ tem uma resolução de aproximadamente 0.1. Quando diminuímos a distância, melhoramos a resolução para 0.05 e 0.02 para distâncias de $750 \mathrm{~m}$ (linha vermelha) e $375 \mathrm{~m}$ (linha azul), respectivamente. O mesmo comportamento é observado quando aumentamos a área de coleção dos detectores. Para $A_{d e t}=10.18 \mathrm{~m}^{2}$, em azul, a reconstrução obteve uma resolução de aproximadamente 0.2, que diminui para 0.05 quando usamos detectores com $A_{d e t}=40.71 \mathrm{~m}^{2}$, em vermelho, e por fim, obtivemos uma resolução de aproximadamente 0.03 para detectores com $A_{d e t}=90.61 \mathrm{~m}^{2}$, esses resultados encontram-se na tabela 6.1.

Os testes realizados aqui, num cenário controlado, validam a implementação do algoritmo de "dethinning" utilizado. Podemos então prosseguir e aplicar o algoritmo, assim como o processo de reconstrução, sobre cascatas geradas pelo programa CORSIKA. 


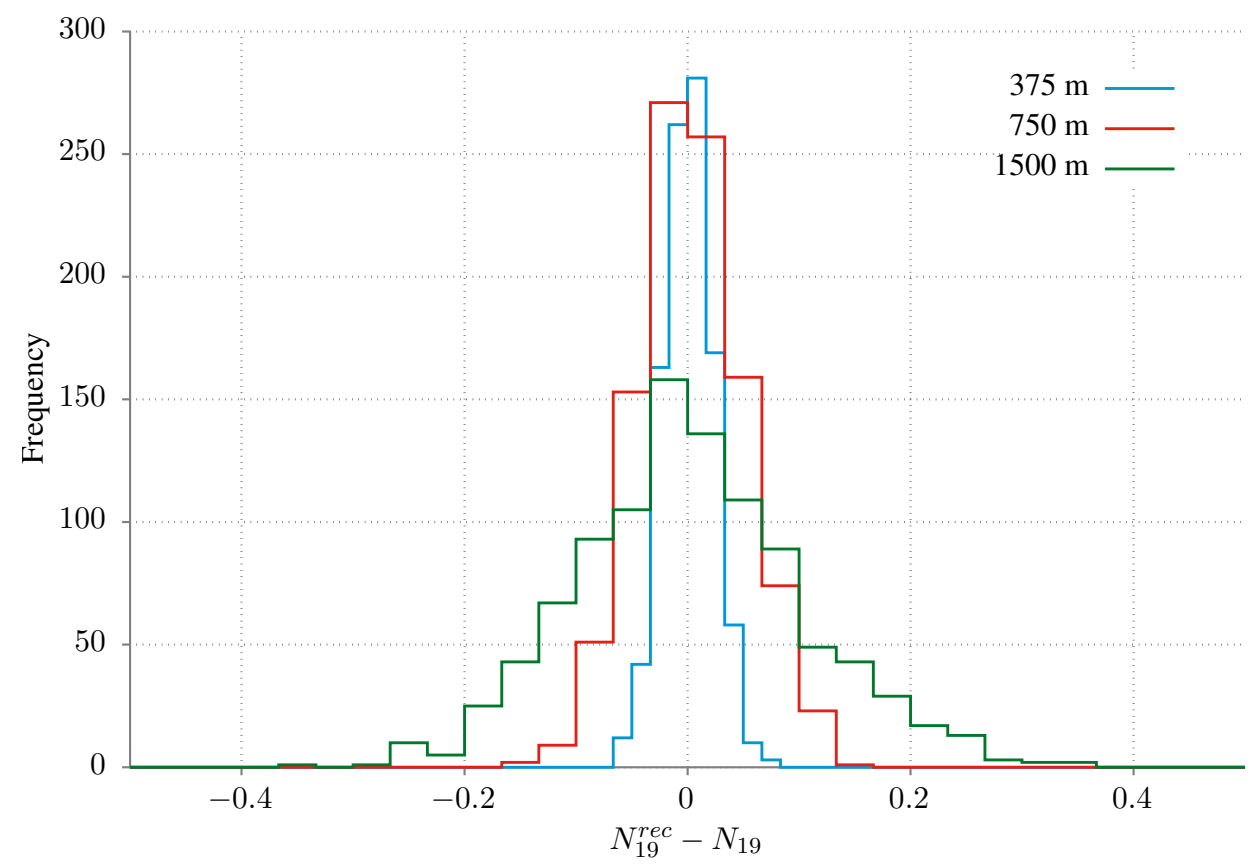

Figura 6.11: Reconstrução do parâmetro livre $N_{19}$ para diferentes espaçamento dos detectores. A linha azul representa a reconstrução de $N_{19}$ para detectores separados por $375 \mathrm{~m}$, a linha vermelha para detectores separados por $750 \mathrm{~m}$ e a linha verde para detectores separados por $1500 \mathrm{~m}$ igual separação encontrada no Observatório Pierre Auger.

\subsection{Reconstrução com simulações de EAS}

Com a simulação do arranjo de detectores validada sobre um cenário controlado, aplicamos o mesmo processo e reconstruímos o observável $N_{19}$ de dados de EAS simulados pelo programa CORSIKA. Aplicamos esse processo sobre dados de EAS iniciados por próton ou ferro, com energia entre $10^{18.5}$ até $10^{19.5} \mathrm{eV}$ e ângulos $\theta=60^{\circ} \mathrm{e} \phi=0^{\circ}$. Primeiro reconstruímos a direção de chegada dos EAS para que em seguida pudéssemos iniciar a reconstrução do parâmetro $N_{19}$, pois o mesmo depende da inclinação de chegada do EAS.

Inicialmente, realizou-se um estudo do observável $N_{19}$ para chuveiros iniciados por próton com energia de $10^{19} \mathrm{eV}$ e ângulos zenital de $60^{\circ}$ e azimutal $0^{\circ}$. Sobre esse processo avaliamos a resolução angular e a precisão da reconstrução de $\left\langle N_{19}\right\rangle$ usando EAS simulados com os três principais modelos de interações hadrônicas. Além disso, também estudamos o evolução do parâmetro reconstruído no intervalo de energia entre $10^{18.5}$ até $10^{19.5} \mathrm{eV}$.

\subsubsection{Reconstruindo a direção de chegada para dados de EAS}

Aplicamos o processo de reconstrução descrito na seção 6.2 e utilizamos o modelo de frente de chuveiros com curvatura parabólica. Analisamos a distribuição angular de $\theta$ e $\phi$ 


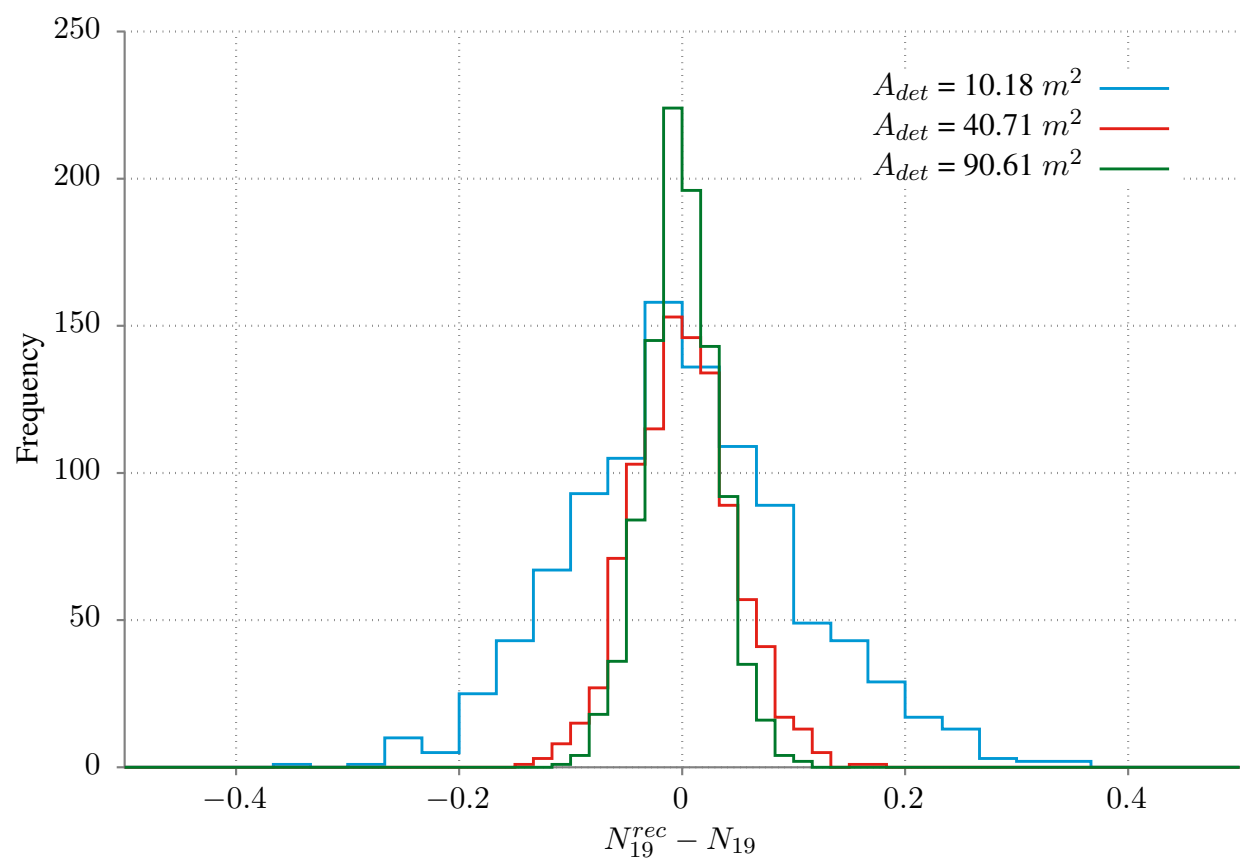

Figura 6.12: Reconstrução do parâmetro livre $N_{19}$ para diferentes área de exposição dos detectores. A linha verde representa a reconstrução de $N_{19}$ para detectores com área de $90.61 \mathrm{~m}^{2}$, a linha vermelha com área de $40.71 \mathrm{~m}^{2}$ e a linha azul com área de $10.18 \mathrm{~m}^{2}$ igual a área do detectores encontrado no Observatório Pierre Auger.

reconstruídos, mostradas nas figuras 6.13 e 6.14. Todos os modelos apresentaram uma distribuição semelhante e valores médios iguais, como era esperado. Para uma amostra de 1000 EAS, encontramos o valor de $\langle\theta\rangle=59.01 \pm 2.84_{R M S}^{\circ}$ e $\langle\phi\rangle=-0.18 \pm 2.70_{R M S}^{\circ}$ para o modelo EPOSLHC, em vermelho, $\langle\theta\rangle=59.20 \pm 2.62_{R M S}^{\circ}$ e $\langle\phi\rangle=0.10 \pm 2.64_{R M S}^{\circ}$ para o modelo SIBYLL2.3, em azul, e $\langle\theta\rangle=59.19 \pm 2.70_{R M S}^{\circ}$ e $\langle\phi\rangle=0.11 \pm 2.52_{R M S}^{\circ}$ para o modelo QGSJETII-04, em verde. Na média a reconstrução obteve uma incerteza sistemática de aproximadamente $1^{\circ}$ para $\theta$ e $0.2^{\circ}$ para $\phi$. Esse viés é natural, pois o processo de reconstrução pressupõe algumas hipóteses sobre a flutuação dos sinais nos detectores:

1. O modelo de "dethinning" é válido e recupera corretamente a flutuação espacial e temporal das partículas;

2. A propagação da frente do chuveiro tem uma curvatura parabólica;

3. A flutuação no tempo de disparo de cada detector segue uma distribuição gaussiana independente da distância ao eixo do chuveiro.

A partir desses resultados, podemos calcular a resolução angular do processo de reconstrução utilizando a equação 6.5 onde obtemos $1.5^{\circ}$ para SIBYLL2.3, $1.6^{\circ}$ para EPOSLHC e $1.5^{\circ}$ para QGSJETII-04. Essa resolução angular é consistente com aquela observada na reconstrução 


\begin{tabular}{|c|c|c|c|}
\hline \multicolumn{4}{|c|}{ Distância $[\mathbf{m}]\left(A_{d e t}=10.18 \mathbf{m}^{2}\right)$} \\
\hline & 1500 & 750 & 375 \\
\hline$\left\langle N_{19}\right\rangle$ & $1.00 \pm 0.10_{R M S}$ & $1.00 \pm 0.05_{R M S}$ & $1.00 \pm 0.02_{R M S}$ \\
\hline \multicolumn{4}{|c|}{ Área $\left[\mathrm{m}^{2}\right](\mathrm{d}=1500 \mathrm{~m})$} \\
\hline & 10.18 & 40.71 & 90.61 \\
\hline$\left\langle N_{19}\right\rangle$ & $1.00 \pm 0.10_{R M S}$ & $1.00 \pm 0.05_{R M S}$ & $1.00 \pm 0.03_{R M S}$ \\
\hline
\end{tabular}

Tabela 6.1: Valores da reconstrução de $N_{19}$ para diferentes distâncias entre os detectores e áreas de coleção.

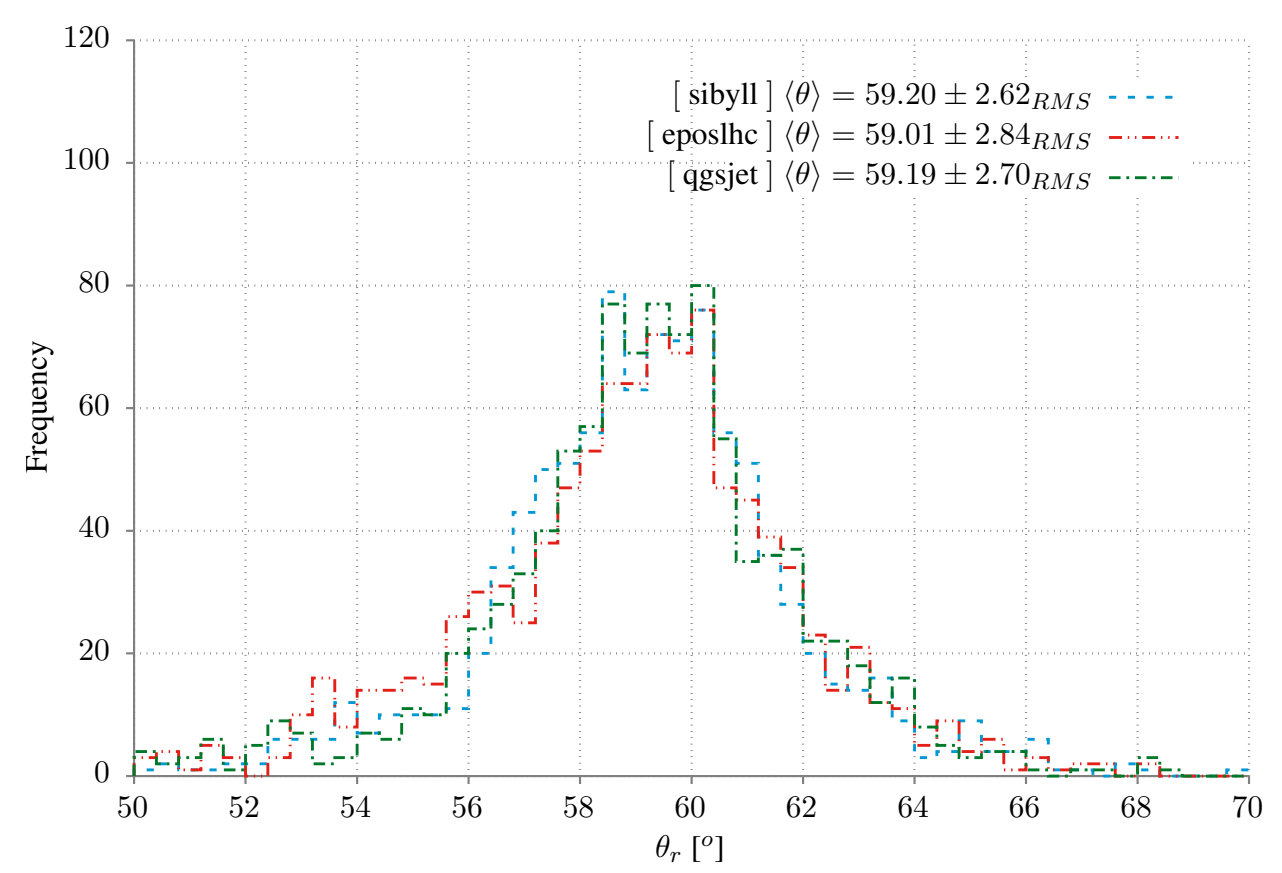

Figura 6.13: Reconstrução da distribuição de $\theta$ para os modelos de interação hadrônica SIBYLL2.3(azul), EPOSLHC(vermelho) e QGSJETII-04(verde). Foram reconstruídos 1000 EAS inciados por próton com energia de $10^{19} \mathrm{eV}$ e inclinação $\theta=60^{\circ}$ e $\phi=0^{\circ}$.

geométrica de chuveiros a partir dos sinais nos detectores de superfície do Observatório Pierre Auger [77].

\subsubsection{Número de múons}

Uma vez reconstruída a direção de chegada $(\theta$ e $\phi)$, podemos reconstruir o observável $N_{19}$ de EAS utilizando o processo de reconstrução descrito na seção 6.3. Na figura 6.15, é mostrada a distribuição de $N_{19}$ onde obtivemos o valor médio de $\left\langle N_{19}\right\rangle=1.13 \pm 0.24_{R M S}$, $\left\langle N_{19}\right\rangle=1.12 \pm 0.22_{R M S}$ e $\left\langle N_{19}\right\rangle=1.02 \pm 0.19_{R M S}$ para SIBYLL2.3, EPOSLHC e QGSJETII- 


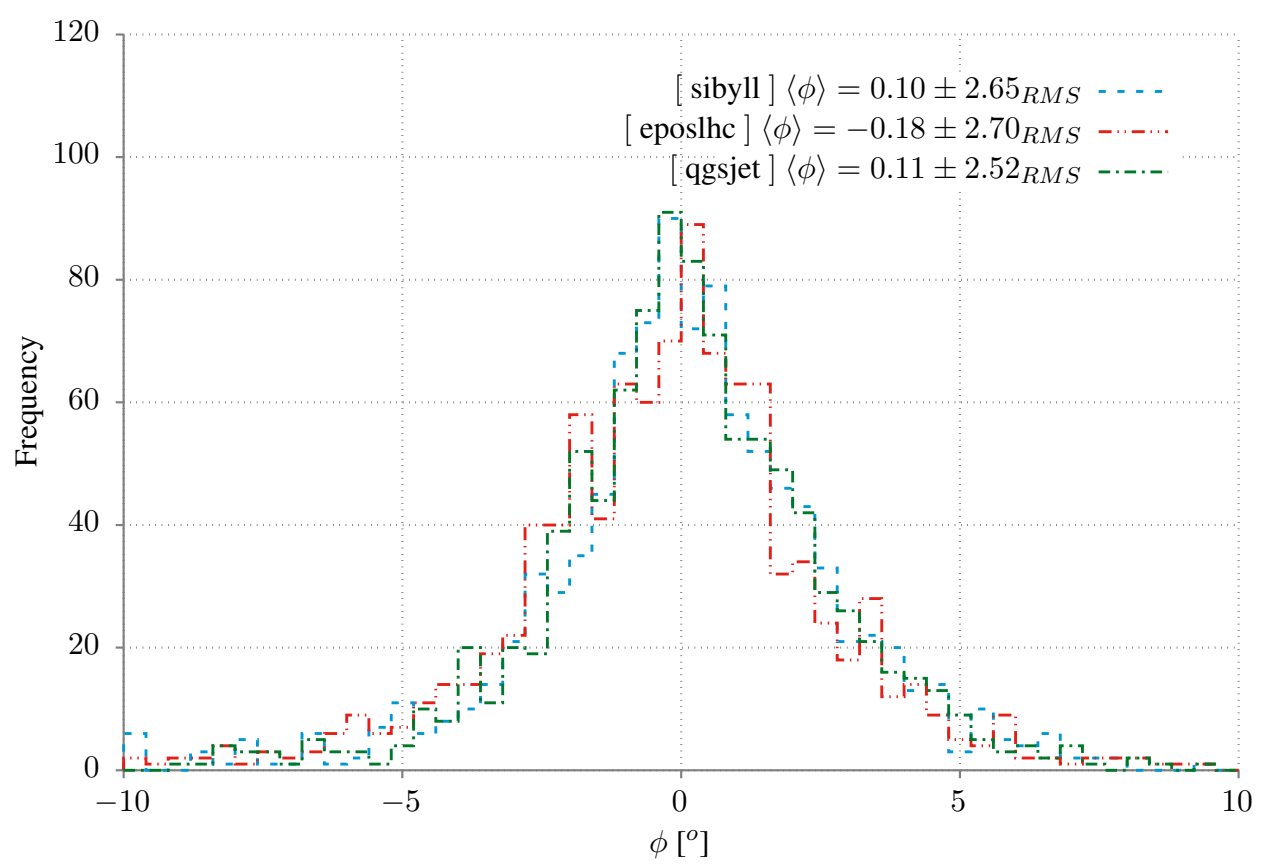

Figura 6.14: Reconstrução da distribuição de $\phi$ para os modelos de interação hadrônica SIBYLL2.3(azul), EPOSLHC(vermelho) e QGSJETII-04(verde). Foram reconstruídos 1000 EAS inciados por próton com energia de $10^{19} \mathrm{eV}$ e inclinação $\theta=60^{\circ}$ e $\phi=0^{\circ}$.

04 respectivamente. Claramente, vemos que o processo de reconstrução de $N_{19}$ apresenta um

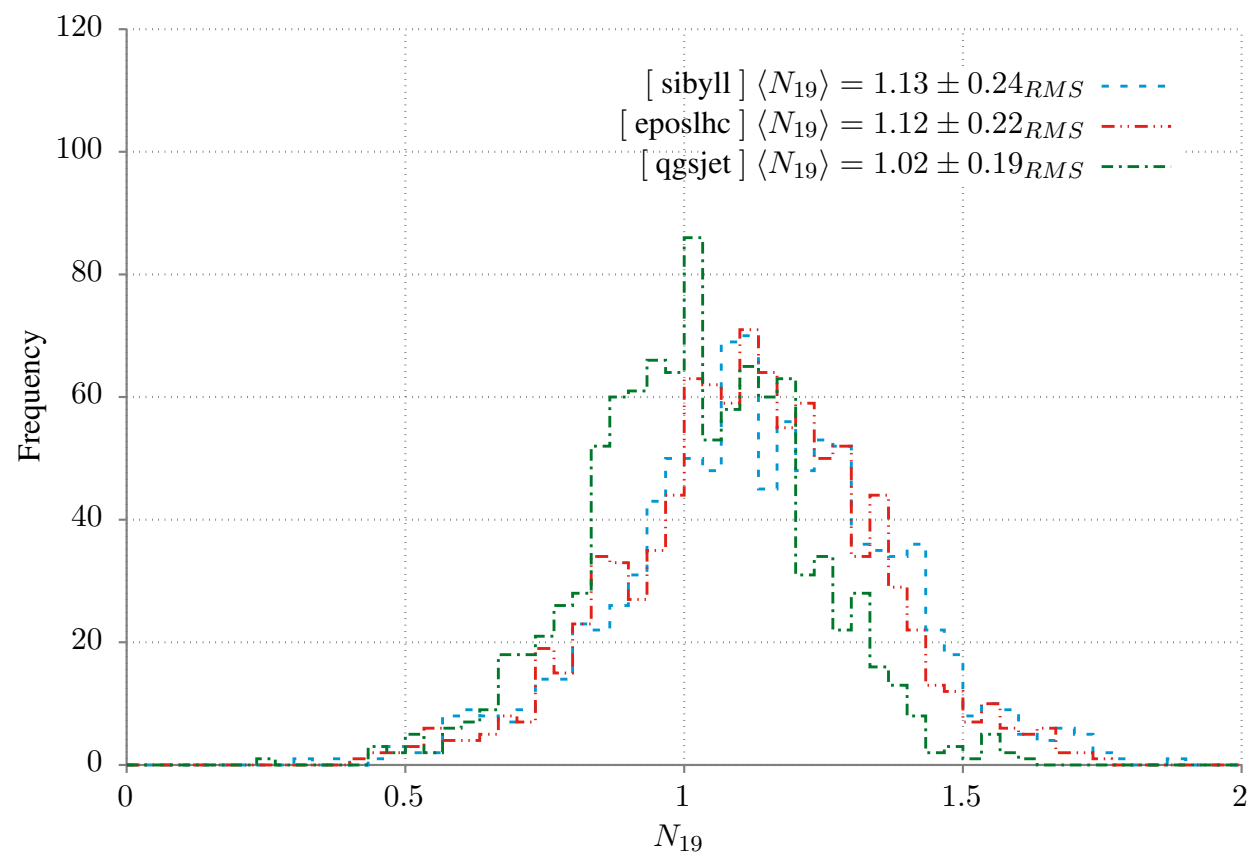

Figura 6.15: Reconstrução da distribuição de $N_{19}$ para os modelos de interação hadrônica SIBYLL2.3(azul), EPOSLHC(vermelho) e QGSJETII-04(verde).Foram reconstruídos 1000 EAS inciados por próton com energia de $10^{19} \mathrm{eV}$ e inclinação $\theta=60^{\circ}$ e $\phi=0^{\circ}$. 
viés de aproximadamente 0.1 para todos os modelos. Esse desvio relativo na reconstrução de $N_{19}$, é conhecido e foi estudado em [11], onde é suposto que a maior fonte de incerteza pode estar associada ao perfil de densidade de referência $\left(\rho_{\mu, 19}\right)$. Para resolver esse problema, a Colaboração Pierre Auger construiu um estimador não enviesado para o número total de múons no solo que fosse independente do modelo e do ângulo de inclinação do EAS. Para esse estimador, usaram um polinômio de segunda ordem para corrigir $N_{19}$ reconstruído com precisão de $3 \%$ para todos os modelos.

\subsubsection{Evolução em função da energia}

Ao final, é mostrada na 6.16 , a reconstrução do observável $N_{19}$ para chuveiros com energia entre $10^{18.5}$ e $10^{19.5} \mathrm{eV}$ iniciados por raios cósmicos com composição química próton ou ferro. A diferença na reconstrução de $N_{19}$ é constante, independente do intervalo de energia estudado e, além disso, todas apresentaram um viés de aproximadamente 0.1. Assim, como na análise os modelos SIBYLL2.3 e EPOSLHC possuem um número de múons próximo. Já o QGSJETII-04 apresenta um número menor de múons em todo intervalo.

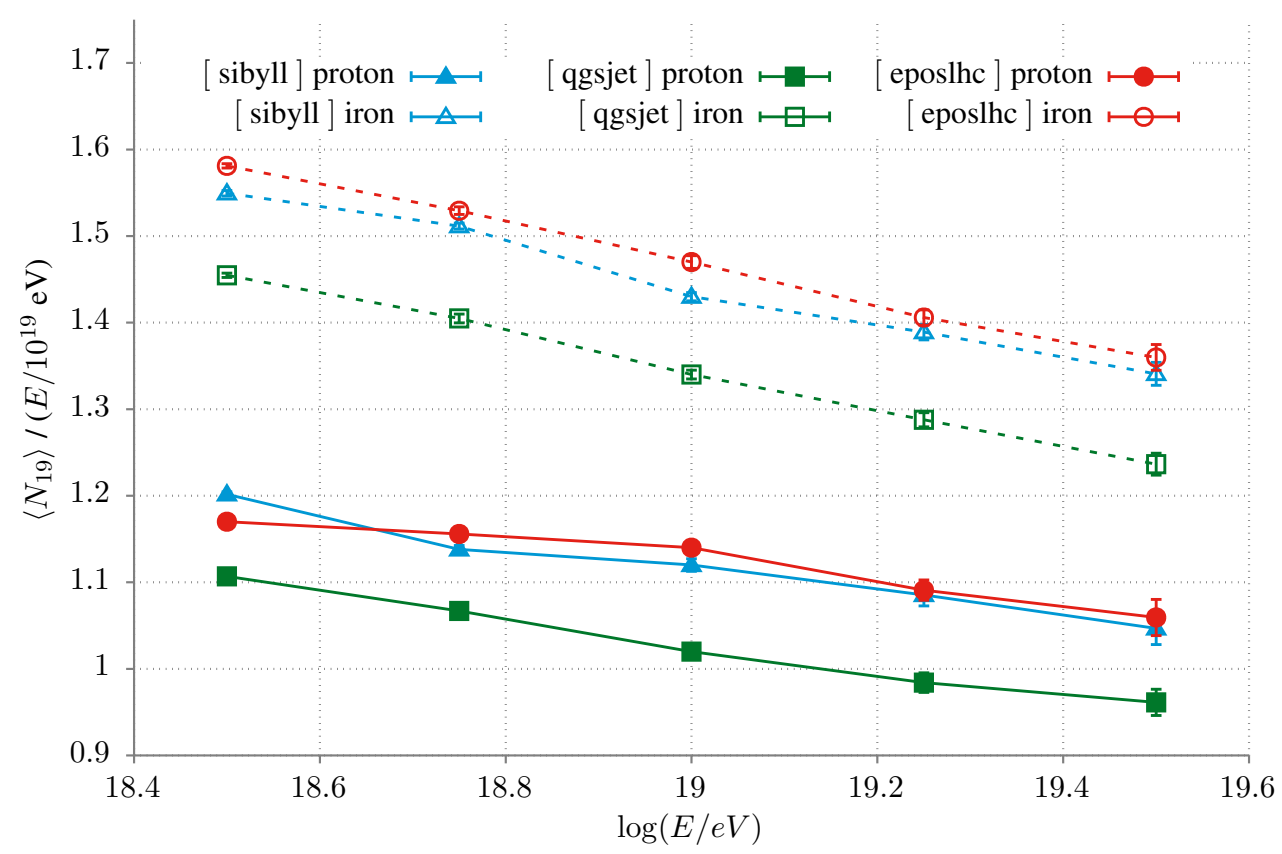

Figura 6.16: Evolução da reconstrução do número de múons para chuveiros com energia entre $10^{18.5}$ até $10^{19.5} \mathrm{eV}$ e ângulo $\theta=60^{\circ} \mathrm{e} \phi=0^{\circ}$. Em vermelho é mostrado o resultado da reconstrução para o modelo interações hadrônicas EPOSLHC, em azul, SIBYLL2.3 e em verde, QGSJETII. 


\section{Capítulo 7}

\section{Conclusões}

Um dos estudos realizados nessa tese mostrou que os observáveis de EAS são insensíveis às mudanças na distribuição de pseudorapidez das partículas secundárias produzidas na primeira interação. As alterações foram realizadas na região frontal da distribuição de pseudorapidez das partículas secundárias e conservou-se a energia total, assim como o número total de partículas. Dessa forma, modificou-se a direção de saída das partículas secundárias no referencial de laboratório e, consequentemente, tais partículas secundárias possuem uma distribuição de energia diferente no referencial de laboratório.

Contudo, as variações nos observáveis foram pequenas, menores que o erro estatístico para uma amostra de 1000 chuveiros. Espera-se que a diferença entre as novas distribuições em relação à original para os observáveis $\left\langle X_{\max }\right\rangle$ e $\left\langle X_{m a x}^{\mu}\right\rangle$ seja menor que $2 \mathrm{~g} / \mathrm{cm}^{2}$. Enquanto isso, para o observável $\left\langle\rho_{1000}\right\rangle$ deverá ser menor que 0.006 múons $/ \mathrm{m}^{2}$ e o $\left\langle N_{19}\right\rangle$ menor que 0.006. Esses valores são muito pequenos e inacessíveis experimentalmente. Dessa forma, podemos dizer que o desenvolvimento subsequente da cascata atenua rapidamente as variações introduzidas na sua primeira geração de partículas. As mudanças na distribuição de pseudorapidez aqui implementadas representam situações extremas, provavelmente além dos vínculos atuais da região frontal e na própria região central. O tratamento adotado também foi puramente fenomenológico, no sentido de que não nos preocupamos com a origem teórica de uma possível alteração na distribuição de pseudorapidez na região frontal. O objetivo principal foi testar a sensibilidade de observáveis da cascata a mudanças de parâmetros nessa região.

Esse modelo de modificação da distribuição $d N / d \eta$ também foi testado em situações extremas. Concentramos todas as partículas secundárias na região frontal ou na central e os resultados não foram diferentes. Todos as mudanças inseridas na primeira interação se diluim e desaparecem durante o desenvolvimento do chuveiro. Ou seja, mudanças no momento das partículas secundárias produzidas na primeira interação não alteram os observáveis de 
chuveiro atmosféricos estudados nesta tese.

Precisamos ter cuidado com essa conclusão, pois ela é limitada ao cenário estudado. Neste trabalho estudamos um único cenário de composição química pura de ferro ou próton. Porém, a composição química exata de UHECR não é bem compreendida até o momento. Por exemplo, dados do Observatório Pierre Auger[39], mostram algumas evidências do número de massa média para um intervalo de energia. Estudos sobre esse cenário de composição mista podem inserir novas incertezas que não foram exploradas nesta tese. Outro cenário não explorado nesta tese foi modificações na distribuição $d N / d \eta$ que não conservassem a multiplicidade ou a elasticidade da primeira interação. Como discutido na referência [15], parâmetros das interações hadrônicas, como a seção de choque, multiplicidade, elasticidade e razão de carga impactam no desenvolvimento do desenvolvimento de EAS. Esses parâmetros além de alterar os observáveis do desenvolvimento longitudinal, também poderiam alterar a distribuição de pseudorapidez e os observáveis da componente muônica estudados nesta tese.

Realizamos também um estudo dos principais modelos de interações hadrônicas utilizados em simulações de chuveiros atmosféricos. A análise mostrou que a componente muônica dos chuveiros é diferente para cada modelo. O estudo mostrou que as diferenças observadas entre os modelos são também dependentes da distância ao eixo da cascata. Por exemplo, para chuveiros com energia de $10^{19} \mathrm{eV}$ iniciados por próton com inclinação de $\theta=60^{\circ} \mathrm{e}$ $\phi=0^{\circ}$, a densidade lateral de múons mostrou uma diferença da ordem de $10 \%$ entre os modelos EPOSLHC e SIBYLL2.3 quando comparados ao QGSJETII-04, para densidade lateral de múons em torno de 1000 m. Além disso, perto do ponto de impacto do chuveiro, os três modelos mostraram uma densidade lateral de múons diferente. O desenvolvimento longitudinal da cascata também apresentou diferenças entre os modelos que vão de $0 \%$ a $20 \%$ dependendo da profundidade atmosférica. Na região próxima ao ponto da primeira interação, a diferença chega a ser da ordem de $60 \%$. A diferença encontrada na produção de múons em função da profundidade atmosférica chegou até 30\% entre os modelos EPOSLHC e quando comparados com o QGSJETII-04. Assim como na distribuição lateral de múons, a produção de múons perto do ponto da primeira interação apresentou uma diferença da ordem de 20\% na comparação -EPOSLHC, 60\% na comparação SIBYLL2.3-QGSJETII e 90\% na comparação QGSJETII-04-EPOSLHC. Os observáveis $X_{\max }, X_{\max }^{\mu}, \rho_{1000}$ e $N_{19}$ também são diferentes para os três modelos, como mostrado nas figuras 4.4, 4.9, 4.13 e 4.7. Além disso, as diferenças nesses observáveis se mantêm praticamente constantes no intervalo de energia entre $10^{18.5}$ e $10^{19.5}$ eV para composições químicas puras de próton ou ferro.

Para uma comparação mais direta com dados de observatórios de raios cósmicos e para estimar a incerteza introduzida pelo processo de reconstrução do conteúdo muônico de um chuveiro, incluímos dois efeitos de detector sobre a variável $N_{19}$ : a granularidade da rede de 
detectores e a área de coleção dos detectores da rede. Tais efeitos de detector levaram a uma reconstrução com um pequeno viés em $N_{19}$, correspondente a uma diferença observada entre o valor médio reconstruído e o valor verdadeiro de 0.1 para todos os modelos. Esse desvio é conhecido e foi estudado em [73], onde é suposto que a maior fonte de incerteza pode estar associada ao perfil de referência da densidade de múons $\left(\rho_{19}\right)$. Na mesma referência, um procedimento de correção é proposto para tornar o estimador final de $N_{19}$ livre de viés. Para a estimativa de reconstrução do $N_{19}$ não foi realizado um estudo mais profundo do número de eventos mínimos necessários para distinguir os modelos de interações hadrônicas.

Ao final, podemos concluir que as diferenças observadas nas distribuições laterais de múons para os modelos estudados nesta tese poderão ser exploradas com dados do projeto AMIGA, já que este terá acesso via contagem direta de múons à função de distribuição lateral dessas partículas. Outra possibilidade interessante é a exploração experimental das diferenças acentuadas entre os modelos na região próxima ao eixo da cascata $(\sim 300 \mathrm{~m})$. Por exemplo, o plano de extensão do Observatório Pierre Auger, denominado AugerPrime [40], também prevê um aumento do alcance dinâmico de sua eletrônica que, em princípio, permitiria uma medida do sinal nos tanques de superfície nessa região sem os problemas atuais de saturação. 
Apêndice A

Análise dos observáveis 


\section{A.1 Densidade lateral de múons em função da distância ao eixo do chuveiro}

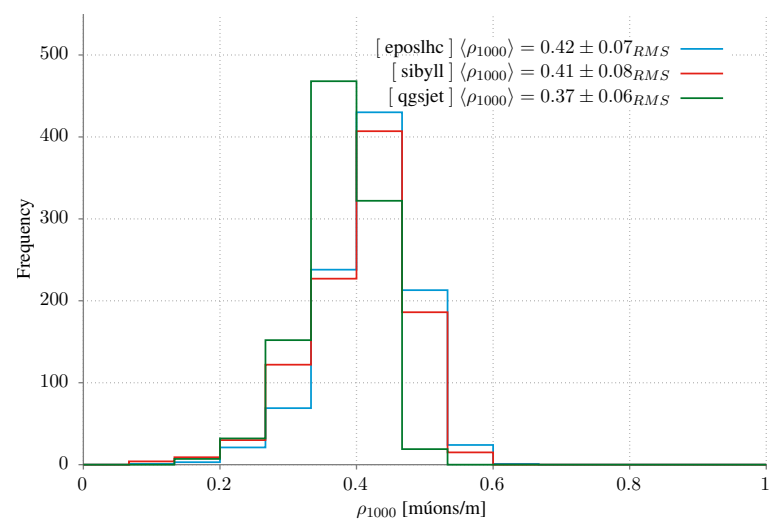

(a) Próton $10^{18.50} \mathrm{eV}$

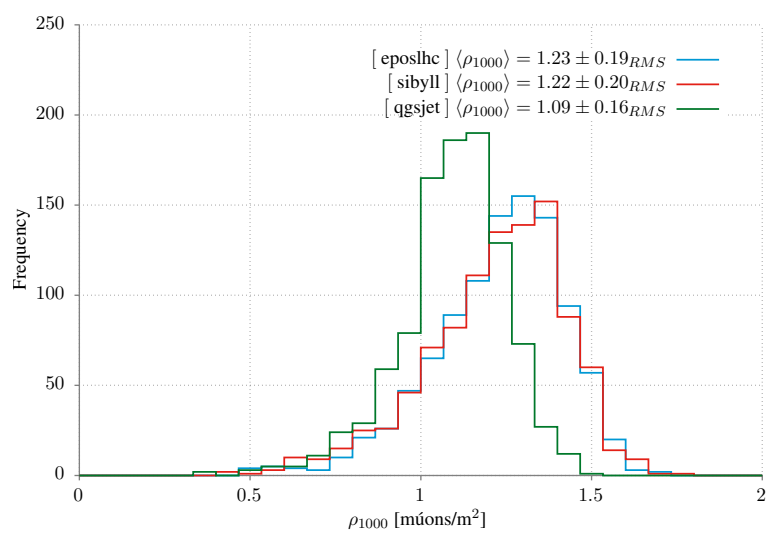

(c) Próton $10^{19.00} \mathrm{eV}$

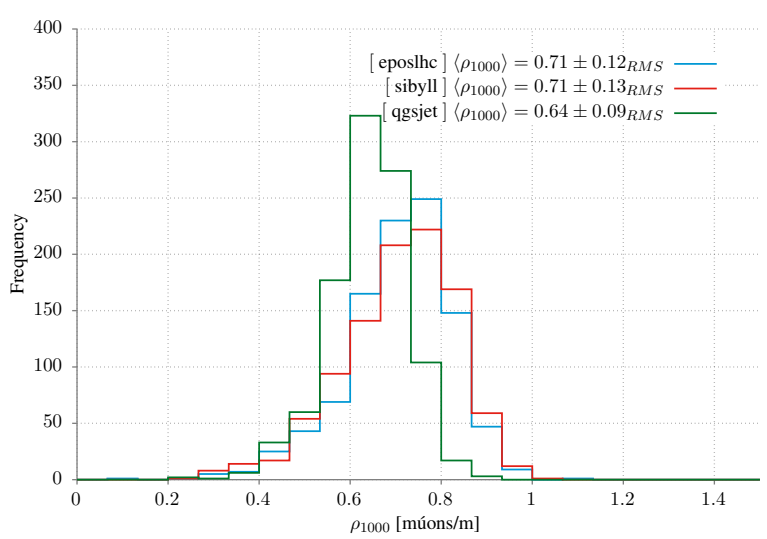

(b) Próton $10^{18.75} \mathrm{eV}$

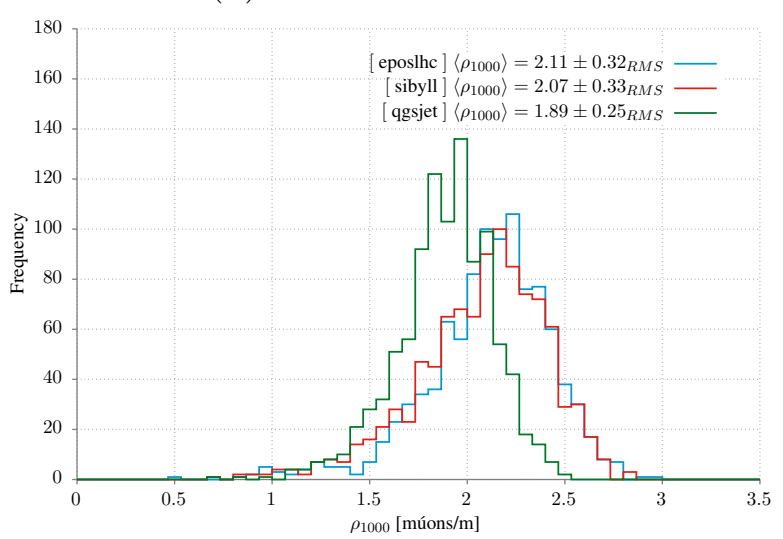

(d) Próton $10^{19.25} \mathrm{eV}$

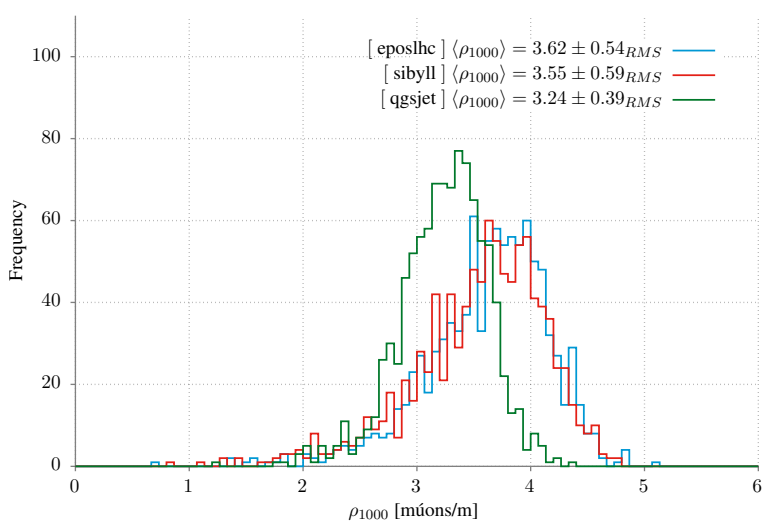

(e) Próton $10^{19.50} \mathrm{eV}$

Figura A.1: Distribuições da análises de $\rho_{1000}$ para chuveiros iniciados por próton. Esses resultados foram utilizados para geração do gráfico de $\left\langle\rho_{1000}\right\rangle$ em função da energia. 


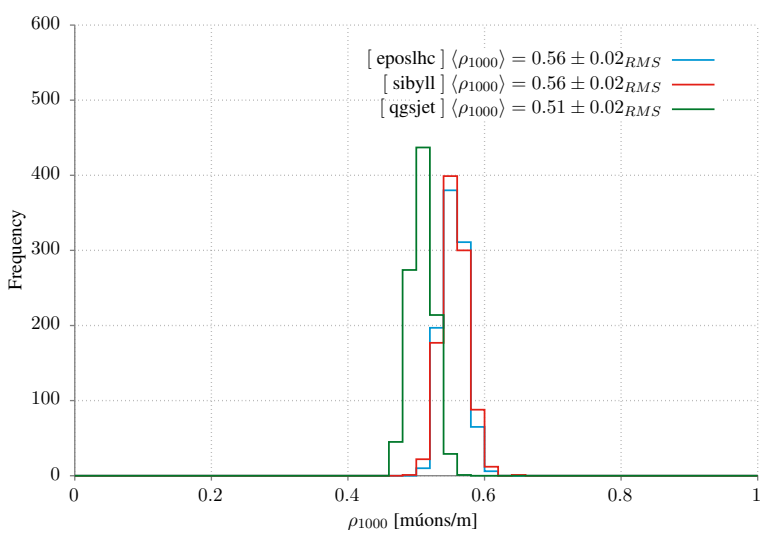

(a) Ferro $10^{18.50} \mathrm{eV}$

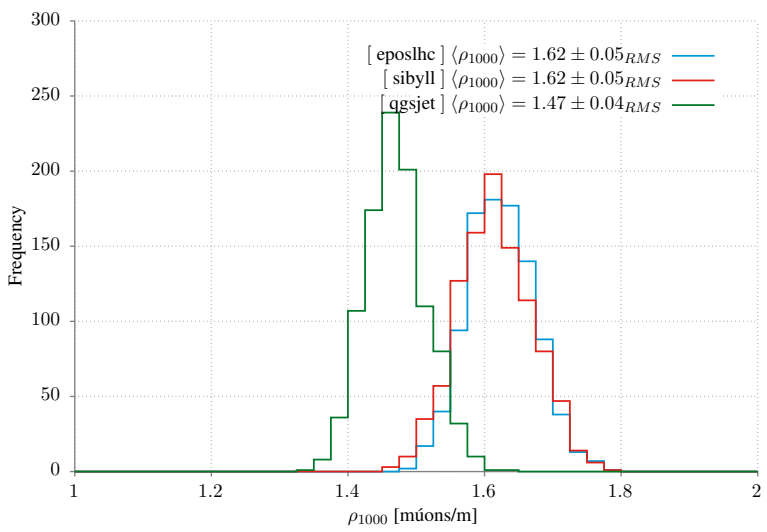

(c) Ferro $10^{19.00} \mathrm{eV}$

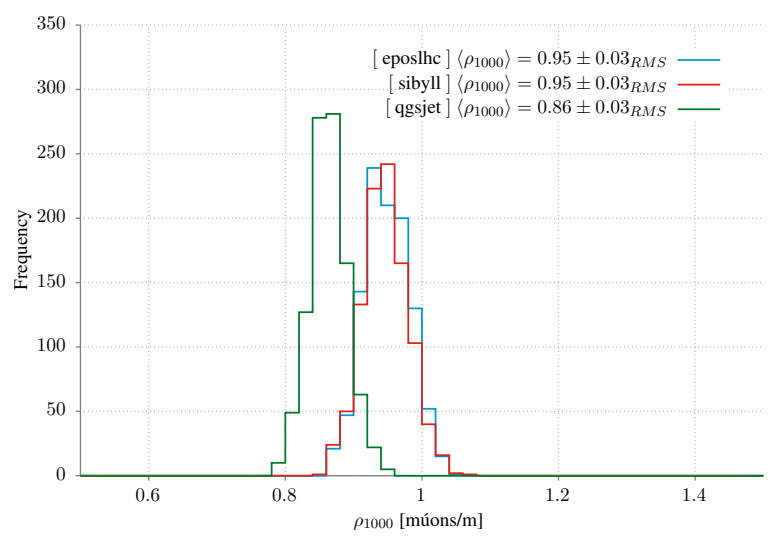

(b) Ferro $10^{18.75} \mathrm{eV}$

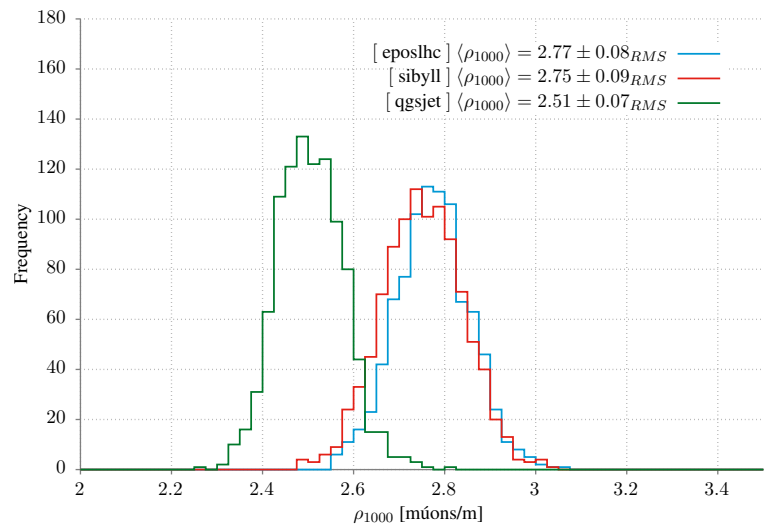

(d) Ferro $10^{19.25} \mathrm{eV}$

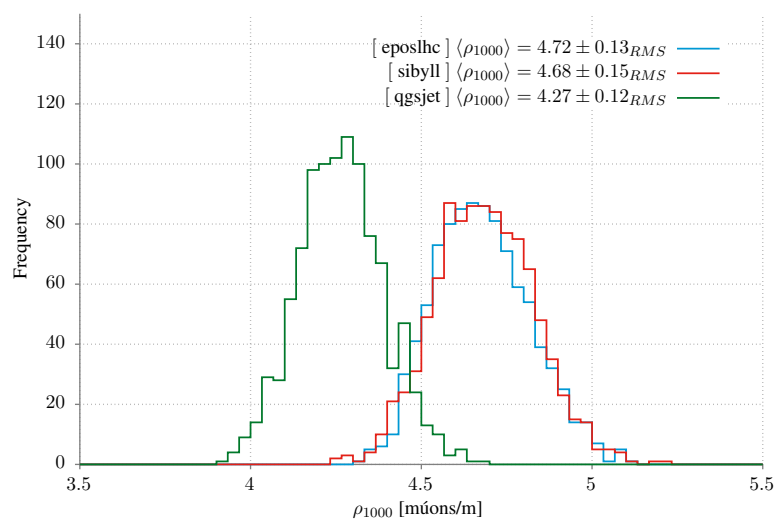

(e) Ferro $10^{19.50} \mathrm{eV}$

Figura A.2: Distribuições das análises de $\rho_{1000}$ para chuveiros iniciados por ferro. Esses resultados foram utilizados para geração do gráfico de $\left\langle\rho_{1000}\right\rangle$ em função da energia. 


\section{A.2 Produção de múons em função da profundidade atmosférica}

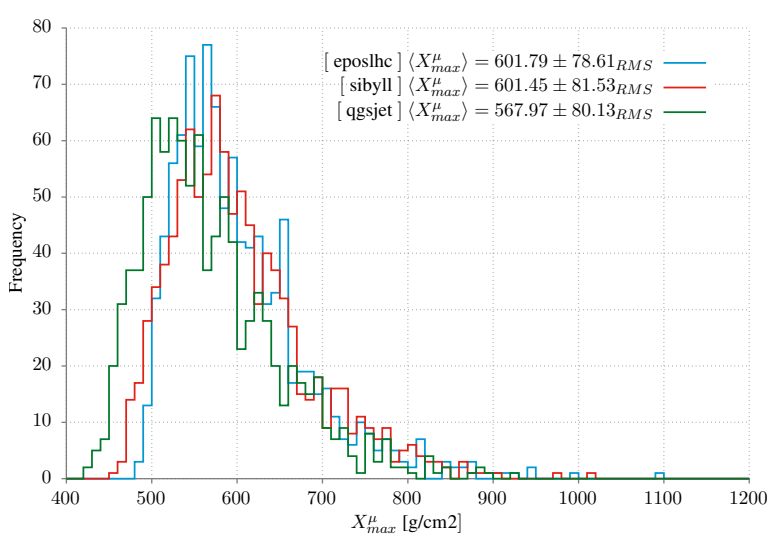

(a) Próton $10^{18.50} \mathrm{eV}$

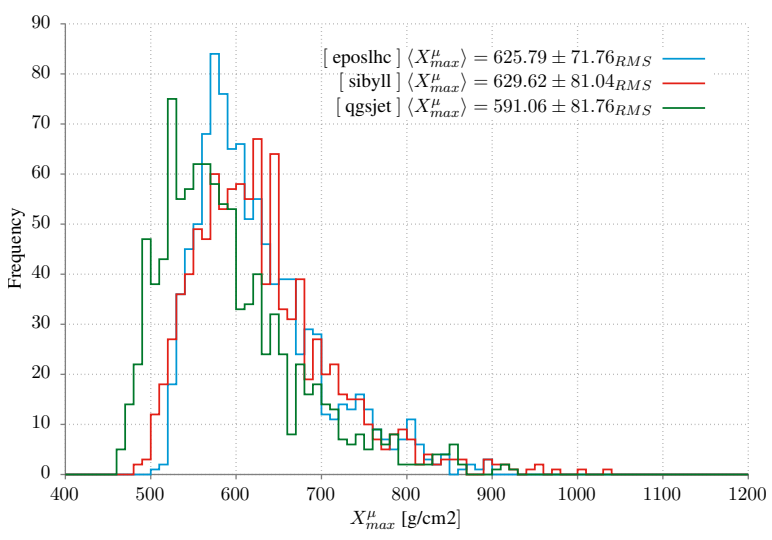

(c) Próton $10^{19.00} \mathrm{eV}$

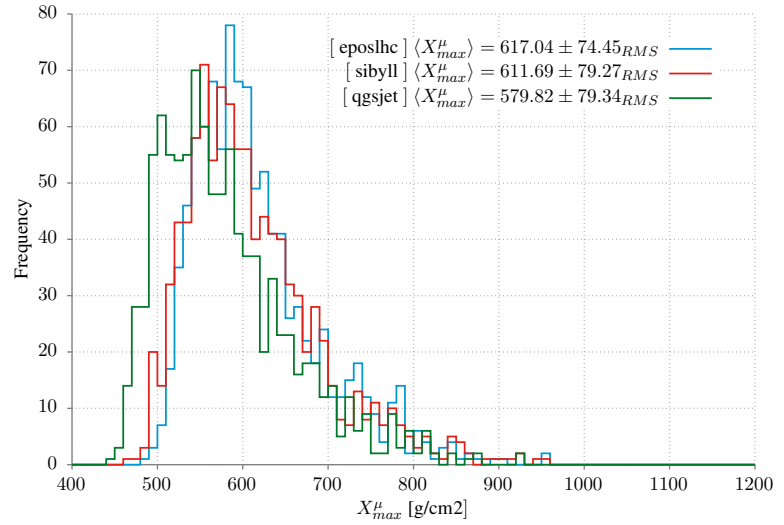

(b) Próton $10^{18.75} \mathrm{eV}$

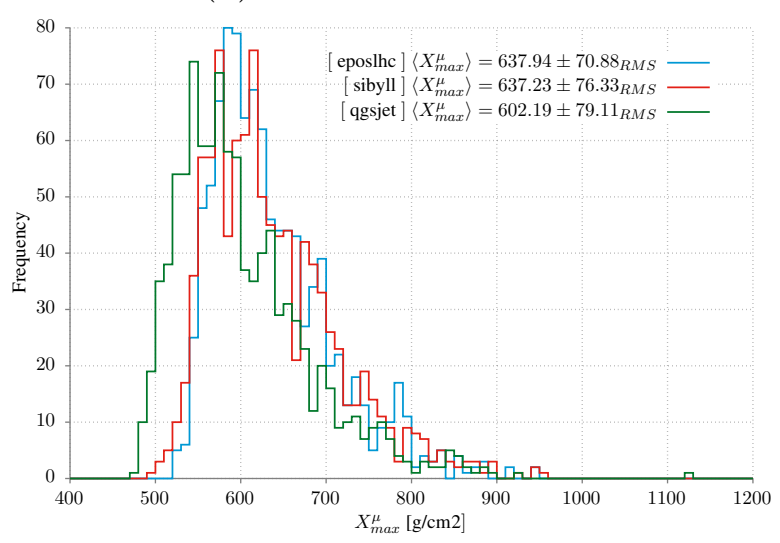

(d) Próton $10^{19.25} \mathrm{eV}$

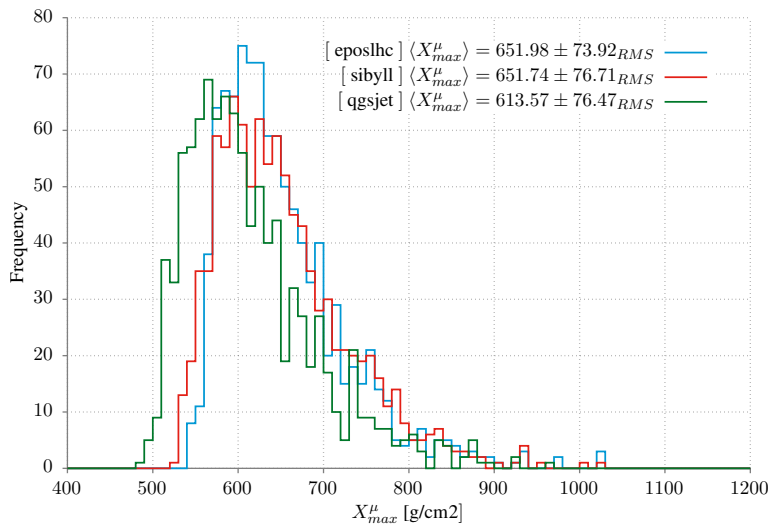

(e) Próton $10^{19.50} \mathrm{eV}$

Figura A.3: Distribuições da análises de $X_{\max }^{\mu}$ para chuveiros iniciados por próton. Esses resultados foram utilizados para geração do gráfico de $\left\langle X_{\max }^{\mu}\right\rangle$ em função da energia. 


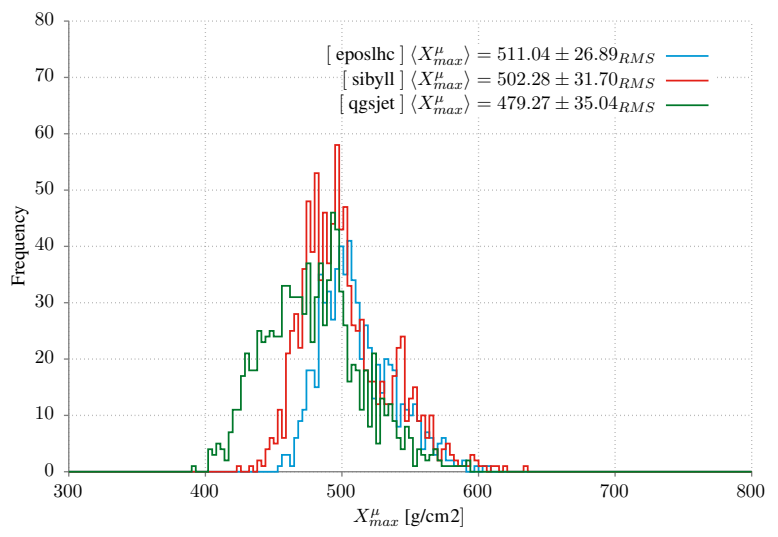

(a) Ferro $10^{18.50} \mathrm{eV}$

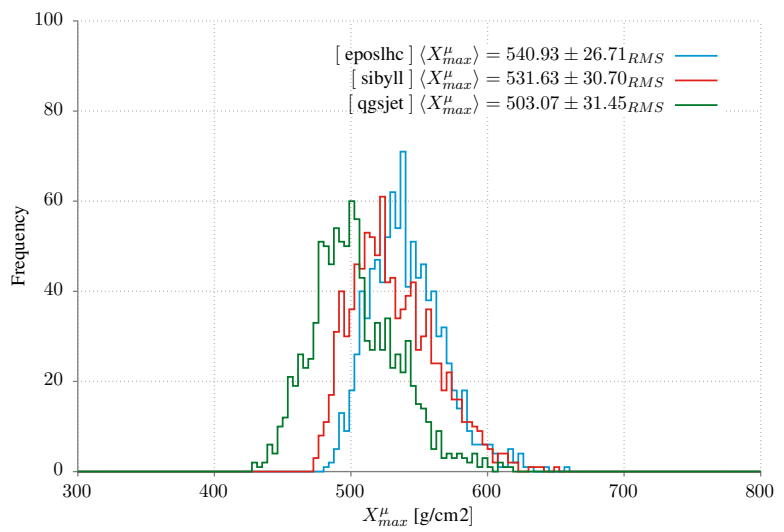

(c) Ferro $10^{19.00} \mathrm{eV}$

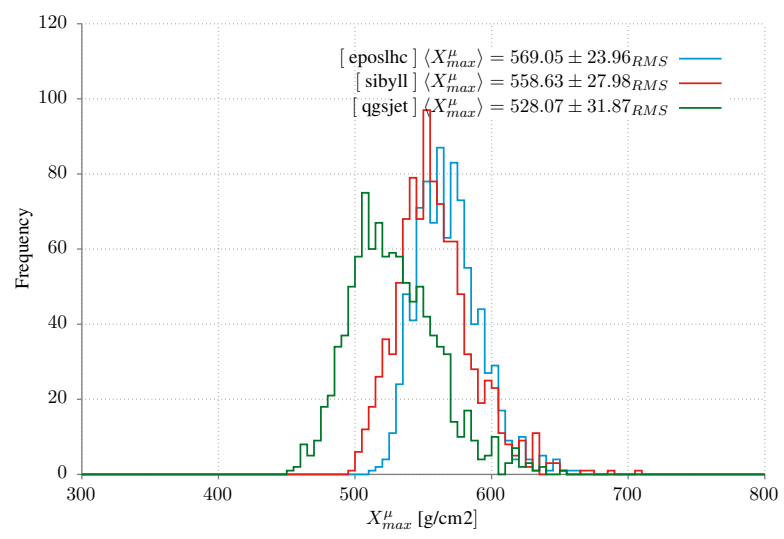

(e) Ferro $10^{19.50} \mathrm{eV}$

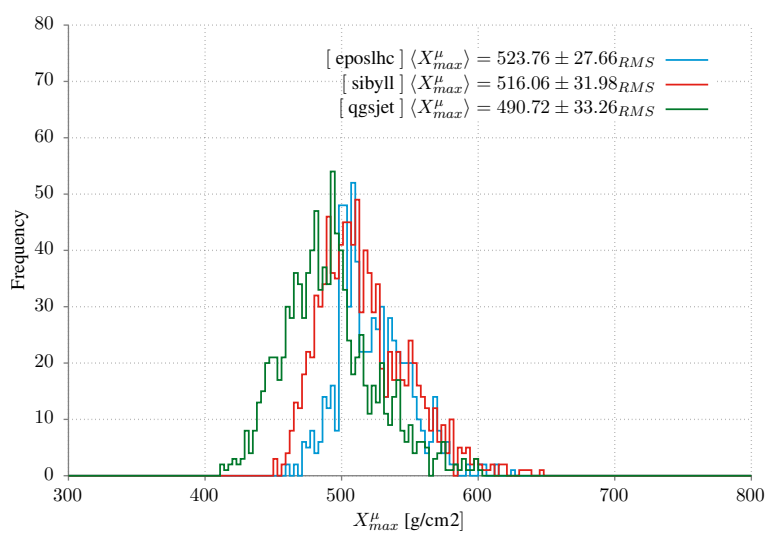

(b) Ferro $10^{18.75} \mathrm{eV}$

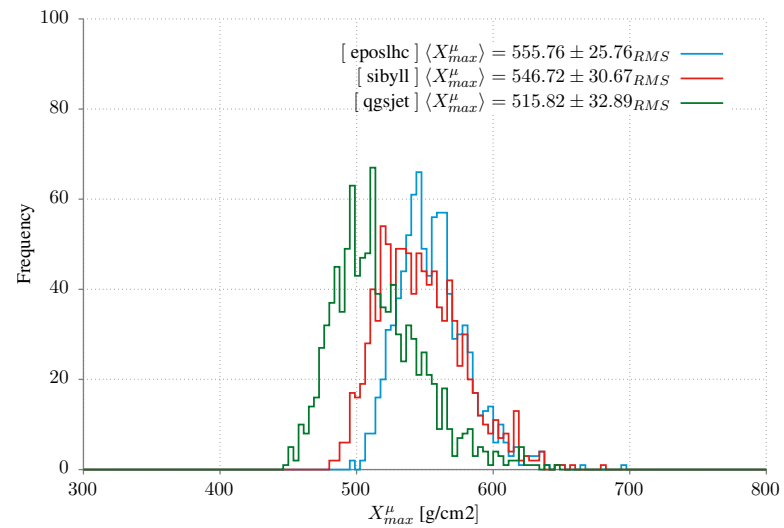

(d) Ferro $10^{19.25} \mathrm{eV}$ 


\section{A.3 Desenvolvimento longitudinal do chuveiro}

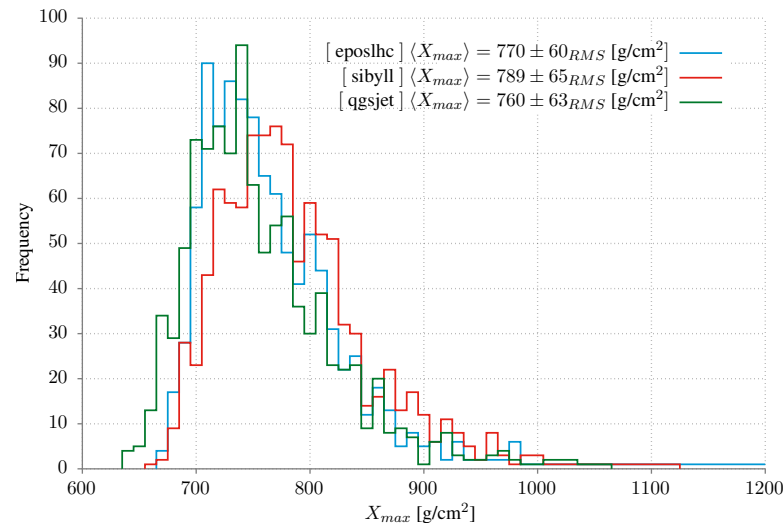

(a) Próton $10^{18.50} \mathrm{eV}$

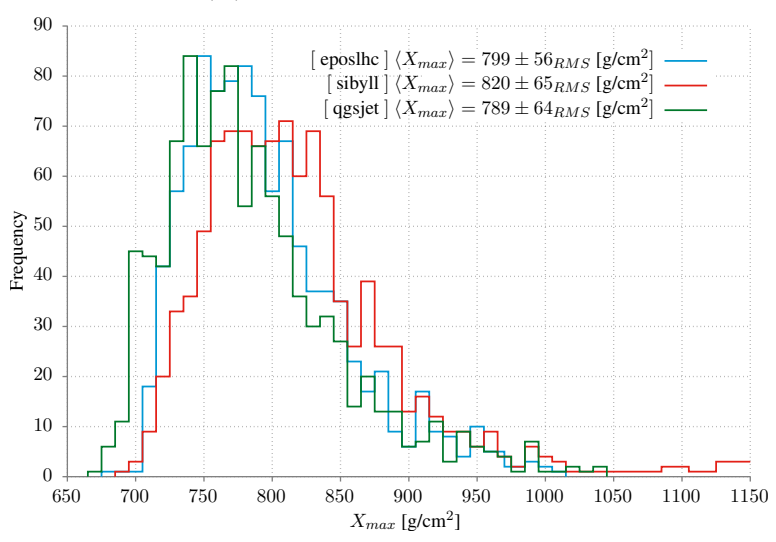

(c) Próton $10^{19.00} \mathrm{eV}$

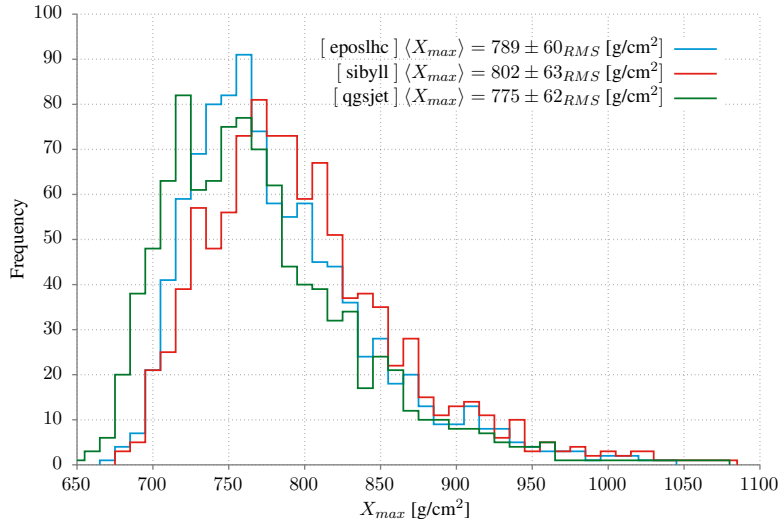

(b) Próton $10^{18.75} \mathrm{eV}$

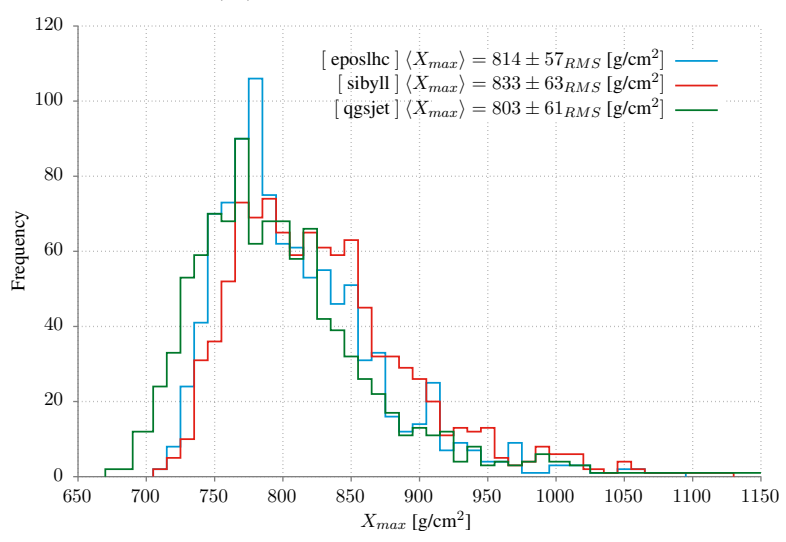

(d) Próton $10^{19.25} \mathrm{eV}$

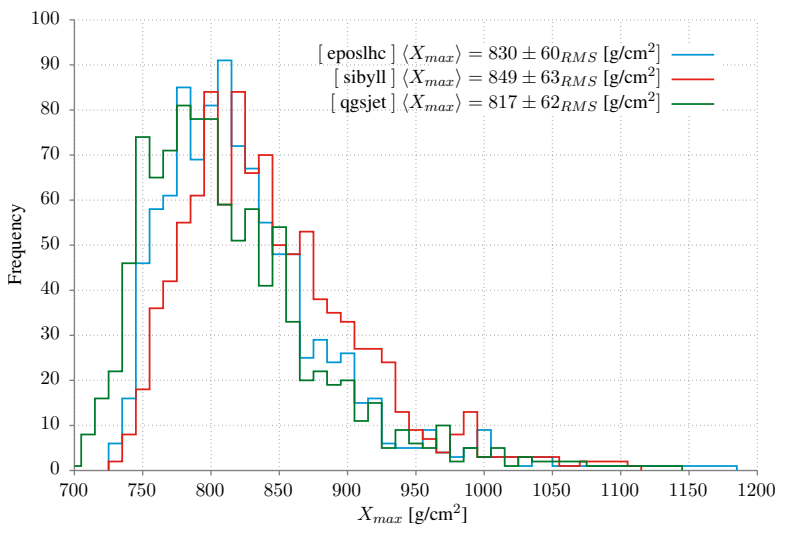

(e) Próton $10^{19.50} \mathrm{eV}$

Figura A.5: Distribuições da análises de $X_{\max }$ para chuveiros iniciados por próton. Esses resultados foram utilizados para geração do gráfico de $\left\langle X_{\max }\right\rangle$ em função da energia. 


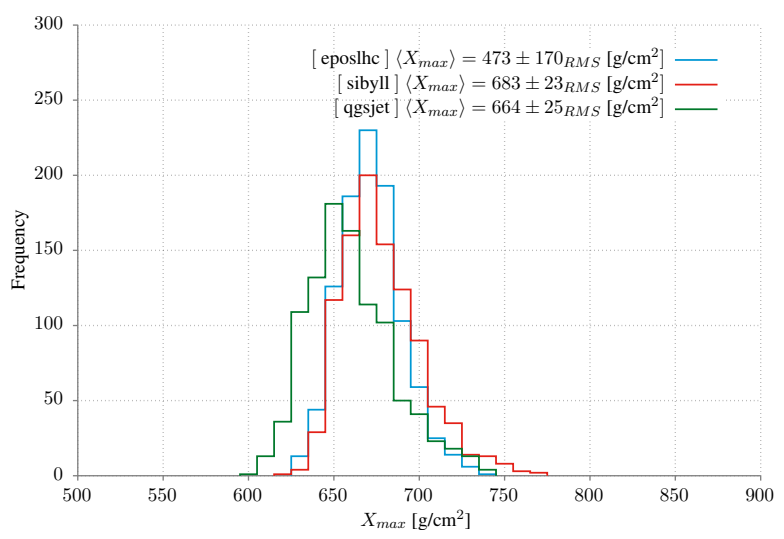

(a) Ferro $10^{18.50} \mathrm{eV}$

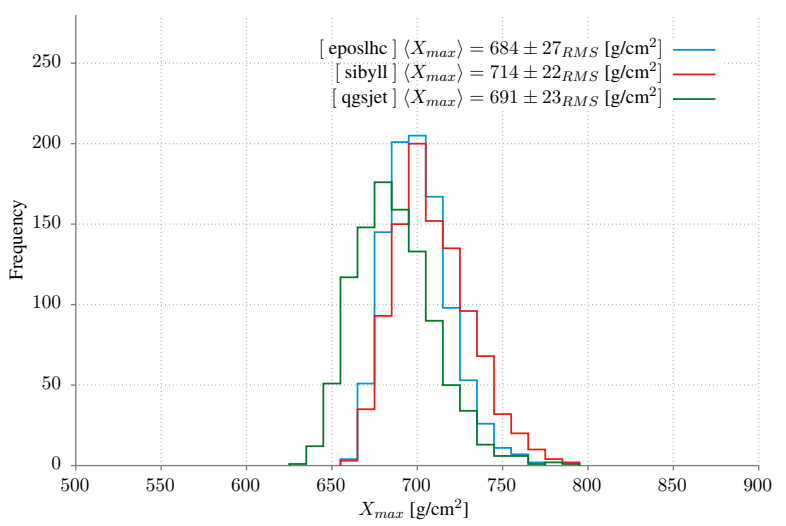

(c) Ferro $10^{19.00} \mathrm{eV}$

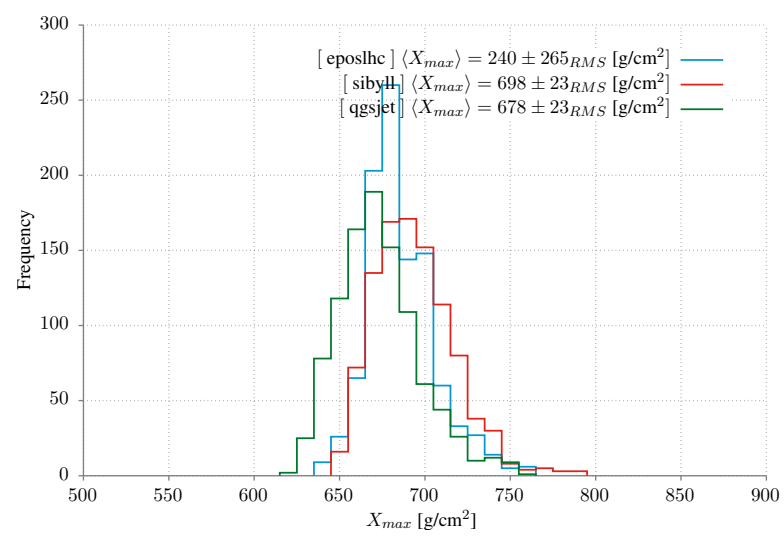

(b) Ferro $10^{18.75} \mathrm{eV}$

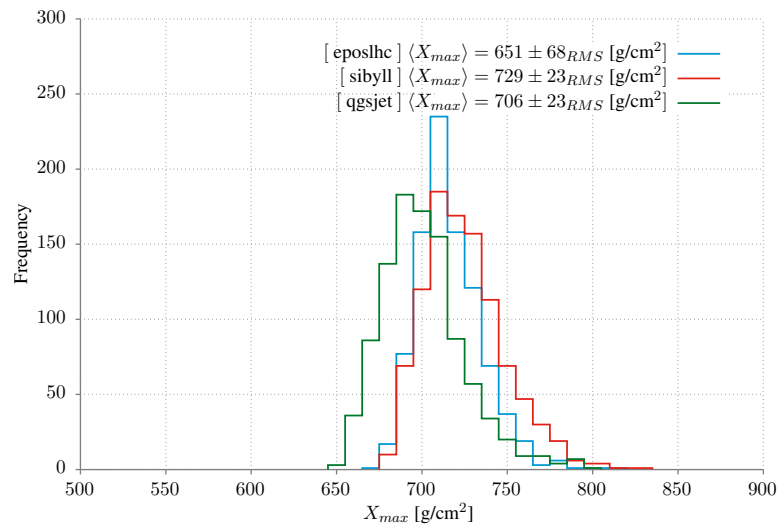

(d) Ferro $10^{19.25} \mathrm{eV}$

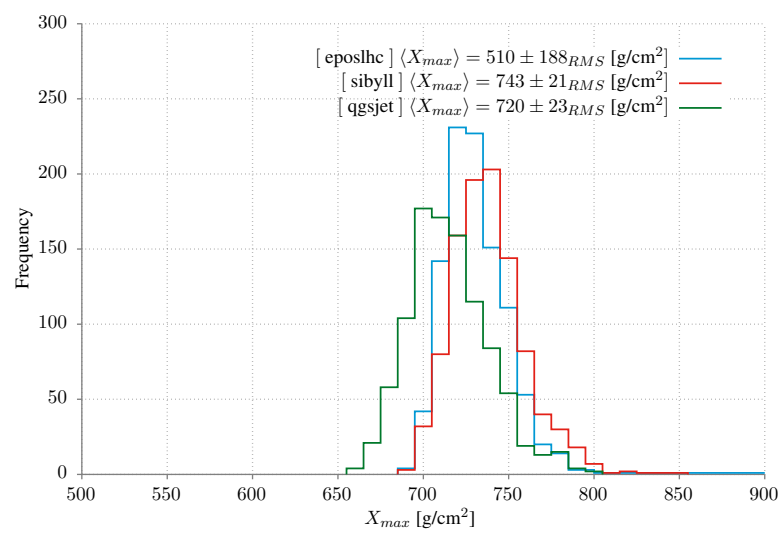

(e) Ferro $10^{19.50} \mathrm{eV}$

Figura A.6: Distribuições das análises de $X_{\max }$ para chuveiros iniciados por ferro. Esses resultados foram utilizados para geração do gráfico de $\left\langle X_{\max }\right\rangle$ em função da energia. 


\section{A.4 Número de múons no nível de observação}

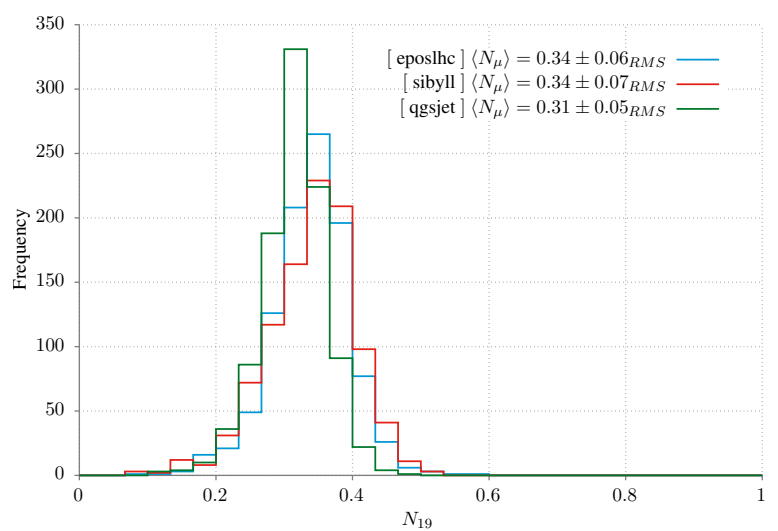

(a) Próton $10^{18.50} \mathrm{eV}$

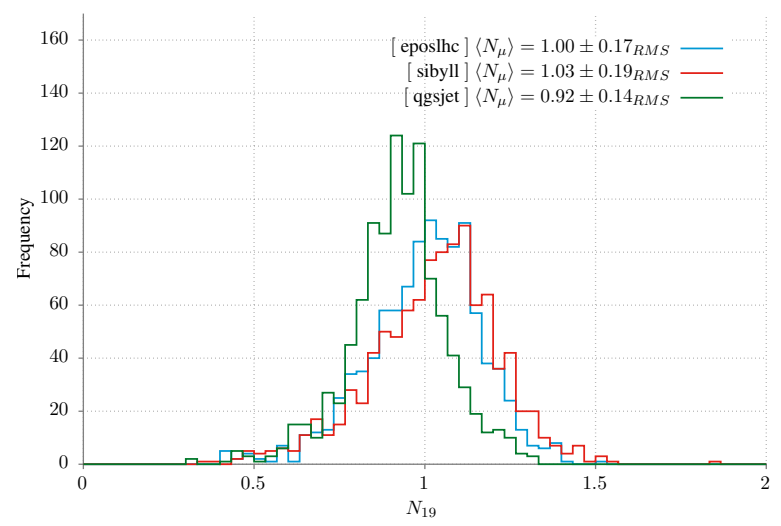

(c) Próton $10^{19.00} \mathrm{eV}$

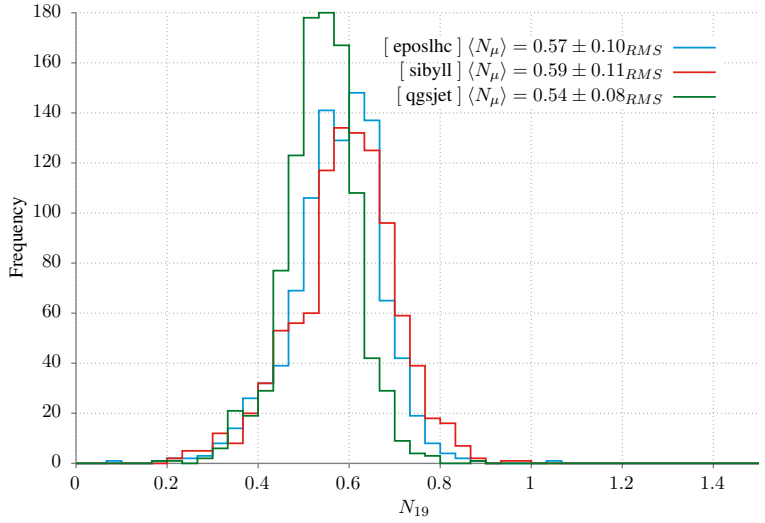

(b) Próton $10^{18.75} \mathrm{eV}$

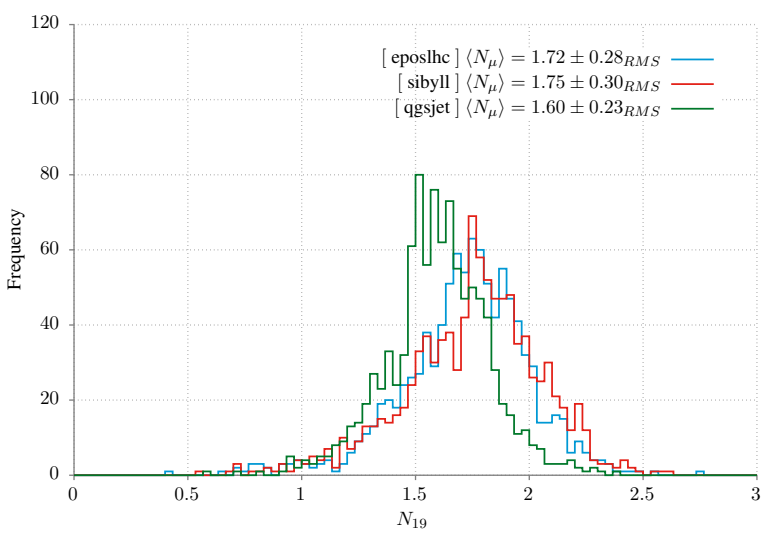

(d) Próton $10^{19.25} \mathrm{eV}$

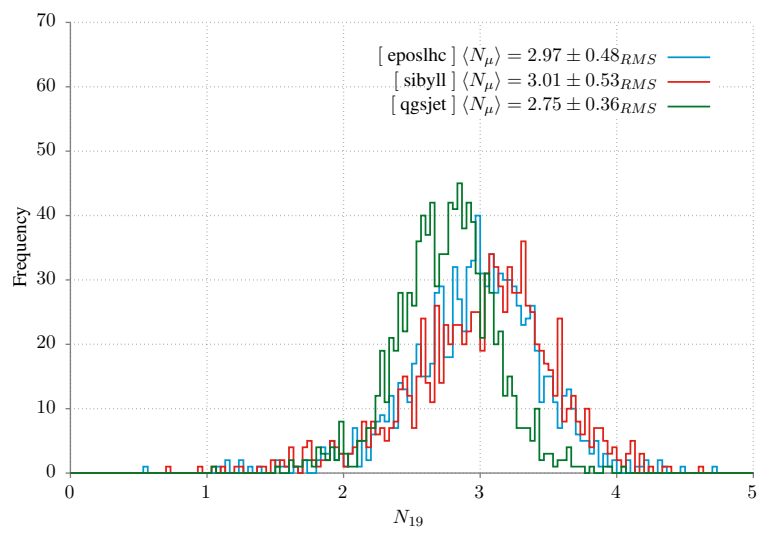

(e) Próton $10^{19.50} \mathrm{eV}$

Figura A.7: Distribuições da análises de $N_{\mu}$ para chuveiros iniciados por próton. Esses resultados foram utilizados para geração do gráfico de $\left\langle N_{\mu}\right\rangle$ em função da energia. 


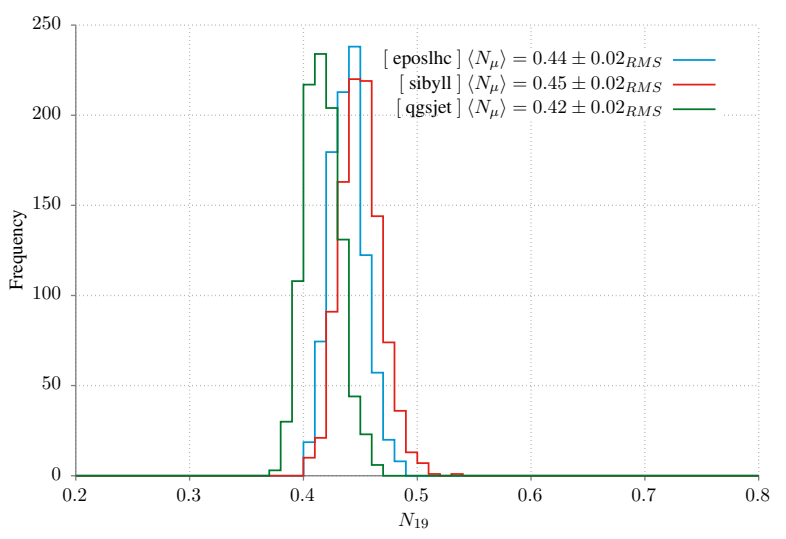

(a) Ferro $10^{18.50} \mathrm{eV}$

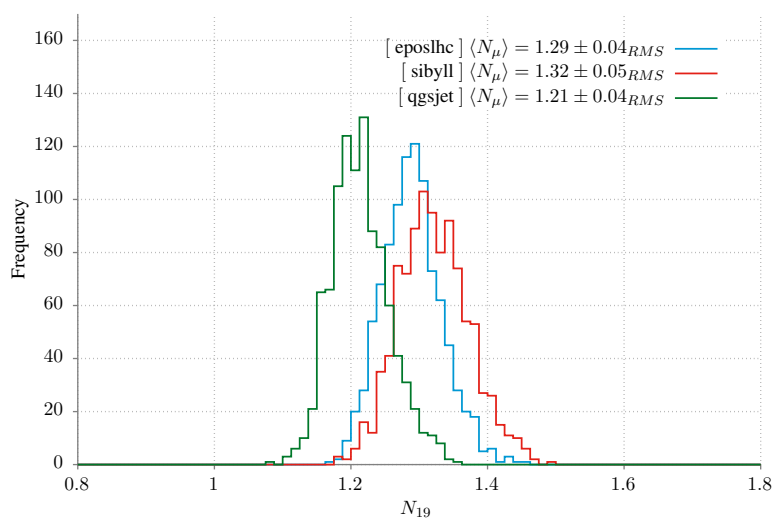

(c) Ferro $10^{19.00} \mathrm{eV}$

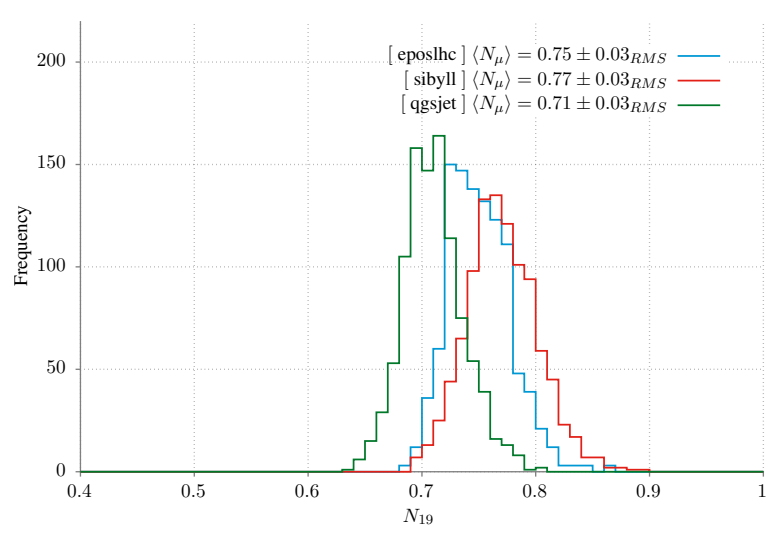

(b) Ferro $10^{18.75} \mathrm{eV}$

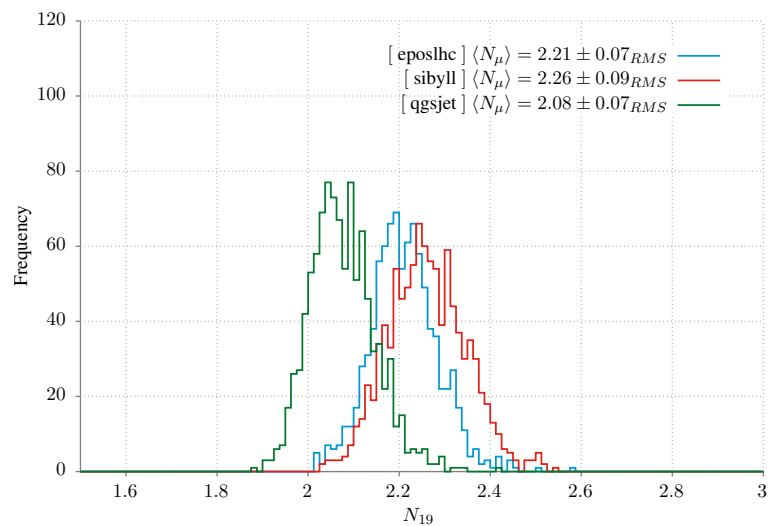

(d) Ferro $10^{19.25} \mathrm{eV}$

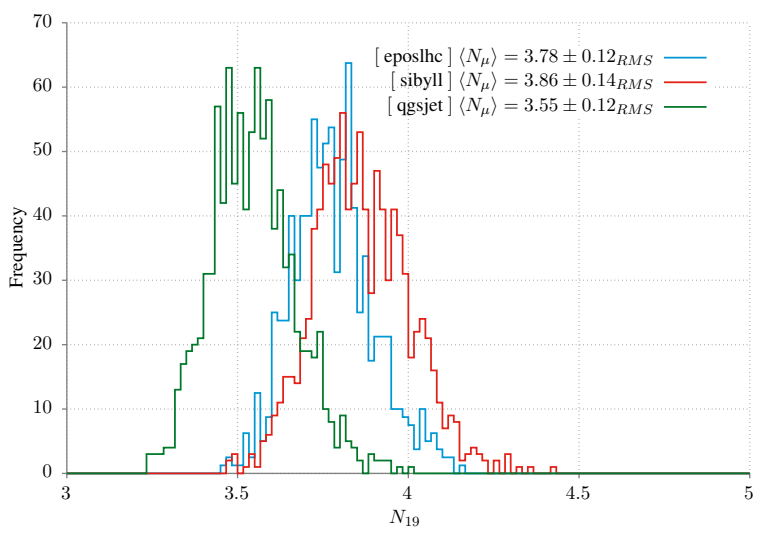

(e) Ferro $10^{19.50} \mathrm{eV}$

Figura A.8: Distribuições das análises de $N_{\mu}$ para chuveiros iniciados por ferro. Esses resultados foram utilizados para geração do gráfico de $\left\langle N_{\mu}\right\rangle$ em função da energia. 
Apêndice B

Distribuição de pseudorapidez 


\section{B.1 Distribuição de múons por intervalo de pseudora- pidez}

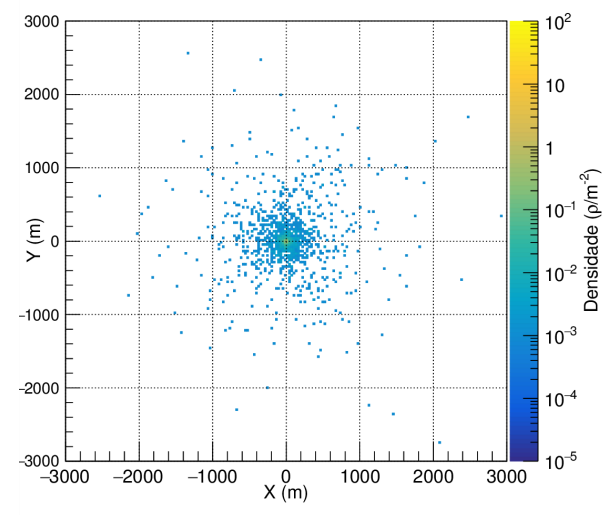

(a) $-2<\eta \leq 0$

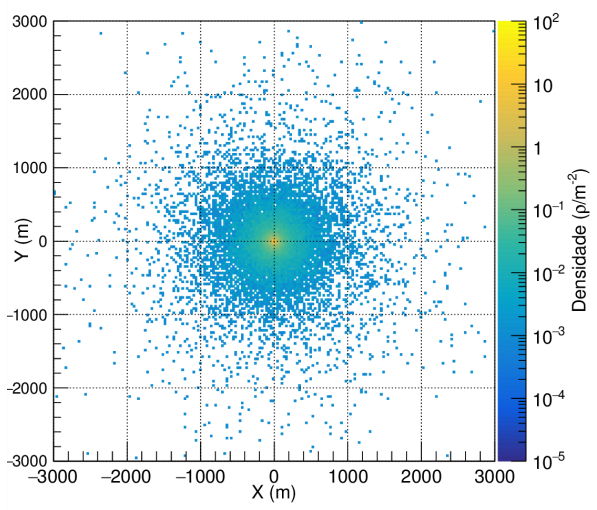

(c) $2<\eta \leq 4$

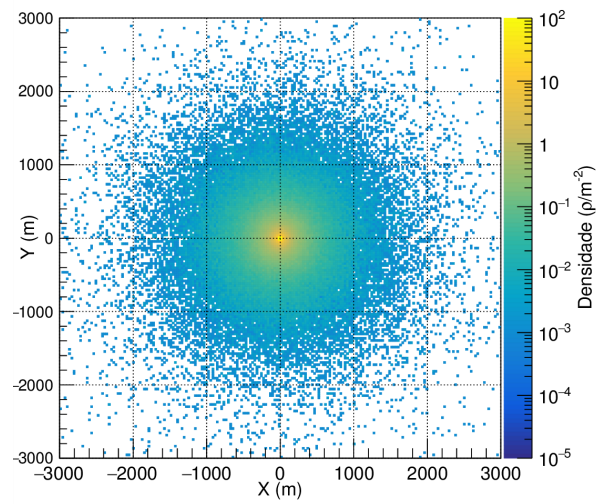

(e) $6<\eta \leq 8$

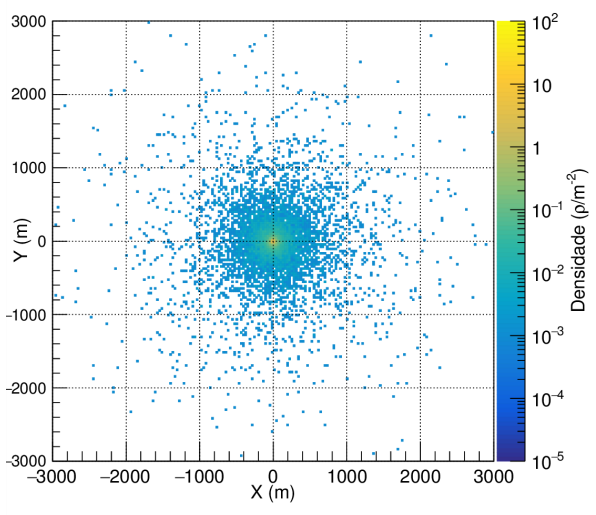

(b) $0<\eta \leq 2$

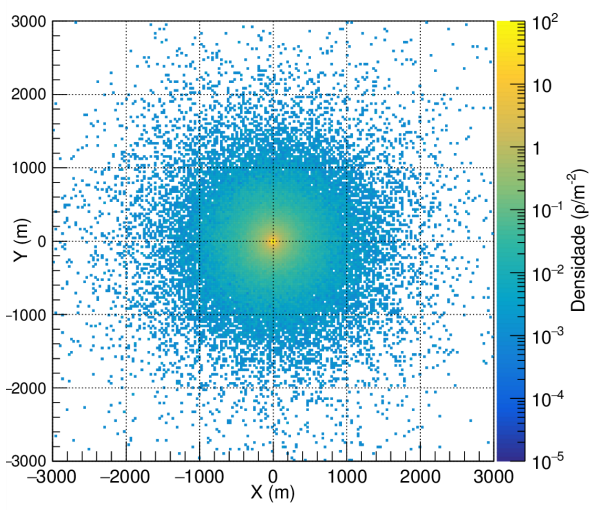

(d) $4<\eta \leq 6$

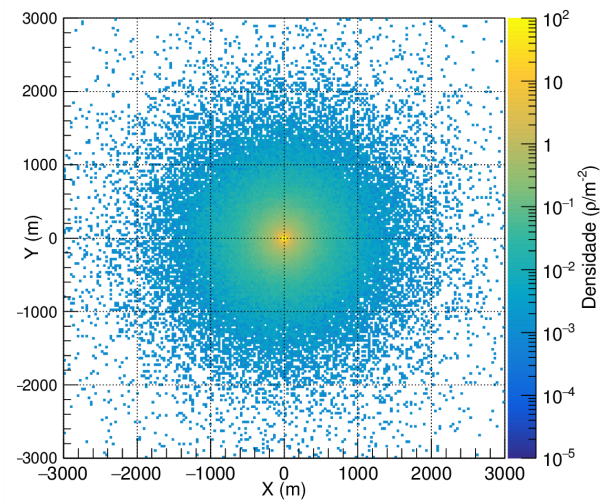

(f) $8<\eta<\infty$

Figura B.1: Mapas bidimensional da distribuição de múons no nível de observação para um chuveiro com energia de $10^{17} \mathrm{eV}$ inciado por um próton com inclinação $\theta={ }^{\circ}$. 
Apêndice $C$

Reconstrução dos observáveis 


\section{C.1 Distância radial no plano de propagação do chu- veiro}

Para determinar a distância do detector $r_{i}$ no plano de frente do chuveiro com vetor normal $\hat{n}$, precisamos definir a equação geral do plano $\pi$ que descreve a frente do chuveiro, que é dada por

$$
\pi: a x+b y+c z=d,
$$

onde $(a, b, c)$ são as componentes do versor normal ao plano $\hat{n}$, que em coordenadas esféricas são dadas por

$$
a=\sin (\theta) \cos (\phi), b=\sin (\theta) \sin (\phi) \text { e } c=\cos (\theta),
$$

e $d=-a x_{0}-b y_{0}-c z_{0} \operatorname{com}\left(x_{0}, y_{0}, z_{0}\right)$ sendo a origem do plano e a distância $r_{i}^{\prime}$ é calculada usando-se a relação de distância entre ponto e plano, dada por

$$
d=\frac{a x+b y+c z+d}{\sqrt{a^{2}+b^{2}+c^{2}}}=u x+v y .
$$

Enfim, conhecido $\rho_{i}=\sqrt{x_{i}^{2}+y_{i}^{2}}$ e a distância do ponto ao plano $r_{i}^{\prime}$, podemos calcular $r_{i}$ pela seguinte equação

$$
r_{i}^{2}=\rho_{i}^{2}-r_{i}^{\prime 2} .
$$

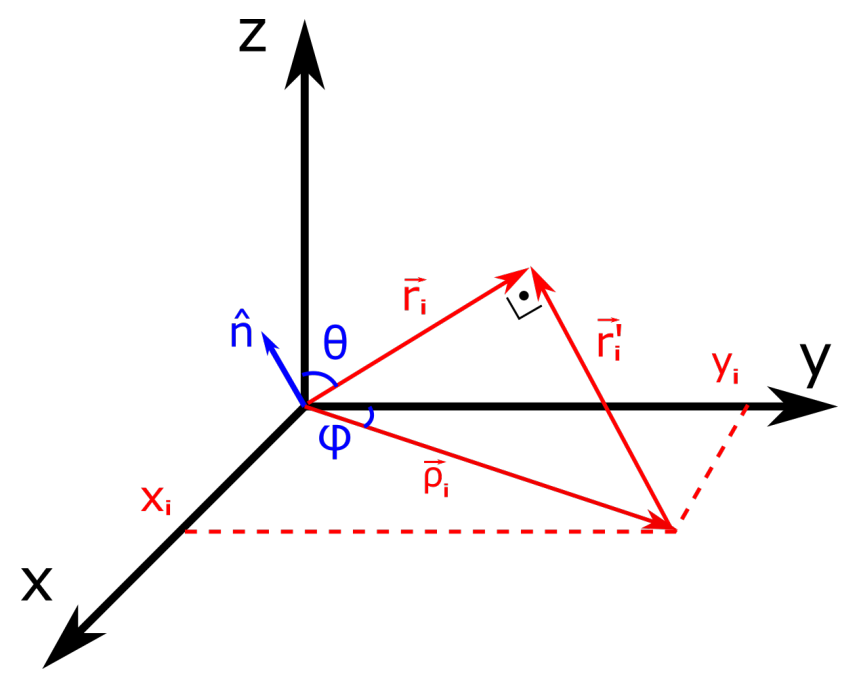

Figura C.1: Representação geométrica da propagação da frente de chuveiro plana. 


\section{C.2 Tamanho do chuveiro médio $\left(N_{19}\right)$}

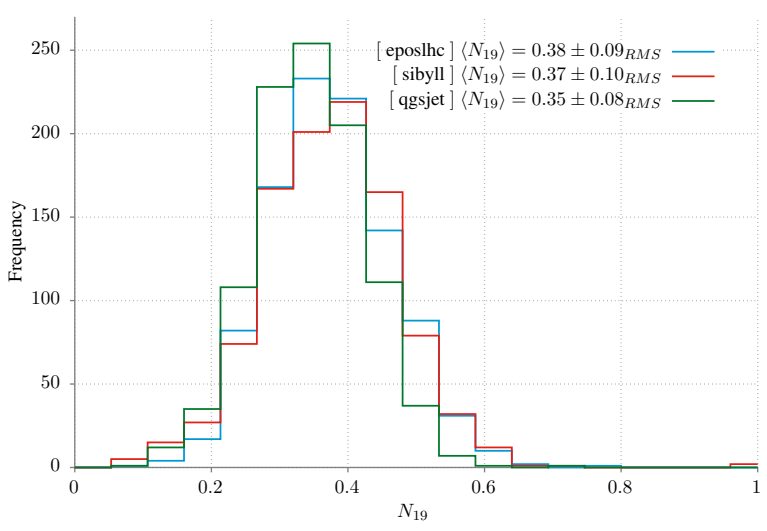

(a) Próton $10^{18.50} \mathrm{eV}$

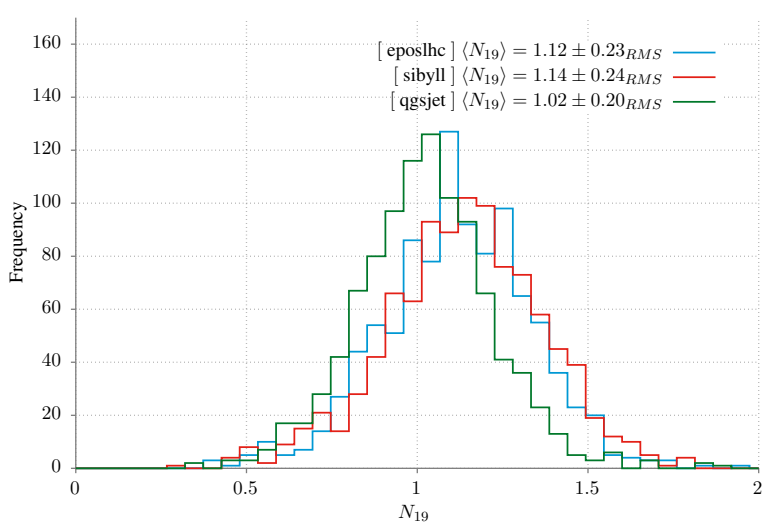

(c) Próton $10^{19.00} \mathrm{eV}$

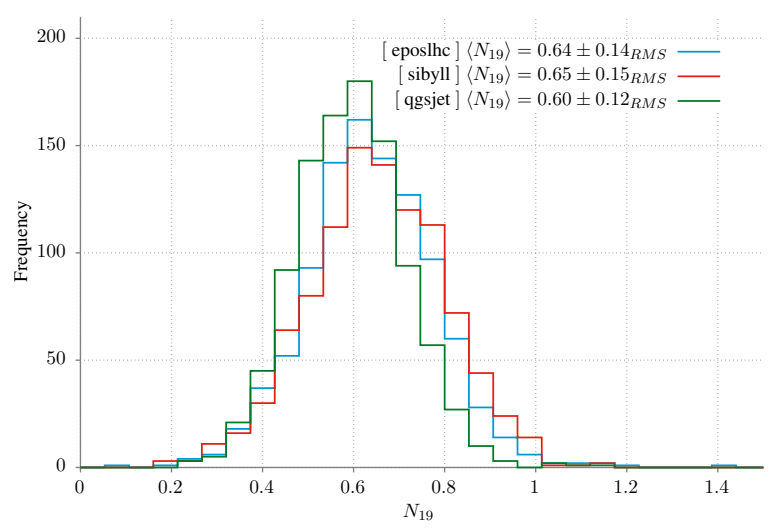

(b) Próton $10^{18.75} \mathrm{eV}$

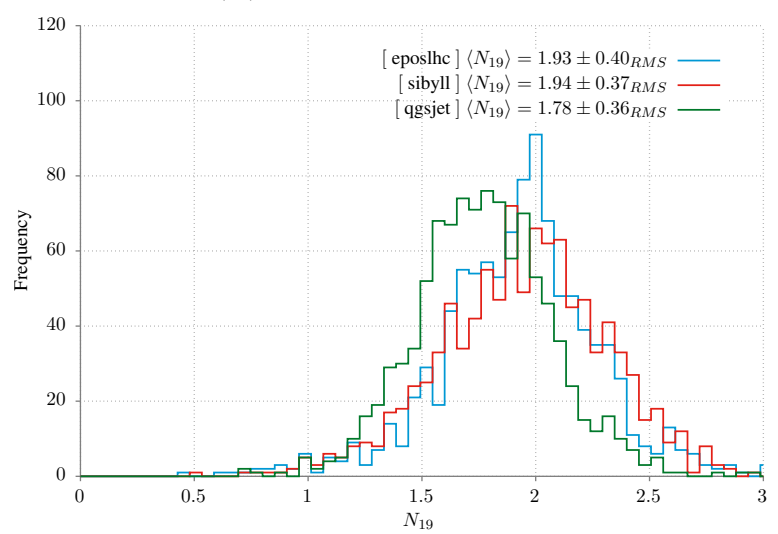

(d) Próton $10^{19.25} \mathrm{eV}$

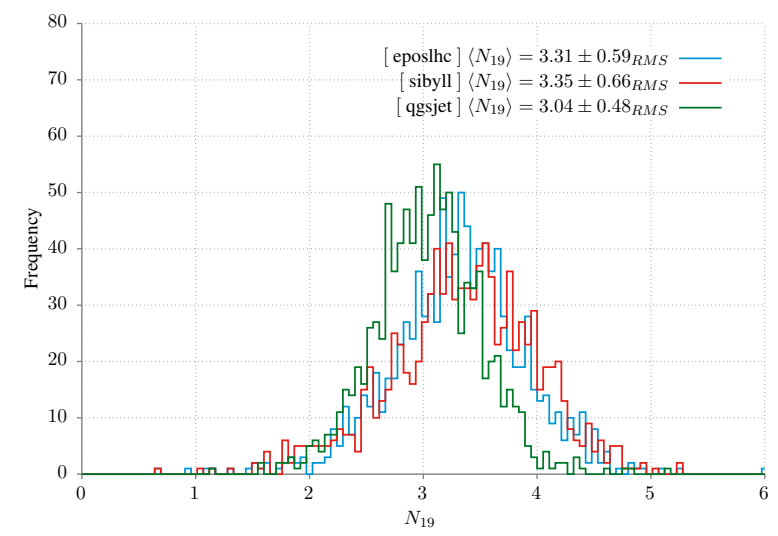

(e) Próton $10^{19.50} \mathrm{eV}$

Figura C.2: Distribuições da reconstrução de $N_{19}$ para chuveiro iniciados por próton. Esses resultados foram utilizados para geração do gráfico de $\left\langle N_{19}\right\rangle$ em função da energia. 


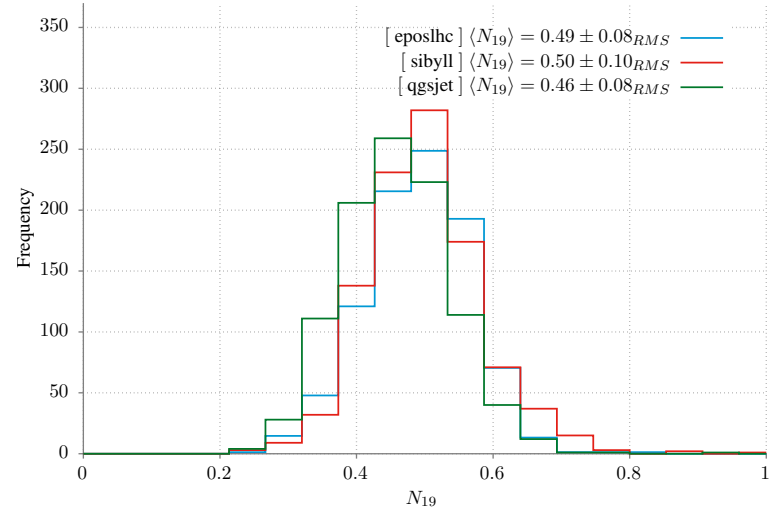

(a) Ferro $10^{18.50} \mathrm{eV}$

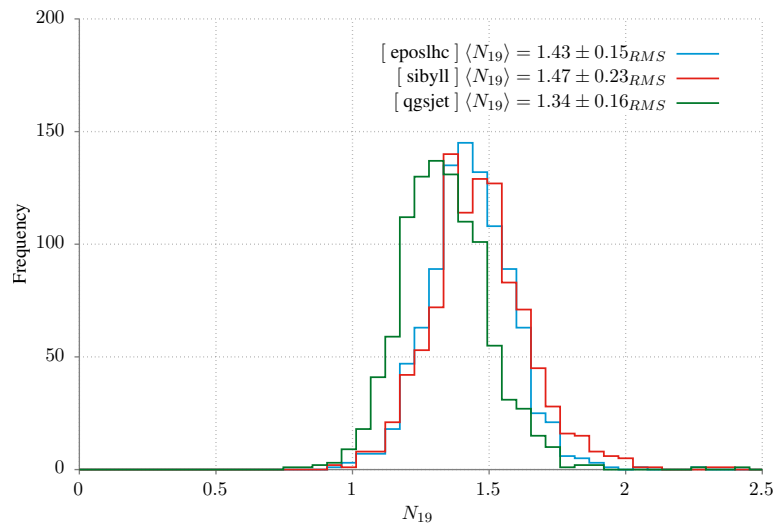

(c) Ferro $10^{19.00} \mathrm{eV}$

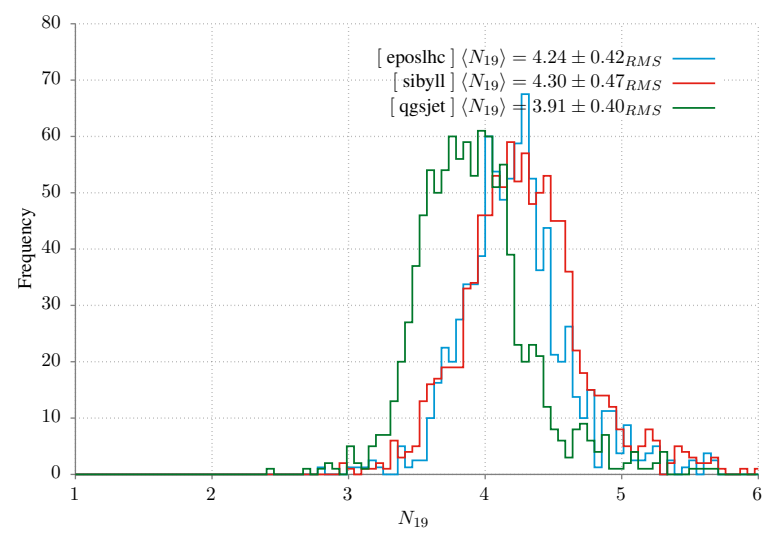

(e) Ferro $10^{19.50} \mathrm{eV}$

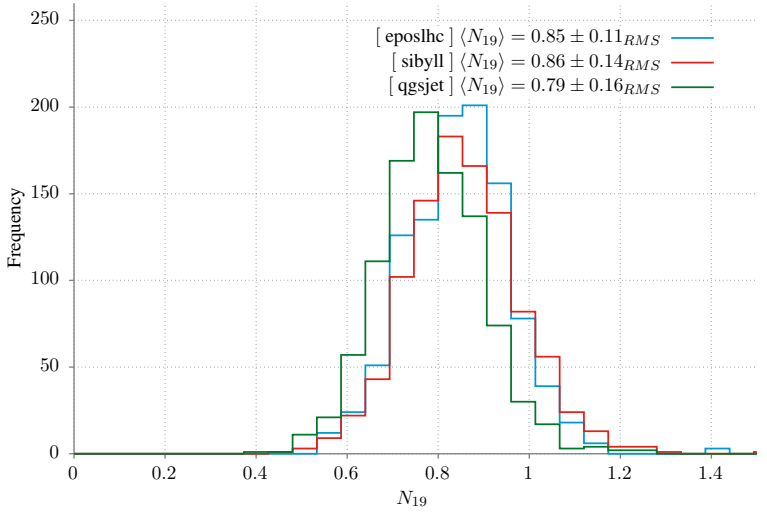

(b) Ferro $10^{18.75} \mathrm{eV}$

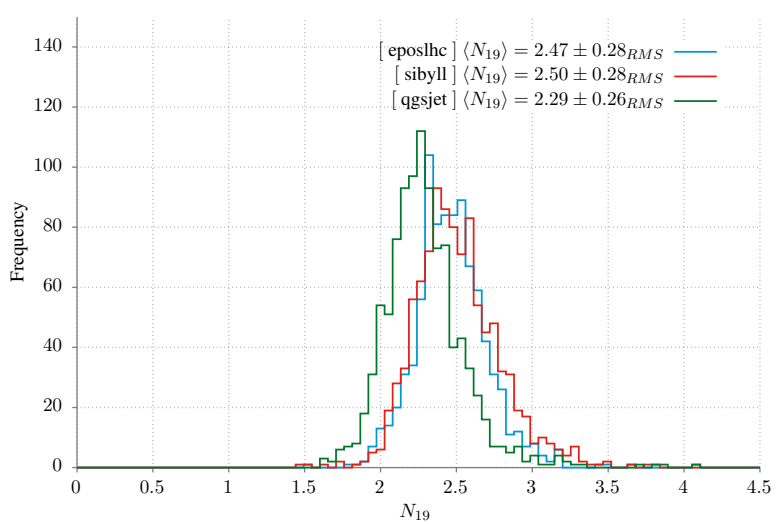

(d) Ferro $10^{19.25} \mathrm{eV}$ 
Apêndice D

Simulações do CORSIKA 


\title{
D.1 Exemplo de arquivo de entrada para simulação de EAS
}

\author{
RUNNR 0 \\ Run number \\ EVTNR 1 \\ Number of first shower event \\ NSHOW 1 \\ Number of showers to generate \\ PRMPAR 14 \\ Particle type of primary particle \\ ESLOPE -2.7 \\ Slope of primary energy spectrum \\ ERANGE $1 \mathrm{e}+101 \mathrm{e}+10$ \\ Energy range of primary particle \\ THETAP 6060 \\ Range of zenith angle (degree) \\ PHIP $\quad 0 \quad 0$ \\ Range of azimuth angle (degree) \\ SEED 100 \\ Random number sequence \\ SEED 100 \\ Random number sequence \\ OBSLEV 1420.E2 \\ Observation level (in $\mathrm{cm}$ ) \\ FIXCHI 0. \\ Starting altitude ( $/ \mathrm{cm} * * 2)$ \\ MAGNET $20.397-14.391$ \\ Magnetic field malargue/Argentina \\ HADFLG $0 \quad 0 \quad 0000002$ \\ Flags hadr.interact.\&fragmentation \\ $\begin{array}{lllll}\text { ECUTS } & 0.3 & 0.3 & 0.003 & 0.003\end{array}$ \\ Energy cuts for particles \\ MUADDI T \\ Additional info for muons \\ MUMULT T \\ Muon multiple scattering angle \\ ELMFLG T T \\ em. interaction flags (NKG,EGS) \\ STEPFC 1.0 \\ Mult. scattering step length fact \\ RADNKG 200.E2 \\ Outer radius for NKG lat.dens.distr. \\ EPOPAR input ../epos/epos.param \\ EPOPAR fname inics ../epos/epos.inics \\ EPOPAR fname iniev ../epos/epos.iniev \\ EPOPAR fname initl ../epos/epos.initl \\ EPOPAR fname inirj ../epos/epos.inirj \\ EPOPAR fname inihy ../epos/epos.ini1b \\ !initialization input file for epos \\ ! initialization input file for epos \\ ! initialization input file for epos \\ ! initialization input file for epos \\ ! initialization input file for epos \\ ! initialization input file for epos \\ EPOPAR fname check none \\ EPOPAR fname histo none \\ EPOPAR fname data none \\ EPOPAR fname copy none \\ ARRANG 0 . \\ LONGI $\mathrm{T}$ 10. $\mathrm{T} \mathrm{T}$ \\ ECTMAP 1.E4 \\ !dummy output file for epos \\ !dummy output file for epos \\ !dummy output file for epos \\ !dummy output file for epos \\ Rotation of array to north \\ Longit.distr. \& step size \& fit \& out \\ Cut on gamma factor for printout
}




$\begin{array}{lc}\text { MAXPRT } 1 & \text { Max. number of printed events } \\ \text { DIRECT ./ } & \text { Output directory } \\ \text { OUTFILE ./DAT000000.sec } & \text { Output of secondary particles } \\ \text { THIN } 1 \text { e-06 } 3.2 e+061 & \text { Thinning definition } \\ \text { THINH } 1.100 . & \text { Hadronic thinning definition } \\ \text { USER you } & \\ \text { EXIT } & \end{array}$




\section{D.2 Exemplo do arquivo de partículas secundárias}

\begin{tabular}{rrrrrrr}
8 & $1.000000000 \mathrm{E}+10$ & 14 & $2.785206223 \mathrm{E}+06$ & 14 & \multicolumn{1}{c}{14} \\
1 & 14 & $9.538421 \mathrm{E}-01$ & $1.557085 \mathrm{E}-02$ & $-1.665378 \mathrm{E}-01$ & $-3.850962 \mathrm{E}-02$ \\
2 & 9 & $6.863351 \mathrm{E}+08$ & $6.863351 \mathrm{E}+08$ & $6.171934 \mathrm{E}-02$ & $1.263798 \mathrm{E}-01$ \\
3 & 7 & $7.214467 \mathrm{E}+07$ & $7.214467 \mathrm{E}+07$ & $-4.037810 \mathrm{E}-01$ & $-1.946760 \mathrm{E}-01$ \\
4 & 8 & $3.088405 \mathrm{E}+08$ & $3.088405 \mathrm{E}+08$ & $-4.022788 \mathrm{E}-02$ & $-4.401456 \mathrm{E}-01$ \\
5 & 64 & $1.583558 \mathrm{E}+08$ & $1.583558 \mathrm{E}+08$ & $5.111631 \mathrm{E}-01$ & $4.434977 \mathrm{E}-01$ \\
6 & 11 & $1.478071 \mathrm{E}+08$ & $1.478071 \mathrm{E}+08$ & $7.628177 \mathrm{E}-03$ & $-3.535428 \mathrm{E}-01$ \\
7 & 13 & $6.996107 \mathrm{E}+09$ & $6.996107 \mathrm{E}+09$ & $9.879928 \mathrm{E}-03$ & $7.380277 \mathrm{E}-01$ \\
8 & 8 & $1.630410 \mathrm{E}+09$ & $1.630410 \mathrm{E}+09$ & $2.016898 \mathrm{E}-02$ & $-2.810283 \mathrm{E}-01$
\end{tabular}

A primeira linha do arquivo contêm na sequência: O número de partículas produzidas após a primeira interação, a energia e o códido do raio cósmico primário. As demais informações da primeira linha são irrelevantes.

As demais linhas mostram a informação de cada partícula produzida após a interação. A informação está organizada da seguinte maneira:

1. Um número de identificação;

2. Código da partícula;

3. Energia;

4. Momento Longitudinal;

5. Momento Tranversal; 


\section{Referências Bibliográficas}

[1] J. MATTHEWS. A Heitler model of extensive air showers. Astroparticle Physics, v.22, n.5-6, p.387-397, January 2005.

[2] THOMAS K. GAISSER. Cosmic rays and particle physics. Cambridge University Press, 2016.

[3] V. BARONE and E. PREDAZZI. High-energy particle diffraction. Berlim: Spinger Verlag, 2002.

[4] DAVID D'ENTERRIA ET AL. Constraints from the first LHC data on hadronic event generators for ultra-high energy cosmic-ray physics. Astroparticle Physics, 35(2):98 $113,2011$.

[5] MARIANGELA SETTIMO. Measurement of the cosmic ray energy spectrum using hybrid events of the Pierre Auger Observatory. The European Physical Journal Plus, $127(8): 87,2012$.

[6] DENIS ALLARD, E. PARIZOT AND A. V. OLINTO. On the transition from galactic to extragalactic cosmic-rays: spectral and composition features from two opposite scenarios. Astropart. Phys., 27:61-75, 2007.

[7] VEBIAMIN BEREZINSKY, A. Z. GAZIZOV AND S. I. GRIGORIEVA. Dip in UHECR spectrum as signature of proton interaction with CMB. Phys. Lett., B612:147-153, 2005.

[8] A. AAB ET AL. Depth of maximum of air-shower profiles at the Pierre Auger Observatory. I. Measurements at energies above $10^{17.8} \mathrm{eV}$. Phys. Rev. D, 90:122005, Dez 2014 .

[9] R. U. ABBASI ET AL. Pierre Auger Observatory and Telescope Array: Joint contributions to the 34th International Cosmic Ray . Conference (ICRC 2015), 2015.

[10] PIERRE AUGER COLABORATION. Observation of a large-scale anisotropy in the arrival directions of cosmic rays above $8 \times 1018 \mathrm{eV}$. Science, 357(6357):1266-1270, 2017.

[11] A. AAB ET AL. Muons in air showers at the Pierre Auger Observatory: Mean number in highly inclined events. Phys. Rev. D, 91:032003, Feb 2015.

[12] A. AAB ET AL. Testing Hadronic Interactions at Ultrahigh Energies with Air Showers Measured by the Pierre Auger Observatory. Phys. Rev. Lett., 117:192001, Oct 2016. 
[13] T. PIEROG ET AL. EPOS LHC: Test of collective hadronization with data measured at the CERN Large Hadron Collider. Phys. Rev. C, 92:034906, Sep 2015.

[14] TANGUY PIEROG. Air Shower Simulation with a New Generation of post-LHC Hadronic Interaction Models in CORSIKA. In 35th International Cosmic Ray Conference, 2017.

[15] RALF ULRICH, RALPH ENGEL AND MICHAEL UNGER. Hadronic multiparticle production at ultrahigh energies and extensive air showers. Phys. Rev. D, 83:054026, Mar 2011.

[16] HENDRIK SOARES. Influência da seção de choque na interpretação da composição de raios cósmicos ultra energéticos. Master's thesis, Instituto de Física de São Carlos USP, 2013.

[17] LYNDON EVANS and PHILIP BRYANT. LHC Machine. Journal of Instrumentation, 3(08):S08001, 2008.

[18] GLENNYS R. FARRAR and JEFFREY D. ALLEN. A new physical phenomenon in ultra-high energy collisions. EPJ Web of Conferences, 53:07007, 2013.

[19] J. ALVAREZ-MUNIZ, L. CAZON, R. CONCEIÇÃO, J. DIAS DE DEUS, C. PAJARES AND M. PIMENTA. Muon production and string percolation effects in cosmic rays at the highest energies. 2012.

[20] JEFFREY ALLEN and GLENNYS FARRAR. Testing models of new physics with UHE air shower observations. In Proceedings, 33rd International Cosmic Ray Conference (ICRC2013): Rio de Janeiro, Brazil, July 2-9, 2013, page 1182, 2013.

[21] TANGUY PIEROG. LHC data and extensive air showers. EPJ Web of Conferences, 52:03001, 2013.

[22] HANS-JOACHIM DRESCHER. Remnant break-up and muon production in cosmic ray air showers. Phys. Rev. D, 77:056003, Mar 2008.

[23] AHN ET AL. Cosmic ray interaction event generator SIBYLL2.3 2.1. Phys. Rev. D, 80:094003, Nov 2009.

[24] S. OSTAPCHENKO. Monte Carlo treatment of hadronic interactions in enhanced Pomeron scheme: QGSJETII-04-II model. Phys. Rev. D, 83:014018, Jan 2011.

[25] A. AAB ET AL. Muon counting using silicon photomultipliers in the AMIGA detector of the Pierre Auger observatory. Journal of Instrumentation, 12(03):P03002, 2017.

[26] M. KOBAL. A thinning method using weight limitation for air-shower simulations. Astroparticle Physics, 15(3):259 - 273, 2001.

[27] B.T. STOKE, R. CADY, D. IVANOV, J.N. MATTHEWS AND G.B. THOMSON. Dethinning extensive air shower simulations. Astroparticle Physics, 35(11):759 - 766, 2012 . 
[28] THE PIERRE AUGER COLlabORATION. The Pierre Auger Cosmic Ray Observatory. Nuclear Instruments AND Methods in Physics Research Section A: Accelerators, Spectrometers, Detectors AND Associated Equipment, 798:172 - 213, 2015.

[29] R.M. BALTRUSAITIS ET AL. The Utah Fly's Eye detector. Nuclear Instruments AND Methods in Physics Research Section A: Accelerators, Spectrometers, Detectors AND Associated Equipment, 240(2):410 - 428, 1985.

[30] V. F. HESS. Über Beobachtungen der durchdringenden Strahlung bei sieben Freiballonfahrten. Physikalische Zeitschrift, 13:1084-1091, November 1912.

[31] C. M. G. LATTES, H. MUIRHEADAND G. P. S. OCCHIALini AND C. F. POWELL. PROCESSES INVOLVING CHARGED MESONS. Nature, 159:694-697, 1947. [,42(1947)].

[32] PIERRE AUGER, P. EHRENFEST, R. MAZE, J. DAUdin AND ROBLEY A. FRÉON. Extensive Cosmic-Ray Showers. Rev. Mod. Phys., 11:288-291, Jul 1939.

[33] G. W. CLARK, J. EARL, W. L. KRAUSHAAR, J. LINSLEY, B. B. ROSSI, F. SCHERB AND D. W. SCOTT, D. W. Cosmic-Ray Air Showers at Sea Level. Phys. Rev., 122:637654, Apr 1961.

[34] Y TOYODA ET AL. Studies of primary cosmic rays in the energy region $10^{14}$ to $10^{17} \mathrm{eV}$ (Bolivian Air Shower Joint Experiment). International Cosmic Ray Conference, 2:708, 1965.

[35] JOHN LINSLEY. Evidence for a Primary Cosmic-Ray Particle with Energy $10^{20} \mathrm{eV}$. Phys. Rev. Lett., 10:146-148, Feb 1963.

[36] A. A. PENZIAS and R. W. WILSON. A Measurement of Excess Antenna Temperature at $4080 \mathrm{Mc} / \mathrm{s}$. Astrophysical Journal, 142:419-421, July 1965.

[37] T. HARA ET AL. Detection of the atmospheric scintillation light from air showers. International Cosmic Ray Conference, 3:369, 1970.

[38] H. E. BERGESON ET AL. Measurement of Light Emission from Remote Cosmic-Ray Air Showers. Phys. Rev. Lett., 39:847-849, Sep 1977.

[39] J. ABRAHAM ET AL. Measurement of the depth os shower maximum of cosmic rays above $10^{18}$ eV. Nuclear Physics Letters, v.104, n.9, p.091101, Mar 2010.

[40] A. AAB ET AL. The Pierre Auger Observatory Upgrade - Preliminary Design Report. 2016.

[41] D. ARDOUIN ET AL. Geomagnetic origin of the radio emission from cosmic ray induced air showers observed by CODALEMA. Astroparticle Physics, 31(3):192 - 200, 2009.

[42] J. R. PRESCOTT, J. H. HOUGH, J. K. PIDCOCK. Mechanism of radio emission from extensive air showers. Nature Physical Science, 233(41):109-110, Oct 1971. 
[43] H. BETHE and W. HEITLER. On the stopping os fast particles and the creation of positive electrons. Proceedings of Royal Society London A, v.146,n. 856, p.83-112, August 1934.

[44] M. LONGAIR. High energy astrophysics. Cambridge University Press, 2011.

[45] W. HEITLER. The quantum theory of radiation. London: Oxford University Press, 1954.

[46] S. J. LINDENBAUM and R. M. STERNHEIMER. Isobaric Nucleon Model for Pion Production in Nucleon-Nucleon Collisions. Physical Review, 105:1874-1899, March 1957.

[47] A. CAPELLA, U. SUKHATME, C. I. TAN AND J. TRAN THANH VAN. Dual parton model. Physics Reports, 236(4):225 - 329, 1994.

[48] A. B. KAIDALOV. High-energy hadronic interactions (20 years of the Quark-Gluon Strings Model). Physics of Atomic Nuclei, 66(11):1994-2016, 2003.

[49] JAIME ALVAREZ-MUNIZ, RALPH ENGEL, T. K. GAISSER, JEFERSON A. ORTIZ AND TODOR STANEV. Hybrid simulations of extensive air showers. Phys. Rev. D, 66:033011, Aug 2002.

[50] K. HAGIWARA ET AL. Review of Particle Properties. Phys. Rev. D, 66:010001, Jul 2002.

[51] J. ABRAHAM ET AL. The fluorescence detector of the Pierre Auger Observatory. Nuclear Instruments AND Methods in Physics Research Section A: Accelerators, Spectrometers, Detectors AND Associated Equipment, 620(2):227 - 251, 2010.

[52] C. MEURER and N. SCHARF ET AL. HEAT a low energy enhancement of the Pierre Auger Observatory. Astrophysics AND Space Sciences Transactions, 7(2):183-186, 2011.

[53] J. ABRAHAM ET. AL. Observation of the Suppression of the Flux of Cosmic Rays above $4 \times 10^{19} \mathrm{eV}$. Phys. Rev. Lett., 101:061101, Aug 2008.

[54] W. D. APEL ET AL. Ankle-like feature in the energy spectrum of light elements of cosmic rays observed with KASCADE-GRANDE. Phys. Rev. D, 87:081101, Apr 2013.

[55] R. ALOISIO, V. BEREZINSKY AND A. GAZIZOV. Transition from galactic to extragalactic cosmic rays. Astroparticle Physics, 39-40:129 - 143, 2012. Cosmic Rays Topical Issue.

[56] KENNETH GREISEN. End to the cosmic ray spectrum? Phys. Rev. Lett., 16:748-750, Apr 1966.

[57] G. T. ZATSEPIN and V. A. ZATSEPIN. Upper limit of the spectrum of cosmic rays. JETP Lett., 4:78-80, 1966. [Pisma Zh. Eksp. Teor. Fiz.4,114(1966)].

[58] D. HARARI, S. MOLLERACH AND E. ROULET. On the ultrahigh energy cosmic ray horizon. Journal of Cosmology AND Astroparticle Physics, 2006(11):012, 2006. 
[59] GEORGE R. BLUMENTHAL. Energy loss of high-energy cosmic rays in pair-producing collisions with ambient photons. Phys. Rev. D, 1:1596-1602, Mar 1970.

[60] FELIX RIEHN ET AL. The hadronic interaction model SIBYLL2.3 2.3c AND Feynman scaling. PoS, ICRC2017:301, 2017.

[61] KLAUS WERNER, FU-MING LIU AND T. PIEROG. Parton ladder splitting AND the rapidity dependence of transverse momentum spectra in deuteron-gold collisions at the BNL Relativistic Heavy Ion Collider. Phys. Rev. C, 74:044902, Oct 2006.

[62] T. REGGE. Introduction to complex orbital momenta. Il Nuovo Cimento (1955-1965), 14(5):951-976, Dec 1959.

[63] T. PIEROG, IU. KARPENKO, J. M. KATZY, E. YATSENKO AND K. WERNER. EPOS LHC: Test of collective hadronization with data measured at the CERN Large Hadron Collider. Phys. Rev. C, 92:034906, Sep 2015.

[64] N. N. KALMYKOV AND S. S. OSTAPACHENKO. The nucleus-nucleus interaction, nuclear fragmentation, and fluctuations of extensive air showers. Physics of Atomic Nuclei, 56:346-353, March 1993.

[65] M. L. GOOD and W. D. WALKER. Diffraction Dissociation of Beam Particles. Phys. Rev., 120:1857-1860, Dec 1960.

[66] RALPH ENGEL, DIETER HECK AND TANGUY PIEROG. Extensive air showers and hadronic interactions at high energy. Ann. Rev. Nucl. Part. Sci., 61:467-489, 2011.

[67] DAVID D'ENTERRIA, RALPH ENGEL, TANGUY PIEROG, SERGEY OSTAPCHENKO AND KLAUS WERNER. Constraints from the first LHC data on hadronic event generators for ultra-high energy cosmic-ray physics. Astroparticle Physics, 35(2):98 $-113,2011$.

[68] T. PIEROG and K. WERNER. Muon Production in Extended Air Shower Simulations. Phys. Rev. Lett., 101:171101, Oct 2008.

[69] A. ADUSZKIEWICZ ET AL. Measurement of meson resonance production in $\pi^{-}+\mathrm{C}$ interactions at SPS energies. The European Physical Journal C, 77(9):626, Sep 2017.

[70] L. PORTUGAL and T. KODAMA. Gluon saturation effects at the nuclear surface: inelastic cross section of proton-nucleus in the ultra-high-energy cosmic ray domain. Nuclear Physics A, v.837, n.1-2, p.1-14, June 2010.

[71] Centro Nacional de Processamento de Alto Desempenho sm São Paulo. https://www.cenapad.unicamp.br/. Acessado: 02/09/2018.

[72] Sistema de Computação Petaflópica do SINAPAD - SDumont. http://sdumont.lncc.br/. Acessado: 02/09/2018.

[73] A. AAB ET AL. Muons in air showers at the Pierre Auger Observatory: Measurement of atmospheric production depth. Phys. Rev. D, 90:012012, Jul 2014. 
[74] D. HECK and J. KNAPP. The CORSIKA Air Shower Simulation Program. FZKA report-6019, 1998. Disponível em : <http://www.slac.stanford.edu/cgiwrap/getdoc/slac-r-265.pdf>. Acesso em: 9 Maio 2013.

[75] GEANT4. https://geant4.web.cern.ch/. Acessado: 10/09/2018.

[76] ROOT a Data analysis Framework - ROOT a Data analysis Framework. https://root.cern.ch/. Acessada: 30-07-2018.

[77] C. BONIFAZI. The angular resolution of the Pierre Auger Observatory. Nuclear Physics B - Proceedings Supplements, 190:20 - 25, 2009. Proceedings of the Cosmic Ray International Seminars.

[78] H.P. DEMBINSKI, P. BILLOIR, O. DELIGNY AND T. HEBBEKER. A phenomenological model of the muon density profile on the ground of very inclined air showers. Astroparticle Physics, 34(2):128 - 138, 2010.

[79] P. BILLOIR. A sampling procedure to regenerate particles in a ground detector from a thinned air shower simulation output. Astroparticle Physics, 30:270-285, December 2008.

[80] C. BONIFAZI, A. LETESSIER-SELVON AND E.M. SANTOS. A model for the time uncertainty measurements in the Auger surface detector array. Astroparticle Physics, 28(6):523 - 528, 2008. 